\title{
Toward partnership in care for patients with COPD
}

Citation for published version (APA):

Stoilkova-Hartmann, A. (2017). Toward partnership in care for patients with COPD: focus on coping and education. [Doctoral Thesis, Maastricht University]. Maastricht University. https://doi.org/10.26481/dis.20170927ash

Document status and date:

Published: 01/01/2017

DOI:

10.26481/dis.20170927ash

Document Version:

Publisher's PDF, also known as Version of record

\section{Please check the document version of this publication:}

- A submitted manuscript is the version of the article upon submission and before peer-review. There can be important differences between the submitted version and the official published version of record.

People interested in the research are advised to contact the author for the final version of the publication, or visit the DOI to the publisher's website.

- The final author version and the galley proof are versions of the publication after peer review.

- The final published version features the final layout of the paper including the volume, issue and page numbers.

Link to publication

\footnotetext{
General rights rights.

- You may freely distribute the URL identifying the publication in the public portal. please follow below link for the End User Agreement:

www.umlib.nl/taverne-license

Take down policy

If you believe that this document breaches copyright please contact us at:

repository@maastrichtuniversity.nl

providing details and we will investigate your claim.
}

Copyright and moral rights for the publications made accessible in the public portal are retained by the authors and/or other copyright owners and it is a condition of accessing publications that users recognise and abide by the legal requirements associated with these

- Users may download and print one copy of any publication from the public portal for the purpose of private study or research.

- You may not further distribute the material or use it for any profit-making activity or commercial gain

If the publication is distributed under the terms of Article $25 \mathrm{fa}$ of the Dutch Copyright Act, indicated by the "Taverne" license above, 


\section{Toward PARTNERSHIP in care for patients with COPD: focus on coping and education}

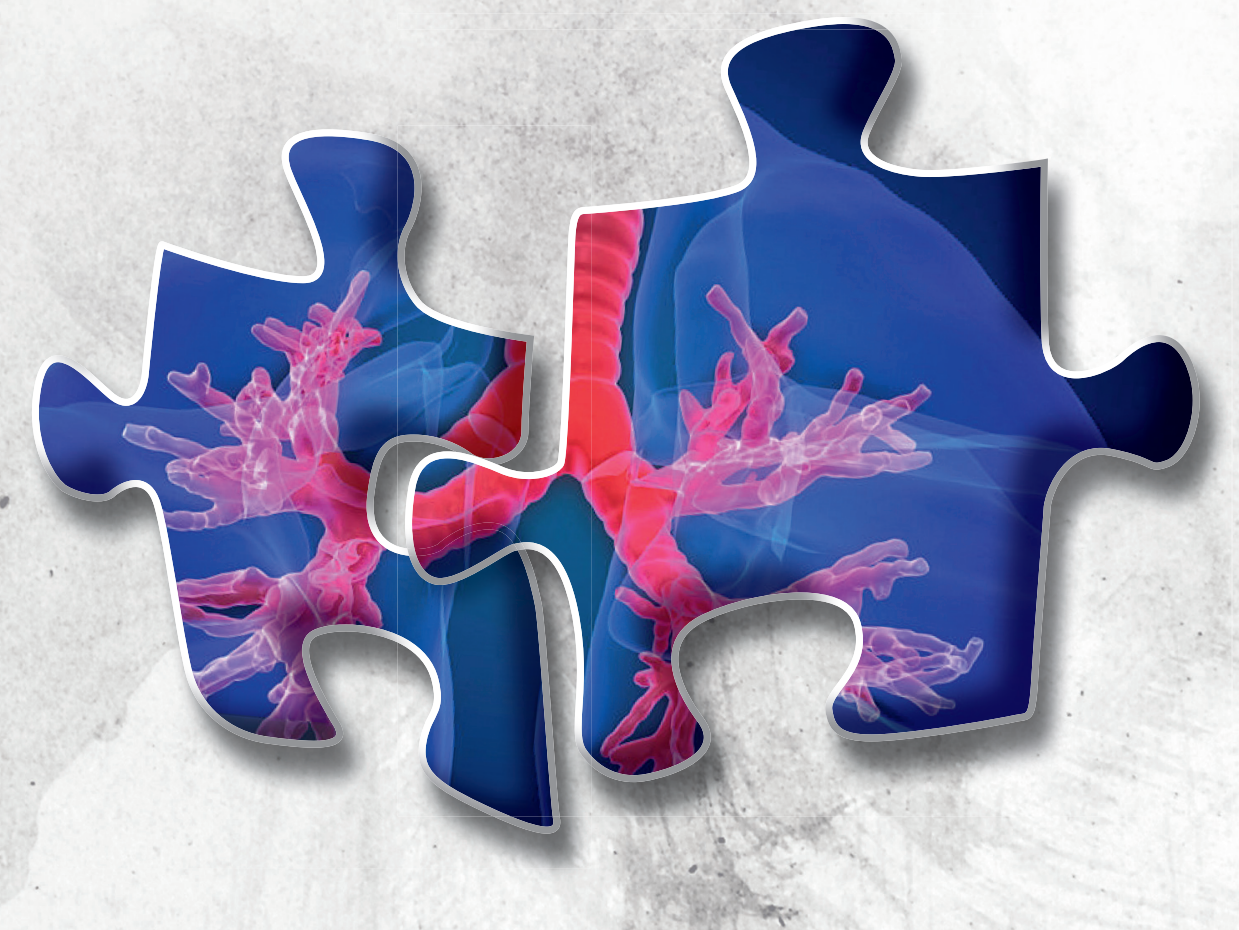



Toward partnership in care for patients with COPD:

focus on coping and education 
Copyright (C) Ana Stoilkova-Hartmann, Maastricht 2017

All rights reserved. No part of this book may be reproduced or transmitted in any form or by any means, without prior permission in writing by the author.

Layout: $\quad$ Tiny Wouters

Cover design: Kerstin Lechler

Printing: ProefschriftMaken

ISBN: 978-94-6295-719-0

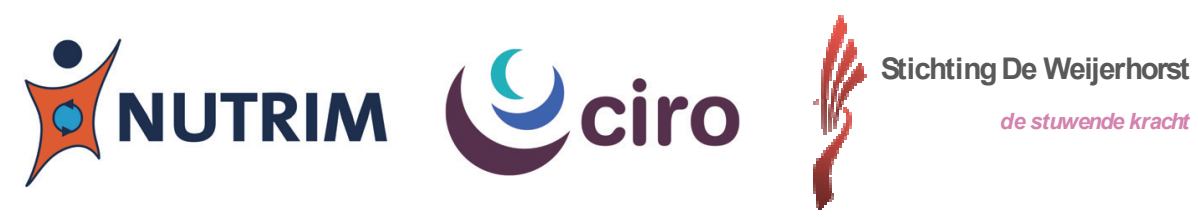

The research described in this thesis was performed at the Department of Respiratory Medicine, NUTRIM School of Nutrition and Translational Research in Metabolism at Maastricht University Medical Center+, Maastricht, The Netherlands; and at CIRO, centre of expertise for chronic organ failure, Horn, The Netherlands.

The publication of this thesis was financially supported by the Department of Respiratory Medicine, Maastricht University Medical Center+ and CIRO, centre of expertise for chronic organ failure, Horn, The Netherlands.

The studies described in this thesis were supported by The Weijerhorst Foundation. 


\title{
Toward partnership in care for patients with COPD: focus on coping and education
}

\author{
Dissertation \\ to obtain the degree of Doctor at the Maastricht University, \\ on the authority of the Rector Magnificus, Prof. dr. Rianne M. Letschert \\ in accordance with the decision of the Board of Deans, \\ to be defended in public on \\ Wednesday 27 September 2017 at 16:00 hours
}

by

Ana Stoilkova-Hartmann 


\section{Supervisor}

Prof. dr. E.F.M. Wouters

\section{Co-supervisors}

Dr. D.J.A. Janssen

Dr. F.M.E. Franssen

\section{Assessment Committee}

Prof. dr. F. Smeenk (chairman)

Prof. dr. S. Kremers

Prof. dr. R. Ponds

Prof. dr. S. Singh (University Hospital of Leicester, Leicester, United Kingdom)

Prof. dr. J. van der Palen (Medisch Spectrum Twente, Enschede, The Netherlands) 
It is not the strongest of the species that survive, nor the most intelligent,

but the one most responsive to change.

a quotation attributed to Charles Darwin 



\section{Contents}

Chapter 1 General introduction 9

Chapter 2 The relationship between coping styles and clinical outcomes in $\quad 21$ patients with COPD entering pulmonary rehabilitation COPD. 2013;10(3):316-23

Chapter 3 Coping styles in patients with COPD before and after pulmonary rehabilitation

Respiratory Medicine. 2013;107(6):825-33

Chapter 4 Differences in change in coping styles between good responders, 59 moderate responders and non-responders to pulmonary rehabilitation Respiratory Medicine. 2015;109(12):1540-5

Chapter 5 Educational programmes in COPD management interventions:

A systematic review

Respiratory Medicine. 2013;107(11):1637-50

Chapter 6 Attitudes of healthcare professionals providing pulmonary rehabilitation toward partnership in care Heart \& Lung: The Journal of Acute and Critical Care. 2015;44(4):347-52

Chapter 7 Discussion. Perspectives on education in COPD

Submitted

Summary

Samenvatting

Valorisation

Abbreviations

Acknowledgements

List of publications

Curriculum vitae 



\section{Chapter 1}

GENERAL INTRODUCTION 



\section{COPD as a respiratory disease and societal burden}

Chronic Obstructive Pulmonary Disease (COPD) is a common preventable and treatable disease, characterised by chronic airflow limitation, an enhanced inflammatory response of the lungs and progressive respiratory symptoms. ${ }^{1,2}$ Chronic inflammation in the airways and the lung parenchyma leads to accumulating pathologic changes and results in progressively deteriorating pulmonary function. ${ }^{3}$ Exacerbations and co-occurring chronic diseases (comorbidities) contribute to the overall severity in individual patients. ${ }^{4}$

The prevalence of COPD is directly related to the prevalence of tobacco smoking. ${ }^{5,6}$ However, in many countries, cumulative exposure to outdoor and indoor air pollution, resulting from burning of wood and other biomass fuels, has been identified as a major risk factor for COPD. ${ }^{7}$ Aging itself, is a risk factor for COPD and aging of the airways and parenchyma mimics some of the structural changes associated with COPD. ${ }^{8}$

COPD represents a significant economic and social burden. ${ }^{9,10}$ The World Health Organisation (WHO) estimates that COPD will be the third most common worldwide cause of death and disability by 2030 , from its fifth ranking in $2002 .^{11}$ Despite worldwide medical research and health care efforts, COPD mortality rates doubled between 1969 and 2013 in the United States population, in contrast with other major causes of death like stroke, heart disease, diabetes, unintended injuries and cancer. ${ }^{12}$ Additionally, the burden of COPD is expected to increase significantly over the next decades due to an aging population and continued exposure to the risk factors. ${ }^{9}$

\section{COPD as a systemic disease}

In addition to the pulmonary manifestations, patients with COPD are at increased risk for several comorbidities, including cardiovascular disease, skeletal muscle dysfunction, metabolic syndrome, lung cancer and osteoporosis. ${ }^{4,13}$ While it was previously hypothesised that these systemic manifestations develop in response to the "spill over" of inflammatory mediators from the lungs, nowadays reduced physical activity levels, poor nutrition and body composition accelerated aging and impaired repair mechanisms are recognised as pathophysiologic factors, subsequently leading to skeletal muscle wasting and cardiovascular, metabolic and bone diseases. ${ }^{13}$ These comorbid conditions can occur in patients with mild, moderate or severe airflow limitation and they can significantly affect quality of life. ${ }^{14}$ Psychological disorders, such as depression and anxiety, are also common in COPD patients - factors that can affect both, quality of life and compliance with therapy. ${ }^{15,16}$ 


\section{Pharmacologic and non-pharmacologic management of COPD}

Although preventing disease progression and reduction of mortality remain the longterm goals for treatment development, these goals are not yet achievable given the largely symptomatic treatment options currently available. As highlighted in the latest version of the Global Initiative for Chronic Obstructive Lung Disease (GOLD) consensus report, airflow limitation $\left(\mathrm{FEV}_{1}\right)$ alone is a poor descriptor of the disease status, and therefore the degree of airflow limitation has been amended by symptoms and exacerbation rate. ${ }^{17}$ Four categories (A-D) have been established in which patients can be classified based on symptoms' scores and exacerbation history. ${ }^{17}$ Hence, the immediate goals of COPD treatment focus on attenuating symptoms, improving daily function and quality of life, reducing acute exacerbations, and reducing mortality risk. $^{18}$

\section{Pharmacologic options}

Pharmacologic therapy is used to reduce symptoms, reduce the frequency and severity of exacerbations, increase exercise tolerance and improve overall health status. ${ }^{17}$ Inhaled bronchodilators administered either as monotherapy or together as combination bronchodilator therapy, are generally considered a mainstay of pharmacologic treatment for COPD. ${ }^{17,19,20}$ Because bronchodilator therapy is commonly self-administered via pressurised metered-dose inhalers (MDIs) or drypowder inhalers (DPIs), it is important that patients receive adequate training in inhaler technique. ${ }^{21}$ Although treatment with bronchodilators can improve emptying of the lungs, reduce hyperinflation and dyspnoea, and improve the patient's ability to exercise, these current therapies have not been conclusively shown to ameliorate the long-term decline in lung function or improve the patient's prognosis. ${ }^{17}$

\section{Smoking cessation}

Smoking cessation is generally considered to be the only effective treatment for avoiding or reducing the progression of COPD. ${ }^{22}$ Individual and group counselling by health professionals has been shown to significantly increase cessation rates over selfinitiated strategies. ${ }^{23,24}$ However, supportive intervention programmes that include counselling, nicotine replacement therapy (e.g. nicotine gum, inhaler, nasal spray, transdermal patch, sublingual tablet, or lozenge) and/or pharmacology (e.g. varenicline, bupropion or nortriptyline), have been shown to be more effective rather than when these components are used on their own. ${ }^{17}$ 


\section{Pulmonary rehabilitation}

Pulmonary rehabilitation (PR) is defined as "a comprehensive intervention based on a thorough patient assessment followed by patient tailored therapies that include, but are not limited to, exercise training, education, and behaviour change, designed to improve the physical and psychological condition of people with chronic respiratory disease and to promote the long-term adherence to health-enhancing behaviours." ${ }^{25}$ $\mathrm{PR}$ and pharmacologic therapy are not competitive but rather, must work closely together, if they are to result in a more successful outcome. ${ }^{26}$ Moreover, PR has become a standard of care for COPD patients and has been shown to be the most effective non-pharmacologic intervention for improving health status in COPD patients. $^{2}$

In large clinical studies, PR has been shown to increase exercise tolerance, ${ }^{27}$ and to improve recovery after hospitalisation for an exacerbation. ${ }^{28}$ Accordingly, a recent meta-analyses concluded that pulmonary rehabilitation relieves dyspnoea and fatigue, improves emotional function, enhances patients' sense of control that individuals have over their condition and is beneficial in improving health-related quality of life and exercise tolerance. $^{29}$

\section{Education for patients with COPD}

Educational programmes are increasingly used and play an important role in the treatment of COPD, although the interventions are diverse. ${ }^{30,31}$ Patient education as a topic, used as a term in PubMed MeSH Database is defined as "teaching or training of patients concerning their own health needs." Specifically, patient education is a process of teaching and learning of patients and clients in all clinical settings in a planned systematic, sequential and logical manner. ${ }^{32}$ The purpose of patient education is to increase the competence and confidence of patients for selfmanagement, with an ultimate goal - to increase the patients' responsibility and independence for self-care. ${ }^{33}$ However, education alone is insufficient in accomplishing this; in addition, changes in behaviour, especially the acquisition of selfcare skills, are also required. ${ }^{34}$ Thus, the educational component of PR has gradually evolved from a traditional, didactic approach to the promotion of adaptive behaviour change, especially collaborative self-management. ${ }^{25}$

\section{Collaborative self-management and behaviour change}

The functional impairment, symptom burden and impaired quality of life in patients with COPD are not simply consequences of the underlying physiological disorder but, 
also depend on the patients' adaptation to their illness, treatments, and comorbidities. ${ }^{31}$ Hence, collaborative self-management education promotes selfefficacy through increasing the patients' knowledge and skills required to participate with healthcare professionals in optimally managing their illness. ${ }^{25,35}$ Concurrently, the healthcare professional's team can guide patients' health behaviour change by enhancing efficacy beliefs and confidence in outcomes, which in turn, will result in sustained treatment effects after programmes have been completed. ${ }^{31}$ Several studies in COPD patients suggest that self-management education and support can improve health status, ${ }^{33,36-38}$ reduce emergency visits ${ }^{33,39}$ and hospitalisations. ${ }^{30,33}$ The programmes should take the patient's perspective into account, be tailored individually, include core generic strategies aimed at behavioural change, such as goal setting, problem solving, decision-making, and taking action based on a predefined action plan; and may vary with the course of the patient's disease and comorbidities. $^{25,31,40}$

\section{Definition of coping and importance for self-management}

Distressing and disabling chronic illness, challenges patients' effective coping. ${ }^{41}$ As an adaptive response to a chronic illness, coping is defined as selecting and acting on the information derived from the individual's symptom recognition and interpretation. ${ }^{42}$ Some patients deal with their duties and difficulties, which are the result of their confrontation and evaluation of their chronic illness, more successfully than others. ${ }^{43}$ Poor coping is suggested by maladaptive behaviours such as nonadherence to treatment recommendations, missing medical appointments, not taking prescribed medication, or avoiding laboratory testing. ${ }^{44}$ Previous coping styles certainly impact how patients react under the stress of chronic illness. ${ }^{45}$

Patients with COPD often experience fatigue, impaired health status, loss of independence, work absenteeism, and social isolation. ${ }^{46}$ In addition, these individuals may endure psychological problems, including depression, anxiety and poor coping with their symptoms. ${ }^{15,42,47}$ For example, a passive coping style was related to an impaired level of daily functioning; ${ }^{48}$ whereas, in patients with advanced COPD, inability to cope with the effects of their disease was linked to an increased mortality. $^{49}$

Having strong support systems enhances resilience and widens access to coping strategies, ${ }^{44}$ thus, learning effective coping styles is particularly important for patients with COPD. Furthermore, adequate coping styles are important for self-management of COPD. ${ }^{47,50}$ Moreover, coping styles seem to be important for the maintenance of post-rehabilitation effects. ${ }^{51}$ Additionally, knowledge of the patient's baseline coping styles and a high index of suspicion for factors that threaten resilience, are essential to 
accurate assessment and achievement of optimal patient coping. ${ }^{52}$ Recognition of the differing patterns helps to inform healthcare provider responses that, if tailored appropriately, will be perceived as supportive rather than confrontational. ${ }^{53}$ To date, it remains unknown whether and to what extent coping styles may change following comprehensive PR; and whether and to what extent coping styles are associated with the clinical outcomes following a PR programme.

\section{Partnership in care - patient involvement in COPD management}

Medicine is undergoing a revolution - that extends far beyond what is usually covered by the term personalised medicine - that will transform the reactive practice of healthcare into a proactive discipline - a discipline that is predictive, preventive, personalised, and participatory (P4) medicine. ${ }^{54}$ These four key attributes of the P4 medicine healthcare paradigm refer to: taking into account a person's genetic or protein profile (personalised); anticipating health problems and focusing on wellness, not disease (preventative); directing appropriate treatment, and avoiding drug reactions (predictive); and empowering patients to take more responsibility for their health and care (participatory). ${ }^{55} \mathrm{P} 4$ medicine will be fuelled by systems approaches to disease, emerging technologies and analytical tools which will help in bringing patients, physicians and members of the health-care community into alignment. ${ }^{54}$

Practice guidelines advocate partnership in care between patients with COPD and their healthcare providers., 25 The WHO defines partnership as " $a$ collaborative relationship between two or more parties based on trust, equality and mutual understanding for the achievement of a specified goal. Partnership involves risks as well as benefits, making shared accountability critical." ${ }^{56}$ Hence, partnership encompasses: "absolute interdependence, mutual accountability, collaborative relationship, equal participation in decision-making and shared power." ${ }^{57}$ Establishing effective partnership between patients and healthcare providers is essential to collaborative self-management education and support. ${ }^{35}$ This productive interaction requires an "informed and activated patient" and a "prepared practice team" which will support and promote self-management to their patients within the clinical consultations. ${ }^{40}$ Nevertheless, whether all patients are able to act as an equal partner, and moreover, whether healthcare providers are capable to provide behavioural support and are ready to accept their patients as an equal partner, remains unknown. 


\section{Aims of the thesis}

The general aim of this thesis was to study coping styles, educational programmes and attitudes of healthcare professionals as potential contributing factors to selfmanagement and partnership in care for patients with COPD (Figure 1.1).

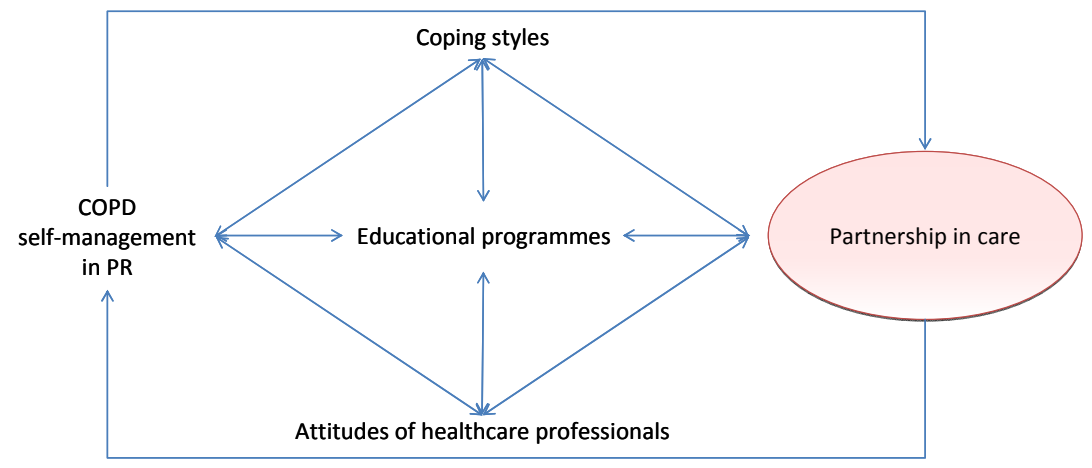

Figure 1.1 Schematic representation of the general aim of the thesis.

\section{The research questions addressed in this thesis were}

1. What is the distribution of coping styles in COPD patients entering PR;

2. Whether and to what extent do coping styles of COPD patients entering PR contribute to patients' clinical outcomes?

3. Whether a comprehensive interdisciplinary PR programme is able to change coping styles in patients with COPD as reflected in:

a. the extent to which coping styles change following PR;

b. the difference between changes in coping styles between patients who had a very good response and patients with a moderate and no improvement in either exercise tolerance or health status after PR?

4. Which educational topics and methods of delivery of educational components are integrated in educational programmes of current COPD management?

5. Whether patient-clinician partnership in care is supported by PR professionals? 


\section{Outline of the thesis}

Chapter 2 presents a cross-sectional observational study of distribution of coping styles in COPD patients entering PR. This chapter also compares coping styles of COPD patients stratified by presence of clinically relevant symptoms of anxiety and depression entering PR and further explores their relation with exercise tolerance and disease-specific health status.

Chapter 3 presents a longitudinal analysis of the effects of a comprehensive interdisciplinary PR programme and its ability to change coping styles in patients with COPD. It further investigates the role of coping styles as predictors of changes in exercise tolerance, symptoms of anxiety and depression and disease-specific health status following PR.

Chapter 4 presents a longitudinal comparison of changes in coping styles after PR between patients who had a very good response in exercise tolerance and/or disease-specific health status and patients with a moderate and no improvement in these two outcomes after PR.

Chapter 5 presents a systematic literature review which delineates educational topics integrated in current COPD management programmes; also, it examines strengths, weaknesses, and methods of delivery of the educational programmes.

Chapter 6 presents a multicentre analysis of attitudes of healthcare professionals providing PR toward patient self-management and specifically assesses their attitudes about the importance of patients' competencies necessary for the process of partnership in care.

Chapter $\mathbf{7}$ is a general discussion summarising the potential contributing factors to self-management and partnership in care for patients with COPD identified in this thesis, as well as the thesis' implications and future directions. 


\section{References}

1. Mannino DM. COPD: epidemiology, prevalence, morbidity and mortality, and disease heterogeneity. Chest 2002;121:121S-6S.

2. Vestbo J, Hurd SS, Agusti AG, Jones PW, Vogelmeier C, Anzueto A, et al. Global strategy for the diagnosis, management, and prevention of chronic obstructive pulmonary disease: GOLD executive summary. Am J Respir Crit Care Med 2013;187:347-65.

3. Briggs DD, Jr. Chronic obstructive pulmonary disease overview: prevalence, pathogenesis, and treatment. J Manag Care Pharm 2004;10:S3-10.

4. Hillas G, Perlikos F, Tsiligianni I, Tzanakis N. Managing comorbidities in COPD. Int J Chron Obstruct Pulmon Dis 2015;10:95-109.

5. Fukuchi $Y$, Nishimura M, Ichinose $M$, Adachi M, Nagai A, Kuriyama T, et al. COPD in Japan: the Nippon COPD Epidemiology study. Respirology 2004;9:458-65.

6. Halbert RJ, Natoli JL, Gano A, Badamgarav E, Buist AS, Mannino DM. Global burden of COPD: systematic review and meta-analysis. The European respiratory journal 2006;28:523-32.

7. Salvi SS, Barnes PJ. Chronic obstructive pulmonary disease in non-smokers. Lancet 2009;374:733-43.

8. Maciewicz RA, Warburton D, Rennard SI. Can increased understanding of the role of lung development and aging drive new advances in chronic obstructive pulmonary disease? Proc Am Thorac Soc 2009;6:614-7.

9. Lopez AD, Shibuya K, Rao C, Mathers CD, Hansell AL, Held LS, et al. Chronic obstructive pulmonary disease: current burden and future projections. The European respiratory journal 2006;27:397-412.

10. Mathers CD, Loncar D. Projections of global mortality and burden of disease from 2002 to 2030. PLoS Med 2006;3:e442.

11. World Health Organization. Chronic obstructive pulmonary disease (COPD) 2011. Available from: http://www.who.int/respiratory/copd. Accessed October 30, 2015.

12. Ma J, Ward EM, Siegel RL, Jemal A. Temporal Trends in Mortality in the United States, 1969-2013. Jama 2015;314:1731-9.

13. Barnes PJ. Chronic obstructive pulmonary disease: effects beyond the lungs. PLoS Med 2010;7:e1000220.

14. Agusti A, Calverley PM, Celli B, Coxson HO, Edwards LD, Lomas DA, et al. Characterisation of COPD heterogeneity in the ECLIPSE cohort. Respir Res 2010;11:122.

15. Janssen DJ, Spruit MA, Leue C, Gijsen C, Hameleers H, Schols JM, et al. Symptoms of anxiety and depression in COPD patients entering pulmonary rehabilitation. Chron Respir Dis 2010;7:147-57.

16. Maurer J, Rebbapragada V, Borson S, Goldstein R, Kunik ME, Yohannes AM, et al. Anxiety and depression in COPD: current understanding, unanswered questions, and research needs. Chest 2008;134:43S-56S

17. Global Strategy for the Diagnosis, Management and Prevention of COPD, Global Initiative for Chronic Obstructive Lung Disease (GOLD) 2015. Available from: http://www.goldcopd.org/.

18. Pauwels RA, Buist AS, Calverley PM, Jenkins CR, Hurd SS. Global strategy for the diagnosis, management, and prevention of chronic obstructive pulmonary disease. NHLBI/WHO Global Initiative for Chronic Obstructive Lung Disease (GOLD) Workshop summary. Am J Respir Crit Care Med 2001;163:1256-76.

19. Currie GP, Rossiter C, Miles SA, Lee DK, Dempsey OJ. Effects of tiotropium and other long acting bronchodilators in chronic obstructive pulmonary disease. Pulm Pharmacol Ther 2006;19:112-9.

20. Mahler DA. The effect of inhaled beta2-agonists on clinical outcomes in chronic obstructive pulmonary disease. J Allergy Clin Immunol 2002;110:S298-303.

21. Montuschi P. Pharmacological treatment of chronic obstructive pulmonary disease. Int J Chron Obstruct Pulmon Dis 2006;1:409-23.

22. Skold CM, Hed J, Eklund A. Smoking cessation rapidly reduces cell recovery in bronchoalveolar lavage fluid, while alveolar macrophage fluorescence remains high. Chest 1992;101:989-95.

23. Lancaster T, Stead LF. Individual behavioural counselling for smoking cessation. The Cochrane database of systematic reviews 2000:CD001292. 
24. Stead LF, Lancaster T. Group behaviour therapy programmes for smoking cessation. The Cochrane database of systematic reviews 2000:CD001007.

25. Spruit MA, Singh SJ, Garvey C, ZuWallack R, Nici L, Rochester C, et al. An official American Thoracic Society/European Respiratory Society statement: key concepts and advances in pulmonary rehabilitation. Am J Respir Crit Care Med 2013;188:e13-64.

26. Corhay JL, Dang DN, Van Cauwenberge H, Louis R. Pulmonary rehabilitation and COPD: providing patients a good environment for optimizing therapy. Int J Chron Obstruct Pulmon Dis 2014;9:27-39.

27. Lacasse Y, Brosseau L, Milne S, Martin S, Wong E, Guyatt GH, et al. Pulmonary rehabilitation for chronic obstructive pulmonary disease. The Cochrane database of systematic reviews 2002:CD003793.

28. Puhan MA, Gimeno-Santos E, Scharplatz M, Troosters T, Walters EH, Steurer J. Pulmonary rehabilitation following exacerbations of chronic obstructive pulmonary disease. The Cochrane database of systematic reviews 2011:CD005305.

29. McCarthy B, Casey D, Devane D, Murphy K, Murphy E, Lacasse Y. Pulmonary rehabilitation for chronic obstructive pulmonary disease. The Cochrane database of systematic reviews 2015;2:CD003793.

30. Effing T, Monninkhof EM, van der Valk PD, van der Palen J, van Herwaarden CL, Partidge MR, et al. Self-management education for patients with chronic obstructive pulmonary disease. Cochrane Database Syst Rev 2007:CD002990.

31. Effing TW, Bourbeau J, Vercoulen J, Apter AJ, Coultas D, Meek P, et al. Self-management programmes for COPD: moving forward. Chron Respir Dis 2012;9:27-35.

32. Dreeben O. Patient education in rehabilitation: Jones and Bartlett Publishers, LLC; 2010.

33. Bourbeau J, Julien M, Maltais F, Rouleau M, Beaupre A, Begin R, et al. Reduction of hospital utilization in patients with chronic obstructive pulmonary disease: a disease-specific self-management intervention. Arch Intern Med 2003;163:585-91.

34. Rice K, Bourbeau J, MacDonald R, Wilt TJ. Collaborative self-management and behavioral change. Clin Chest Med 2014;35:337-51.

35. Bourbeau J, Nault D, Dang-Tan T. Self-management and behaviour modification in COPD. Patient Educ Couns 2004;52:271-7.

36. Howland J, Nelson EC, Barlow PB, McHugo G, Meier FA, Brent P, et al. Chronic obstructive airway disease. Impact of health education. Chest 1986;90:233-8.

37. Blake RL, Jr., Vandiver TA, Braun S, Bertuso DD, Straub V. A randomized controlled evaluation of a psychosocial intervention in adults with chronic lung disease. Fam Med 1990;22:365-70.

38. Littlejohns P, Baveystock CM, Parnell H, Jones PW. Randomised controlled trial of the effectiveness of a respiratory health worker in reducing impairment, disability, and handicap due to chronic airflow limitation. Thorax 1991;46:559-64.

39. Adams SG, Smith PK, Allan PF, Anzueto A, Pugh JA, Cornell JE. Systematic review of the chronic care model in chronic obstructive pulmonary disease prevention and management. Arch Intern Med 2007;167:551-61.

40. Bourbeau J, Nault D. Self-management strategies in chronic obstructive pulmonary disease. Clin Chest Med 2007;28:617-28, vii.

41. Blumenthal JA, Emery CF, Smith PJ, Keefe FJ, Welty-Wolf K, Mabe S, et al. The effects of a telehealth coping skills intervention on outcomes in chronic obstructive pulmonary disease: primary results from the INSPIRE-II study. Psychosom Med 2014;76:581-92.

42. O'Neill ES. Illness representations and coping of women with chronic obstructive pulmonary disease: a pilot study. Heart Lung 2002;31:295-302.

43. Lazarus RS, Folkman S. Stress, appraisal and coping. New York: Springer; 1984.

44. Grady KL, Wang E, White-Williams C, Naftel DC, Myers S, Kirklin JK, et al. Factors associated with stress and coping at 5 and 10 years after heart transplantation. J Heart Lung Transplant 2013;32:43746.

45. Mohr C, Braun S, Bridler R, Chmetz F, Delfino JP, Kluckner VJ, et al. Insufficient coping behavior under chronic stress and vulnerability to psychiatric disorders. Psychopathology 2014;47:235-43. 
46. Rabe KF, Hurd S, Anzueto A, Barnes PJ, Buist SA, Calverley P, et al. Global strategy for the diagnosis, management, and prevention of chronic obstructive pulmonary disease: GOLD executive summary. Am J Respir Crit Care Med 2007;176:532-55.

47. McCathie HC, Spence SH, Tate RL. Adjustment to chronic obstructive pulmonary disease: the importance of psychological factors. Eur Respir J 2002;19:47-53.

48. Scharloo M, Kaptein AA, Weinman J, Hazes JM, Willems LN, Bergman W, et al. Illness perceptions, coping and functioning in patients with rheumatoid arthritis, chronic obstructive pulmonary disease and psoriasis. J Psychosom Res 1998;44:573-85.

49. Ashutosh K, Haldipur C, Boucher ML. Clinical and personality profiles and survival in patients with COPD. Chest 1997;111:95-8.

50. Monninkhof E, van der Aa M, van der Valk P, van der Palen J, Zielhuis G, Koning K, et al. A qualitative evaluation of a comprehensive self-management programme for COPD patients: effectiveness from the patients' perspective. Patient Educ Couns 2004;55:177-84.

51. Wempe JB, Wijkstra PJ. The influence of rehabilitation on behaviour modification in COPD. Patient Educ Couns 2004;52:237-41.

52. Blount RL, Simons LE, Devine KA, Jaaniste T, Cohen LL, Chambers CT, et al. Evidence-based assessment of coping and stress in pediatric psychology. J Pediatr Psychol 2008;33:1021-45.

53. Ramfelt E, Lutzen K. Patients with cancer: their approaches to participation in treatment plan decisions. Nurs Ethics 2005;12:143-55.

54. Hood L, Friend SH. Predictive, personalized, preventive, participatory (P4) cancer medicine. Nat Rev Clin Oncol 2011;8:184-7.

55. Hood L. Systems biology and p4 medicine: past, present, and future. Rambam Maimonides Med J 2013;4:e0012.

56. World Health Organisation. Patient safety. APPS definition of partnership. Available from: http://www.who.int/patientsafety/implementation/apps/definition/en/. Accessed November 06, 2015.

57. World Health Organisation. Building a Working Definition of Partnership. Available from: http://www.who.int/patientsafety/implementation/apps/resources/defining_partnerships-apps.pdf. Accessed November 06, 2015. 


\section{Chapter 2}

THE RELATIONSHIP BETWEEN COPING STYLES AND CLINICAL OUTCOMES IN PATIENTS WITH COPD ENTERING PULMONARY REHABILITATION

Ana Stoilkova, Emiel F.M. Wouters, Martijn A. Spruit, Frits M.E. Franssen, Daisy J.A: Janssen 


\section{Abstract}

\section{Background}

Symptoms of anxiety, depression and exercise intolerance contribute to an impaired health status in patients with Chronic Obstructive Pulmonary Disease (COPD). Coping styles may also be related to symptoms and health status. Objectives of this study were to assess the distribution of coping styles in patients entering pulmonary rehabilitation (PR) with and without anxiety and/or depression; and to assess whether coping styles contribute to exercise intolerance and reduced health status.

\section{Methods}

Coping styles were studied in 698 patients using the Utrecht Coping List (UCL). Disease-specific health status (St. George's Respiratory Questionnaire, SGRQ), anxiety and depression (Hospital Anxiety and Depression Scale, HADS), exercise tolerance (6minute walking distance, 6MWD) and clinical characteristics were assessed.

\section{Results}

High levels (16.5\%) of active confronting coping style were rarely reported. A minority of patients used low levels (17.5\%) of passive reaction pattern coping style. Differences in coping profiles were present between patients with and without anxiety and/or depression. A higher level of active confronting coping style was associated with a higher 6MWD (Beta 0.092, $p<0.01$ ), while a higher level of avoidance coping style was associated with a lower 6MWD (Beta $-0.074, p=0.017$ ). The UCL subscales were not related to SGRQ total score $(p>0.05)$.

\section{Conclusions}

In COPD patients entering PR, coping styles were associated with symptoms of anxiety, depression and exercise intolerance, but not associated with disease-specific health status. Future studies should examine whether interventions aiming at optimising coping styles during PR can improve outcomes for patients with COPD. 


\section{Introduction}

Chronic obstructive pulmonary disease (COPD) is an important cause of morbidity and mortality worldwide, and in turn, a major public health problem. COPD is defined as a progressive chronic inflammatory condition of the lungs, characterized by airflow limitation which is not completely reversible. ${ }^{1}$ While dyspnoea, wheezing, chronic coughing and sputum are the main respiratory symptoms, skeletal muscle weakness and exercise intolerance are important extra-pulmonary features of COPD. ${ }^{2-4}$

Patients with COPD may also experience psychological disturbances such as anxiety and depression, low self-efficacy, decline in cognitive functioning and coping difficulties. ${ }^{5,6}$ Coping is defined as a combination of constantly changing behavioural and/or cognitive efforts to manage situational demands which are the result of a person's confrontation and evaluation of a stressor. ${ }^{7}$ Patients' coping with daily symptoms and limitations may have more influence on important patient-centred outcomes (i.e., exercise intolerance and health status) than the impaired lung function. ${ }^{8}$ To date, this has not been confirmed. Therefore, the relationship between coping styles, exercise intolerance and disease-specific health status in patients with COPD remains unknown.

Previously, a coping style associated with withdrawal was correlated with higher levels of anxiety and depression and a reduced disease-specific health status in patients with COPD. ${ }^{6}$ Moreover, the relationship between symptoms of anxiety and/or depression and an impaired disease-specific health status has been established in COPD [5]. Therefore, symptoms of anxiety and depression need to be considered as possible confounding variables of the relationship between coping styles and health status.

Medical care for patients with chronic illnesses nowadays emphasizes on patientcentred care provided by interdisciplinary teams, which involves self-management education and shared decision making. ${ }^{9}$ For example, pulmonary rehabilitation (PR) is designed to reduce symptoms and to improve functional status and independence in patients with COPD, by offering a patient-tailored interdisciplinary program focusing on physical, psychological and social functioning. ${ }^{10}$ It may be important that members of the PR team consider patient's individual coping style.

The aims of the present cross-sectional observational study were to assess the distribution of coping styles in COPD patients with and without clinically relevant symptoms of anxiety and depression entering PR; and to assess whether and to what extent coping styles contribute to exercise intolerance, as well as to disease-specific 
health status. We hypothesised a priori that the distribution of coping styles differs among patients with and without clinically relevant symptoms of anxiety and/or depression. Furthermore, we hypothesised that coping styles of patients with COPD entering PR are related to exercise intolerance and disease-specific health status.

\section{Methods}

\section{Design}

A cross-sectional observational study was used to assess the distribution of coping styles in COPD patients with and without clinically relevant symptoms of anxiety and depression entering PR.

\section{Patients}

Patients with mild to very severe COPD, admitted between January 2005 and December 2009 to $\mathrm{CIRO}+$, a centre of expertise for chronic organ failure (Horn, the Netherlands) for a comprehensive interdisciplinary PR program were included in this study. ${ }^{11}$ The diagnosis of COPD was based on the Global Initiative for Chronic Obstructive Lung Disease (GOLD) criteria. ${ }^{12}$ Ethical approval was not indicated because all of the tests were done as part of the clinical routine and retrospectively analysed. The institutional board of directors of $\mathrm{CIRO}+$, Horn, the Netherlands reviewed and approved the use of patients' records, data analysis and reporting for the study.

\section{Instruments}

As part of the clinical routine, the following parameters were assessed before start of PR: demographics; exercise tolerance (6-minute walking distance $(6 \mathrm{MWD})^{13}$ ); arterial blood gases; body composition (body-mass index (BMI) and fat-free mass index $\left.(\mathrm{FFMI})^{14}\right)$; dyspnoea (Medical Research Council dyspnoea scale $(\mathrm{MRC})^{15}$ ) and coexisting morbidities (Charlson co-morbidity index ${ }^{16}$ ). Furthermore, pulmonary function was assessed using spirometry (Masterlab ${ }^{\circledR}$, Germany). Post-bronchodilator forced expiratory volume in the first second $\left(\mathrm{FEV}_{1}\right)$ and forced vital capacity (FVC) were calculated from the flow-volume curve and were expressed as percentage of reference values. ${ }^{17}$

\section{Coping styles}

The Utrecht Coping List (UCL) was used to assess coping styles. ${ }^{18}$ It represents a generic measure of coping applicable to stressors in general or to a given situation. ${ }^{18}$ The UCL consists of 47 items describing a specific coping behaviour, divided in seven 
subscales: active confronting, palliative reaction, avoidance, seeking social support, passive reaction pattern, expressing emotions and reassuring thoughts (See Supplemental material, Table S2.1 for details). Response options for each item are: 'seldom or never' (1 point), 'sometimes' ( 2 points), 'often' (3 points) and 'very often' (4 points). Mean total scores are calculated for every subscale. A higher score indicates an increased tendency towards using that specific coping style. Furthermore, scores are categorized in: very low, low, medium, high, or very high; based on Dutch norm scores, which are calculated for men and women in different age categories. ${ }^{18}$

\section{Symptoms of anxiety and depression}

The Hospital Anxiety and Depression Scale (HADS) was used to evaluate the presence of symptoms of anxiety and/or depression. ${ }^{19}$ The HADS is a self-administered questionnaire, consisting of 14 items divided into two subscales: anxiety (HADS-A) and depression (HADS-D). Scores for both subscales range from 0 (optimal) to 21 (worst) points. A score equal to or greater than 10 represents the presence of clinically relevant symptoms of anxiety or depression. ${ }^{19}$ The HADS was used frequently among COPD patients undergoing PR. ${ }^{5}$

\section{Disease-specific health status}

Disease-specific health status was assessed using the self-administered St. George's Respiratory Questionnaire (SGRQ). ${ }^{20}$ A total score and three domain scores (symptoms, activity and impact) are provided. Scores range from 0 (best) to 100 points (worst).

\section{Statistics}

Data were analysed using SPSS 17.0 (SPSS Inc. Chicago, IL). Continuous variables were tested for normality and are presented as mean and standard deviation (SD). Categorical variables were described as frequencies. Independent sample $t$-tests were used to study differences in mean UCL subscales scores between patients with and without symptoms of anxiety and/or depression. For the assessment of possible differences in coping profiles between patients with and without symptoms of anxiety and/or depression, two linear regression models using forced entry method were developed. For the first model, the mean UCL subscale scores were entered as dependent variables, while the HADS-A score ( $<10$ points or $\geq 10$ points), age, sex, $\mathrm{FEV}_{1}, \mathrm{MRC}$ and $6 \mathrm{MWD}$ were entered as independent variables. Model two only differs in the use of HADS-D score instead of HADS-A score.

Forced entry linear regression analysis was also used to assess the relationship between coping styles and exercise intolerance. The 6MWD was entered as dependent variable and the seven mean coping subscale scores were entered as 
independent variables. Additionally, the following variables that showed bivariate correlation with 6MWD (Pearson correlation coefficient $>0.30$ ) were also entered as independent variables: age, sex, MRC dyspnoea scale, FEV ${ }_{1}, B M I, F F M I, S G R Q$ total score, HADS-A score and HADS-D score.

Furthermore, to study the relationship between coping styles and diseasespecific health status, we developed a linear regression model using forced entry method with the SGRQ total score as dependent variable and the seven mean coping subscales as independent variables. The 6MWD, FEV 1 , MRC dyspnoea scale, HADS-A score and HADS-D score showed bivariate correlation with SGRQ total score and were also entered as independent variables. The following variables did not show bivariate correlation with SGRQ total score and were not included in the final model: sex, age, Charlson comorbidity index score, BMI and long-term oxygen therapy.

All tests were two tailed with alpha set at $p<0.05 .^{21}$

\section{Results}

\section{General patient characteristics}

We included 698 patients (GOLD stage I and II, 280 patients (40.1\%); GOLD stage III, 275 patients (39.4\%); GOLD stage IV, 143 patients (20.5\%)). In general, patients had a normal BMI and FFMI; an impaired exercise tolerance; and an impaired diseasespecific health status (Table 2.1). Clinically relevant symptoms of anxiety were reported by 209 patients $(29.9 \%)$, while clinically relevant symptoms of depression were reported by 162 patients (23.3\%).

\section{Coping styles}

High levels of active confronting coping style were reported by $16.5 \%$ of the patients (Figure 2.1). Furthermore, about half of the patients reported medium levels of: palliative reaction, seeking social support, and/or reassuring thoughts coping styles. Additionally, most patients used a medium (38.5\%) or high (43.9\%) levels of passive reaction pattern coping style.

\section{Coping styles and symptoms of anxiety}

Statistically significant differences were found between patients with and without clinically relevant symptoms of anxiety in the following UCL coping styles: active confronting, palliative reaction, avoidance, passive reaction pattern and expressing emotions coping style (all $p<0.0005$ ). This was confirmed by linear regression analysis after adjusting for age, sex, $\mathrm{FEV}_{1}, \mathrm{MRC}$ and 6MWD (Figure 2.2). 
Table 2.1 General patient characteristics

\begin{tabular}{|c|c|}
\hline & Patients ( $n=698)$ \\
\hline Age (years) & $63.5(9.6)$ \\
\hline $\mathrm{FEV}_{1}$ (litres) & $1.3(0.5)$ \\
\hline $\mathrm{FEV}_{1}(\%$ predicted $)$ & 47.6 (17.9) \\
\hline $\mathrm{FEV}_{1} / \mathrm{FVC}(\%)$ & $39.2(11.3)$ \\
\hline Charlson comorbidity index (points) & $1.7(1.1)$ \\
\hline MRC dyspnoea scale (grade) & $3.3(1.1)$ \\
\hline $\mathrm{BMI}\left(\mathrm{kg} \cdot \mathrm{m}^{-2}\right)$ & $25.4(4.8)$ \\
\hline FFMI (kg.m $\left.{ }^{-2}\right)$ & $16.4(2.2)$ \\
\hline SGRQ Symptoms (points) & $59.7(20.6)$ \\
\hline SGRQ Activity (points) & $70.1(20.0)$ \\
\hline SGRQ Impact (points) & $41.9(18.5)$ \\
\hline SGRQ Total (points) & $53.5(16.7)$ \\
\hline 6MWD (meters) & $442.1(119.1)$ \\
\hline $\mathrm{PaO}_{2}(\mathrm{kPa})$ & $9.4(1.3)$ \\
\hline $\mathrm{PaCO}_{2}(\mathrm{kPa})$ & $5.3(0.6)$ \\
\hline $\mathrm{HbCO}(\%)$ & $2.6(2.1)$ \\
\hline Current smokers, n (\%)* & $268(40.1)$ \\
\hline HADS-A (points) & $7.1(4.3)$ \\
\hline HADS-D (points) & $6.6(3.8)$ \\
\hline
\end{tabular}

Data are presented as mean (standard deviation, SD) or number of patients (\%). * $n=668$.

Abbreviations: $\mathrm{FEV}_{1}$ : forced expiratory volume in the first second; FVC: forced vital capacity; MRC: Medical Research Council; BMI: body mass index; FFMI: fat-free mass index; SGRQ: St. George Respiratory Questionnaire; 6MWD: 6-minute walking distance; $\mathrm{PaO}_{2}$ : resting arterial oxygen tension; $\mathrm{PaCO}_{2}$ : resting arterial carbon dioxide tension; HbCO: arterial blood carboxyhemoglobin; HADS-A: Hospital Anxiety and Depression Scale, anxiety subscale; HADS-D: Hospital Anxiety and Depression Scale, depression subscale.

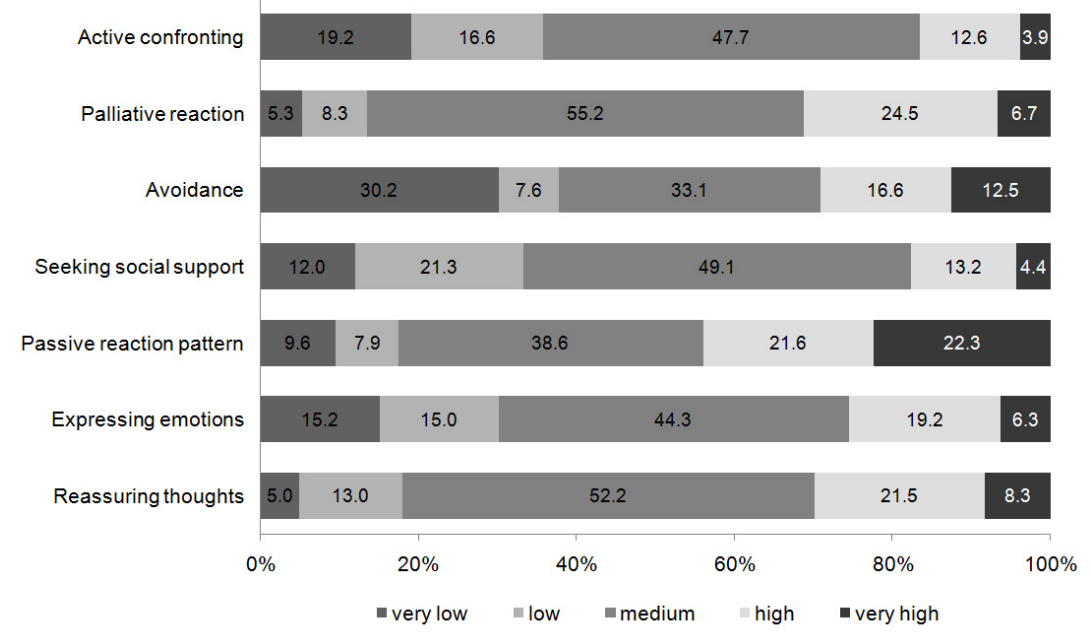

Figure 2.1 Distribution of UCL coping styles in COPD patients entering PR. Proportion of patients using a very low, low, medium, high or very high level of coping style. 
Indeed, patients with symptoms of anxiety reported a lower use of active confronting style (Beta=-0.177, $p<0.0005$ ) and an increased use of palliative reaction (Beta $=0.131$, $p=0.001$ ), avoidance (Beta $=0.136, p<0.0005)$, passive reaction pattern (Beta $=0.474$, $p<0.0005$ ) and expressing emotions (Beta $=0.177, p<0.0005)$ coping styles. Mean UCL scores of seeking social support (Beta=-0.001, n.s.) and reassuring thoughts (Beta $=0.033$, n.s.) coping styles were comparable for patients with and without clinically relevant symptoms of anxiety $(p>0.05)$.

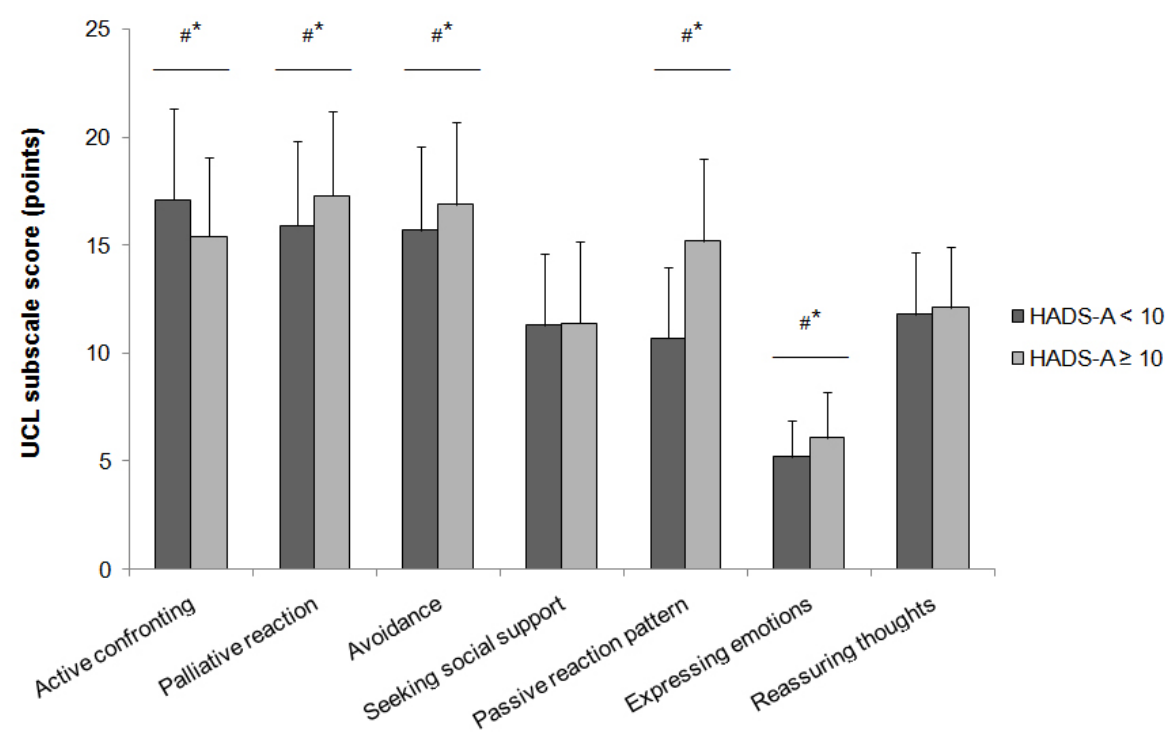

Figure 2.2 UCL subscale scores of patients with and without symptoms of anxiety.

Data are presented as mean (standard deviation, SD). ${ }^{*} p<0.0005$, based on independent sample T test; * $p \leq 0.001$, based on linear regression analysis, adjusted for age, sex, FEV ${ }_{1}, \mathrm{MRC}$ and 6MWD. Abbreviations: $\mathrm{FEV}_{1}$ : forced expiratory volume in the first second; MRC: Medical Research Council; 6MWD: 6-minute walking distance; HADS-A: Hospital Anxiety and Depression Scale, anxiety subscale.

\section{Coping styles and symptoms of depression}

Mean UCL coping style scores of: active confronting, avoidance and passive reaction pattern coping style were statistically significant different between patients with and without clinically relevant symptoms of depression, as assessed by independent sample $t$-tests (all $p<0.0005$ ). This was confirmed by linear regression analysis after adjusting for age, sex, $\mathrm{FEV}_{1}, \mathrm{MRC}$ and $6 \mathrm{MWD}$ (Figure 2.3). Patients with symptoms of depression reported a lower use of active confronting coping style (Beta=-0.163, $p<0.0005)$ and an increased use of avoidance (Beta=0.134, $p=0.001$ ) and passive 
reaction pattern (Beta $=0.397, p<0.0005$ ) coping styles. Additionally, patients with symptoms of depression reported lower levels of seeking social support coping (Beta=-0.083, $p=0.04$ ) than patients without symptoms of depression.

See Supplemental material, Table S2.2 for distribution of UCL coping styles of patients with COPD, stratified for clinically relevant symptoms of anxiety and/or depression.

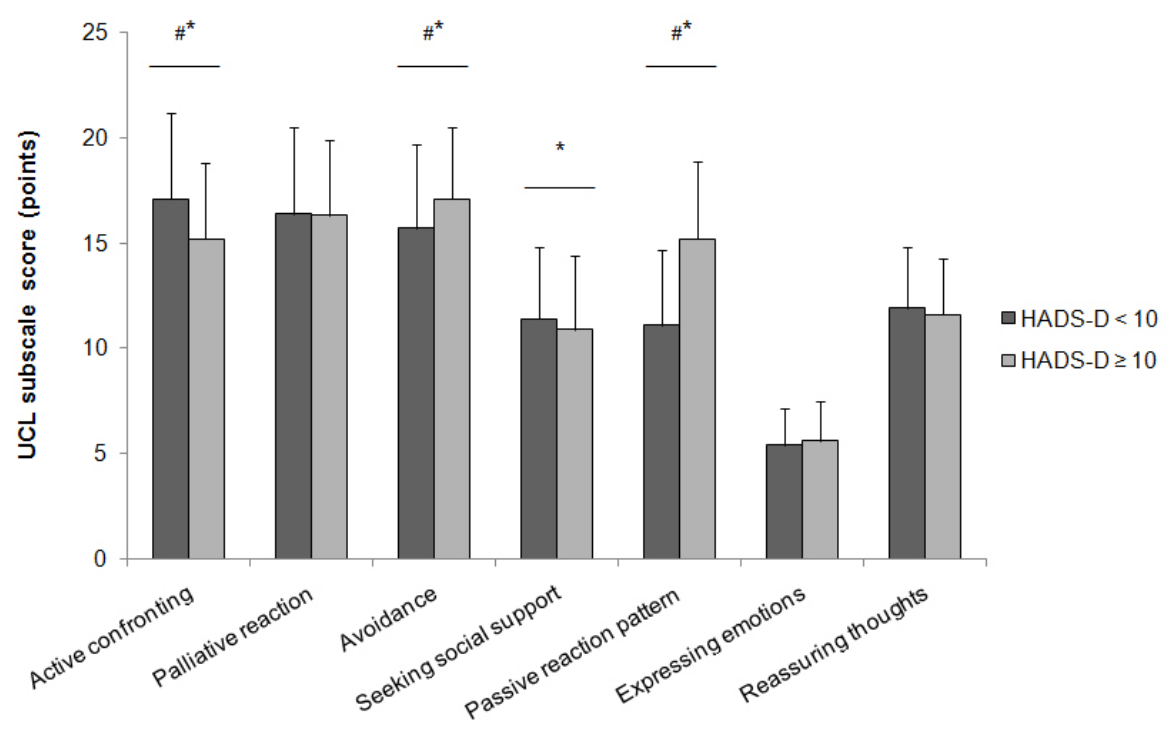

Figure 2.3 UCL subscale scores of patients with and without symptoms of depression.

Data are presented as mean (standard deviation, SD). ${ }^{\#} p<0.0005$, based on independent sample T test; $* p<0.05$, based on linear regression analysis, adjusted for age, sex, $\mathrm{FEV}_{1}, \mathrm{MRC}$ and 6MWD. Abbreviations: $\mathrm{FEV}_{1}$ : forced expiratory volume in the first second; MRC: Medical Research Council; 6MWD: 6-minute walking distance; HADS-D: Hospital Anxiety and Depression Scale, depression subscale.

\section{Coping styles and exercise intolerance}

Several coping styles showed a relationship with 6MWD, after controlling for sex, age, MRC, FEV 1 , BMI, FFMI, SGRQ total score, HADS-A score and HADS-D score (Table 2.2). A higher level of active confronting coping style was associated with a higher 6MWD, while a higher level of avoidance coping style was associated with a lower 6MWD. This linear regression model explained $51.2 \%$ of the variance in 6MWD. 
Table 2.2 The relationship of UCL coping styles with 6MWD: linear regression model.

\begin{tabular}{llcc}
\hline & Correlates & Standardized Beta & $p$-value \\
\hline 6 MWD & Sex & 0.025 & n.s. \\
$\left(R^{2}=0.512\right.$, & Age & -0.278 & $<0.0005$ \\
$p<0.0005)$ & MRC dyspnoea scale & -0.277 & $<0.0005$ \\
& FEV 1 & 0.210 & $<0.0005$ \\
BMI & -0.226 & $<0.0005$ \\
& FFMI & 0.184 & $<0.01$ \\
& SGRQ Total score & -0.259 & $<0.0005$ \\
& UCL Active confronting coping style & 0.092 & $<0.01$ \\
& UCL Palliative reaction coping style & 0.047 & n.s. \\
& UCL Avoidance coping style & -0.074 & 0.02 \\
& UCL Seeking social support coping style & -0.009 & n.s. \\
& UCL Passive reaction pattern coping style & -0.035 & n.s. \\
UCL Expressing emotions coping style & -0.031 & n.s. \\
UCL Reassuring thoughts coping style & -0.064 & n.s. \\
& HADS-A & 0.074 & n.s. \\
HADS-D & 0.017 & n.s. \\
\hline
\end{tabular}

$n=698$. Abbreviations: n.s.: non-significant; 6MWD: 6-minute walking distance; MRC: Medical Research Council; $\mathrm{FEV}_{1}$ : forced expiratory volume in the first second; BMI: body mass index; FFMI: fat-free mass index; SGRQ: St. George Respiratory Questionnaire; UCL: Utrecht Coping List; HADS-A: Hospital Anxiety and Depression Scale, anxiety subscale; HADS-D: Hospital Anxiety and Depression Scale, depression subscale.

\section{Coping styles and disease-specific health status}

Coping styles were not related to SGRQ total score after adjusting for FEV $1,6 M W D$, MRC dyspnoea scale, HADS-A score and HADS-D score (Table 2.3). However, 6MWD, MRC dyspnoea score, HADS-A score and HADS-D score were associated with diseasespecific health status, explaining $48.2 \%$ of SGRQ total score.

Table 2.3 The relationship of UCL coping styles with SGRQ total score: linear regression model.

\begin{tabular}{llcc}
\hline & Correlates & Standardized Beta & $\boldsymbol{p}$-value \\
\hline SGRQ Total score & 6MWD & -0.214 & $<0.0005$ \\
$\left(R^{2}=0.482\right.$, & MRC dyspnoea scale & 0.343 & $<0.0005$ \\
$p<0.0005)$ & FEV 1 & -0.024 & n.s. \\
& UCL Active confronting coping style & 0.051 & n.s. \\
& UCL Palliative reaction coping style & 0.017 & n.s. \\
& UCL Avoidance coping style & -0.058 & n.s. \\
& UCL Seeking social support coping style & 0.025 & n.s. \\
& UCL Passive reaction pattern coping style & 0.068 & n.s. \\
& UCL Expressing emotions coping style & -0.058 & n.s. \\
& UCL Reassuring thoughts coping style & 0.005 & n.s. \\
& HADS-A & 0.203 & $<0.0005$ \\
& HADS-D & 0.170 & $<0.0005$ \\
\hline
\end{tabular}

$n=698$. Abbreviations: n.s.: non-significant; SGRQ: St. George Respiratory Questionnaire; 6MWD: 6-minute walking distance; MRC: Medical Research Council; FEV 1 : forced expiratory volume in the first second; UCL: Utrecht Coping List; HADS-A: Hospital Anxiety and Depression Scale, anxiety subscale; HADS-D: Hospital Anxiety and Depression Scale, depression subscale. 
Excluding non-significant independent variables from both models above, did not change the models significantly (Supplemental Table S2.3 and Table S2.4).

\section{Discussion}

\section{Key findings}

The present study shows that only a minority of the COPD patients entering PR uses a high or very high level of active confronting coping style. Also, a minority of patients uses a very low or low level of passive reaction pattern coping style. Furthermore, patients with and without symptoms of anxiety and/or depression reported different coping profiles. Finally, coping styles are related to exercise intolerance, but not to disease-specific health status.

\section{Coping styles and symptoms of anxiety and/or depression}

The present study shows differences in coping profiles among COPD patients entering PR with and without clinically relevant symptoms of anxiety and/or depression. In fact, patients with symptoms of anxiety and/or depression reported a lower use of active confronting coping style and an increased use of avoidance and passive reaction pattern coping style than patients without symptoms of anxiety and/or depression. Studies including patients with rheumatoid arthritis and patients with chronic pain showed that the use of an active confronting coping style was associated with a higher life satisfaction, higher levels of daily functioning and psychological well-being, and better adjustment to the condition with a lower level of depression or helplessness. ${ }^{7,22-24}$ In patients with COPD hospitalized for an acute exacerbation was shown that a passive reaction pattern coping style and avoidance coping style were used more frequently by patients with psychological distress. ${ }^{25}$ In addition, Scharloo and colleagues showed that a passive reaction pattern style is an important determinant of mental health. ${ }^{26}$ Previous study demonstrated that patients with COPD who frequently used catastrophic withdrawal coping strategies experienced a higher level of anxiety and depression. ${ }^{6}$ Our study, in the context of these prior studies shows the relationship of coping styles with psychological distress in patients with COPD entering PR.

\section{Coping styles and exercise intolerance}

The present study shows that not only patient characteristics like age, dyspnoea, lung function, body composition and disease-specific health status are determinants of exercise intolerance, but also coping styles. Indeed, a higher level of active 
confronting coping style is positively related to exercise tolerance, while higher levels of avoidance coping style are associated with increased impairment in exercise tolerance. This may be explained by the fact that the use of an active confronting coping style is related to higher self-esteem, life satisfaction and compliance with medical advice, whereas avoidance coping style refers to poorer physical functioning in terms of depression, well-being and functional disability. ${ }^{24}$

\section{Coping styles and disease-specific health status}

In contrast to our hypothesis, coping styles were not associated with disease-specific health status, after adjusting for $\mathrm{FEV}_{1}, 6 \mathrm{MWD}$, MRC dyspnoea scale and HADS scores. Previously, Buchi and colleagues showed no relationship between coping styles, as assessed with the Freiburg Coping Questionnaire, and generic health status in COPD patients attending PR. ${ }^{27}$ Nevertheless, McCathie showed a relationship between coping styles and disease-specific health status in outpatients with COPD. ${ }^{6}$ This disparity might be explained by the use of different instruments to assess coping styles. For example, McCathie and colleagues assessed coping styles using the Coping with Illness Questionnaire. ${ }^{6}$ Furthermore, Scharloo and colleagues, showed a relationship between coping styles and generic health status, as assessed with Medical Outcomes Study SF-20. ${ }^{28}$ Moreover, in these studies symptoms of anxiety and depression were not taken into account as possible confounding variables of the relationship between coping styles and health status. This may contribute to the fact that in the present study no relationship was found between coping styles and health status. It is also possible that differences in coping profiles exist between COPD patients entering PR and COPD outpatients. In fact, a previous study reported a difference in the use of coping styles between COPD outpatients and COPD patients who were hospitalized. ${ }^{29}$ The COPD outpatients used predominantly optimistic, supporting and confronting coping styles, described as healthy coping styles, while hospitalized patients relied on fatalistic, palliative and supporting coping styles, described as both - healthy and less healthy coping styles. ${ }^{29}$

\section{Clinical implications}

PR has been shown to improve disease-specific health status, exercise intolerance, dyspnoea, symptoms of anxiety and depression and patients' control over their disease. ${ }^{30}$ Despite these benefits, part of the eligible patients declines participation or drops out during the program. ${ }^{31}$ Moreover, the long-term outcome of PR may be predicted by coping styles. ${ }^{27}$ Coping styles may be a target for interventions during PR. In fact, interventions can optimise coping styles. For example, a systematic review showed that self-management education interventions were able to improve coping styles of patients with rheumatoid arthritis. ${ }^{23}$ These interventions included: group 
sessions aimed at stimulating active confronting coping by teaching self-management skills or skills in dealing with stress; education support groups providing a climate for emotional support and recommendations on coping and self-treatments; and cognitive-behavioural therapy training coping strategies and improving skills in cognitive, emotional and behavioural dealing with the disease. ${ }^{23}$

Self-management education interventions are largely based on the principles of patient's cognitions and behavioural change with the aim to stimulate the patient's active participation in disease management. ${ }^{32}$ Coping styles may be important factors to consider in self-management interventions. However, interventions targeting coping skills and behaviour change are not routinely carried out in the current practice of PR. ${ }^{33}$ Including coping interventions may be important for the best current disease control, as well as for future risk reduction of exacerbations, hospitalization, and the long-term consequences of COPD. ${ }^{34}$ Future studies are needed to examine whether interventions aiming at optimising coping styles during PR can improve outcomes for patients with COPD.

\section{Limitations}

Several methodological issues should be considered in interpreting the results of this study. First, the present study is a cross-sectional study and therefore, does not allow conclusions about causal pathways between symptoms of anxiety and depression, exercise intolerance, and coping styles in patients with COPD. Hence, longitudinal studies are necessary to confirm the present findings. Second, we have chosen the UCL to assess coping styles. However, a variety of coping questionnaires is available. ${ }^{6,7,18}$ The UCL was previously applied in COPD outpatients, and has shown satisfactory psychometric properties in a Dutch population. ${ }^{18,26}$ Other instruments define different coping styles categories and the use of another instrument might have changed our results. Third, multiple instruments exist for assessment of symptoms of anxiety and/or depression. We used the HADS, a well validated instrument frequently used in patients with COPD. However, the choice of the instrument might have influenced our results. Forth, the present study has only included COPD patients entering PR, which may limit the external validity of the present findings. It remains unknown whether and to what extent coping styles of patients with COPD entering PR are comparable with coping styles of patients with COPD who were not referred to, or refused PR. Nevertheless, insight into the coping styles of COPD patients entering PR might provide further directions for development of a patient-tailored PR program. Finally, the current findings need to be interpreted in the light of the number of comparisons that were made in the present study. Nonetheless, multiple findings in the same direction, rather than a single statistically significant result, suggest that these are not due to chance alone. 


\section{Conclusions}

Most patients with COPD entering PR report a very low or low level of active confronting coping style and/or a medium, high or very high level of passive reaction pattern coping style. Coping profiles are different among COPD patients entering PR with and without clinically relevant symptoms of anxiety and/or depression. Finally, coping styles have a relationship with exercise intolerance, but are not related to disease-specific health status. Therefore, it is important to pay attention to coping styles in COPD patients entering PR. Future studies are warranted to examine whether interventions aiming at influencing coping styles can improve patient's coping and thereby, symptoms of anxiety, depression and exercise intolerance. 


\section{References}

1. Pauwels RA, Rabe KF. Burden and clinical features of chronic obstructive pulmonary disease (COPD). Lancet 2004;364:613-20.

2. Wouters EF. Management of severe COPD. Lancet 2004;364:883-95.

3. Seymour JM, Spruit MA, Hopkinson NS, Natanek SA, Man WD, Jackson A, Gosker HR, Schols AM, Moxham J, Polkey MI, Wouters EF. The prevalence of quadriceps weakness in COPD and the relationship with disease severity. Eur Respir J 2010;36:81-8.

4. Spruit MA, Polkey MI, Celli B, Edwards LD, Watkins ML, Pinto-Plata V, Vestbo J, Calverley PM, TalSinger R, Agusti A, Coxson HO, Lomas DA, Macnee W, Rennard S, Silverman EK, Crim CC, Yates J, Wouters EF. Predicting Outcomes from 6-Minute Walk Distance in Chronic Obstructive Pulmonary Disease. J Am Med Dir Assoc 2012;13:291-7.

5. Janssen DJ, Spruit MA, Leue C, Gijsen C, Hameleers H, Schols JM, Wouters EF. Symptoms of anxiety and depression in COPD patients entering pulmonary rehabilitation. Chron Respir Dis 2010;7:147-57.

6. McCathie HC, Spence SH, Tate RL. Adjustment to chronic obstructive pulmonary disease: the importance of psychological factors. Eur Respir J 2002;19:47-53.

7. Lazarus RS, Folkman S. Stress, appraisal and coping. New York: Springer; 1984.

8. Annegarn J, Meijer K, Passos VL, Stute K, Wiechert J, Savelberg HH, Schols AM, Wouters EF, Spruit MA. Problematic Activities of Daily Life are Weakly Associated With Clinical Characteristics in COPD. J Am Med Dir Assoc 2012;13:284-90.

9. Epping-Jordan JE, Pruitt SD, Bengoa R, Wagner EH. Improving the quality of health care for chronic conditions. Qual Saf Health Care 2004;13:299-305.

10. Lacasse Y, Brosseau L, Milne S, Martin S, Wong E, Guyatt GH, Goldstein RS. Pulmonary rehabilitation for chronic obstructive pulmonary disease. Cochrane Database Syst Rev 2002(3):CD003793.

11. Spruit MA, Vanderhoven-Augustin I, Janssen PP, Wouters EF. Integration of pulmonary rehabilitation in COPD. Lancet 2008;371:12-3.

12. Fabbri LM, Hurd SS. Global Strategy for the Diagnosis, Management and Prevention of COPD: 2003 update. Eur Respir J 2003;22:1-2.

13. Hernandes NA, Wouters EF, Meijer K, Annegarn J, Pitta F, Spruit MA. Reproducibility of 6-minute walking test in patients with COPD. Eur Respir J 2011;38:261-7.

14. Schols AM, Soeters PB, Dingemans AM, Mostert R, Frantzen PJ, Wouters EF. Prevalence and characteristics of nutritional depletion in patients with stable COPD eligible for pulmonary rehabilitation. Am Rev Respir Dis 1993;147:1151-6.

15. Spruit MA, Pennings HJ, Janssen PP, Does JD, Scroyen S, Akkermans MA, Mostert R, Wouters EF. Extra-pulmonary features in COPD patients entering rehabilitation after stratification for MRC dyspnea grade. Respir Med 2007;101:2454-63.

16. Charlson ME, Pompei P, Ales KL, MacKenzie CR. A new method of classifying prognostic comorbidity in longitudinal studies: development and validation. J Chronic Dis 1987;40:373-83.

17. Quanjer PH, Tammeling GJ, Cotes JE, Pedersen OF, Peslin R, Yernault JC. Lung volumes and forced ventilatory flows. Report Working Party Standardization of Lung Function Tests, European Community for Steel and Coal. Official Statement of the European Respiratory Society. Eur Respir J Suppl 1993; 16:5-40.

18. Schreurs PJG, van de Willige G, Brosschot JF, Tellegen B, Graus GMH. De Utrechtse Coping Lijs, UCL omgaan met problemen en gebeurtenissen [The Utrecht Coping List]. Lisse, the Netherlands: Swets en Zeitlinger; 1993.

19. Zigmond AS, Snaith RP. The hospital anxiety and depression scale. Acta Psychiatr Scand 1983;67: 361-70.

20. Jones PW, Quirk FH, Baveystock CM. The St George's Respiratory Questionnaire. Respir Med 1991; 85(Suppl B):25-31; discussion 3-7.

21. Altman DG, Gore SM, Gardner MJ, Pocock SJ. Statistical guidelines for contributors to medical journals. Br Med J (Clin Res Ed) 1983;286:1489-93. 
22. Brown GK, Nicassio PM. Development of a questionnaire for the assessment of active and passive coping strategies in chronic pain patients. Pain 1987;31:53-64.

23. Savelkoul M, de Witte L, Post M. Stimulating active coping in patients with rheumatic diseases: a systematic review of controlled group intervention studies. Patient Educ Couns 2003;50:133-43.

24. Maes S, Leventhal H, de Ridder DTD. Coping with chronic illness. In Handbook of Coping. In: Zeidner M, Endler NS, editors. New York: Wiley \& Sons; 1996:221-51.

25. Andenaes R, Kalfoss $\mathrm{MH}$, Wahl AK. Coping and psychological distress in hospitalized patients with chronic obstructive pulmonary disease. Heart Lung 2006;35:46-57.

26. Scharloo M, Kaptein AA, Weinman JA, Willems LN, Rooijmans HG. Physical and psychological correlates of functioning in patients with chronic obstructive pulmonary disease. J Asthma 2000;37: 17-29.

27. Buchi S, Villiger B, Sensky T, Schwarz F, Wolf C, Buddeberg C. Psychosocial predictors of long-term success of in-patient pulmonary rehabilitation of patients with COPD. Eur Respir J 1997;10:1272-7.

28. Scharloo M, Kaptein AA, Weinman J, Hazes JM, Willems LN, Bergman W, Rooijmans HG. Illness perceptions, coping and functioning in patients with rheumatoid arthritis, chronic obstructive pulmonary disease and psoriasis. J Psychosom Res 1998;44:573-85.

29. Yuet LM, Alexander M, Chun CJ. Coping and adjustment in Chinese patients with chronic obstructive pulmonary disease. Int J Nurs Stud 2002;39:383-95.

30. Ries AL. Pulmonary rehabilitation: summary of an evidence-based guideline. Respir Care 2008;53: 1203-7.

31. Sutherland ER, Cherniack RM. Management of chronic obstructive pulmonary disease. $N$ Engl J Med 2004;350:2689-97.

32. Bourbeau J. The role of collaborative self-management in pulmonary rehabilitation. Semin Respir Crit Care Med 2009;30:700-7.

33. Bourbeau J. Making pulmonary rehabilitation a success in COPD. Swiss Med Wkly 2010;140:w13067.

34. Postma D, Anzueto A, Calverley P, Jenkins C, Make BJ, Sciurba FC, Similowski T, van der Molen T, Eriksson G. A new perspective on optimal care for patients with COPD. Prim Care Respir J 2011;20:205-9. 


\section{Supplemental material}

\section{Methods}

Instrument - The Utrecht Coping List

Table S2.1 The Utrecht Coping List subscales.

\begin{tabular}{ll}
\hline Subscale & Definition \\
\hline Active confronting & Evaluate the situation from all angles, put order to things; aimful and \\
(7 items) & confident action to solve the problem \\
Palliative reaction & Distraction searching not to have to think about the problem, trying to \\
(8 items) & feel better by smoking, drinking or relaxing \\
Avoidance & Letting the problem to deal with itself, not confronting it; waiting for what \\
(8 items) & will happen \\
Seeking social support & Looking for comfort and understanding by others; sharing ones troubles \\
(6 items) & or asking for help \\
Passive reaction pattern & Completely being involved in the situation; feeling down, worrying or \\
(7 items) & isolating oneself, not being able to do something about the situation; \\
& worrying about the past \\
Expressing emotions & Showing annoyance or anger; releasing tension \\
(3 items) & \\
Reassuring thoughts & Reassuring oneself with thoughts; others experience difficulties at times \\
(5 items) & too; worse things could happen; feeling courageous \\
\hline
\end{tabular}

\section{Statistics}

The distribution of coping styles was presented after stratification for clinically relevant symptoms of anxiety and/or depression. The UCL subscale levels 'very low' and 'low' were combined into 'low'; the levels 'high' and 'very high' were combined into 'high'. Differences in distribution of coping styles between patients with and without clinically relevant symptoms of anxiety and/or depression were assessed by using Chi-square tests.

Two forced entry linear regression models, by excluding the non-significant independent variables, were developed in order to reassess the relationship between coping styles and exercise intolerance, as well as between coping styles and diseasespecific health status, respectively. For the first model, the 6MWD was entered as dependent variable, and the following variables that were significantly related to $6 \mathrm{MWD}$ in the regression model as reported in Table 2.2 of the manuscript $(p<0.05)$, were re-entered as independent variables: age, MRC dyspnoea scale, FEV ${ }_{1}, B_{M I}, F F M I$, SGRQ Total score, UCL active confronting coping style and UCL avoidance coping style. For the second linear regression model, the SGRQ total score was entered as 
dependent variable, and the variables which showed a relationship with SGRQ total score in the regression model as reported in Table 2.3 of the manuscript $(p<0.05)$, were re-entered as independent variables: 6MWD, MRC dyspnoea scale, HADS-A and HADS-D.

\section{Results}

\section{Distribution of coping styles in patients with and without clinically relevant symptoms of anxiety}

The distribution of coping styles of patients with COPD with and without clinically relevant symptoms of anxiety and/or depression is shown in Table S2.2.

A statistically significant difference was reported between patients with and without clinically relevant symptoms of anxiety in the following subscales: active confronting coping; seeking social support coping; passive reaction pattern and expressing emotions coping style. A high level of active confronting coping style was rarely reported by patients with symptoms of anxiety. Furthermore, $81.3 \%$ of the patients with symptoms of anxiety showed a high level of passive reaction pattern coping style, while approximately half of the patients (48.9\%) without symptoms of anxiety predominantly showed a medium level of this coping style. The levels of palliative reaction coping; avoidance and reassuring thoughts coping styles were comparable between patients with and without clinically relevant symptoms of anxiety.

\section{Distribution of coping styles in patients with and without clinically relevant symptoms of depression}

A statistically significant difference was reported between patients with and without clinically relevant symptoms of depression in the level of: active confronting coping style, avoidance coping and passive reaction pattern coping style (Table S2.2). Patients with symptoms of depression showed a tendency to use lower levels of an active confronting coping style. Additionally, $84.0 \%$ of the patients with symptoms of depression showed a high level of passive reaction coping style, while only $31.9 \%$ of the patients without symptoms of depression used a high level of passive reaction pattern coping style. The levels of: palliative reaction; seeking social support; expressing emotions and reassuring thoughts coping styles were comparable between patients with and without clinically relevant symptoms of depression. 


\section{Coping styles and exercise intolerance}

Table S2.3 shows the relationship between several coping styles and exercise intolerance, after excluding non-significant independent variables from the model and confirms the previous findings. Indeed, the use of higher levels of active confronting coping was associated with a better 6MWD, whereas the use of higher levels of avoidance was related to a worse 6MWD. The $R^{2}$ of the forced entry linear regression model for 6MWD was 0.505 ( $p<0.0005)$.

\section{Coping styles and disease-specific health status}

The association between 6MWD, MRC dyspnoea scale, HADS-A score and HADS-D score with SGRQ total did not change significantly (Table S2.4), when compared with the findings based on the results when non-significant independent variables were taken into account. The $R^{2}$ of the forced entry linear regression model for SGRQ total score was $0.473(p<0.0005)$.

Table S2.2 Distribution of UCL coping styles after stratification for clinically relevant symptoms of anxiety and/or depression.

\begin{tabular}{|c|c|c|c|c|c|c|c|}
\hline $\begin{array}{l}\text { Coping style } \\
\text { level }\end{array}$ & & $\begin{array}{c}\text { HADS-A<10 } \\
n=489\end{array}$ & $\begin{array}{c}\text { HADS-A } \geq 10 \\
n=209\end{array}$ & $p$-value & $\begin{array}{c}\text { HADS-D<10 } \\
n=536\end{array}$ & $\begin{array}{c}\text { HADS-D } \geq 10 \\
n=162\end{array}$ & $p$-value \\
\hline \multirow[t]{3}{*}{ Active confronting } & low & 151 (30.9) & $99(47.4)$ & & $170(31.7)$ & $80(49.4)$ & \\
\hline & medium & $235(48.1)$ & 98 (46.9) & $<0.0005$ & $264(49.3)$ & $69(42.6)$ & $<0.0005$ \\
\hline & high & $103(21.1)$ & $12(5.7)$ & & $102(19.0)$ & $3(8.0)$ & \\
\hline \multirow[t]{3}{*}{ Palliative reaction } & low & $70(14.3)$ & $25(12.0)$ & & 69 (12.9) & $26(16.0)$ & \\
\hline & medium & $275(56.2)$ & $110(52.6)$ & 0.272 & 294 (54.9) & $91(56.2)$ & 0.413 \\
\hline & high & $144(29.4)$ & $74(35.4)$ & & $173(32.3)$ & $45(27.8)$ & \\
\hline \multirow[t]{3}{*}{ Avoidance } & low & $188(38.4)$ & $76(36.4)$ & & $210(39.2)$ & $54(33.3)$ & \\
\hline & medium & $167(34.2)$ & $64(30.6)$ & 0.316 & $184(34.3)$ & $47(29.0)$ & 0.023 \\
\hline & high & $134(27.4)$ & $69(33.0)$ & & $142(26.5)$ & $61(37.7)$ & \\
\hline \multirow[t]{3}{*}{ Seeking social support } & low & 149 (30.5) & $84(40.2)$ & & $168(31.3)$ & $65(40.1)$ & \\
\hline & medium & $257(52.6)$ & $85(40.7)$ & 0.013 & $271(50.6)$ & $71(43.8)$ & 0.115 \\
\hline & high & $83(17.0)$ & $40(19.1)$ & & $97(18.1)$ & $26(16.0)$ & \\
\hline \multirow{3}{*}{ Passive reaction pattern } & low & $113(23.1)$ & $9(4.3)$ & & $117(21.8)$ & $5(3.1)$ & \\
\hline & medium & 239 (48.9) & $30(14.4)$ & $<0.0005$ & $248(46.3)$ & $21(13.0)$ & $<0.0005$ \\
\hline & high & $137(28.0)$ & $170(81.3)$ & & 171 (31.9) & $136(84.0)$ & \\
\hline \multirow[t]{3}{*}{ Expressing emotions } & low & 165 (33.7) & $46(22.0)$ & & $164(30.6)$ & 47 (29.0) & \\
\hline & medium & $228(46.6)$ & $81(38.8)$ & $<0.0005$ & $236(44.0)$ & $73(45.1)$ & 0.929 \\
\hline & high & 96 (19.6) & $82(39.2)$ & & $136(25.4)$ & $42(25.9)$ & \\
\hline \multirow[t]{3}{*}{ Reassuring thoughts } & low & $94(19.2)$ & $32(15.3)$ & & $92(17.2)$ & $34(21.0)$ & \\
\hline & medium & 247 (50.5) & $117(56.0)$ & 0.333 & 277 (51.7) & $87(53.7)$ & 0.282 \\
\hline & high & $148(30.3)$ & $60(28.7)$ & & $167(31.2)$ & $41(25.3)$ & \\
\hline
\end{tabular}

Data are presented as number of patients (\%). Abbreviations: HADS-A: Hospital Anxiety and Depression Scale, anxiety subscale; HADS-D: Hospital Anxiety and Depression Scale, depression subscale. 
Table S2.3 The relationship of UCL coping styles with 6MWD: linear regression model.

\begin{tabular}{llcc}
\hline & Correlates & Standardized Beta & $\boldsymbol{p}$-value \\
\hline 6 MWD & Age & -0.280 & $<0.0005$ \\
$\left(R^{2}=0.505\right.$, & MRC dyspnoea scale & -0.276 & $<0.0005$ \\
$p<0.0005)$ & FEV 1 & 0.222 & $<0.0005$ \\
& BMI & -0.245 & $<0.0005$ \\
& FFMI & 0.202 & $<0.0005$ \\
& SGRQ Total score & -0.237 & $<0.0005$ \\
& UCL Active confronting coping style & 0.052 & 0.05 \\
& UCL Avoidance coping style & -0.075 & $<0.01$ \\
\hline
\end{tabular}

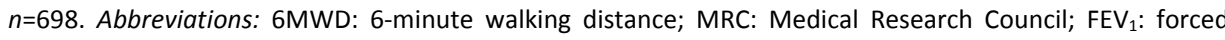
expiratory volume in the first second; BMI: body mass index; FFMI: fat-free mass index; SGRQ: St. George Respiratory Questionnaire; UCL: Utrecht Coping List.

Table S2.4 The relationship of UCL coping styles with SGRQ total score: linear regression model.

\begin{tabular}{llcc}
\hline & Correlates & Standardized Beta & $\boldsymbol{p}$-value \\
\hline SGRQ Total score & 6MWD & -0.216 & $<0.0005$ \\
$\left(R^{2}=0.473\right.$, & MRC dyspnoea scale & 0.356 & $<0.0005$ \\
$p<0.0005)$ & HADS-A & 0.213 & $<0.0005$ \\
& HADS-D & 0.164 & $<0.0005$ \\
\hline
\end{tabular}

n=698. Abbreviations: 6MWD: 6-minute walking distance; MRC: Medical Research Council; SGRQ: St. George Respiratory Questionnaire; HADS-A: Hospital Anxiety and Depression Scale, anxiety subscale; HADSD: Hospital Anxiety and Depression Scale, depression subscale. 


\section{Chapter 3}

\section{COPING STYLES IN PATIENTS WITH COPD BEFORE AND AFTER PULMONARY REHABILITATION}

Ana Stoilkova, Daisy J.A. Janssen, Frits M.E. Franssen, Martijn A. Spruit, Emiel F.M. Wouters

Respiratory Medicine. 2013;107(6):825-833 


\section{Abstract}

\section{Introduction}

Pulmonary rehabilitation (PR) improves physical and psychological symptoms in COPD patients. Patients' coping with daily symptoms and limitations may have more influence on important patient-centred outcomes than the impaired lung function. To date, it remains unknown whether and to what extent coping styles change following $P R$, and whether coping styles are associated with the outcomes of a comprehensive PR.

\section{Methods}

Coping styles were assessed in 303 COPD patients before and after a PR programme using the Utrecht Coping List (UCL). Additionally, lung function, St. George's Respiratory Questionnaire (SGRQ), Hospital Anxiety and Depression Scale, anxiety (HADS-A) and depression (HADS-D) subscales and six-minute walking distance (6MWD) were recorded.

\section{Results}

The level of active confronting coping style increased $(p<0.05)$, whereas the levels of avoidance $(p<0.05)$, passive reaction pattern and reassuring thoughts coping styles decreased following PR (both $p<0.001$ ). More than $50 \%$ of the patients changed their level of active confronting, passive reaction pattern or expressing emotions coping style. Coping styles and/or changes in coping styles after PR were related to changes in exercise tolerance, anxiety and depression, but were not related to changes in health status. Following PR, SGRQ total score, HADS-A and HADS-D scores decreased (all $p<0.001)$, while 6MWD increased $(p<0.05)$.

\section{Conclusion}

Comprehensive PR results in change in coping styles of COPD patients. Coping styles are related to improvements in exercise tolerance, anxiety and depression, but they are not related with changes in health status after PR. Further studies are needed to evaluate the outcome of interventions actively targeting coping styles. 


\section{Introduction}

Patients with COPD may experience fatigue, impaired health status, loss of independence, work absenteeism, and social isolation. ${ }^{1}$ In addition, patients with COPD may endure psychological problems, including depression, anxiety and poor coping with their symptoms. ${ }^{2,3}$

Coping, as an adaptive response to a chronic illness, is defined as selecting and acting on the information derived from the individual's symptom recognition and interpretation. $^{3}$ Some patients deal with their duties and difficulties, which are the result of their confrontation and evaluation of their chronic illness more successfully than others. ${ }^{4}$ Previous studies suggest that adequate coping styles are important for self-management of COPD., 5 Two cross-sectional studies in COPD patients demonstrated that coping styles were associated with symptoms of anxiety and depression, exercise intolerance, and health status. ${ }^{7,8}$ Further, a passive coping style was related to an impaired level of daily functioning. ${ }^{9}$ Finally, in patients with advanced COPD, inability to cope with the effects of their disease was linked to an increased mortality. ${ }^{10}$

PR with its interdisciplinary, comprehensive, patient-centred approach is an effective intervention for improving symptoms and reducing disability in patients with COPD. $^{11}$ Coping styles seem to be important for the maintenance of postrehabilitation effects. ${ }^{12}$ Moreover, many patients entering PR predominantly use a passive reaction pattern coping style. ${ }^{8}$ To date, it remains unknown whether and to what extent: 1) coping styles may change following comprehensive PR; and 2 ) baseline coping styles are associated with the changes in exercise tolerance, mood status and health status following a PR programme.

\section{Methods}

\section{Design}

The present study was a retrospective analysis of coping styles in COPD patients before and after completion of a comprehensive PR programme.

\section{Participants}

Patients with mild to very severe COPD admitted to CIRO+, a centre of expertise for chronic organ failure (Horn, the Netherlands) for a comprehensive PR programme ${ }^{13}$ between January 2010 and December 2011 were included. In total, 303 patients: 
$128(42.2 \%)$ inpatients and 175 (57.8\%) outpatients had complete data on the primary and secondary outcome variables and were included for analyses. The diagnosis of COPD was based on the definition provided by the Global initiative for chronic Obstructive Lung Disease (GOLD). ${ }^{1}$

\section{Pulmonary rehabilitation programme}

Following the baseline assessment, patients participated in an 8-week inpatient or 14 week outpatient comprehensive PR programme. ${ }^{14}$ The interdisciplinary team supervised by a chest physician, consisted of respiratory nurses, dietician, occupational therapist, physiotherapist, psychologist and social worker. Components of the programme included daily exercise training; nutritional support and psychological counselling (if indicated); and 20 group educational sessions of one hour. All of the patients included in this study underwent group educational sessions which were conducted as part of PR. (See Supplemental material for components of the educational programme.) In contrast, individual psychological counselling was offered to patients with psychological problems, such as symptoms of depression, anxiety, adaptation problems and personality disorders. The PR programme did not include an intervention aimed at changing patients' individual coping styles. All outcomes were recorded in the clinical routine. Approval from the institutional board of directors was obtained to use patients' records for the study and patients' confidentiality was maintained.

\section{Outcome measures}

General characteristics of patients, such as sex, age and marital status were recorded during the baseline assessment. Pulmonary function (forced expiratory volume in the first second $\left(\mathrm{FEV}_{1}\right)$ and forced vital capacity $(\mathrm{FVC})$ ), body-mass index (BMI), exercise tolerance (two 6-minute walking distance (6MWD) tests, and severity of dyspnoea (Medical Research Council dyspnoea scale (MRC)) were assessed at baseline and after completion of PR, as described before. ${ }^{15,16}$

\section{Coping styles}

The primary outcomes of interest were coping styles, assessed with the Utrecht Coping List (UCL). ${ }^{17}$ The UCL consists of 47 items, which represent seven different coping styles. The seven coping subscales are: active confronting coping (confronting problems and employing purposeful strategies, e.g., tackle problems immediately) (6 items); palliative reaction (distracting one's attention from the problems and includes smoking and drinking, e.g., forget problems by going out) (4 items); avoidance (waiting and keeping clear of the problem e.g., avoid difficult situations) (3 items); seeking social support (seeking comfort and help from others, e.g., sharing 
one's worries) (5 items); passive reaction pattern (rumination and drawing back, e.g., not feeling able to do something) (5 items); expressing emotions (e.g., showing annoyance or anger; releasing tension) (2 items); and fostering reassuring thoughts (e.g., self-encouragement through such thoughts as 'worse things can happen') ( 2 items). Patients were asked to rate how often they used certain coping behaviours. Four response options for each item were offered: 'seldom or never' (1 point), 'sometimes' ( 2 points), 'often' (3 points) and 'very often' (4 points). Mean total scores are calculated for every subscale. A higher score indicates an increased tendency towards using that specific coping style. Furthermore, scores are categorised in: very low, low, medium, high, or very high, based on Dutch norm scores, which are calculated for men and women in different age categories. ${ }^{17}$ The UCL has been widely used for the assessment of coping styles in other conditions such as osteoarthritis, eating disorders and Parkinson's disease. ${ }^{18-20}$

\section{Symptoms of anxiety and depression}

The validated Dutch version of the Hospital Anxiety and Depression Scale (HADS) was used to assess symptoms of anxiety and depression. ${ }^{21}$ The HADS is a self-administered questionnaire, consisting of 14 items divided into an anxiety subscale (HADS-A) and depression subscale (HADS-D). Scores for both subscales range from 0 (optimal) to 21 (worst) points. A score equal to or greater than 10 represents the presence of clinically relevant symptoms of anxiety or depression (sensitivity $0.69(95 \% \mathrm{Cl}$, $0.48-0.84)$; specificity $0.85(95 \% \mathrm{Cl}, 0.74-0.91)) .^{22,23}$

\section{Disease-specific health status}

Disease-specific health status was assessed using the self-administered St. George's Respiratory Questionnaire (SGRQ). ${ }^{24}$ A total score and three domain scores (symptoms, activity and impact) are provided. Scores range from 0 (best) to 100 points (worst). The SGRQ was reported to be valid and reliable in patients with COPD. $^{24}$

\section{Statistical analysis}

Statistical analysis was performed using SPSS 20.0 (SPSS Inc. Chicago, IL). Categorical variables were described as frequencies, while continuous variables were tested for normality and are presented as mean \pm SD. Paired $t$-tests were used to compare the following outcome parameters before and after PR: UCL subscale scores, SGRQ total and subscale scores, HADS scores, BMI and 6MWD. Frequencies were used to show the change in distribution per level of coping style. Ordinal data were analysed using nonparametric tests. Four multiple linear stepwise regression models were developed to assess the association between baseline coping styles, changes in coping styles and 
outcomes of PR. SGRQ total score, 6MWD, HADS-A score, or HADS-D score were entered as dependent variable in the four models, respectively. UCL subscale scores and changes in UCL subscale scores were entered as independent variables, as well as possible confounders. A $p$-value of $\leq 0.05$ was considered as statistically significant.

\section{Results}

\section{Patient characteristics}

Patients had an impaired disease-specific health status, and a reduced exercise tolerance (Table 3.1). Baseline coping styles of COPD patients were: active confronting $16.1 \pm 3.7$ points; palliative reaction $15.9 \pm 3.5$ points; avoidance $15.6 \pm 3.4$ points; seeking social support $11.9 \pm 3.2$ points; passive reaction pattern $11.8 \pm 3.3$ points; expressing emotions $5.3 \pm 1.5$ points; and reassuring thoughts $11.3 \pm 2.4$ points. Following PR, SGRQ total score improved $(-6.3 \pm 12.9$ points, $p<0.001)$. Also HADS-A and HADS-D scores improved after PR (-1.7 \pm 3.6 points; and $-1.6 \pm 3.7$ points, respectively, both $p<0.001)$. The proportion of patients reporting clinically relevant symptoms of anxiety (HADS-A score $\geq 10$ points) changed from $28.7 \%$ to $13.2 \%$ after PR $(p<0.001)$, while the proportion of patients reporting clinically relevant symptoms of depression (HADS-D score $\geq 10$ points) changed from $29.4 \%$ to $15.8 \%$ after PR $(p<0.001)$. Finally, 6MWD increased $28.9 \pm 51.2$ meters $(p<0.05)$.

Table 3.1 Baseline patient characteristics

\begin{tabular}{lc}
\hline & Patients (n=303) \\
\hline Age (years) & $62.3(8.3)$ \\
Sex (male), $\mathrm{n}(\%)$ & $161(53.1 \%)$ \\
Marital status (married/living with partner), $\mathrm{n}(\%)$ & $213(70.3 \%)$ \\
$\mathrm{FEV}_{1}$ (litres) & $1.3(0.6)$ \\
$\mathrm{FEV}_{1}$ (\% predicted) & $47.7(19.5)$ \\
$\mathrm{FEV}_{1} /$ FVC (\%) & $38.0(12.1)$ \\
MRC dyspnoea scale (grade) ${ }^{*}$ & $3.4(1.1)$ \\
BMI (kg.m ${ }^{-2}$ ) & $25.8(5.2)$ \\
SGRQ Symptoms (points) & $58.6(20.24)$ \\
SGRQ Activity (points) & $75.0(18.1)$ \\
SGRQ Impact (points) & $44.7(18.9)$ \\
SGRQ Total (points) & $56.2(15.5)$ \\
6MWD (meters) & $441.6(112.2)$ \\
HADS-A (points) & $7.4(4.2)$ \\
HADS-D (points) & $7.1(4.1)$ \\
\hline
\end{tabular}

Data are presented as mean (standard deviation, SD) or number of patients (\%). ${ }^{*} n=284$. Abbreviations: $\mathrm{FEV}_{1}$ : forced expiratory volume in the first second; FVC: forced vital capacity; MRC: Medical Research Council; BMI: body mass index; SGRQ: St. George Respiratory Questionnaire; 6MWD: six-minute walking distance; HADS-A: Hospital Anxiety and Depression Scale, anxiety subscale; HADS-D: Hospital Anxiety and Depression Scale, depression subscale. 


\section{Coping styles before and after PR programme}

The level of active confronting coping style increased following PR $(+0.4 \pm 3.5$ points, $p<0.05)$. The level of avoidance coping style decreased after PR $(-0.6 \pm 3.7$ points, $p<0.05)$, as well as the levels of passive reaction pattern coping style $(-0.6 \pm 3.1$ points, $p<0.001)$ and reassuring thoughts coping style $(-0.5 \pm 2.5$ points, $p<0.001)$. The levels of palliative reaction, seeking social support and expressing emotions coping styles did not change following PR ( $p>0.05)$ (Figure 3.1). For the UCL subscales active confronting, passive reaction pattern and expressing emotions coping style, more than $50 \%$ of the patients changed their level of coping style to another (lower or higher) level (Figure 3.2). For example, 22 (34.4\%) of 64 patients using at baseline a very low active confronting coping style, did not change their level of coping style. Fifteen patients (23.4\%) changed into a low level, 25 patients (39.0\%) changed into a medium level, one patient (1.6\%) changed into a high and one patient $(1.6 \%)$ changed into a very high level of active confronting coping style after PR. The percentage of all patients that increased their very low level into a higher level of active confronting coping style was $65.6 \%$ (Figure 3.2). For the UCL subscales palliative reaction, avoidance, seeking social support and reassuring thoughts, the majority of the patients did not change their level of use after PR. See Supplemental material for differences in baseline and changes in coping styles among genders following PR.

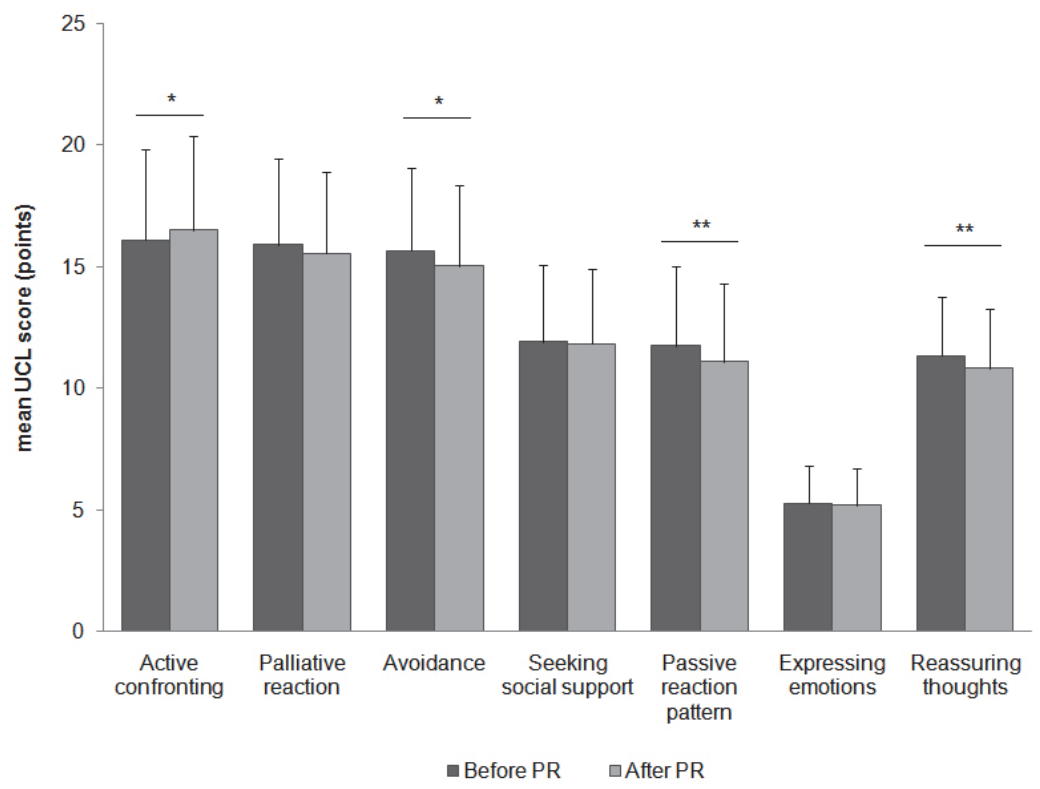

Figure 3.1 UCL subscale scores before and after PR programme.

Data are presented as mean (standard deviation, SD). ${ }^{*} p$-value based on Paired-Samples T Test, $p<0.05$. ${ }^{* *} p$-value based on Paired-Samples T Test, $p<0.001$. 


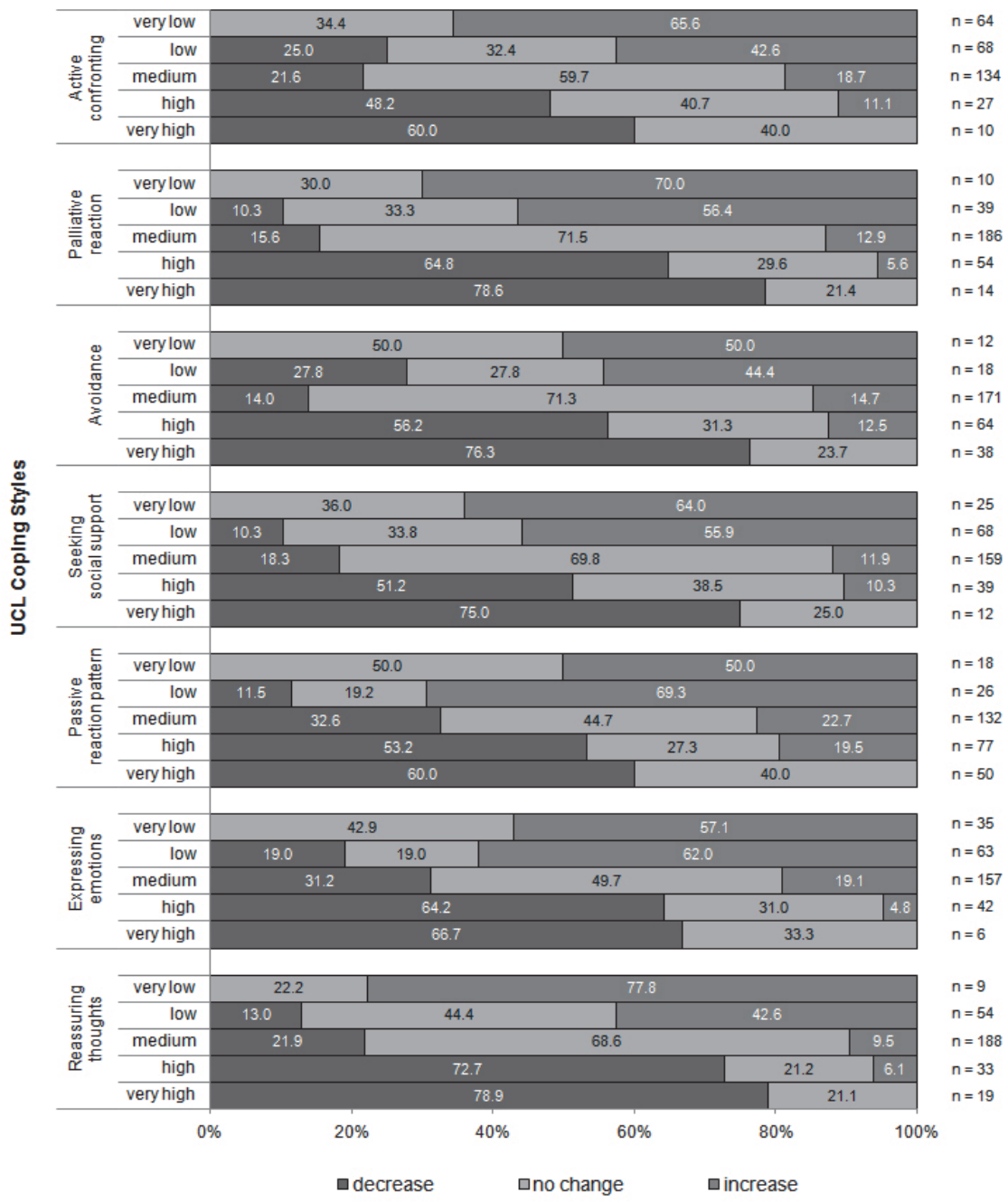

Figure 3.2 Changes in level per coping style.

Data are presented as percentage (\%). $n=303$. Decrease $=$ change to a lower level. No change $=$ same level of coping style. Increase = change to a higher level.

\section{Relationship between coping styles, changes in coping styles and outcomes of PR}

None of the coping styles or changes in coping styles was related to change in diseasespecific health status following PR. However, baseline SGRQ total score, HADS-D score, 6MWD; and change in HADS-D score and change in 6MWD were related to change in SGRQ total score (Table 3.2). 
Table 3.2 Results of stepwise regression analysis for baseline coping styles, changes in coping styles and change in disease-specific health status.

\begin{tabular}{llcc}
\hline$\Delta$ SGRQ total score & Correlates & Standardized Beta & $p$-value \\
\hline$R^{2}=0.37, F=13.332$ & baseline SGRQ total score & -0.486 & 0.000 \\
$p=0.000$ & baseline HADS-D score & 0.283 & 0.000 \\
& baseline 6MWD & -0.204 & 0.000 \\
& D HADS-D score & 0.428 & 0.000 \\
& $\Delta$ GMWD & -0.269 & 0.000 \\
\hline
\end{tabular}

$n=282$. Abbreviations: $\mathrm{FEV}_{1}$ : forced expiratory volume in the first second; FVC: forced vital capacity; MRC: Medical Research Council; BMI: body mass index; SGRQ: St. George Respiratory Questionnaire; 6MWD: sixminute walking distance; HADS-A: Hospital Anxiety and Depression Scale, anxiety subscale; HADS-D: Hospital Anxiety and Depression Scale, depression subscale.

The following variables were no significant predictors and were excluded from the model: Sex, Age, MRC dyspnoea scale, FEV 1 \% pred., BMI, $\triangle$ BMI, HADS-A, $\triangle$ HADS-A, UCL (Utrecht Coping List) Active confronting, UCL Palliative reaction, UCL Avoidance, UCL Seeking social support, UCL Passive reaction pattern, UCL Expressing emotions, UCL Reassuring thoughts, $\triangle \mathrm{UCL}$ Active confronting, $\triangle \mathrm{UCL}$ Palliative reaction, $\triangle \mathrm{UCL}$ Avoidance, $\triangle \mathrm{UCL}$ Seeking social support, $\triangle \mathrm{UCL}$ Passive reaction pattern, $\triangle \mathrm{UCL}$ Expressing emotions, $\Delta \mathrm{UCL}$ Reassuring thoughts.

Furthermore, baseline 6MWD, SGRQ total score, seeking social support coping style; and change in SGRQ total score were related to change in exercise tolerance (Table 3.3).

Table 3.3 Results of stepwise regression analysis for baseline coping styles, changes in coping styles and change in exercise tolerance.

\begin{tabular}{llcc}
\hline$\Delta$ GMWD & Correlates & Standardized Beta & $\boldsymbol{p}$-value \\
\hline$R^{2}=0.18, F=5.926$ & baseline 6MWD & -0.259 & 0.000 \\
$p=0.016$ & baseline SGRQ total score & -0.163 & 0.016 \\
& $\Delta$ SGRQ total score & -0.370 & 0.000 \\
& baseline UCL Seeking social support & -0.166 & 0.003 \\
\hline
\end{tabular}

$n=282$. Abbreviations: $\mathrm{FEV}_{1}$ : forced expiratory volume in the first second; FVC: forced vital capacity; MRC: Medical Research Council; BMI: body mass index; SGRQ: St. George Respiratory Questionnaire; 6MWD: sixminute walking distance; HADS-A: Hospital Anxiety and Depression Scale, anxiety subscale; HADS-D: Hospital Anxiety and Depression Scale, depression subscale.

The following variables were no significant predictors and were excluded from the model: Sex, Age, MRC dyspnoea scale, FEV $1 \%$ pred., BMI, $\triangle$ BMI, HADS-A, $\triangle$ HADS-A, HADS-D, $\triangle$ HADS-D, UCL (Utrecht Coping List) Active confronting, UCL Palliative reaction, UCL Avoidance, UCL Passive reaction pattern, UCL Expressing emotions, UCL Reassuring thoughts, $\triangle$ UCL Active confronting, $\triangle$ UCL Palliative reaction, $\triangle$ UCL Avoidance, $\Delta U C L$ Seeking social support, $\Delta U C L$ Passive reaction pattern, $\triangle$ UCL Expressing emotions, $\Delta U C L$ Reassuring thoughts.

Determinants of change in HADS-A score were baseline HADS-A score, HADS-D score, active confronting, passive reaction pattern, expressing emotions, reassuring thoughts coping styles; and change in HADS-D score and change in passive reaction pattern coping style (Table 3.4). These variables were able to explain $64 \%$ of the change in HADS-A score after PR. 
Table 3.4 Results of stepwise regression analysis for baseline coping styles, changes in coping styles and change in anxiety score.

\begin{tabular}{llcc}
\hline$\Delta$ HADS-A score & Correlates & Standardized Beta & $p$-value \\
\hline$R^{2}=0.64, F=5.382$ & baseline HADS-A score & -0.766 & 0.000 \\
$p=0.021$ & baseline HADS-D score & 0.425 & 0.000 \\
& D HADS-D score & 0.577 & 0.000 \\
& baseline UCL Active confronting & -0.110 & 0.015 \\
& baseline UCL Passive reaction pattern & 0.226 & 0.000 \\
& baseline UCL Expressing emotions & -0.091 & 0.021 \\
& baseline UCL Reassuring thoughts & 0.140 & 0.001 \\
& $\Delta$ Passive reaction pattern & 0.165 & 0.000 \\
\hline
\end{tabular}

$n=282$. Abbreviations: $\mathrm{FEV}_{1}$ : forced expiratory volume in the first second; FVC: forced vital capacity; MRC: Medical Research Council; BMI: body mass index; SGRQ: St. George Respiratory Questionnaire; 6MWD: sixminute walking distance; HADS-A: Hospital Anxiety and Depression Scale, anxiety subscale; HADS-D: Hospital Anxiety and Depression Scale, depression subscale.

The following variables were no significant predictors and were excluded from the model: Sex, Age, MRC dyspnoea scale, $\mathrm{FEV}_{1} \%$ pred., BMI, $\triangle \mathrm{BMI}$, SGRQ Total baseline, $\triangle \mathrm{SGRQ}$ Total, 6MWD baseline, $\triangle 6 \mathrm{MWD}$, UCL (Utrecht Coping List) Palliative reaction, UCL Avoidance, UCL Seeking social support, $\triangle$ UCL Active confronting, $\triangle \mathrm{UCL}$ Palliative reaction, $\triangle \mathrm{UCL}$ Avoidance, $\Delta \mathrm{UCL}$ Seeking social support, $\Delta \mathrm{UCL}$ Expressing emotions, $\triangle$ UCL Reassuring thoughts.

Finally, change in HADS-D score in response to PR was associated with baseline HADS-A score, HADS-D score, palliative reaction and expressing emotions coping styles; and change in HADS-A score, change in SGRQ total score, and change in expressing emotions coping style (Table 3.5). These variables were able to explain $65 \%$ of the change in HADS-D score following PR.

Table 3.5 Results of stepwise regression analysis for baseline coping styles, changes in coping styles and change in depression score.

\begin{tabular}{llcc}
\hline$\Delta$ HADS-D score & Correlates & Standardized Beta & $p$-value \\
\hline$R^{2}=0.65, F=5.076$ & baseline HADS-A score & 0.553 & 0.000 \\
$p=0.025$ & baseline HADS-D score & -0.723 & 0.000 \\
& $\Delta$ HADS-A score & 0.586 & 0.000 \\
& $\Delta$ SGRQ Total score & 0.144 & 0.000 \\
& baseline UCL Palliative reaction & -0.130 & 0.001 \\
& baseline UCL Expressing emotions & 0.155 & 0.001 \\
& $\Delta$ Expressing emotions & 0.102 & 0.025 \\
\hline
\end{tabular}

$n=282$. Abbreviations: $\mathrm{FEV}_{1}$ : forced expiratory volume in the first second; FVC: forced vital capacity; MRC: Medical Research Council; BMI: body mass index; SGRQ: St. George Respiratory Questionnaire; 6MWD: sixminute walking distance; HADS-A: Hospital Anxiety and Depression Scale, anxiety subscale; HADS-D: Hospital Anxiety and Depression Scale, depression subscale.

The following variables were no significant predictors and were excluded from the model: Sex, Age, MRC dyspnoea scale, FEV1 \% pred., BMI, $\triangle$ BMI, SGRQ Total baseline, 6MWD baseline, $\triangle 6 \mathrm{MWD}$, UCL (Utrecht Coping List) Active confronting, UCL Avoidance, UCL Seeking social support, UCL Passive reaction pattern, UCL Reassuring thoughts, $\triangle \mathrm{UCL}$ Active confronting, $\triangle \mathrm{UCL}$ Palliative reaction, $\triangle \mathrm{UCL}$ Avoidance, $\Delta \mathrm{UCL}$ Seeking social support, $\triangle \mathrm{UCL}$ Passive reaction pattern, $\triangle \mathrm{UCL}$ Reassuring thoughts. 


\section{Discussion}

\section{Key findings}

The present study has two important findings. First, the results indicate that comprehensive interdisciplinary PR programme is able to change coping styles in patients with COPD. Second, coping styles are predictors of changes in exercise tolerance, symptoms of anxiety and depression, but are not related to changes in disease-specific health status following PR.

\section{Change in coping styles as response to a comprehensive PR programme}

Improvements in exercise tolerance, symptoms of anxiety and depression and disease-specific health status after PR in patients with COPD are well documented. ${ }^{25}$ However, the influence of a PR programme on coping styles has rarely been studied in COPD. ${ }^{26}$ In the present study, the level of active confronting coping style increased, whereas the levels of avoidance, passive reaction pattern and reassuring thoughts coping styles decreased after PR. Additionally, the mean differences in all coping subscales can be small, but within each coping subscale - changes can be significant, as shown in Figure 3.2. These findings support the hypothesis of Lazarus and Folkman, stating that coping styles are process-oriented, which means that they depend on the nature of the stressor and they are prone to change, rather than people are being "pre-programmed" to use the same coping style regardless of the stressful situation. ${ }^{4}$

COPD patients rely less on active confronting coping style when compared to the general population. ${ }^{27} \mathrm{~A}$ recent study in COPD patients entering PR showed that patients with symptoms of anxiety and/or depression reported a lower use of active confronting and an increased use of avoidance and passive reaction pattern coping styles than patients without symptoms of anxiety and/or depression. ${ }^{8}$ Active confronting coping style describes problem-focused concentrated efforts on acting upon the illness or modifying the situation, which may result in better adjustment with regard to patient's COPD. ${ }^{28}$ Furthermore, a decrease in avoidance, passive reaction pattern and reassuring thoughts coping styles, suggests that patients with COPD after PR will be more willing to confront their situation and address the problems. ${ }^{17}$ Therefore, the increase in the level of active confronting and decrease in the levels of avoidance and passive reaction pattern coping styles can be considered as positive outcomes of PR. In contrast, studies by Janelli et al. ${ }^{29}$ and Scherer et al., ${ }^{30}$ which assessed general coping behaviours before and after a group teaching programme for patients with COPD, found no changes in coping styles. Possible explanations for these differences are dissimilarities in the contents of the programmes and the use of a different coping instrument (Jalowiec Coping Scale). 


\section{Coping styles as predictors of change in clinical outcomes after PR}

None of the baseline coping styles and changes in levels of coping styles after PR was associated with a change in disease-specific health status. This confirms the findings of Buchi et al., who found no significant relationship between generic health status and coping styles in COPD patients attending PR. ${ }^{31}$ However, a study by Ketelaars et al., showed that avoidance and expressing emotions coping styles were the best predictors of disease-specific health status, next to the lung function and exercise tolerance. ${ }^{32}$ They assessed coping styles in patients with COPD entering PR using another instrument, the COPD Coping Questionnaire, ${ }^{32}$ which may explain these inconsistent findings. Moreover, coping styles only modestly explained the variance of disease-specific health status. ${ }^{32}$

Coping styles are determinants of exercise tolerance. ${ }^{8}$ A lower use of baseline seeking social support coping style was associated with an increase in exercise capacity after PR. This confirms previous findings suggesting that use of seeking social support coping style is not associated with better outcomes in COPD patients. On the contrary, this coping style is associated with worse total functioning and higher anxiety levels. ${ }^{27}$

In the present study, coping styles were related to changes in symptoms of anxiety following PR. Increased levels of baseline active confronting and baseline expressing emotions coping styles, were associated with lower levels of anxiety after PR. Increased levels of baseline passive reaction pattern, reassuring thoughts coping styles and change in passive reaction pattern coping style, were associated with increased anxiety levels after PR. A consistent body of research in COPD patients, shows that the use of active confronting coping style is associated with positive outcomes and lower levels of psychological distress, ${ }^{8,26}$ whereas the use of passive reaction pattern coping style is associated with increased psychological distress. ${ }^{8,27}$ Our findings support these results. Additionally, patients who reported at baseline more use of reassuring thoughts may be less able to reduce levels of anxiety following PR. On the other hand, we found that expressing emotions coping style, generally described as a passive and maladaptive coping style, ${ }^{26,29}$ can contribute to lowering the level of anxiety following PR. The disparity between studies with regard to the adaptive significance of expressing emotions coping style can be explained by the fact that this may depend on the controllability of the confronted stressor, as described by Andenaes et al. ${ }^{33}$

Coping styles were also related to the changes in the levels of depression following PR. Patients, who at baseline reported more use of expressing emotions coping style, may benefit less from PR in terms of higher level of depression following PR. Also, decrease in this coping style after PR showed an association with decrease in 
symptoms of depression following PR. In contrast, patients who at baseline reported more use of palliative reaction coping style may benefit more from PR in terms of improvements in symptoms of depression. Previously, a study in COPD outpatients showed that higher use of palliative reaction coping style is associated with less prescribed pulmonary medication. ${ }^{27}$ The use of palliative reaction coping style refers to efforts to control negative emotions by means of distraction, or the use of psychoactive substances. ${ }^{17}$ This suggests that patients try to distract their thoughts instead of constantly directing their attention to the chronic stimuli of COPD and they less tend to recognise, interpret and report its symptoms.

The data presented in this study illustrate that coping styles of patients with COPD are important in relation to symptoms of anxiety and depression, as it was shown before. ${ }^{8}$ Furthermore, the association between coping styles and exercise intolerance, symptoms of anxiety and depression, may not translate simply into improvements in disease-specific health status, which can possibly be related to the time needed for these patients to experience the effects in the daily living. The exact interrelation between coping styles and these clinical outcomes warrants further investigation.

Nowadays, self-management interventions implemented in PR programmes for COPD patients should stimulate behavioural change and active participation of patients through education and the promotion of self-management behaviour. ${ }^{34}$ These interventions will empower patients with specific disease-related skills that emphasise disease control through behaviour change, ${ }^{35}$ which may actually lead to a consistent modification of patients' coping styles. Indeed, self-management of COPD includes sufficient coping behaviour. ${ }^{36}$ Moreover, an inclusion of interventions which will incorporate structured psychosocial elements aiming at behaviour modification in PR is essential. ${ }^{12}$ Nevertheless, it remains unknown whether interventions can modify coping styles of patients with COPD, as well as if these interventions can improve other outcomes such as patients' physical and psychological symptoms and exercise tolerance. De Ridder and Schreurs suggested in a review that interventions may be able to change coping styles in patients with chronic diseases. ${ }^{37}$ However, the results only showed improvement of a few coping styles and problem-focused styles in particular. $^{37}$ Interestingly, in all of the included studies a cognitive behavioural approach was used. Techniques used to influence emotion-focused coping style were cognitive restructuring and relaxation, while training of problem-solving skills, social skills, communication skills, decision making and negotiating were used as techniques to influence problem-focused coping. ${ }^{37}$ The authors suggest that besides strategies for enhancement of a particular coping style, the appraisal of stressful situations, the use of coping resources and the strategic application of particular coping styles, should also be considered in future development of interventions. ${ }^{37}$ 


\section{Methodological considerations}

Several limitations should be taken into consideration when interpreting the results. Co-morbidities were not assessed, which may have an impact on coping styles and may limit the generalizability of our findings. Further, several instruments to assess coping styles are available and other instruments define different coping styles categories. ${ }^{3,7,26,31}$ Thus, the use of another instrument might have changed our results. Nonetheless, the UCL was previously applied in COPD patients, and has shown satisfactory psychometric properties in a Dutch population. ${ }^{17,27}$ Also, multiple instruments exist for assessment of symptoms of anxiety and/or depression. We used the HADS, a well validated instrument frequently used in patients with COPD. ${ }^{2}$ However, the choice of the instrument might have influenced our results. Finally, it cannot be determined which component (or sum of components) of PR has resulted in the changes in coping styles. Nevertheless, evidence for the possible direct effect of PR on patients' coping styles might provide future opportunities for development of a patient-tailored PR programme.

\section{Conclusions and implications for clinical practice}

The present study has shown that coping styles may change following PR. Moreover, coping styles and changes in coping styles may influence outcomes of PR. Indeed, coping with COPD involves an adjustment to daily limitations. ${ }^{32}$ Therefore, enhancement of understanding of healthcare professionals of the patient's coping styles and the adaptation process is needed. The findings from the present study suggest that components included in a comprehensive PR can stimulate a change in the patients' coping styles, even without the inclusion of intervention aiming at changing coping styles. Hence, these results also suggest that PR may be a venue in which it is possible to offer interventions aimed at modification of coping styles. However, further studies are warranted to evaluate the outcomes of interventions actively targeting coping styles. 


\section{References}

1. Rabe KF, Hurd S, Anzueto A, Barnes PJ, Buist SA, Calverley P, et al. Global strategy for the diagnosis, management, and prevention of chronic obstructive pulmonary disease: GOLD executive summary. Am J Respir Crit Care Med 2007;176:532-55.

2. Janssen DJ, Spruit MA, Leue C, Gijsen C, Hameleers H, Schols JM, et al. Symptoms of anxiety and depression in COPD patients entering pulmonary rehabilitation. Chron Respir Dis 2010;7:147-57.

3. O'Neill ES. Illness representations and coping of women with chronic obstructive pulmonary disease: a pilot study. Heart Lung 2002;31:295-302.

4. Lazarus RS, Folkman S. Stress, appraisal and coping. New York: Springer; 1984.

5. Monninkhof E, van der Aa M, van der Valk P, van der Palen J, Zielhuis G, Koning K, et al. A qualitative evaluation of a comprehensive self-management programme for COPD patients: effectiveness from the patients' perspective. Patient Educ Couns 2004;55:177-84.

6. WHO. Preparing a health care workforce for the 21st century - the challenge of chronic conditions. Geneva: World Health Organization; 2005.

7. McCathie HC, Spence SH, Tate RL. Adjustment to chronic obstructive pulmonary disease: the importance of psychological factors. Eur Respir J 2002;19:47-53.

8. Stoilkova A, Wouters EFM, Spruit MA, Franssen FME, Janssen DJA. The relationship between coping styles and clinical outcomes in patients with COPD entering pulmonary rehabilitation. COPD: Journal Of Chronic Obstructive Pulmonary Disease 2013;10: 316-23.

9. Scharloo M, Kaptein AA, Weinman J, Hazes JM, Willems LN, Bergman W, et al. Illness perceptions, coping and functioning in patients with rheumatoid arthritis, chronic obstructive pulmonary disease and psoriasis. J Psychosom Res 1998;44:573-85.

10. Ashutosh K, Haldipur C, Boucher ML. Clinical and personality profiles and survival in patients with COPD. Chest 1997;111:95-8.

11. Spruit MA, Singh SJ, Garvey C, ZuWallack R, et al. An Official American Thoracic Society / European Respiratory Society Statement: Key concepts and advances in pulmonary rehabilitation - An Executive Summary. Am J Respir Crit Care Med:(Under review).

12. Wempe JB, Wijkstra PJ. The influence of rehabilitation on behaviour modification in COPD. Patient Educ Couns 2004;52:237-41.

13. Spruit MA, Vanderhoven-Augustin I, Janssen PP, Wouters EF. Integration of pulmonary rehabilitation in COPD. Lancet 2008;371:12-3.

14. Franssen FM, Broekhuizen R, Janssen PP, Wouters EF, Schols AM. Effects of whole-body exercise training on body composition and functional capacity in normal-weight patients with COPD. Chest 2004;125:2021-8.

15. Spruit MA, Pennings HJ, Janssen PP, Does JD, Scroyen S, Akkermans MA, et al. Extra-pulmonary features in COPD patients entering rehabilitation after stratification for MRC dyspnea grade. Respir Med 2007;101:2454-63.

16. Hernandes NA, Wouters EF, Meijer K, Annegarn J, Pitta F, Spruit MA. Reproducibility of 6-minute walking test in patients with COPD. The European respiratory journal : official journal of the European Society for Clinical Respiratory Physiology 2011;38:261-7.

17. Schreurs PJG, van de Willige G, Brosschot JF, Tellegen B, Graus GMH. De Utrechtse Coping Lijs, UCL omgaan met problemen en gebeurtenissen [The Utrecht Coping List]. Lisse, the Netherlands: Swets en Zeitlinger; 1993.

18. Hopman-Rock M, Kraaimaat FW, Bijlsma JW. Quality of life in elderly subjects with pain in the hip or knee. Qual Life Res 1997;6:67-76.

19. Turner H, Bryant-Waugh R, Peveler R, Bucks RS. A psychometric evaluation of an English version of the Utrecht Coping List. Eur Eat Disord Rev 2012;20:339-42.

20. Schreurs KMG, De Ridder DTD, Bensing JM. A one year study of coping, social support and quality of life in Parkinson's disease. Psychology and Health 2000;15:109-21. 
21. Spinhoven P, Ormel J, Sloekers PP, Kempen GI, Speckens AE, Van Hemert AM. A validation study of the Hospital Anxiety and Depression Scale (HADS) in different groups of Dutch subjects. Psychol Med 1997;27:363-70.

22. Zigmond AS, Snaith RP. The hospital anxiety and depression scale. Acta Psychiatr Scand 1983;67: 361-70.

23. Brennan C, Worrall-Davies A, McMillan D, Gilbody S, House A. The Hospital Anxiety and Depression Scale: a diagnostic meta-analysis of case-finding ability. J Psychosom Res 2010;69:371-8.

24. Jones PW, Quirk FH, Baveystock CM, Littlejohns P. A self-complete measure of health status for chronic airflow limitation. The St. George's Respiratory Questionnaire. Am Rev Respir Dis 1992;145:1321-7.

25. Nici L, Donner C, Wouters E, Zuwallack R, Ambrosino N, Bourbeau J, et al. American Thoracic Society/European Respiratory Society statement on pulmonary rehabilitation. Am J Respir Crit Care Med 2006;173:1390-413.

26. Ninot G, Fortes M, Poulain M, Brun A, Desplan J, Prefaut C, et al. Gender difference in coping strategies among patients enrolled in an inpatient rehabilitation program. Heart Lung 2006;35:130-6.

27. Scharloo M, Kaptein AA, Weinman JA, Willems LN, Rooijmans HG. Physical and psychological correlates of functioning in patients with chronic obstructive pulmonary disease. J Asthma 2000; 37:17-29.

28. Maes S, Leventhal H, de Ridder DTD. Coping with chronic illness. In Handbook of Coping. In: Zeidner M, Endler NS, eds. New York: Wiley \& Sons; 1996:221-51.

29. Janelli LM, Scherer YK, Schmieder LE. Can a pulmonary health teaching program alter patients' ability to cope with COPD? Rehabil Nurs 1991;16:199-202.

30. Scherer YK, Janelli LM, Schmieder LE. A time-series perspective on effectiveness of a health teaching program on chronic obstructive pulmonary disease. J Healthc Educ Train 1992;6:7-13.

31. Buchi S, Villiger B, Sensky T, Schwarz F, Wolf C, Buddeberg C. Psychosocial predictors of long-term success of in-patient pulmonary rehabilitation of patients with COPD. Eur Respir J 1997;10:1272-7.

32. Ketelaars CA, Schlosser MA, Mostert R, Huyer Abu-Saad H, Halfens RJ, Wouters EF. Determinants of health-related quality of life in patients with chronic obstructive pulmonary disease. Thorax 1996;51: 39-43.

33. Andenaes $\mathrm{R}$, Kalfoss $\mathrm{MH}$, Wahl AK. Coping and psychological distress in hospitalized patients with chronic obstructive pulmonary disease. Heart Lung 2006;35:46-57.

34. Bourbeau J. The role of collaborative self-management in pulmonary rehabilitation. Semin Respir Crit Care Med 2009;30:700-7.

35. Bourbeau J, Nault D, Dang-Tan T. Self-management and behaviour modification in COPD. Patient Educ Couns 2004;52:271-7.

36. Worth H. Self management in COPD: one step beyond? Patient Educ Couns 1997;32:S105-9.

37. de Ridder D, Schreurs K. Developing interventions for chronically ill patients: is coping a helpful concept? Clin Psychol Rev 2001;21:205-40. 


\section{Supplemental material}

\section{Methods}

\section{Educational programme as part of pulmonary rehabilitation programme}

The group education contained a variety of topics: physiology of the lungs; usefulness and necessity of exercise and effects of physical training; acute exacerbations, early detection and treatment; shortness of breath, fear of shortness of breath and influence of posture and movement on breathing; role of respiratory medication; oxygen therapy, chronic effects and practical use of oxygen; energy conservation; nutrition. Short discussion on different coping styles in general, and active confronting and passive reaction pattern coping styles in specific, in the session of "How do I stay in motion?" was provided by the psychosocial team.

\section{Coping styles among genders}

\section{Background}

A study exploring coping styles among women and men with mild to moderate COPD following inpatient pulmonary rehabilitation (PR) programme reported differences in coping styles between the genders, suggesting that women and men with COPD differ in the ways they cope with their disease. ${ }^{1}$ We aimed to assess baseline coping styles and changes in coping styles among the genders following PR in our sample of patients with mild to very severe COPD.

\section{Statistical analysis}

Unpaired $t$ test, associated mean difference and 95\% confidence intervals were used to compare coping styles between female and male patients.

\section{Results}

The UCL coping styles scores at baseline and changes in these coping styles for male and female patients after 8 weeks of PR are shown in Table S3.1.

At baseline, unpaired $t$ test showed a significant difference between the levels of palliative reaction, avoidance and reassuring thoughts coping styles used by women and men. Women used higher levels of these three coping styles at baseline. In 
contrast, no significant differences were shown between the baseline levels reported by women and men for active confronting, seeking social support, passive reaction pattern and expressing emotions coping styles.

Following PR, unpaired $t$ tests showed that the change in the level of expressing emotions coping style differed significantly between male and female patients. The level increased significantly in women, whereas it decreased in men. No significant differences were shown between the change in coping styles reported by women and men for active confronting, palliative reaction, avoidance, seeking social support, passive reaction pattern and reassuring thoughts coping styles.

Table S3.1 UCL subscale scores in women and men before and after pulmonary rehabilitation.

\begin{tabular}{|c|c|c|c|c|c|c|}
\hline Coping style & & $\begin{array}{c}\text { Before PR } \\
n=303\end{array}$ & $p$-value $* * *$ & $\begin{array}{l}\text { Mean change } \\
\text { (SD) }\end{array}$ & $95 \% \mathrm{Cl}$ & $p$-value*** \\
\hline \multirow[t]{2}{*}{ Active confronting } & women* & $15.80(3.72)$ & 0.266 & $0.72(3.38)$ & {$[-0.22,1.37]$} & 0.155 \\
\hline & men** & $16.31(3.76)$ & & $0.14(3.61)$ & {$[-0.22,1.37]$} & \\
\hline \multirow[t]{2}{*}{ Palliative reaction } & women* & $16.64(3.46)$ & $<0.0005$ & $-0.18(3.42)$ & {$[-1.07,0.42]$} & 0.388 \\
\hline & men** & $15.24(3.45)$ & & $-0.50(3.16)$ & {$[-1.07,0.42]$} & \\
\hline \multirow[t]{2}{*}{ Avoidance } & women* & $16.14(3.16)$ & 0.018 & $-0.77(3.66)$ & {$[-1.11,0.58]$} & 0.538 \\
\hline & men** & $15.22(3.54)$ & & $-0.50(3.78)$ & {$[-1.11,0.58]$} & \\
\hline \multirow{2}{*}{$\begin{array}{l}\text { Seeking social } \\
\text { support }\end{array}$} & women* & $12.14(3.41)$ & 0.220 & $0.04(3.20)$ & {$[-0.45,0.88]$} & 0.525 \\
\hline & men** & $11.70(2.90)$ & & $-0.18(2.70)$ & {$[-0.46,0.89]$} & \\
\hline \multirow{2}{*}{$\begin{array}{l}\text { Passive reaction } \\
\text { pattern }\end{array}$} & women* & $12.11(2.97)$ & 0.074 & $-0.66(2.95)$ & {$[-0.70,0.69]$} & 0.992 \\
\hline & men** & 11.44 (3.49) & & $-0.66(3.17)$ & {$[-0.70,0.69]$} & \\
\hline \multirow[t]{2}{*}{ Expressing emotions } & women* & $5.28(1.37)$ & 0.825 & $0.15(1.47)$ & {$[0.08,0.74]$} & 0.015 \\
\hline & men** & 5.24 (1.69) & & $-0.25(1.43)$ & {$[-0.80,0.74]$} & \\
\hline \multirow[t]{2}{*}{ Reassuring thoughts } & women* & $11.65(2.47)$ & 0.033 & $-0.43(2.74)$ & {$[-0.73,0.39]$} & 0.548 \\
\hline & men** & $11.05(2.38)$ & & $-0.60(2.20)$ & {$[-0.74,0.39]$} & \\
\hline
\end{tabular}

Data are presented as mean (standard deviation, SD). * $n=142, * * n=161, * * * p$-value based on UnpairedSamples T Test. Abbreviation: $\mathrm{Cl}$ : Confidence interval.

\section{Reference}

1. Ninot G, Fortes M, Poulain M, Brun A, Desplan J, Prefaut C, et al. Gender difference in coping strategies among patients enrolled in an inpatient rehabilitation program. Heart Lung 2006;35:130-6. 


\section{Chapter 4}

\section{DIFFERENCES IN CHANGE IN COPING STYLES}

BETWEEN GOOD RESPONDERS, MODERATE RESPONDERS AND NON-RESPONDERS TO PULMONARY REHABILITATION

Ana Stoilkova-Hartmann, Daisy J.A. Janssen, Frits M.E. Franssen, Emiel F.M. Wouters 


\section{Abstract}

\section{Introduction}

Pulmonary rehabilitation (PR) improves exercise tolerance and health status in patients with chronic obstructive pulmonary disease (COPD). Data on the effects of PR on coping styles are limited. Aim of the present study was to compare changes in coping styles between patients who had a good, moderate and no improvement in either exercise tolerance or health status after PR.

\section{Methods}

Coping styles of 439 COPD patients undergoing PR were assessed by the Utrecht Coping List (UCL) at baseline and after PR. Patients' pulmonary function, six-minute walking distance (6MWD), St. George's Respiratory Questionnaire (SGRQ) and Hospital Anxiety and Depression Scale (HADS-A and HADS-D) were recorded. Good, moderate and non-responders were defined on the basis of minimally clinically important difference (MCID) for SGRQ total score and/or 6MWD.

\section{Results}

Overall, $54.0 \%$ of the patients fulfilled the criteria for good responders, while $22.1 \%$ were moderate responders. Change in passive reaction pattern coping style differed significantly between good responders and non-responders following PR $(p<0.001)$. Moreover, within the groups, changes in coping styles after PR occurred among the good responders, whereas the majority of moderate responders' and non-responders' coping styles were not significantly influenced by PR.

\section{Conclusion}

Good responders decreased their passive reaction pattern coping style in contrast to non-responders after PR. In general, PR did not change the coping among moderate and non-responders. Further research is warranted to determine whether including interventions targeting coping styles may modify coping behaviour of COPD patients, as well as improvement in exercise tolerance or health status after PR. 


\section{Introduction}

Pulmonary rehabilitation (PR) is a comprehensive intervention, consisting of exercise training, education, nutritional intervention and psychosocial support. ${ }^{1}$ It enables patients with respiratory diseases to improve their day-to-day activities and restore the highest level of independent functioning. ${ }^{2}$ PR has been shown to improve dyspnoea, symptoms of anxiety and depression, exercise tolerance and health status in patients with chronic obstructive pulmonary disease (COPD). ${ }^{3,4}$ Nevertheless, individual responses to PR are variable. Previous research suggests that almost onethird of the patients, who followed a PR programme, were non-responders in terms of health status or exercise tolerance. ${ }^{5}$

Adequate coping behaviour is needed in order for patients to successfully selfmanage their COPD. ${ }^{6}$ Among other goals, a comprehensive PR programme aims to modify patients' behavioural patterns and coping styles, ${ }^{7}$ which may lead to increased autonomy and active participation of COPD patients in the management of their disease. A recent study has shown that PR can change coping styles in patients with COPD. ${ }^{8}$ Nonetheless, to date it remains unknown whether changes in coping styles are comparable for patients who respond very well with respect to exercise tolerance and/or disease-specific health status following PR and those patients with a moderate and/ or without improvement in these outcomes.

Insight in coping styles of good responders, moderate responders and nonresponders to PR may support in adapting the treatment programme of these patients to their needs with the aim of improving patients' benefit from PR. Therefore, the present study sought to compare changes in coping styles after PR between patients who had a very good response in exercise tolerance and/or disease-specific health status, patients with a moderate response and patients with no improvement in these two outcomes after PR.

\section{Methods}

\section{Participants and study design}

The study was conducted in patients with mild to very severe COPD admitted to CIRO, a centre of expertise for chronic organ failure (Horn, the Netherlands) for a comprehensive PR programme ${ }^{9}$ in the period between January 2009 and December 2012. The diagnosis of COPD was based on the definition provided by the Global initiative for chronic Obstructive Lung Disease (GOLD). ${ }^{10}$ Part of the patients was included in previous studies concerning coping styles. ${ }^{8,11}$ Ethical approval was not 
indicated because all of the tests were conducted as part of the clinical programme. All data were prospectively obtained and retrospectively analysed. Ethical approval was not indicated because all of the tests were done as part of the routine initial assessment ${ }^{9}$ and analysed retrospectively. The Board of Directors of CIRO approved the use of de-identified patients' records.

\section{Rehabilitation programme}

The PR programme consisted of an 8-week inpatient or 14 week outpatient comprehensive programme. ${ }^{12} \mathrm{PR}$ included: exercise training, nutritional support; occupational therapy, exacerbation management, dyspnoea management, psychological counselling if indicated, and 20 group educational sessions of one hour, which were described elsewhere. ${ }^{8}$

\section{Measurements}

The following patient characteristics were measured at baseline and after completion of PR according to recommended procedures: demographics; current smoking status; use of long-term oxygen therapy (LTOT); pulmonary function (forced expiratory volume in the first second $\left(\mathrm{FEV}_{1}\right)$ and forced vital capacity (FVC)), body-mass index (BMI) and Medical Research Council (MRC) dyspnoea scale. ${ }^{13}$

Functional exercise capacity was measured at baseline by using two six-minute walking distance (6MWD) tests performed on two consecutive days. ${ }^{14,15}$ In addition, the 6MWD test was performed after PR and the change between this test and the best baseline 6MWD was recorded. ${ }^{14,15}$

Disease-specific health status was examined using the St. George's Respiratory Questionnaire (SGRQ) at baseline and after PR. ${ }^{16}$ SGRQ provides three domain scores (symptoms, activities and impact) and a total score, ranging from 0 (optimal) to 100 points (worst). ${ }^{16}$

Symptoms of anxiety and depression were evaluated using the validated Dutch version of the Hospital Anxiety and Depression Scale (HADS) at baseline and after PR. ${ }^{17}$ The HADS is divided into an anxiety subscale (HADS-A) and a depression subscale (HADS-D). Scores for both subscales range from 0 (optimal) to 21 (worst) points. ${ }^{18}$

Coping styles were assessed with the Utrecht Coping List (UCL) at baseline and after PR. ${ }^{19}$ The UCL consists of 47 items, divided into seven coping subscales: active confronting coping (confronting problems and employing purposeful strategies); palliative reaction (distracting one's attention from the problems); avoidance (waiting and keeping clear of the problem); seeking social support (seeking comfort and help from others); passive reaction pattern (rumination and drawing back); expressing emotions (showing annoyance or anger; releasing tension); and fostering reassuring thoughts (self-encouragement). Patients were asked to rate how often they used 
certain coping behaviours. Four response options for each item were offered: 'seldom or never' (1 point), 'sometimes' ( 2 points), 'often' (3 points) and 'very often' (4 points). Mean total scores are calculated for every subscale. A higher score indicates an increased tendency towards using that specific coping style. ${ }^{19}$

\section{Good responders, moderate responders and non-responders}

Since improvement in either SGRQ and/or 6MWD is beneficial, and because changes in these two variables after PR are not strongly correlated, a composite measure of response was used in the present study. ${ }^{5}$ Accordingly, good responders were defined arbitrarily as experiencing an improvement of twice the minimal clinically important difference (MCID) in SGRQ total score (decrease of $\geq 8$ points) ${ }^{20}$ and/or 6MWD (increase of $\geq 50$ meters). ${ }^{21}$ Moderate responders were defined arbitrarily, as patients with improvement of once the MCID in SGRQ (decrease of $\geq 4$ to $<8$ points) ${ }^{20}$ and/or $6 M W D$ (increase of $\geq 25$ to $<50$ meters) ${ }^{21}$ scores. Non-responders were defined arbitrarily, as experiencing no improvement of one time MCID in either of the two aforementioned outcomes: decrease of $<4$ points in $S G R Q^{20}$ and/or increase of $<25$ meters in 6MWD. ${ }^{21}$ Twice the generally accepted MCID improvement was used before in studies examining surgical interventions in patients with severe emphysema. 22,23

\section{Statistical analysis}

Data analysis was performed using SPSS 23.0 statistical analysis software (SPSS Inc. Chicago, IL). Categorical variables are represented as proportions. Continuous variables are represented as means \pm standard deviation (SD), unless otherwise indicated. Baseline characteristics and changes in HADS, BMI, and UCL domain scores were compared between the good responders, moderate responders and nonresponders using one-way analysis of variance (ANOVA) followed by the Bonferroni post hoc comparisons. In addition, to evaluate the nominal variables $\chi^{2}$ tests were used. Paired samples $t$-tests were used to assess the changes after PR stratified for good, moderate and non-responders. To examine a possible relationship between dyspnoea and coping styles, bivariate correlations were carried out. A two-tailed value of $p<0.05$ was considered statistically significant. 


\section{Results}

\section{Patient characteristics}

In total, 439 patients (169 (38.5\%) inpatients and 270 (61.5\%) outpatients) with complete data on relevant variables were included in this study. Patients had on average severe systemic airflow limitation, impaired exercise tolerance and an impaired disease-specific health status (Table 4.1). After PR, the total group showed significant improvements in SGRQ total score, 6MWD, MRC dyspnoea scale, HADS-A scores and HADS-D scores (Table 4.1). An improvement of twice the MCID was reported by 186 patients (42.4\%) on SGRQ total score and by 135 patients $(30.8 \%)$ on 6MWD.

Table 4.1 Patient characteristics, before and after PR.

\begin{tabular}{|c|c|c|c|c|}
\hline Total group, $n=439$ & Before PR & After PR & Mean change $(\Delta)$ & $p$-value ${ }^{+}$ \\
\hline Age (years) & $65.7 \pm 8.8$ & - & - & - \\
\hline Male, $n(\%)$ & $242(55.1)$ & - & - & - \\
\hline Married, $n(\%)$ & $293(66.7)$ & - & - & - \\
\hline LTOT, $n(\%)^{*}$ & $91(22.8)$ & - & - & - \\
\hline Current smoker, $n(\%)$ & $102(23.2)$ & - & - & - \\
\hline $\mathrm{FEV}_{1}$ (litres) $^{* *}$ & $1.31 \pm 0.6$ & $1.34 \pm 0.6$ & $0.03 \pm 0.3$ & 0.029 \\
\hline $\mathrm{FEV}_{1}(\% \text { predicted })^{* *}$ & $47.8 \pm 18.6$ & $48.1 \pm 18.7$ & $0.3 \pm 6.6$ & 0.346 \\
\hline $\mathrm{FEV}_{1} / \mathrm{FVC}(\%)^{* *}$ & $37.9 \pm 11.7$ & $38.5 \pm 11.9$ & $0.6 \pm 4.5$ & 0.005 \\
\hline HADS-A (points) & $7.0 \pm 4.3$ & $5.7 \pm 4.0$ & $-1.3 \pm 3.6$ & $<0.001$ \\
\hline HADS-D (points) & $6.7 \pm 4.1$ & $5.5 \pm 3.8$ & $-1.2 \pm 3.7$ & $<0.001$ \\
\hline SGRQ Total score (points) & $54.3 \pm 16.3$ & $48.7 \pm 16.0$ & $-5.6 \pm 12.1$ & $<0.001$ \\
\hline $6 \mathrm{MWD}(\mathrm{m})$ & $446.0 \pm 109.8$ & $474.2 \pm 111.5$ & $28.2 \pm 57.5$ & $<0.001$ \\
\hline BMI $\left(\mathrm{kg} / \mathrm{m}^{2}\right)^{* * *}$ & $25.7 \pm 5.5$ & $25.9 \pm 5.1$ & $0.2 \pm 1.2$ & 0.062 \\
\hline MRC dyspnoea scale (grade) $* * * *$ & $3.4 \pm 1.1$ & $2.8 \pm 1.0$ & $-0.6 \pm 1.1$ & $<0.001$ \\
\hline
\end{tabular}

Data are presented as mean \pm standard deviation (SD) or number of patients (\%). ${ }^{*} n=400, *^{*} n=433$, $* * * n=435, * * * * n=304{ }^{*} p$-value based on paired samples $t$-test. $p$-value of the bold numbers is defined as $p<0.05$.

Abbreviations: $\mathrm{FEV}_{1}$ : forced expiratory volume in the first second; FVC: forced vital capacity; LTOT: longterm oxygen therapy; HADS-A: Hospital Anxiety and Depression Scale, anxiety subscale; HADS-D: Hospital Anxiety and Depression Scale, depression subscale; SGRQ: St. George Respiratory Questionnaire; 6MWD: six-minute walking distance; BMI: body mass index; MRC: Medical Research Council.

\section{Comparison between good responders, moderate responders and non-responders}

In total, 237 (54.0\%) patients were defined as good responders. Out of these, 153 (34.9\%) patients had an improvement of twice the MCID in one of the two outcomes (SGRQ total score or 6MWD), while 84 (19.1\%) patients had an improvement of twice the MCID in both outcomes after PR. Moderate response to PR showed 97 (22.1\%) patients. Furthermore, with no improvement in SGRQ and/or 6MWD after PR were 
105 (23.9\%) patients. At baseline, good responders were more likely to have: higher scores on MRC dyspnoea scale, HADS-A and HADS-D, worse SGRQ total score, lower $6 \mathrm{MWD}$, and a higher level of $\mathrm{UCL}$ passive reaction pattern coping style than moderate and/or non-responders (all $p<0.05$ ) (Table 4.2).

Table 4.2 Baseline characteristics, comparison between good responders, moderate responders and non-responders to PR.

\begin{tabular}{|c|c|c|c|c|}
\hline & \multicolumn{3}{|c|}{ Good responders $^{\#}$ Moderate responders ${ }^{x}$ Non-responders ${ }^{2}$} & \multirow{2}{*}{$p$-value ${ }^{+}$} \\
\hline & $n=237(54.0)$ & $n=97(22.1)$ & $n=105(23.9)$ & \\
\hline Age (years) & $65.6 \pm 8.7$ & $67.3 \pm 9.0$ & $64.6 \pm 8.6$ & 0.091 \\
\hline Sex (male), $n(\%)$ & $132(55.7)$ & $58(59.8)$ & $52(49.5)$ & 0.330 \\
\hline Marital status (married) $n(\%)$ & $158(66.7)$ & $64(66.0)$ & $71(67.6)$ & 0.707 \\
\hline LTOT, $n(\%)^{*}$ & $58(26.6)$ & $17(19.8)$ & $16(16.7)$ & 0.116 \\
\hline Current smoker, $n(\%)$ & $62(26.2)$ & $22(22.7)$ & $18(17.1)$ & 0.118 \\
\hline $\mathrm{FEV}_{1}$ (litres) $* *$ & $1.3 \pm 0.6$ & $1.3 \pm 0.6$ & $1.3 \pm 0.6$ & 0.911 \\
\hline $\mathrm{FEV}_{1}(\%$ predicted $) * *$ & $47.2 \pm 18.7$ & $49.1 \pm 19.3$ & $48.1 \pm 18.0$ & 0.691 \\
\hline $\mathrm{FEV}_{1} / \mathrm{FVC}(\%)^{* *}$ & $38.0 \pm 11.7$ & $38.3 \pm 12.2$ & $37.7 \pm 11.2$ & 0.951 \\
\hline HADS-A (points) & $7.5 \pm 4.4^{\ddagger}$ & $6.5 \pm 4.2$ & $6.4 \pm 3.8$ & 0.027 \\
\hline HADS-D (points) & $7.2 \pm 4.2^{\ddagger}$ & $6.4 \pm 4.0$ & $6.1 \pm 3.8$ & 0.046 \\
\hline SGRQ Total score (points) & $58.5 \pm 15.2^{\S^{\dagger}}$ & $50.0 \pm 16.9$ & $48.6 \pm 15.5$ & $<0.001$ \\
\hline 6MWD (m) & $429.0 \pm 111.1^{\ddagger}$ & $456.1 \pm 114.9$ & $475.2 \pm 94.6$ & 0.001 \\
\hline BMI $\left(\mathrm{kg} / \mathrm{m}^{2}\right) * * *$ & $26.0 \pm 5.6$ & $25.5 \pm 5.6$ & $25.4 \pm 5.1$ & 0.582 \\
\hline MRC dyspnoea scale (grade)**** & $3.5 \pm 1.1^{\ddagger}$ & $3.3 \pm 1.1$ & $3.2 \pm 1.2$ & 0.044 \\
\hline UCL Active confronting (points) & $16.6 \pm 3.8$ & $16.8 \pm 4.0$ & $16.6 \pm 4.5$ & 0.863 \\
\hline UCL Palliative reaction (points) & $16.5 \pm 3.3$ & $16.3 \pm 3.7$ & $16.4 \pm 3.8$ & 0.906 \\
\hline UCL Avoidance (points) & $15.9 \pm 3.7$ & $15.6 \pm 3.4$ & $16.3 \pm 3.8$ & 0.379 \\
\hline UCL Seeking social support (points) & $11.9 \pm 3.3$ & $11.2 \pm 3.4$ & $11.9 \pm 3.9$ & 0.201 \\
\hline UCL Passive reaction pattern (points) & $12.3 \pm 3.5^{\neq \&}$ & $11.3 \pm 3.5$ & $11.1 \pm 3.0$ & 0.003 \\
\hline UCL Expressing emotions (points) & $5.2 \pm 1.5$ & $5.4 \pm 1.7$ & $5.3 \pm 1.8$ & 0.728 \\
\hline UCL Reassuring thoughts (points) & $11.9 \pm 2.6$ & $11.5 \pm 2.8$ & $12.2 \pm 2.8$ & 0.209 \\
\hline
\end{tabular}

Data are presented as mean \pm standard deviation (SD) or number of patients $(\%) . * n=400, * * n=433$, $* * * n=435, * * * * n=304{ }^{+} p$-value based on ANOVA and $\chi^{2}$ analysis. $p$-value of the bold numbers is defined as $p<0.05$. ${ }^{\S} p<0.001$, based on Bonferroni Post Hoc test comparing between good responders and moderate responders. ${ }^{\dagger} p<0.001$, based on Bonferroni Post Hoc test comparing between good responders and nonresponders. ${ }^{\ddagger} p<0.05$, based on Bonferroni Post Hoc test comparing between good responders and nonresponders. \& $p<0.05$, based on Bonferroni Post Hoc test comparing between good responders and moderate responders. "Good responder defined arbitrarily as a patient with two times Minimum Clinical Important Difference (MCID) improvement in SGRQ and/or 6MWD scores. "Moderate responder defined arbitrarily as a patient with one time MCID improvement in SGRQ and/or 6MWD scores. ${ }^{\mho}$ Non-responder defined arbitrarily as a patient without one time MCID improvement in SGRQ and/or 6MWD scores.

Abbreviations: see legend table 1; UCL: Utrecht Coping List.

Following PR, good responders reported a larger improvement in HADS-A score, HADS-D score and MRC dyspnoea scale than moderate and/or non-responders. Change in passive reaction pattern coping style differed significantly between good responders and non-responders after PR $(p<0.001$, Table 4.3). Additionally, good responders significantly increased their level of $\mathrm{UCL}$ active confronting coping style 
$(p=0.008)$, while they decreased the levels of the UCL subscales of palliative reaction $(p=0.030)$, passive reaction pattern $(p<0.001)$ and reassuring thoughts $(p=0.002)$ coping styles from baseline (Table 4.3). Within the moderate responders' group, improvements from baseline were shown in HADS-A and HADS-D scores ( $p=0.042$ and $p=0.003$, respectively). None of the moderate responders' coping styles significantly changed after PR (all $p>0.05$, Table 4.3). Non-responders significantly increased their BMI $(p=0.024)$, while they decreased the level of reassuring thoughts coping styles $(p=0.046)$ from baseline (Table 4.3).

Table 4.3 Changes after PR, comparison within- and between-group differences of good responders, moderate responders and non-responders

\begin{tabular}{|c|c|c|c|c|}
\hline & $\begin{array}{c}\text { Good Responders }^{\#} \\
n=237(54.0) \\
\end{array}$ & $\begin{array}{c}\text { Moderate responders }^{x} \\
n=97(22.1)\end{array}$ & $\begin{array}{c}\text { Non-responders }^{\mho} \\
n=105(23.9)\end{array}$ & $p$-value ${ }^{+}$ \\
\hline$\triangle$ SGRQ total score & $-12.3 \pm 10.9$ & $-1.1 \pm 6.7$ & $5.6 \pm 7.6$ & - \\
\hline$\triangle 6 M W D$ & $54.4 \pm 55.4$ & $17.1 \pm 29.4$ & $-20.7 \pm 45.5$ & - \\
\hline$\Delta \mathrm{FEV}_{1} *$ & $0.0 \pm 0.3$ & $0.0 \pm 0.3$ & $0.0 \pm 0.4$ & 0.901 \\
\hline$\Delta \mathrm{FEV}_{1}(\% \text { predicted })^{*}$ & $0.9 \pm 7.0$ & $0.0 \pm 6.5$ & $-0.8 \pm 5.7$ & 0.094 \\
\hline$\Delta \mathrm{FEV}_{1} / \mathrm{FVC}^{*}$ & $0.5 \pm 4.7$ & $0.9 \pm 4.2$ & $0.8 \pm 5.7$ & 0.094 \\
\hline$\triangle$ HADS-A & $-2.0 \pm 3.8^{\& ! \ddagger}$ & $-0.6 \pm 3.0^{+}$ & $-0.5 \pm 3.4$ & $<0.001$ \\
\hline$\triangle$ HADS-D & $-1.8 \pm 4.0^{! \ddagger}$ & $-1.0 \pm 3.3^{+}$ & $-0.3 \pm 3.2$ & 0.002 \\
\hline$\Delta \mathrm{BMI}^{* *}$ & $0.1 \pm 1.2$ & $0.0 \pm 1.4$ & $0.2 \pm 0.9^{+}$ & 0.552 \\
\hline$\Delta \mathrm{MRC}$ dyspnoea scale*** & $-0.7 \pm 1.1^{! \ddagger}$ & $-0.4 \pm 0.9^{\ddagger}$ & $-0.3 \pm 1.1^{\dagger}$ & 0.019 \\
\hline$\Delta$ UCL Active confronting & $0.7 \pm 3.7^{+}$ & $-0.1 \pm 3.5$ & $0.4 \pm 3.8$ & 0.206 \\
\hline$\Delta$ UCL Palliative reaction & $-0.5 \pm 3.5^{\dagger}$ & $-0.4 \pm 3.2$ & $-0.3 \pm 3.4$ & 0.835 \\
\hline$\triangle$ UCL Avoidance & $-0.5 \pm 3.8$ & $-0.2 \pm 3.6$ & $-0.5 \pm 4.4$ & 0.841 \\
\hline$\Delta$ UCL Seeking social support & $-0.1 \pm 3.2$ & $0.1 \pm 2.9$ & $0.3 \pm 3.2$ & 0.536 \\
\hline$\Delta$ UCL Passive reaction pattern & $-1.0 \pm 3.3^{\S \ddagger}$ & $-0.4 \pm 2.9$ & $0.5 \pm 3.1$ & $<0.001$ \\
\hline$\Delta \mathrm{UCL}$ Expressing emotions & $0.1 \pm 1.6$ & $-0.2 \pm 1.6$ & $0.0 \pm 1.7$ & 0.332 \\
\hline$\Delta \mathrm{UCL}$ Reassuring thoughts & $-0.5 \pm 2.7^{+}$ & $-0.2 \pm 3.0$ & $-0.5 \pm 2.5^{+}$ & 0.602 \\
\hline
\end{tabular}

Data are presented as mean \pm standard deviation (SD) or percentage (\%). ${ }^{*} n=433,{ }^{* *} n=435,{ }^{* * *} n=304$. ${ }^{+} p$-value based on ANOVA comparing good responders, moderate responders and non-responders. $p$-value of the bold numbers is defined as $p<0.05$. ${ }^{\S} p<0.001$, based on Bonferroni Post Hoc test comparing between good responders and non-responders. ${ }^{\&} p<0.05$, based on Bonferroni Post Hoc test comparing between good responders and moderate responders. $p<0.05$, based on Bonferroni Post Hoc test comparing between good responders and non-responders. ${ }^{\dagger} p<0.05$, based on paired samples $t$-test comparing before and after PR within groups. ${ }^{\ddagger} p<0.001$, based on paired samples $t$-test comparing before and after PR within groups. "Good responder defined arbitrarily as a patient with two times Minimum Clinical Important Difference (MCID) improvement in SGRQ and/or 6MWD scores. "Moderate responder defined arbitrarily as a patient with one time MCID improvement in SGRQ and/or 6MWD scores. ${ }^{\mho}$ Non-responder defined arbitrarily as a patient without one time MCID improvement in SGRQ and/or 6MWD scores.

Abbreviations: see legend table 1; UCL: Utrecht Coping List.

Pearson's correlation indicated that: baseline MRC dyspnoea scale was positively correlated with baseline passive reaction pattern coping style $(r=0.202, p<0.001)$; MRC dyspnoea scale after PR was positively correlated with passive reaction pattern coping style after PR $(r=0.148, p=0.009)$; and change in MRC dyspnoea scale was positively 
correlated with change in passive reaction pattern coping style $(r=0.212, p<0.001)$. None of the rest of coping styles or changes in coping styles was related to dyspnoea or change in dyspnoea following PR (all $p>0.05$ ).

\section{Discussion}

The present study demonstrates differences in changes in coping styles after PR between good responders, moderate responders and non-responders, defined arbitrarily by a composite measure of response in functional exercise tolerance and/or disease-specific health status. Change in passive reaction pattern coping style differed significantly between the two groups of good responders and non-responders following PR. Moreover, PR resulted in a significant change in good responders' coping styles; whereas the majority of the moderate and non-responders' coping styles, were not significantly influenced by PR.

\section{Characteristics of good responders, moderate responders and non- responders and effect of PR}

More than half of the patients in the present study showed a response of twice the MCID in SGRQ and/or 6MWD. Garrod et al. ${ }^{5}$ and Scott et al. ${ }^{24}$ demonstrated that approximately $80 \%$ of the patients and almost $70 \%$ of the patients reported improvement of once the MCID on at least one of these two important outcomes after PR, respectively. In the latter study, responders were found to have a higher baseline BMI, lower baseline BODE index score (a composite index of body weight, airflow limitation, dyspnoea and exercise tolerance) and a higher baseline $\mathrm{FEV}_{1}$ when compared to non-responders. ${ }^{24}$ Nevertheless, in the studies by Garrod et al. ${ }^{5}$ and Scott et al., ${ }^{24}$ response was defined based on improvement in either SGRQ or 6MWD using a decrease of 4 points and/or increase of 54 meters, respectively. In contrast, our study in comparison with the aforementioned research, differs in the use of criteria set rather high (improvement of twice the MCID in either SGRQ or 6MWD) in defining the good responders group which is usually considered in high risk/highly burdensome interventions. $^{22,23}$ Nonetheless, we additionally defined 97 (22\%) patients with improved SGRQ (decrease of $\geq 4$ to $<8$ points) and/or 6MWD (increase of $\geq 25$ to $<50$ meters) scores as moderate responders, resulting in total of 334 (76.1\%) patients with an improvement in SGRQ of minimum 4 points and/or 6MWD of minimum 25 meters. Additionally, these two earlier studies did not evaluate patients' coping styles.

Our findings demonstrate a decrease in the levels of anxiety and depression after PR for good responders and moderate or non-responders. Actually, the good 
responders' group showed an improvement in HADS scores of more than 1.5 point, defined as MCID of the HADS scores in COPD patients. ${ }^{25}$ In contrast, in the moderate and non-responders groups the improvements were less than the MCID of the HADS scores. However, previous research suggests that patients scoring highest on the HADS scores at baseline have the greatest reductions after PR. ${ }^{26}$

\section{Coping styles of good responders, moderate responders and non- responders}

Data concerning the effect of PR on coping styles in patients with COPD are scarce. A study by Ninot et al. ${ }^{27}$ using the Coping Inventory for Stressful Situations, demonstrated increase in problem-focused strategies, decrease in emotion-focused strategies and mixed results on the use of avoidance between men and women following inpatient PR. Interestingly, in the present study the patient group showing improvements of twice the MCID in SGRQ and/or 6MWD, reported significant changes in coping styles. On the contrary, moderate responders did not change their coping after PR, while among non-responders, only reassuring thoughts (selfencouragement) coping style decreased from baseline. Moreover, the decrease in the level of passive reaction pattern coping style in the good responder group, seen as a positive outcome of $\mathrm{PR}$, was not found in the non-responders group. Indeed, passive reaction pattern coping style is associated with worse mental health, ${ }^{11,28,29}$ and it may prevent patients from taking the appropriate initiatives during an exacerbation. ${ }^{30}$ It is worth taking into consideration that the effects on coping styles in the current study were achieved by a comprehensive PR programme which did not contain a specific coping intervention that targeted coping styles of all enrolled patients into PR. However, further investigation is warranted on the possible relationship between coping styles and response in other outcomes, such as physical and psychological symptom burden, self-management skills and care dependency.

In addition, our findings indicated a positive linear relationship between dyspnoea and passive reaction pattern coping style. Nevertheless, this association was rather weak, possibly suggesting that interventions targeting physiological parameters may not lead to improved coping of patients with COPD.

\section{Interventions targeting coping styles}

There is some evidence for interventions targeting coping styles as a tool to improve coping and behaviour in patients with chronic diseases. ${ }^{31-33}$ Kroese et al. ${ }^{31}$ conducted a self-management intervention in type 2 diabetes patients aiming at development of proactive coping styles (e.g. goal setting and identifying barriers). An improved response was reported in all psychological (e.g. proactive coping and self-efficacy) and behavioural variables (e.g. self-care, diet and physical activity) during the 3-month 
initial phase and these improvements were maintained over 12 months. ${ }^{31}$ Similarly, in patients with rheumatic diseases, interventions aimed at stimulating active coping by teaching self-management skills or skills in dealing with pain and stress were recommended..$^{32}$ Uitterhoeve et al. ${ }^{33}$ performed a systematic review of psychosocial interventions for patients with advanced cancer. Behaviour therapy, including one or more of the following: learning specific coping styles, visualisation or cognitive approaches focussing on changing specific thoughts or beliefs, guided imagery and relaxation exercises, was used in 12 out of 13 identified trials. ${ }^{33}$ The authors reported an improved coping, especially a reduction in suppression of negative affect and an improvement in the restraint of inconsiderate and impulsive behaviour. ${ }^{33}$ It is unclear if these effects are of clinical significance, as most effects were of a small magnitude. Nevertheless, authors concluded that as the effects reflected changes on measures that are important to patients with advanced cancer, such as alleviated distress or improved patient's (perceived) functioning in daily life, even small effects can be clinically relevant. $^{33}$

Thus, teaching coping strategies might maximise adjustment to a chronic disease such as COPD, as well as it might support in maintaining the results of PR. ${ }^{6,734}$ Blumenthal et al. ${ }^{35}$ in a randomised controlled trial (RCT) on telehealth coping styles intervention demonstrated clinically meaningful improvements in quality of life (QoL) and exercise tolerance. This coping styles intervention reduced depression, anxiety, dyspnoea and fatigue and improved vitality, social and emotional role functioning, overall mental health, communication with caregivers and exercise tolerance. ${ }^{35}$ Lee et al. $^{36}$ conducted a nurse-led RCT, which offered problem-solving therapy on coping, self-efficacy and depressive symptoms for COPD patients. A subgroup of clinically depressed patients in the intervention group experienced decreased depressive symptoms and increased self-efficacy after 6 months. ${ }^{36}$ Marques et al. ${ }^{37}$ in a RCT made a step forward by involving family members of patients with COPD and investigating the impact of a family-based PR programme on patients and family members' coping strategies to manage COPD. The PR programme consisted of exercise training, psychosocial support and education during 12 weeks. Family members of the familybased PR attended the psychosocial support and education sessions together with patients, whereas in the control group, family members did not participate. ${ }^{37}$ Authors recommended that integrating the family member in PR contributed to improved family coping strategies to manage the disease, with further improvement in family members' psychologic distress and sexual functioning. ${ }^{37}$ Specifically, patients and family members of the family-based PR made greater use of community resources to cope with their problems than the control group. ${ }^{37}$

Furthermore, the educational component of PR may be a venue for integrating interventions aimed at improving coping styles of patients with COPD. ${ }^{38}$ Motivational interviewing appears to be a complimentary approach to self-management education 
as a method for enhancing personal commitment to change. ${ }^{39}$ Nonetheless, further research is warranted to determine whether including interventions targeting coping styles in the PR programme may modify coping behaviour of COPD patients and can improve other outcomes.

\section{Methodological considerations}

Certain limitations of the present study should be taken into account. First, for defining the good responders to $P R$, we used the arbitrarily high response criterion of twice the MCID in exercise tolerance and/or disease-specific health status rather than the clinically meaningful thresholds of once the MCID in these two outcomes, respectively. ${ }^{20,21}$ Nonetheless, more than half of the patients fulfilled this criterion. Second, the current study explored the response to PR by assessing the patients' response only in exercise tolerance and/or disease-specific health status. However, other variables not under investigation in the present trial may interfere with the response to PR. The following: PR setting, comorbidities, fatigue, level of activities of daily living, exacerbations, inadequate social support, were mentioned as important factors related to changes in the outcomes of PR. ${ }^{40}$ Third, because there were many components included in the PR intervention, it was not possible to determine which aspects of the programme were most beneficial and caused the response to PR. Last, a large number of coping instruments is available to assess a different number and different kind of coping styles. ${ }^{27,34,41,42}$ Hence, the use of another instrument than the UCL might have changed our results. Nevertheless, the UCL has satisfactory psychometric properties in a Dutch population and it was previously applied in COPD patients. $^{19,28,29}$

\section{Conclusions and implications for future research}

We conclude that a PR programme influences coping styles of patients who had a very good response in exercise tolerance and/or health status. On the contrary, PR does not change the coping styles of patients with a moderate response or, does not change the majority of coping styles of patients with no improvement in these two outcomes after PR. It is worth noting that previous research shows a strong relationship between COPD patients' coping styles and symptoms of anxiety and depression, ${ }^{8,11,29,34-36}$ which may imply that further investigation is needed with an aim to establish the exact mechanisms in relation to patient's processes of behaviour change. Further research is needed to explore whether including interventions targeting coping styles in the PR programme may result in changes in coping behaviour of patients with COPD, as well as improvement in other outcomes. 


\section{References}

1. Spruit MA, Singh SJ, Garvey C, ZuWallack R, Nici L, Rochester C, et al. An official American Thoracic Society/European Respiratory Society statement: key concepts and advances in pulmonary rehabilitation. Am J Respir Crit Care Med 2013;188:e13-64.

2. Nici L, Donner C, Wouters E, Zuwallack R, Ambrosino N, Bourbeau J, et al. American Thoracic Society/European Respiratory Society statement on pulmonary rehabilitation. Am J Respir Crit Care Med 2006;173:1390-413.

3. Bhandari NJ, Jain T, Marolda C, ZuWallack RL. Comprehensive pulmonary rehabilitation results in clinically meaningful improvements in anxiety and depression in patients with chronic obstructive pulmonary disease. J Cardiopulm Rehabil Prev 2013;33:123-7.

4. Lacasse Y, Goldstein R, Lasserson TJ, Martin S. Pulmonary rehabilitation for chronic obstructive pulmonary disease. Cochrane Database Syst Rev 2006:CD003793.

5. Garrod R, Marshall J, Barley E, Jones PW. Predictors of success and failure in pulmonary rehabilitation. Eur Respir J 2006;27:788-94.

6. Worth H, Dhein Y. Does patient education modify behaviour in the management of COPD? Patient Educ Couns 2004;52:267-70.

7. Wempe JB, Wijkstra PJ. The influence of rehabilitation on behaviour modification in COPD. Patient Educ Couns 2004;52:237-41.

8. Stoilkova A, Janssen DJA, Franssen FME, Spruit MA, Wouters EFM. Coping styles in patients with COPD before and after pulmonary rehabilitation. Respir Med 2013;107:825-33.

9. Spruit MA, Vanderhoven-Augustin I, Janssen PP, Wouters EF. Integration of pulmonary rehabilitation in COPD. Lancet 2008;371:12-3.

10. Vestbo J, Hurd SS, Agusti AG, Jones PW, Vogelmeier C, Anzueto A, et al. Global strategy for the diagnosis, management, and prevention of chronic obstructive pulmonary disease: GOLD executive summary. Am J Respir Crit Care Med 2013;187:347-65.

11. Stoilkova A, Wouters EFM, Spruit MA, Franssen FME, Janssen DJA. The relationship between coping styles and clinical outcomes in patients with COPD entering pulmonary rehabilitation. COPD: Journal Of Chronic Obstructive Pulmonary Disease 2013;10:316-23.

12. Franssen FM, Broekhuizen R, Janssen PP, Wouters EF, Schols AM. Effects of whole-body exercise training on body composition and functional capacity in normal-weight patients with COPD. Chest 2004;125:2021-8.

13. Spruit MA, Pennings HJ, Janssen PP, Does JD, Scroyen S, Akkermans MA, et al. Extra-pulmonary features in COPD patients entering rehabilitation after stratification for MRC dyspnea grade. Respir Med 2007;101:2454-63.

14. ATS statement: guidelines for the six-minute walk test. Am J Respir Crit Care Med 2002;166:111-7.

15. Hernandez C, Casas A, Escarrabill J, Alonso J, Puig-Junoy J, Farrero E, et al. Home hospitalisation of exacerbated chronic obstructive pulmonary disease patients. Eur Respir J 2003;21:58-67.

16. Jones PW, Quirk FH, Baveystock CM, Littlejohns P. A self-complete measure of health status for chronic airflow limitation. The St. George's Respiratory Questionnaire. Am Rev Respir Dis 1992;145:1321-7.

17. Spinhoven P, Ormel J, Sloekers PP, Kempen GI, Speckens AE, Van Hemert AM. A validation study of the Hospital Anxiety and Depression Scale (HADS) in different groups of Dutch subjects. Psychol Med 1997;27:363-70.

18. Zigmond AS, Snaith RP. The hospital anxiety and depression scale. Acta Psychiatr Scand 1983;67: 361-70.

19. Schreurs PJG, van de Willige G, Brosschot JF, Tellegen B, Graus GMH. De Utrechtse Coping Lijst, UCL omgaan met problemen en gebeurtenissen [The Utrecht Coping List]. Lisse, the Netherlands: Swets en Zeitlinger; 1993.

20. Jones PW. St. George's Respiratory Questionnaire: MCID. Copd 2005;2:75-9. 
21. Holland AE, Hill CJ, Rasekaba T, Lee A, Naughton MT, McDonald CF. Updating the minimal important difference for six-minute walk distance in patients with chronic obstructive pulmonary disease. Arch Phys Med Rehabil 2010;91:221-5.

22. Fishman A, Martinez F, Naunheim K, Piantadosi S, Wise R, Ries A, et al. A randomized trial comparing lung-volume-reduction surgery with medical therapy for severe emphysema. $N$ Engl J Med 2003;348:2059-73.

23. Make BJ, Martinez FJ. Assessment of patients with chronic obstructive pulmonary disease. Proc Am Thorac Soc 2008;5:884-90.

24. Scott AS, Baltzan MA, Fox J, Wolkove N. Success in pulmonary rehabilitation in patients with chronic obstructive pulmonary disease. Can Respir J 2010;17:219-23.

25. Puhan MA, Frey M, Buchi S, Schunemann HJ. The minimal important difference of the hospital anxiety and depression scale in patients with chronic obstructive pulmonary disease. Health Qual Life Outcomes 2008;6:46.

26. Harrison SL, Greening NJ, Williams JE, Morgan MD, Steiner MC, Singh SJ. Have we underestimated the efficacy of pulmonary rehabilitation in improving mood? Respir Med 2012;106:838-44.

27. Ninot G, Fortes M, Poulain M, Brun A, Desplan J, Prefaut C, et al. Gender difference in coping strategies among patients enrolled in an inpatient rehabilitation program. Heart Lung 2006;35:130-6.

28. Scharloo M, Kaptein AA, Weinman J, Hazes JM, Willems LN, Bergman W, et al. Illness perceptions, coping and functioning in patients with rheumatoid arthritis, chronic obstructive pulmonary disease and psoriasis. J Psychosom Res 1998;44:573-85.

29. Scharloo M, Kaptein AA, Weinman JA, Willems LN, Rooijmans HG. Physical and psychological correlates of functioning in patients with chronic obstructive pulmonary disease. J Asthma 2000;37:17-29.

30. Andenaes R, Kalfoss MH, Wahl AK. Coping and psychological distress in hospitalized patients with chronic obstructive pulmonary disease. Heart Lung 2006;35:46-57.

31. Kroese FM, Adriaanse MA, Vinkers CD, van de Schoot R, de Ridder DT. The effectiveness of a proactive coping intervention targeting self-management in diabetes patients. Psychol Health 2013;29:110-25.

32. Savelkoul M, de Witte L, Post M. Stimulating active coping in patients with rheumatic diseases: a systematic review of controlled group intervention studies. Patient Educ Couns 2003;50:133-43.

33. Uitterhoeve RJ, Vernooy M, Litjens M, Potting K, Bensing J, De Mulder P, et al. Psychosocial interventions for patients with advanced cancer - a systematic review of the literature. $\mathrm{Br} J$ Cancer 2004;91:1050-62.

34. McCathie HC, Spence SH, Tate RL. Adjustment to chronic obstructive pulmonary disease: the importance of psychological factors. Eur Respir J 2002;19:47-53.

35. Blumenthal JA, Emery CF, Smith PJ, Keefe FJ, Welty-Wolf K, Mabe S, et al. The effects of a telehealth coping skills intervention on outcomes in chronic obstructive pulmonary disease: primary results from the INSPIRE-II study. Psychosom Med 2014;76:581-92.

36. Lee H, Yoon JY, Lim Y, Jung H, Kim S, Yoo Y, et al. The effect of nurse-led problem-solving therapy on coping, self-efficacy and depressive symptoms for patients with chronic obstructive pulmonary disease: a randomised controlled trial. Age Ageing 2015;44:397-403.

37. Marques A, Jacome C, Cruz J, Gabriel R, Brooks D, Figueiredo D. Family-based psychosocial support and education as part of pulmonary rehabilitation in COPD: a randomized controlled trial. Chest 2015;147:662-72.

38. Stoilkova A, Janssen DJ, Wouters EF. Educational programmes in COPD management interventions: a systematic review. Respir Med 2013;107:1637-50.

39. Benzo R, Vickers K, Ernst D, Tucker S, McEvoy C, Lorig K. Development and feasibility of a selfmanagement intervention for chronic obstructive pulmonary disease delivered with motivational interviewing strategies. J Cardiopulm Rehabil Prev 2013;33:113-23.

40. Trappenburg JC, Troosters T, Spruit MA, Vandebrouck N, Decramer M, Gosselink R. Psychosocial conditions do not affect short-term outcome of multidisciplinary rehabilitation in chronic obstructive pulmonary disease. Arch Phys Med Rehabil 2005;86:1788-92.

41. O'Neill ES. Illness representations and coping of women with chronic obstructive pulmonary disease: a pilot study. Heart Lung 2002;31:295-302. 
42. Buchi S, Villiger B, Sensky T, Schwarz F, Wolf C, Buddeberg C. Psychosocial predictors of long-term success of in-patient pulmonary rehabilitation of patients with COPD. Eur Respir J 1997;10:1272-7. 



\section{Chapter 5}

\section{EDUCATIONAL PROGRAMMES IN COPD \\ MANAGEMENT INTERVENTIONS: \\ A SYSTEMATIC REVIEW}

Ana Stoilkova, Daisy J.A. Janssen, Emiel F.M. Wouters

Respiratory Medicine. 2013;107:1637-1650 


\section{Abstract}

\section{Background}

According to practice guidelines, educational programmes for patients with COPD should address several educational topics. Which topics are incorporated in the existing programmes remains unclear.

\section{Objectives}

To delineate educational topics integrated in current COPD management interventions; and to examine strengths, weaknesses, and methods of delivery of the educational programmes.

\section{Data sources}

A systematic literature search was performed using MEDLINE/PubMed, Cochrane Central Registry of Controlled Clinical Trials, and Web of Science. The authors of included studies were contacted for additional information.

\section{Study selection}

Studies that contained educational programmes incorporated in COPD management interventions were included.

\section{Data extraction}

Data were extracted using a pre-designed data form. The Reach, Efficacy, Adoption, Implementation and Maintenance (RE-AIM) framework was used for evaluating the strengths and weaknesses of the programmes.

\section{Data synthesis}

In total, 81 articles, describing 67 interventions were included. The majority (53.8\%) of the studies incorporated 10 or more educational topics. The following topics were frequently addressed: smoking cessation (80.0\%); medication (76.9\%); exercise (72.3\%); breathing strategies (70.8\%); exacerbations (69.2\%); and stress management $(67.7 \%)$. Printed material and/or brochure (90.5\%) and demonstrations and practice (73.8\%), were the predominant tool and method, respectively. Nurses $(75.8 \%)$, physicians $(37.9 \%)$ and physiotherapists $(34.8 \%)$ were the most involved healthcare professionals.

\section{Conclusions}

Heterogeneity and wide variation in the content and the method of delivery of educational interventions were present. Alignment between educational topics incorporated in the existing programmes and those recommended by the COPD guidelines, involvement of various professionals and combined use of methods should be emphasised. 


\section{Introduction}

Patient education is an important aspect of management programmes for patients with chronic diseases such as chronic obstructive pulmonary disease (COPD). ${ }^{1,2}$ It is recommended to provide education at the time of diagnosis and to continue through end-of-life care. ${ }^{3-5}$ Self-management education refers to any formalised patient educational programme aimed at teaching specific disease-related skills that emphasise disease control through behaviour change. ${ }^{3}$ Its goal is increased adherence to treatment, as well as improved clinical outcomes. ${ }^{3}$ However, studies evaluating outcomes of education in patients with COPD show extremely varied results. Findings range from increased patient knowledge, ${ }^{6}$ and reduction of health care service utilisation; $^{7}$ to a longer hospital stay ${ }^{8}$ or increased risk of dying in the first year in the treatment group when compared to controls. ${ }^{9}$ Nonetheless, interventions evaluated in these studies are complex and among other factors, differences in educational programmes may have contributed to divergent results.

The practice guidelines of the Global strategy for chronic Obstructive Lung Disease (GOLD) $)^{10,11}$ and the American Thoracic Society/European Respiratory Society (ATS/ERS) Statements on pulmonary rehabilitation $(P R)^{5,12}$ emphasise the important role of educational components in COPD management interventions. Therefore, educational programmes should address several topics, such as early recognition and treatment of exacerbations, proper use of medication, informed end-of-life decision making, breathing strategies and secretion clearance techniques., ${ }^{5,12}$ However, which educational topics are incorporated in the existing programmes remains unclear.

The Reach, Efficacy, Adoption, Implementation and Maintenance (RE-AIM) framework for evaluating chronic illness management interventions is a method that systematically considers the strengths and weaknesses of programmes. ${ }^{13}$ The use of RE-AIM evaluation framework in the processes of planning, evaluating, and reporting studies, may guide the translation of research into practice, as well as it may help determining the applicability of programmes to specific settings, type of patients, available resources and assessed outcomes. ${ }^{14}$

This systematic review aims to delineate which educational topics are integrated in educational programmes of the current COPD management interventions. Further, the present review will address the methods of delivery of educational components in these interventions. Finally, the RE-AIM evaluating framework will be used to systematically consider the strengths and weaknesses of the included management interventions. 


\section{Methods}

\section{Data sources and search for relevant studies}

Using MEDLINE/PubMed (1966-2012), Cochrane Central Registry of Controlled Clinical Trials (1966-2012) and Web of Science (1988-2012), a systematic literature search was performed to identify studies which evaluated educational programmes in patients with COPD published between January 1, 1966 and July 1, 2012.

The following three groups of search terms were combined using 'and': (1) 'COPD', 'pulmonary disease, chronic obstructive'; (2) 'health education', 'patient education as topic', 'education'; (3) 'disease management', 'case management', 'selfcare', 'delivery of health care, integrated', 'patient care planning', 'pulmonary rehabilitation'. The keywords within each group were combined using 'or' (see Supplemental material, Search Terms).

To identify additional studies that may have been missed during the initial search, the electronic searches were supplemented by searching the reference lists from eligible articles. Additionally, we contacted the corresponding authors of included studies for additional data and/or clarification of data. Authors received a structured questionnaire by email which consisted of ten questions concerning the setting, modality, duration, healthcare professionals involved in the intervention, content, teaching tools, methods and activities (see Supplemental material, Author Questionnaire).

\section{Study inclusion criteria}

Studies that contained educational programmes incorporated in COPD management interventions were included. Selection of studies was done by two reviewers (AS and DJAJ) based on the following predetermined criteria: (1) condition: patients with a diagnosis of COPD; (2) management interventions including an educational programme (defined as a programme which transfers information to COPD patients on at least one educational topic as recommended by practice guidelines in verbal, written, audio or visual forms) as part of self-management, PR, disease management, chronic care model, case management, or integrated care; (3) design: randomized clinical trials or controlled clinical trials including a control group or comparison group; (4) language: written in English. Studies reporting outcomes with COPD patients in the same group with patients with other diseases were excluded. Disagreements between the two reviewers were resolved by consensus. 


\section{Data extraction}

Data were extracted using a pre-designed data extraction form. The following data were recorded: authors, year of publication, country of origin, population characteristics, number of patients completing the programme, study design, educational topics, tools and methods, involved healthcare professionals, selfmanagement skills, duration and number of educational sessions, follow-up period and outcomes.

\section{Data synthesis, analysis and quality assessment}

Identification of relevant educational topics was based on the topics stated in the practice guidelines and PR statements by Rabe et al., ${ }^{10}$ Vestbo et al., ${ }^{11}$ Nici et al., ${ }^{5}$ and Spruit et al.. ${ }^{12}$ The number of studies including specific educational topics is presented. Didactic tools and educational methods used in individual or group sessions, involved healthcare professionals, as well as self-management skills taught in educational sessions are shown using number of studies and/or percentage.

Further, the criteria of the RE-AIM framework were applied to all eligible studies. RE-AIM consists of five dimensions: Reach: participation rate and representativeness of individuals who are willing to participate in a given programme; Efficacy: the success rate of an intervention on important outcomes, when it is implemented as intended; Adoption: percentage and representativeness of organisations that will begin or adopt a programme; Implementation: quality and consistency of programme delivery when the intervention is implemented as intended in the real word settings; and Maintenance: sustainability of intervention effects on individual's behaviour change, as well as the extent to which a programme becomes institutionalised. ${ }^{14}$ The RE-AIM evaluation framework was recently applied to assess the translation of an evidence-based intervention in patients with asthma. ${ }^{15}$ It categorises several types of chronic illness self-management interventions in the following modalities: one-to-one in-person counselling, group counselling sessions, telephone calls, interactive computer sessions, mailed print and health system policy. In addition, a three-level qualitative rating scale (high, medium or low) for each intervention type is provided. For interventions that used multiple modalities $(n=25)$, the highest rating on the five dimensions according to the RE-AIM framework was recorded.

This systematic review conforms to the PRISMA statement, ${ }^{16}$, (see Supplemental material). 


\section{Results}

\section{Description of studies}

Eventually, 67 interventions reported in 81 articles $^{4,6-9,17-92}$ were identified as COPD management interventions including an educational programme (Figure 5.1). Studies ranged in publication date from 1982 to 2012. Seven interventions were described in more than one article., $7,26,31,37,44,53,54,57,60,61,63,72,75,91$ Out of 67 studies, 60 corresponding authors were contacted. We were unable to contact the authors of 7 studies. ${ }^{19,23,30,35,36,81,86}$ The majority of the contacted authors ( $n=43,72.0 \%$ ) provided the requested information. Fifty-four (80.6\%) studies were randomized controlled trials and $13(19.4 \%)$ studies were controlled clinical trials. For each study, characteristics for which data were extracted are shown in the Supplemental Tables S5.1 and S5.2. Various interventions were evaluated in these studies: selfmanagement $(n=30,44.8 \%)$; PR $(n=13,19.4 \%)$; integrated care $(n=7,10.4 \%)$; disease management $(n=4,6.0 \%)$; a smoking cessation programme $(n=3,4.5 \%)$; case management $(n=3,4.5 \%)$, pharmaceutical care $(n=3,4.5 \%)$; exercise video $(n=2,3.0 \%)$ and cognitive behavioural therapy/COPD educational programme $(n=2,3.0 \%)$.

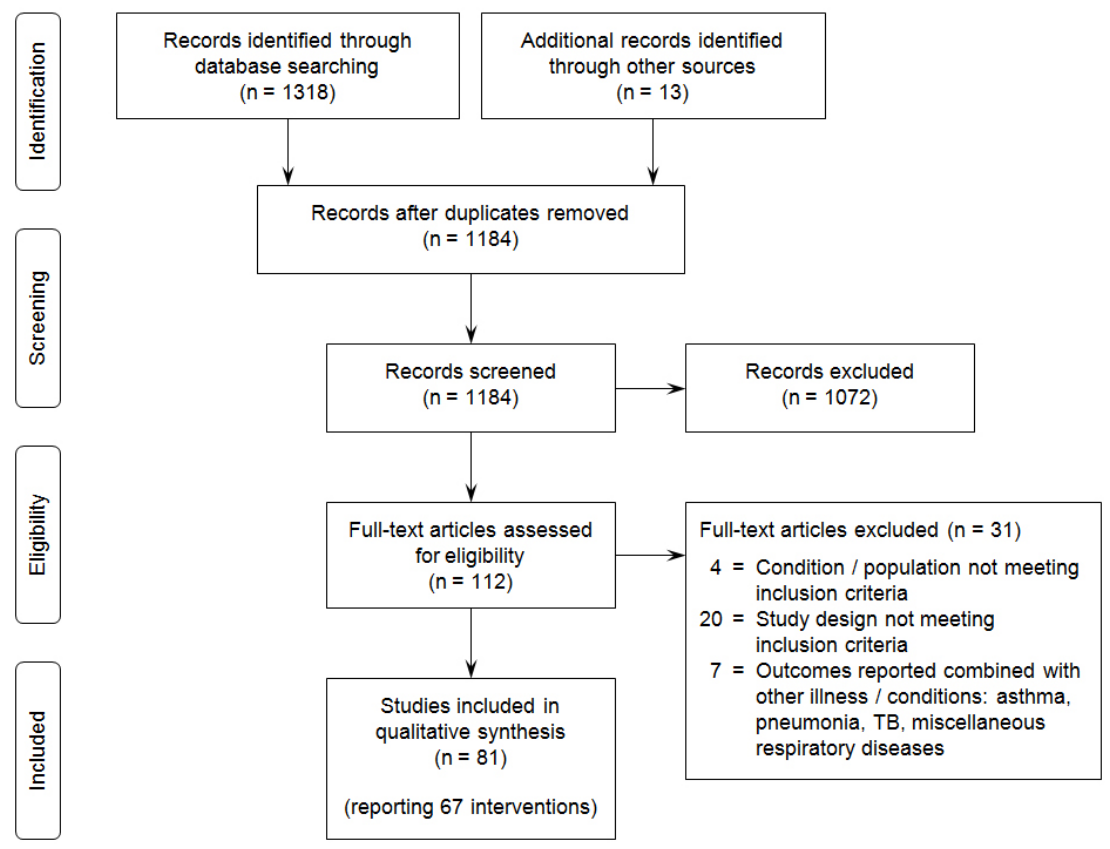

Figure 5.1 Flow diagram of the process that was used to select the relevant studies. PRISMA flow diagram. Adapted from Moher et al.. ${ }^{16}$ 


\title{
Educational topics
}

Based on the educational topics stated in the practice guidelines and PR statements, 18 topics were identified as relevant educational issues for COPD patients (Table 5.1). Out of 65 studies reporting on education, 60 (92.3\%) studies addressed multiple topics in their educational programme. Only five (7.7\%) studies covered a single educational topic such as inhaler technique/device, smoking cessation, exercise and muscle relaxation technique. The majority of the eligible studies $(n=35,53.8 \%)$, incorporated 10 or more educational topics in the curriculum of their programmes. In contrast, $30(46.2 \%)$ studies covered equal-to or less than 9 educational topics from the identified 18 topics in the practice guidelines and PR statements. The most included, were the following 12 educational topics: smoking cessation $(n=52)$; medications $(n=50)$; exercise $(n=47)$; breathing strategies $(n=46)$; exacerbations $(n=45)$; stress management $(n=44)$; respiratory devices $(n=41)$; action plan and nutrition (both $n=40)$; coping with chronic lung disease $(n=38)$; pathophysiology of chronic respiratory disease $(n=36)$; and communicating with a healthcare provider $(n=33)$. Less than half of the programmes included: secretion clearance techniques $(n=32)$; energy conservation $(n=31)$ and pulmonary anatomy and physiology $(n=30)$. End-of-life decision making $(n=6)$; interpretation of medical testing $(n=13)$ and leisure activities $(n=15)$ were the educational topics included in fewer than $25 \%$ of the programmes (Figure 5. 2).

Authors' responses were received for 43 studies. In 23 (53.5\%) of these studies, all patients in the intervention group received the same educational curriculum, whereas in $20(46.5 \%)$ studies, the educational component was tailored to some extent according to the patients' characteristics.

Table 5.1 Educational topics

\author{
Early recognition and treatment of exacerbations \\ Action plan for self-treatment of exacerbations \\ End-of-life decision making \\ Coping with chronic lung disease \\ Normal pulmonary anatomy and physiology \\ Pathophysiology of chronic respiratory disease \\ Interpretation of medical testing \\ Breathing strategies \\ Role and rationale for medications, including oxygen therapy \\ Effective use of respiratory devices \\ Secretion clearance techniques \\ Healthy food intake \\ Irritant avoidance, including smoking cessation \\ Anxiety and panic control, including relaxation techniques and stress management \\ Benefits of exercise and physical activities \\ Energy conservation during activities of daily living \\ Communicating with your healthcare provider \\ Leisure activities
}

The educational topics were adapted from the practice guidelines and PR statements., ${ }^{5,10-12}$ 


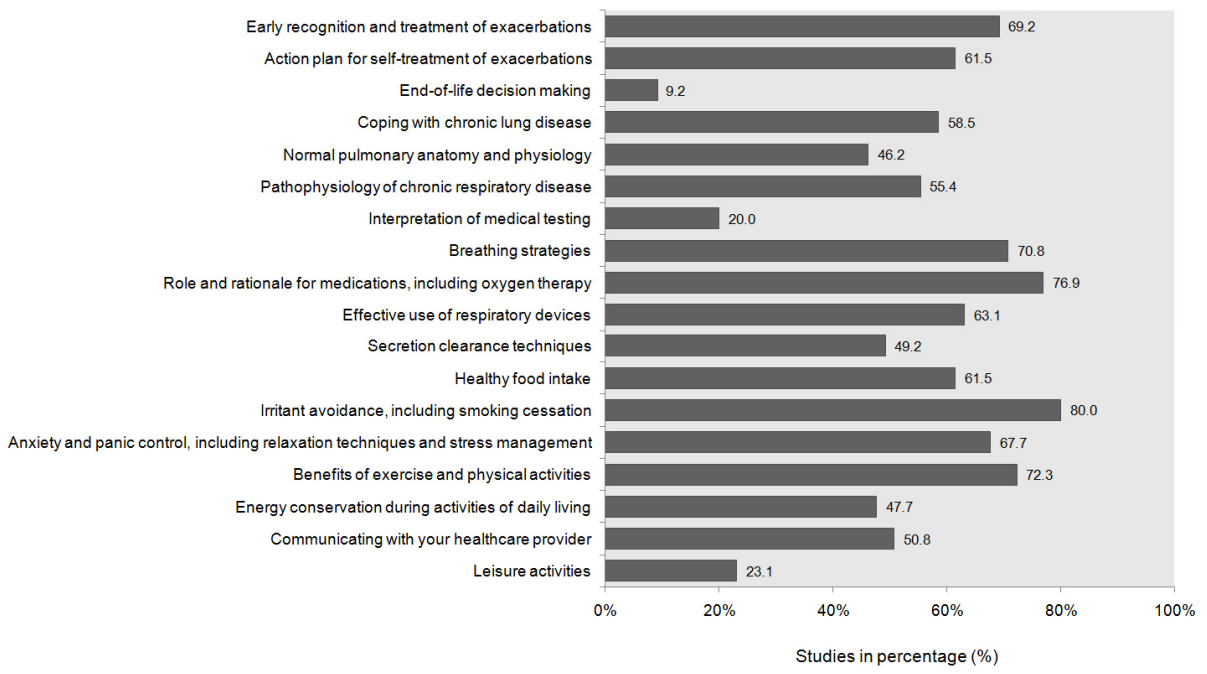

Figure 5.2 Percentage of studies that included each educational topic. $n=65$ studies; 2 studies did not report the included educational topics. ${ }^{35,83}$ The educational topics were selected from the practice guidelines and PR statements.

\section{Educational tools, methods and activities}

The following educational tools were identified: printed materials and/or brochure, flip board, PowerPoint presentation, posters, video and/or internet. In a minority of the programmes other tools were identified (Table 5.2).

Demonstrations and practice was the predominant teaching method used in educational sessions. For the majority of the educational programmes, the following single methods and activities or their combination were used: interactive lecturing, feedback and reinforcement, assessment of information needs and written material adapted to patients' level of literacy. Peer observation was the least used patient educational method (Table 5.2).

\section{Healthcare professionals delivering educational programmes}

In 38 programmes, a team of two or more health care professionals were conducting the programmes. Nurses, physicians and physiotherapists were the most involved healthcare professionals. Psychologists, pharmacists and social workers were less likely to be involved (Table 5.3). 
Table 5.2 Educational tools and methods used in educational sessions.

\begin{tabular}{|c|c|}
\hline Educational tools, $n=42^{*}$ & Educational methods, $n=42 * *$ \\
\hline $\begin{array}{l}\text { PowerPoint presentation, } n=12,(28.6 \%) \\
32,33,44,47,57,58,63,66,69,73,80,92\end{array}$ & $\begin{array}{l}\text { Interactive lecturing } n=28,(66.7 \%) \\
17,20,22,25,27,28,32,33,47,49,55,57-60,63,66-69,73-76,80,82,90,92\end{array}$ \\
\hline $\begin{array}{l}\text { Flip board with large sheets of paper, } n=14,(33.3 \%) \\
7,20,28,32,33,63,67-69,73,74,82,90,92\end{array}$ & $\begin{array}{l}\text { Passive lecturing, } n=12,(28.6 \%) \\
25,44,46,55,57-59,74,80,82,91,92\end{array}$ \\
\hline $\begin{array}{l}\text { Posters, } n=6,(14.3 \%) \\
7,20,25,51,69,92\end{array}$ & $\begin{array}{l}\text { Assessment of information needs, } n=23,(54.8 \%) \\
7-9,22,24,27-29,32,33,47,49,51,55,56,59,60,67,68,72,79,80,92\end{array}$ \\
\hline $\begin{array}{l}\text { Printed material and /or brochure, } n=38 \text {, (90.5\%) } \\
7,8,17,20,22,24,25,27-29,32,33,44,46,47,49,51,55-60,63,66-69,74-76,78-80,82,89,91,92\end{array}$ & $\begin{array}{l}\text { Motivational interviewing technique (building } \\
\text { ambivalence), } n=13,(30.9 \%) \\
7,27-29,44,51,55,66,68,72,79,90,92\end{array}$ \\
\hline $\begin{array}{l}\text { Internet, } n=4,(9.5 \%) \\
55,56,68,92\end{array}$ & $\begin{array}{l}\text { Demonstrations and practice (educator and / or } \\
\text { the learner), } n=31,(73.8 \%) \\
7-9,17,22,24,25,28,32,33,44,49,51,56-60,67-69,72-76,78-80,86,90\end{array}$ \\
\hline Other, $n=7,(17 \%)$ : & $\begin{array}{l}\text { Simulations or case scenarios, } n=13,(30.9 \%) \\
7,22,28,32,44,47,49,59,66,69,80,90,92\end{array}$ \\
\hline \multirow[t]{6}{*}{$\begin{array}{l}\text { COPD exacerbation action plan, diaries, airway models, } \\
\text { set of inhalation devices, box (to practice lifting during } \\
\text { breathing exercise); }{ }^{32,33} \text { education / counselling usually } \\
\text { either face to face or by phone; }{ }^{24,56,72} \text { not structured - } \\
\text { the nurses were having their own material/tools. }\end{array}$} & $\begin{array}{l}\text { Feedback and reinforcement, } n=28,(66.7 \%) \\
7,8,20,22,24,27-29,32,33,44,46,49,51,56,58-60,63,66-68,72,76,78,79,82,92 \\
\text { Have patients summarise transmitted information } \\
\text { (evaluation of patient's comprehension), } n=14 \text {, } \\
(33.3 \%) \\
7,8,17,22,28,44,49,56,59,63,69,73,79,92\end{array}$ \\
\hline & $\begin{array}{l}\text { Evaluate patient's level of self-efficacy, } n=15 \text {, } \\
(35.7 \%) \\
7-9,25,28,44,47,49,55,63,68,72,76,79,92\end{array}$ \\
\hline & $\begin{array}{l}\text { Learning contracts (homework, goals } \\
\text { achievement), } n=16,(38.1 \%) \\
7,8,17,22,27,28,32,33,44,49,58,59,63,67,76,92\end{array}$ \\
\hline & $\begin{array}{l}\text { Group exchange or discussions, } n=20,(47.6 \%) \\
20,25,27,28,32,33,44,57-59,63,66,68,73-76,80,90,92\end{array}$ \\
\hline & $\begin{array}{l}\text { Peer observation (use of an expert patient), } n=2 \text {, } \\
28,92(4.8 \%)\end{array}$ \\
\hline & $\begin{array}{l}\text { Written material adapted to patients' level of } \\
\text { literacy, } n=23,(54.8 \%) \\
7,8,17,22,24,27,28,32,33,46,49,55,56,59,60,63,66,67,74,76,79,90,92\end{array}$ \\
\hline
\end{tabular}

$n$ : number of studies; ${ }^{*}$ not reported, $n=1$ study. ${ }^{9} * *$ not reported, $n=1$ study. ${ }^{89}$ The educational methods were adapted from Bourbeau and Nault. ${ }^{102}$

\section{Self-management skills taught in educational programmes}

Patients with COPD were more frequently taught to: take medications as prescribed, do not smoke, know and control the triggers and symptoms and control exacerbation, than to communicate with significant people and/or modify work and role functions (Table 5.4). 
Table 5.3 Healthcare professionals in educational programmes.

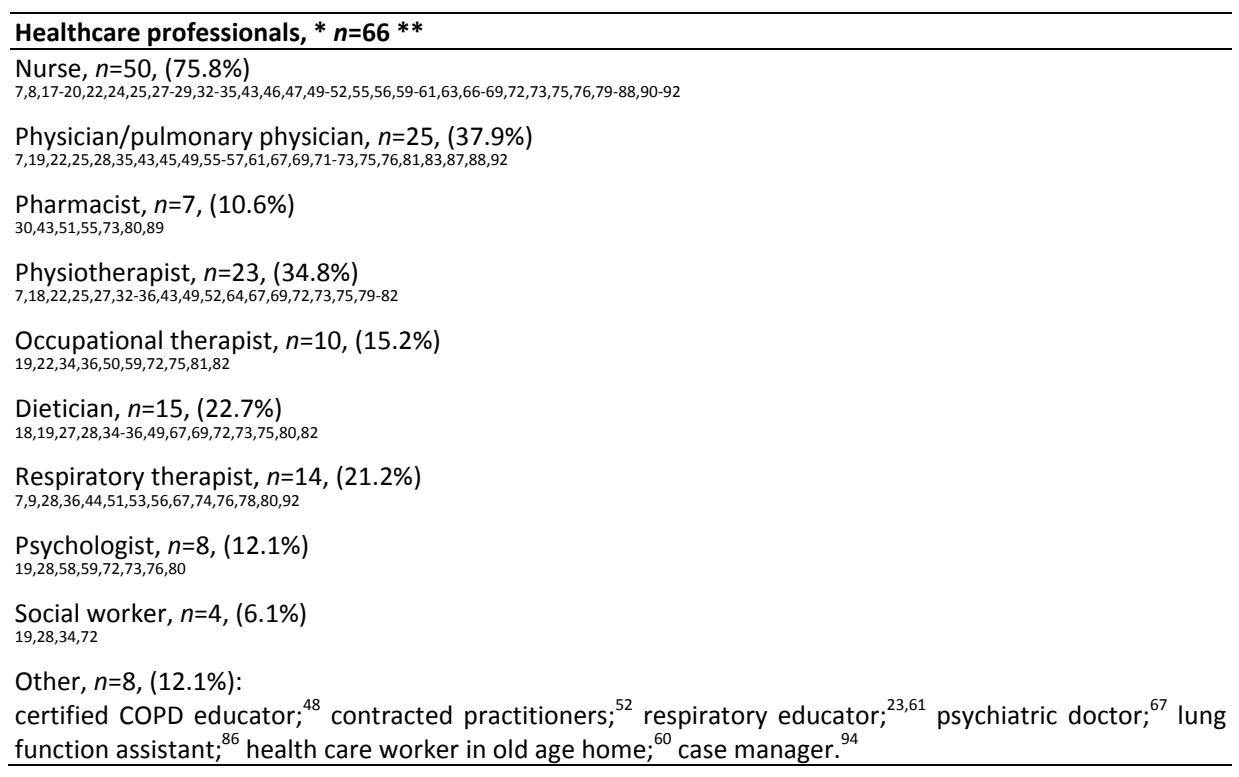

* $n$ : number of studies; ${ }^{* *}$ not reported, $n=1$ study. ${ }^{70}$

Table 5.4 Self-management skills taught in educational programmes.

\section{Self-management skills, ${ }^{*} n=42 * *$}

Know and control the triggers and symptoms, $n=35$, (83.3\%)

$7-9,17,22,24,27,28,32,33,44,46,47,49,51,55-60,63,66-69,72-76,79,80,91,92$

Take medications as prescribed, $n=38,(90.5 \%)$

7-9,17,22,24,25,27-29,32,33,44,46,47,49,51,55,56,58-60,66-69,72-76,78-80,82,86,91,92

Control acute episodes and emergencies, $n=34$, (81.0\%)

$7,8,17,22,24,27-29,32,44,46,47,49,51,55-60,63,66-69,72-74,76,78-80,82,92$

Have a healthy diet, $n=27,(64.3 \%)$

$7,8,17,24,27,28,32,33,44,46,47,49,55,56,58-60,63,66-69,72,73,80,82,92$

Do not smoke, $n=36$, (85.7\%)

$7,8,17,20,22,24,25,27-29,32,33,44,46,47,49,51,55-60,66-69,72-75,79,80,82,91,92$

Use relaxation and stress reduction techniques, $n=30,(71.4 \%)$

$7,8,17,22,24,25,28,32,33,44,47,49,55-60,63,66-68,72-74,76,80,90-92$

Make good use of health care professional, $n=28,(66.7 \%)$

$7-9,22,24,27-29,32,33,44,46,47,55-60,63,66,72-74,76,79,80,92$

Ask for information and help; use available resources in the community, $n=24,(57.1 \%)$

$8,22,25,27,28,32,33,44,46,47,49,55,56,59,60,63,66,68,72,73,76,79,80,92$

Modify work and role functions, $n=16$, (38.1\%)

$8,17,22,28,32,33,46,49,56,59,60,63,72,73,80,82$

Communicate with significant people, $n=19$, (45.2\%)

$7,8,25,27,28,32,33,44,46,49,56,59,60,66,72,73,76,80,92$

Manage negative emotions and psychological reactions to the disease, $n=22,(52.4 \%)$

$7,8,22,28,32,33,44,49,51,56-60,66-68,72,73,76,80,92$

* $n$ : number of studies; $* *$ not reported, $n=1$ study. ${ }^{89}$ The self-management skills were adapted from Bourbeau and Nault. ${ }^{102}$ 


\section{Setting and modality of interventions}

The majority of the studies $(n=46,68.7 \%)$ used outpatient education in the hospital setting (see Supplemental Table S5.1). Furthermore, most studies provided group counselling sessions, whereas, few studies used interactive computer and/or telehealth technology (Table 5.5).

Table 5.5 Intervention modalities on RE-AIM dimensions.

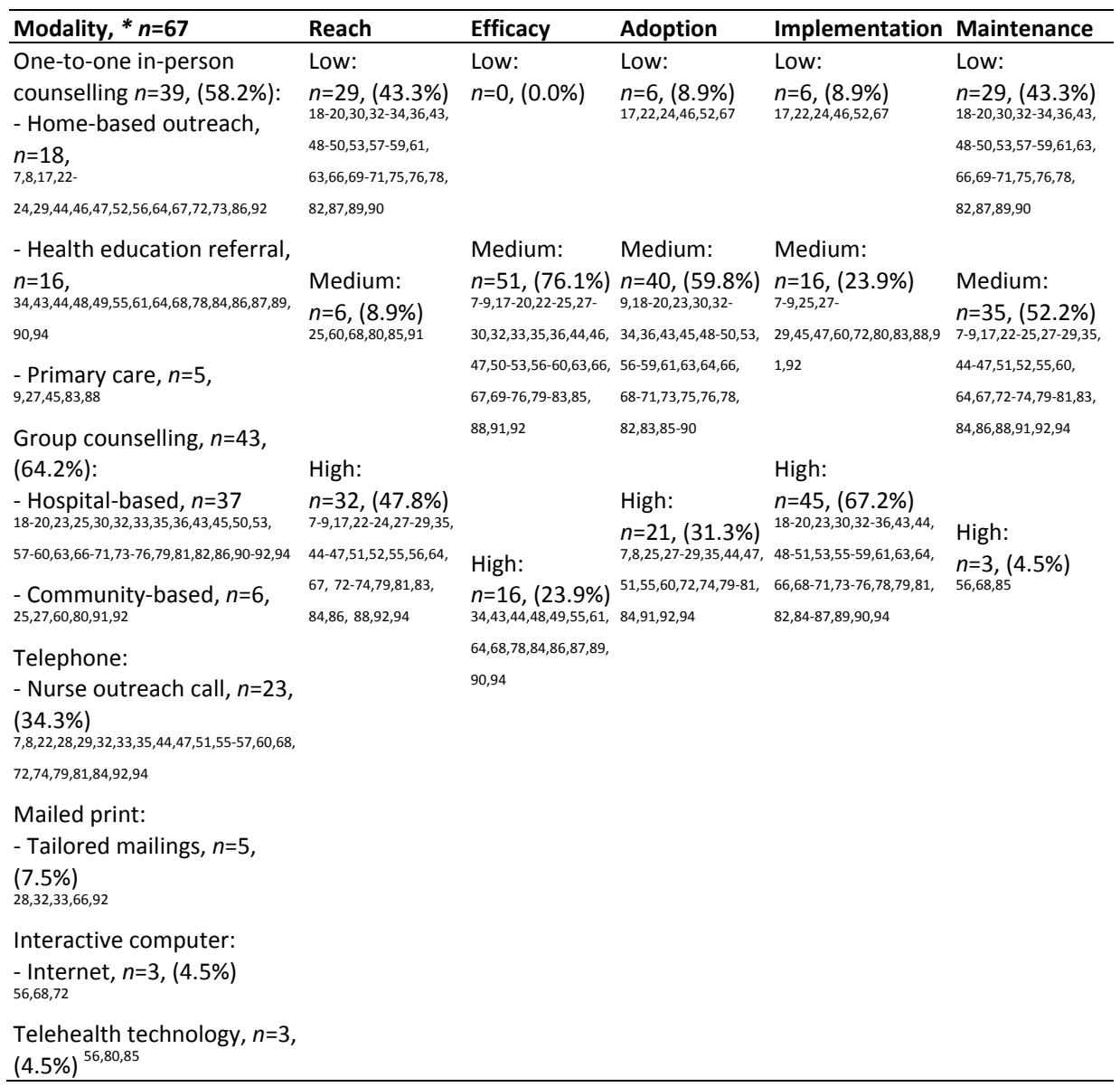

${ }^{*} n$ : number of studies. 


\section{Duration and total number of educational sessions, follow-up length and the RE-AIM analyses}

The duration of educational sessions varied from $10 \mathrm{~min}$ or less ${ }^{76}$ to $180 \mathrm{~min}^{17,57}$ per session with a median of $60 \mathrm{~min}$. In 13 (19.4\%) studies the duration was variable or not reported. The total number of educational sessions ranged from 1 session to 60 sessions, with a median of 6 sessions. Follow-up length ranged from 4 weeks post discharge ${ }^{35,45,49}$ to 5 years $^{20}$ (see Supplemental Table S5.1). Summary of outcomes of the eligible studies containing education is presented in the Supplemental Table S5.2).

Interventions containing educational programmes showed mixed ratings on the "reach" dimension. Furthermore, interventions received predominantly medium ratings on the "efficacy", "adoption" and "maintenance" dimensions. "Implementation" was rated as high for the majority of included studies (Table 5.5).

\section{Discussion and conclusion}

This review has systematically evaluated 67 interventions incorporating education for patients with COPD. Out of 18 identified educational topics, 12 topics were frequently addressed, e.g. smoking cessation, medication, exercise, breathing strategies, exacerbations and stress management. Printed materials and/or brochure were the most used educational tools, while demonstrations and practice was the educational method used in majority of education sessions. Nurses, physicians and physiotherapists were the most frequently involved healthcare professionals. The studies showed heterogeneity in their design, duration and number of educational sessions and follow-up. The majority of the interventions were rated as medium on the 'efficacy', 'adaptation' and 'maintenance' dimensions; the majority of the interventions had high 'implementation'; while on the 'reach' dimension, mixed ratings for the eligible interventions were reported.

\section{Educational topics}

At present, no "gold standard" on specific educational topics which should be integrated in the educational programmes offered to COPD patients is established. Therefore, we used the educational topics as formulated in the current practice guidelines of the GOLD ${ }^{10,11}$ and the ATS/ERS statements on PR, ${ }^{5,12}$ to provide an insight on the relevant educational domains which need to be addressed in the programmes.

The present findings of a very broad variety of educational programmes are consistent with the current literature. Namely, two previous systematic reviews on self-management education for COPD patients provided inconsistent recommendations regarding the form and the content of educational programmes in 
COPD. ${ }^{93,94}$ This is due to diverse study interventions, variations in design, outcomes, follow-up periods and methodological flaws of the included studies. The aforementioned reviews, systematically evaluated 14 and 13 publications, respectively. Furthermore, an underlying cause for these inconsistencies may be an absence of evidence-based recommendations on which educational topics are essential for inclusion. ${ }^{95}$ Additionally, recommendations on the duration, total number of educational sessions and the follow-up length of an educational programme are not included in the current practice guidelines. ${ }^{5,10-12}$

Action plans were used in a majority of the studies, albeit contrasting findings have been reported in the literature. ${ }^{96}$ Use of an action plan within a multi-faceted self-management programme, was stressed by Walters et al. ${ }^{97}$ as a requirement for the use of an action plan as a standard of care in COPD.

The minority of the surveyed authors reported that their educational programme was adapted to the needs and environment of the individual patient. ${ }^{10,11}$ Some tailoring was based on: baseline and/or on-going assessment of disease severity or problems, ${ }^{8,32,33,48}$ smoking status, ${ }^{50,54}$ inhaler technique or device, ${ }^{76,84}$ disease-specific needs and personal goals specified in the action plan, ${ }^{27}$ and patient comprehension and skill acquisition. ${ }^{22}$ In order to assess, from the patient's perspective, COPD patient's information needs for education in PR, the Lung Information Needs Questionnaire (LINQ) has been developed. ${ }^{98}$ In addition, the Understanding COPD (UCOPD) questionnaire, assessing patient's understanding, self-efficacy, selfmanagement skills and satisfaction with the educational component of $P R$, was recently developed by O'Neill et al. ${ }^{99}$ However, only one of the included studies ${ }^{85}$ used the LINQ to systematically identified patient educational needs, whereas none of the studies used the UCOPD. Nevertheless, assessment of educational needs may be important. Indeed, patients and providers do not identify the same individual categories as the greatest learning needs, which in turn lead to patients' educational needs remaining unmet. ${ }^{95}$ More specifically, Wilson et al. ${ }^{95}$ showed that patients request information on welfare and benefits systems. To date, this topic is not included in the current practice guidelines. ${ }^{5,10-12}$

\section{Educational methods and activities}

The present review shows that printed materials and/or brochure were frequently used educational tools, and demonstrations and practice was the educational method used in majority of education sessions. This is in accordance with patient's preferences. Indeed, patients prefer combining demonstration and practice of care strategies with visual aids, and group exchange and discussions, as a way of peer support and shared knowledge, supplemented with written material adapted to patients' level of literacy. ${ }^{95}$ Additionally, educational methods should be chosen in the way that considers patient's style of coding and retrieving the information, reinforce 
patients' active role, enhance self-efficacy and support the integration of knowledge and self-management skills. ${ }^{100}$ In this context, motivational interviewing technique, used in approximately one-third of the included programmes, has emerged over the past few years as an effective framework for engaging patients and facilitating healthrelated behaviour change. ${ }^{101,102}$

\section{Healthcare professionals delivering educational programmes}

Although respiratory therapists in some countries are the key professionals involved in the education of patients with $C O P D,{ }^{103}$ nurses were highly represented healthcare professionals in the current programmes offering education. Inclusion of a pharmacist however, might improve outcomes and management of COPD. Lemmens et al. ${ }^{104}$ suggest that this may be due to the higher intervention intensity of pharmacist education when compared with nurse education. Likewise, involvement of a social worker might address the reported patients' need for education about welfare and benefits systems. ${ }^{95}$ Also psychologists were healthcare professionals rarely involved in education of patients. An active role of psychologists in the process of education, may be an important determinant for facilitating and sustaining successful patient's behaviour change, ${ }^{105}$ which in turn, is the goal of a self-management education. ${ }^{3}$ Nonetheless, to date, skills of healthcare professionals needed to provide effective patient education, are rather vague and generally covered in the guidelines and position statements. ${ }^{5,10-12}$

\section{Self-management skills}

Education should incorporate not only teaching various disease educational topics, but also provide patients with specific skills aimed at patient's behaviour. ${ }^{3,12}$ Acquired knowledge and self-management skills will result in enhanced patient's self-efficacy and improved health behaviour, ${ }^{3}$ which in turn, may lead to decrease in healthcare utilisation. $^{61}$ Other potential benefits of education are active participation in healthcare, increased coping skills and collaborative self- and end-of-life management skills. ${ }^{106,107}$ Coping styles, although closely associated with exercise tolerance and symptoms of anxiety and depression in patients with COPD, ${ }^{108-110}$ were often included as an educational topic in the programmes, but it remains unknown whether they were assessed pre- and/or post-intervention. Pre-intervention testing of personality traits, patient's comprehension, attitudes and self-efficacy may provide an opportunity for development of individually tailored educational programmes. ${ }^{38,100}$

\section{Evaluation of interventions}

The quality assessment according to the RE-AIM framework of the management interventions containing education showed that interventions had a low or a high 
"reach" within the target population. Lowering patients' barriers (scheduling appointments, transportation, repeated telephone call attempts) and increasing patients' convenience to participate in a programme may result in increased "reach" of an intervention. ${ }^{13}$ Furthermore, one-to-one-in person counselling is considered to be a more effective intervention (high efficacy) when compared to the group counselling sessions (medium efficacy), because of the possibility to tailor the programme to the individual. ${ }^{13}$ However, a higher percentage of eligible studies in our review conducted group sessions compared to one-to-one-in person counselling. The high implementation seen in the included interventions generally refers to involvement of experienced providers. ${ }^{13}$ Moreover, few studies, in the current review used internet, interactive computer or telehealth technologies. Incorporating new information technologies may lead to a greater reach of participants by providing care in their homes, as well as it may increase efficacy, adaptation and maintenance. ${ }^{13}$ Glasgow et al. suggest that taking into account multiple dimensions in the process of programme planning, rather than only considering efficacy; will increase the health impact of the interventions. ${ }^{13}$

\section{Limitations}

There are several limitations that need to be considered in interpreting the results. First, non-English-language studies were not included. Second, the reported results in Tables 5.2 and 5.4 were based only on the studies of authors that responded to the questionnaire we have sent. This decision was undertaken based on the difference between authors' responses and limited information reported in the articles. Nonetheless, confirming the accuracy of the extracted data by surveying authors and reporting these results may reduce reporting bias and overcome incomplete reporting of study methods in the primary studies. ${ }^{111}$ Third, heterogeneity in disease severity was present. This might have influenced the inclusion of specific educational topics in the curriculum of selected interventions. Fourth, programmes incorporated additional components e.g., exercise, psychosocial support, in addition to education. Hence, we were unable to analyse the effect of education alone on specific outcomes. Although, it is difficult to separate out the effects of education, ${ }^{112}$ education combined with exercise and support are usually an integral part of self-management programmes, PR or integrated care programmes. ${ }^{2,113}$ Finally, factors that might have influenced the treatment effect, such as: the quality, reproduction and administration of the educational programmes; ${ }^{92}$ as well as the information or the training provided to the healthcare professionals actively involved in the interventions, were not studied. 


\section{Practice implication}

Patient education is an important component of COPD management interventions. ${ }^{5,10-12}$ However, the present results draw attention to the inconstancies between the selected educational topics incorporated in the educational programmes and those recommended by current practice guidelines and PR statements. This may suggests that further research is required to identify which educational topics actually contribute to behaviour change and successful COPD management. Moreover, these findings may imply that more in-depth recommendations on the content and structure of educational programmes in the practice guidelines and statements are warranted. Additionally, only a minority of the educational programmes assessed in this study, provided education tailored to their patients, despite the fact that this recommended in current practice guidelines. ${ }^{5,10-12}$ Developing educational packages, tailored according to the patient's needs, might facilitate equitable patient access to COPD education. Use of a combination of educational tools and methods may be an efficient way for facilitation and retention of self-management learning process in COPD patients. ${ }^{95,100}$ These observations may permit healthcare professionals who design educational programmes to include these requirements in a format that is acceptable to patients. 


\section{References}

1. Littlejohns $\mathrm{P}$, Jones $\mathrm{P}$. Education of patients about chronic obstructive pulmonary disease. Lancet 1992;340:432.

2. Ries AL, Bauldoff GS, Carlin BW, Casaburi R, Emery CF, Mahler DA, et al. Pulmonary rehabilitation: joint ACCP/AACVPR evidence-based clinical practice guidelines. Chest 2007;131:4S-42S.

3. Bourbeau J, Nault D, Dang-Tan T. Self-management and behaviour modification in COPD. Patient Educ Couns 2004;52:271-7.

4. Koff PB, Jones RH, Cashman JM, Voelkel NF, Vandivier RW. Proactive integrated care improves quality of life in patients with COPD. Eur Respir J 2009;33:1031-8.

5. Nici L, Donner C, Wouters E, Zuwallack R, Ambrosino N, Bourbeau J, et al. American Thoracic Society/European Respiratory Society statement on pulmonary rehabilitation. Am J Respir Crit Care Med 2006;173:1390-413.

6. Hill K, Mangovski-Alzamora S, Blouin M, Guyatt G, Heels-Ansdell D, Bragaglia P, et al. Disease-specific education in the primary care setting increases the knowledge of people with chronic obstructive pulmonary disease: a randomized controlled trial. Patient Educ Couns 2010;81:14-8.

7. Bourbeau J, Julien M, Maltais F, Rouleau M, Beaupre A, Begin R, et al. Reduction of hospital utilization in patients with chronic obstructive pulmonary disease: a diseasespecific self-management intervention. Arch Intern Med 2003;163:585-91.

8. Cockcroft A, Bagnall P, Heslop A, Andersson N, Heaton R, Batstone J, et al. Controlled trial of respiratory health worker visiting patients with chronic respiratory disability. Br Med J (Clin Res Ed) 1987;294:225-8.

9. Littlejohns $\mathrm{P}$, Baveystock $\mathrm{CM}$, Parnell $\mathrm{H}$, JonesPW. Randomised controlled trial of the effectiveness of a respiratory health worker in reducing impairment, disability, and handicap due to chronic airflow limitation. Thorax 1991;46:559-64.

10. Rabe KF, Hurd S, Anzueto A, Barnes PJ, Buist SA, Calverley P, et al. Global strategy for the diagnosis, management, and prevention of chronic obstructive pulmonary disease: GOLD executive summary. Am J Respir Crit Care Med 2007;176:532-55.

11. Vestbo J, Hurd SS, Agusti AG, Jones PW, Vogelmeier C, Anzueto A, et al. Global strategy for the diagnosis, management, and prevention of chronic obstructive pulmonary disease: GOLD executive summary. Am J Respir Crit Care Med 2013;187:347-65.

12. Spruit MA, Singh SJ, Garvey C, ZuWallack R, et al. An Official American Thoracic Society/European Respiratory Society statement: key concepts and advances in pulmonary rehabilitation. Am J Respir Crit Care Med 2014;189(12):1570.

13. Glasgow RE, McKay HG, Piette JD, Reynolds KD. The RE-AIM framework for evaluating interventions: what can it tell us about approaches to chronic illness management? Patient Educ Couns 2001;44: 119-27.

14. Glasgow RE. RE-AIMing research for application: ways to improve evidence for family medicine. J Am Board Fam Med 2006;19:11-9.

15. Patel MR, Shah S, Cabana MD, Sawyer SM, Toelle B, Mellis C, et al. Translation of an evidence-based asthma intervention: Physician Asthma Care Education (PACE) in the United States and Australia. Prim Care Respir J 2013;22:29-36.

16. Moher D, Liberati A, Tetzlaff J, Altman DG. Preferred reporting items for systematic reviews and meta-analyses: the PRISMA statement. PLoS Med 2009;6:e1000097.

17. Akinci AC, Olgun N. The effectiveness of nurse-led, homebased pulmonary rehabilitation in patients with COPD in Turkey. Rehabil Nurs 2011;36:159-65.

18. Barakat S, Michele G, George P, Nicole V, Guy A. Outpatient pulmonary rehabilitation in patients with chronic obstructive pulmonary disease. Int J Chron Obstruct Pulmon Dis 2008;3:155-62.

19. Bendstrup KE, Ingemann Jensen J, Holm S, Bengtsson B. Outpatient rehabilitation improves activities of daily living, quality of life and exercise tolerance in chronic obstructive pulmonary disease. Eur Respir J 1997;10:2801-6. 
20. Borglykke A, Pisinger $\mathrm{C}$, Jorgensen $\mathrm{T}$, Ibsen $\mathrm{H}$. The effectiveness of smoking cessation groups offered to hospitalised patients with symptoms of exacerbations of chronic obstructive pulmonary disease (COPD). Clin Respir J 2008;2:158-65.

21. Bourbeau J, Collet JP, Schwartzman K, Ducruet T, Nault D, Bradley C. Economic benefits of selfmanagement education in COPD. Chest 2006;130:1704-11.

22. Boxall AM, Barclay L, Sayers A, Caplan GA. Managing chronic obstructive pulmonary disease in the community. A randomized controlled trial of home-based pulmonary rehabilitation for elderly housebound patients. J Cardiopulm Rehabil 2005;25:378-85.

23. Brough FK, Schmidt CD, Rasmussen T, Boyer M. Comparison of two teaching methods for self-care training for patients with chronic obstructive pulmonary disease. Patient Couns Health Educ 1982;4:111-6.

24. Bucknall CE, Miller G, Lloyd SM, Cleland J, McCluskey S, Cotton M, et al. Glasgow supported selfmanagement trial (GSUST) for patients with moderate to severe COPD: randomised controlled trial. BMJ 2012;344:e1060.

25. Cambach W, Chadwick-Straver RV, Wagenaar RC, van Keimpema AR, Kemper HC. The effects of a communitybased pulmonary rehabilitation programme on exercise tolerance and quality of life: a randomized controlled trial. Eur Respir J 1997;10:104-13.

26. Casas A, Troosters T, Garcia-Aymerich J, Roca J, Hernandez C, Alonso A, et al. Integrated care prevents hospitalisations for exacerbations in COPD patients. Eur Respir J 2006;28:123-30.

27. Chavannes NH, Grijsen M, van den Akker M, Schepers H, Nijdam M, Tiep B, et al. Integrated disease management improves one-year quality of life in primary care COPD patients: a controlled clinical trial. Prim Care Respir J 2009;18:171-6.

28. Chuang $\mathrm{C}$, Levine SH, Rich J. Enhancing cost-effective care with a patient-centric chronic obstructive pulmonary disease program. Popul Health Manag 2011;14:133-6.

29. Coultas D, Frederick J, Barnett B, Singh G, Wludyka P. A randomized trial of two types of nurseassisted home care for patients with COPD. Chest 2005;128:2017-24.

30. De Tullio PL, Corson ME. Effect of pharmacist counseling on ambulatory patients' use of aerosolized bronchodilators. Am J Hosp Pharm 1987;44:1802-6.

31. Dewan NA, Rice KL, Caldwell M, Hilleman DE. Economic evaluation of a disease management program for chronic obstructive pulmonary disease. COPD 2011;8:153-9.

32. Effing $T$, Kerstjens $H$, van der Valk P, Zielhuis $G$, van der Palen J. (Cost)-effectiveness of self-treatment of exacerbations on the severity of exacerbations in patients with COPD: the COPE II study. Thorax 2009;64:956-62.

33. Effing T, Zielhuis $\mathrm{G}$, Kerstjens $\mathrm{H}$, van der Valk $\mathrm{P}$, van der Palen J. Community based physiotherapeutic exercise in COPD self-management: a randomised controlled trial. Respir Med 2011;105:418-26.

34. Efraimsson EO, Hillervik C, Ehrenberg A. Effects of COPD selfcare management education at a nurseled primary health care clinic. Scand J Caring Sci 2008;22:178-85.

35. Egan E, Clavarino A, Burridge L, Teuwen M, White E. A randomized control trial of nursing-based case management for patients with chronic obstructive pulmonary disease. Lippincotts Case Manag 2002;7:170-9.

36. Finnerty JP, Keeping I, Bullough I, Jones J. The effectiveness of outpatient pulmonary rehabilitation in chronic lung disease: a randomized controlled trial. Chest 2001;119:1705-10.

37. Gadoury MA, Schwartzman K, Rouleau M, Maltais F, Julien M, Beaupre A, et al. Self-management reduces both short- and long-term hospitalisation in COPD. Eur Respir J 2005;26:853-7.

38. Gallefoss F. The effects of patient education in COPD in a 1-year follow-up randomised, controlled trial. Patient Educ Couns 2004;52:259-66.

39. Gallefoss F, Bakke PS. How does patient education and selfmanagement among asthmatics and patients with chronic obstructive pulmonary disease affect medication? Am J Respir Crit Care Med 1999;160:2000-5.

40. Gallefoss F, Bakke PS. Patient satisfaction with healthcare in asthmatics and patients with COPD before and after patient education. Respir Med 2000;94:1057-64.

41. Gallefoss F, Bakke PS. Impact of patient education and selfmanagement on morbidity in asthmatics and patients with chronic obstructive pulmonary disease. Respir Med 2000;94:279-87. 
42. Gallefoss F, Bakke PS. Cost-benefit and cost-effectiveness analysis of self-management in patients with COPD e a 1-year follow-up randomized, controlled trial. Respir Med 2002;96:424-31.

43. Gallefoss F, Bakke PS, Rsgaard PK. Quality of life assessment after patient education in a randomized controlled study on asthma and chronic obstructive pulmonary disease. Am J Respir Crit Care Med 1999;159:812-7.

44. Garcia-Aymerich J, Hernandez C, Alonso A, Casas A, Rodriguez-Roisin R, Anto JM, et al. Effects of an integrated care intervention on risk factors of COPD readmission. Respir Med 2007;101:1462-9.

45. Gift AG, Moore T, Soeken K. Relaxation to reduce dyspnea and anxiety in COPD patients. Nurs Res 1992;41:242-6.

46. Hermiz O, Comino E, Marks G, Daffurn K, Wilson S, Harris M. Randomised controlled trial of home based care of patients with chronic obstructive pulmonary disease. BMJ 2002;325:938.

47. Hernandez C, Casas A, Escarrabill J, Alonso J, Puig-Junoy J, Farrero E, et al. Home hospitalisation of exacerbated chronic obstructive pulmonary disease patients. Eur Respir J 2003;21:58-67.

48. Hoogendoorn $M$, van Wetering CR, Schols AM, Rutten-van Molken MP. Is INTERdisciplinary COMmunity-based COPD management (INTERCOM) cost-effective? Eur Respir J 2010;35:79-87.

49. Ip SP, Leung YF, Choy KL. Short-stay in-patient rehabilitation of elderly patients with chronic obstructive pulmonary disease: prospective study. Hong Kong Med J 2004;10:312-8.

50. Jarab AS, Alqudah SG, Khdour M, Shamssain M, Mukattash TL. Impact of pharmaceutical care on health outcomes in patients with COPD. Int J Clin Pharm 2012;34:53-62.

51. Jeffs KJ, Lim WK, Lim M, Berlowitz DJ, Jackson B. The effect of a post acute respiratory outreach service for patients with chronic obstructive pulmonary disease on hospital readmission rates. Respirology 2005;10:239-43.

52. Karapolat H, Atasever A, Atamaz F, Kirazli Y, Elmas F, Erdinc E. Do the benefits gained using a shortterm pulmonary rehabilitation program remain in COPD patients after participation? Lung 2007;185:221-5.

53. Khdour MR, Agus AM, Kidney JC, Smyth BM, Elnay JC, Crealey GE. Cost-utility analysis of a pharmacyled selfmanagement programme for patients with COPD. Int J Clin Pharm 2011;33:665-73.

54. Khdour MR, Kidney JC, Smyth BM, McElnay JC. Clinical pharmacy-led disease and medicine management programme for patients with COPD. Br J Clin Pharmacol 2009;68:588-98.

55. Kunik ME, Braun U, Stanley MA, Wristers K, Molinari V, Stoebner D, et al. One session cognitive behavioural therapy for elderly patients with chronic obstructive pulmonary disease. Psychol Med 2001;31:717-23.

56. Kunik ME, Veazey C, Cully JA, Souchek J, Graham DP, Hopko D, et al. COPD education and cognitive behavioral therapy group treatment for clinically significant symptoms of depression and anxiety in COPD patients: a randomized controlled trial. Psychol Med 2008;38:385-96.

57. Labrecque M, Rabhi K, Laurin C, Favreau H, Moullec G, Lavoie K, et al. Can a self-management education program for patients with chronic obstructive pulmonary disease improve quality of life? Can Respir J 2011;18:e77-81.

58. Lee DT, Lee IF, Mackenzie AE, Ho RN. Effects of a care protocol on care outcomes in older nursing home patients with chronic obstructive pulmonary disease. J Am Geriatr Soc 2002;50:870-6.

59. McGeoch GR, Willsman KJ, Dowson CA, Town GI, Frampton CM, McCartin FJ, et al. Self-management plans in the primary care of patients with chronic obstructive pulmonary disease. Respirology 2006;11:611-8.

60. Monninkhof E, van der Valk P, Schermer T, van der Palen J, van Herwaarden C, Zielhuis G. Economic evaluation of a comprehensive self-management programme in patients with moderate to severe chronic obstructive pulmonary disease. Chron Respir Dis 2004;1:7-16.

61. Monninkhof E, van der Valk P, van der Palen J, van Herwaarden C, Zielhuis G. Effects of a comprehensive selfmanagement programme in patients with chronic obstructive pulmonary disease. Eur Respir J 2003;22:815-20.

62. Moore J, Fiddler H, Seymour J, Grant A, Jolley C, Johnson L, et al. Effect of a home exercise video programme in patients with chronic obstructive pulmonary disease. J Rehabil Med 2009;41:195-200.

63. Moullec G, Favreau H, Lavoie KL, Labrecque M. Does a selfmanagement education program have the same impact on emotional and functional dimensions of HRQoL? COPD 2012;9:36-45. 
64. Moullec G, Lavoie KL, Rabhi K, Julien M, Favreau H, Labrecque M. Effect of an integrated care programme on rehospitalization of patients with chronic obstructive pulmonary disease. Respirology 2012;17:707-14.

65. Na JO, Kim DS, Yoon SH, Jegal YJ, Kim WS, Kim ES, et al. A simple and easy home-based pulmonary rehabilitation programme for patients with chronic lung diseases. Monaldi Arch Chest Dis 2005;63: 30-6.

66. Nguyen HQ, Donesky-Cuenco D, Wolpin S, Reinke LF, Benditt JO, Paul SM, et al. Randomized controlled trial of an internet-based versus face-to-face dyspnea selfmanagement program for patients with chronic obstructive pulmonary disease: pilot study. J Med Internet Res 2008;10:e9.

67. Ninot G, Moullec G, Picot MC, Jaussent A, Hayot M, Desplan M, et al. Cost-saving effect of supervised exercise associated to COPD self-management education program. Respir Med 2011;105:377-85.

68. Paz-Diaz H, Montes de Oca M, Lopez JM, Celli BR. Pulmonary rehabilitation improves depression, anxiety, dyspnea and health status in patients with COPD. Am J Phys Med Rehabil 2007;86:30-6.

69. Petty TL, Dempsey EC, Collins T, Pluss W, Lipkus I, Cutter GR, et al. Impact of customized videotape education on quality of life in patients with chronic obstructive pulmonary disease. J Cardiopulm Rehabil 2006;26:112-7.

70. Poole PJ, Chase B, Frankel A, Black PN. Case management may reduce length of hospital stay in patients with recurrent admissions for chronic obstructive pulmonary disease. Respirology 2001;6:3742.

71. Rea H, McAuley S, Stewart A, Lamont C, Roseman P, Didsbury P. A chronic disease management programme can reduce days in hospital for patients with chronic obstructive pulmonary disease. Intern Med J 2004;34:608-14.

72. Rice KL, Dewan N, Bloomfield HE, Grill J, Schult TM, Nelson DB, et al. Disease management program for chronic obstructive pulmonary disease: a randomized controlled trial. Am J Respir Crit Care Med 2010;182:890-6.

73. Ringbaek TJ, Broendum E, Hemmingsen L, Lybeck K, Nielsen D, Andersen C, et al. Rehabilitation of patients with chronic obstructive pulmonary disease. Exercise twice a week is not sufficient! Respir Med 2000;94:150-4.

74. Sassi-Dambron DE, Eakin EG, Ries AL, Kaplan RM. Treatment of dyspnea in COPD. A controlled clinical trial of dyspnea management strategies. Chest 1995;107:724-9.

75. Sedeno MF, Nault D, Hamd DH, Bourbeau J. A selfmanagement education program including an action plan for acute COPD exacerbations. COPD 2009;6:352-8.

76. Song WS, Mullon J, Regan NA, Roth BJ. Instruction of hospitalized patients by respiratory therapists on metered-dose inhaler use leads to decrease in patient errors. Respir Care 2005;50:1040-5.

77. Sridhar M, Taylor R, Dawson S, Roberts NJ, Partridge MR. A nurse led intermediate care package in patients who have been hospitalised with an acute exacerbation of chronic obstructive pulmonary disease. Thorax 2008;63:194-200.

78. SticklandM,JourdainT,Wong EY,RodgersWM,JendzjowskyNG, Macdonald GF. Using Telehealth technology to deliver pulmonary rehabilitation in chronic obstructive pulmonary disease patients. Can Respir J 2011;18:216-20.

79. Sundblad BM, Larsson K, Nathell L. High rate of smoking abstinence in COPD patients: smoking cessation by hospitalization. Nicotine Tob Res 2008;10:883-90.

80. Theander K, Jakobsson $\mathrm{P}$, Jorgensen $\mathrm{N}$, Unosson M. Effects of pulmonary rehabilitation on fatigue, functional status and health perceptions in patients with chronic obstructive pulmonary disease: a randomized controlled trial. Clin Rehabil 2009;23:125-36.

81. Tougaard L, Krone T, Sorknaes A, Ellegaard H. Economic benefits of teaching patients with chronic obstructive pulmonary disease about their illness. The PASTMA Group. Lancet 1992;339:1517-20.

82. Trappenburg JC, Monninkhof EM, Bourbeau J, Troosters T, Schrijvers AJ, Verheij TJ, et al. Effect of an action plan with ongoing support by a case manager on exacerbation-related outcome in patients with COPD: a multicentre randomised controlled trial. Thorax 2011;66:977-84.

83. Trappenburg JC, Niesink A, de Weert-van Oene GH, van der Zeijden H, van Snippenburg R, Peters A, et al. Effects of telemonitoring in patients with chronic obstructive pulmonary disease. Telemed $J E$ Health 2008;14:138-46. 
84. van der Palen J, Klein JJ, Kerkhoff AH, van Herwaarden CL, Seydel ER. Evaluation of the long-term effectiveness of three instruction modes for inhaling medicines. Patient Educ Couns 1997;32:S87-95.

85. Wakabayashi R, Motegi T, Yamada K, Ishii T, Jones RC, Hyland ME, et al. Efficient integrated education for older patients with chronic obstructive pulmonary disease using the Lung Information Needs Questionnaire. Geriatr Gerontol Int 2011;11:422-30.

86. Watson PB, Town GI, Holbrook N, Dwan C, Toop L, Drennan CJ. Evaluation of a self-management plan for chronic obstructive pulmonary disease. Eur Respir J 1997;10:1267-71.

87. Weinberger M, Murray MD, Marrero DG, Brewer N, Lykens M, Harris LE, et al. Effectiveness of pharmacist care for patients with reactive airways disease: a randomized controlled trial. J Am Med Assoc 2002;288:1594-602.

88. Wilson JS, Fitzsimons D, Bradbury I, Stuart Elborn J. Does additional support by nurses enhance the effect of a brief smoking cessation intervention in people with moderate to severe chronic obstructive pulmonary disease? A randomised controlled trial. Int J Nurs Stud 2008;45:508-17.

89. Wood-Baker R, McGlone S, Venn A, Walters EH. Written action plans in chronic obstructive pulmonary disease increase appropriate treatment for acute exacerbations. Respirology 2006;11:619 26.

90. Zhou Y, Hu G, Wang D, Wang S, Wang Y, Liu Z, et al. Community based integrated intervention for prevention and management of chronic obstructive pulmonary disease (COPD) in Guangdong, China: cluster randomised controlled trial. BMJ 2010;341:c6387.

91. van der Valk P, Monninkhof E, van der Palen J, Zielhuis G, van Herwaarden C. Effect of discontinuation of inhaled corticosteroids in patients with chronic obstructive pulmonary disease: the COPE study. Am J Respir Crit Care Med 2002;166:1358-63.

92. Fan VS, Gaziano JM, Lew R, Bourbeau J, Adams SG, Leatherman S, et al. A comprehensive care management program to prevent chronic obstructive pulmonary disease hospitalizations: a randomized, controlled trial. Ann Intern Med 2012;156:673-83.

93. Effing T, Monninkhof EM, van der Valk PD, van der Palen J, van Herwaarden CL, Partidge MR, et al. Self-management education for patients with chronic obstructive pulmonary disease. Cochrane Database Syst Rev 2007. CD002990.

94. Blackstock F, Webster K. Disease-specific health education for COPD: a systematic review of changes in health outcomes. Health Educ Res 2007;22:703-17.

95. Wilson JS, O'Neill B, Reilly J, MacMahon J, Bradley JM. Education in pulmonary rehabilitation: the patient's perspective. Arch Phys Med Rehabil 2007;88:1704-9.

96. Turnock AC, Walters EH, Walters JA, Wood-Baker R. Action plans for chronic obstructive pulmonary disease. Cochrane Database Syst Rev 2005. CD005074.

97. Walters JA, Turnock AC, Walters EH, Wood-Baker R. Action plans with limited patient education only for exacerbations of chronic obstructive pulmonary disease. Cochrane Database Syst Rev 2010. CD005074.

98. Hyland ME, Jones RC, Hanney KE. The lung information needs questionnaire: development, preliminary validation and findings. Respir Med 2006;100:1807-16.

99. O'Neill B, Cosgrove D, MacMahon J, McCrum-Gardner E, Bradley JM. Assessing education in pulmonary rehabilitation: the understanding COPD (UCOPD) questionnaire. COPD 2012;9:166-74.

100. Bourbeau J, Nault D. Self-management strategies in chronic obstructive pulmonary disease. Clin Chest Med 2007;28:617-28 [vii].

101. Miller WR, Rose GS. Toward a theory of motivational interviewing. Am Psychol 2009;64:527-37.

102. Rubak S, Sandbaek A, Lauritzen T, Christensen B. Motivational interviewing: a systematic review and meta-analysis. Br J Gen Pract 2005;55:305-12.

103. Brooks D, Sottana R, Bell B, Hanna M, Laframboise L, Selvanayagarajah S, et al. Characterization of pulmonary rehabilitation programs in Canada in 2005. Can Respir J 2007;14:87-92.

104. Lemmens KM, Nieboer AP, Huijsman R. A systematic review of integrated use of disease-management interventions in asthma and COPD. Respir Med 2009;103:670-91.

105. Michie S. Designing and implementing behaviour change interventions to improve population health. J Health Serv Res Policy 2008;13(Suppl. 3):64-9. 
106. Zuwallack R. The nonpharmacologic treatment of chronic obstructive pulmonary disease: advances in our understanding of pulmonary rehabilitation. Proc Am Thorac Soc 2007;4:549-53.

107. Worth $\mathrm{H}$, Dhein Y. Does patient education modify behaviour in the management of COPD? Patient Educ Couns 2004;52:267-70.

108. Stoilkova A, Wouters EFM, Spruit MA, Franssen FME, Janssen DJA. The relationship between coping styles and clinical outcomes in patients with COPD entering pulmonary rehabilitation. COPD J Chronic Obstructive Pulm Dis 2013;10:316-23.

109. Stoilkova A, Janssen DJA, Franssen FME, Spruit MA, Wouters EFM. Coping styles in patients with COPD before and after pulmonary rehabilitation. Respir Med 2013;107:825-33.

110. McCathie HC, Spence SH, Tate RL. Adjustment to chronic obstructive pulmonary disease: the importance of psychological factors. Eur Respir J 2002;19:47-53.

111. Mullan RJ, Flynn DN, Carlberg B, Tleyjeh IM, Kamath CC, LaBella ML, et al. Systematic reviewers commonly contact study authors but do so with limited rigor. J Clin Epidemiol 2009;62:138-42.

112. Lacasse $\mathrm{Y}$, Guyatt $\mathrm{GH}$, Goldstein RS. The components of a respiratory rehabilitation program: a systematic overview. Chest 1997;111:1077-88.

113. Bourbeau J. The role of collaborative self-management in pulmonary rehabilitation. Semin Respir Crit Care Med 2009;30:700-7. 


\section{Supplemental material}

\section{Methods}

\section{Search terms}

SEARCH 1: PubMed (conducted 04/07/12)

1. Pulmonary disease, chronic obstructive [MeSH]

\section{AND}

2. Health Education [Mesh] OR Patient Education as Topic [Mesh] OR Education

\section{AND}

3. Disease management OR Case management OR Self-care OR Delivery of health care, integrated OR Patient care planning OR Pulmonary rehabilitation

Limits: Humans, English

SEARCH 2: Cochrane Central Registry of Controlled Clinical Trials (conducted 27/08/12)

1. Pulmonary disease, chronic obstructive [MeSH]

\section{AND}

2. Health Education [Mesh] OR Patient Education as Topic [Mesh] OR Education

\section{AND}

3. Disease management OR Case management OR Self-care OR Delivery of health care, integrated OR Patient care planning OR Pulmonary rehabilitation

Limits: 1966-2012

SEARCH 3: Web of Science (conducted 27/08/12)

1. Pulmonary disease, chronic obstructive

\section{AND}

2. Health Education OR Patient Education as Topic OR Education

\section{AND}

3. Disease management OR Case management OR Self-care OR Delivery of health care, integrated OR Patient care planning OR Pulmonary rehabilitation

Limits: 1-7-2012, English 


\section{Author Questionnaire}

1) What was the setting of the educational intervention (if applicable, multiple answers are possible)?
a) in-patient education in hospital
b) out-patient education in hospital
c) home-based
d) community-based

2) What was the modality of the intervention (if applicable, multiple answers are possible)?
a) one-to-one counselling sessions
b) group counselling sessions
c) telephone
d) interactive computer
e) mailed print
f) other

3) What was the duration and total number of the educational sessions (please give an answer to both)?
a) minutes per session
b) sessions in total

4) Which healthcare professional(s) is (are) involved in education of patients (if applicable, multiple answers are possible)?
a) nurse
b) physician
c) pharmacist
d) physiotherapist
e) occupational therapist
f) dietician
g) respiratory therapist
h) psychologist
i) social worker
j) other 
5) Which of the following educational components / topics were parts of the intervention (if applicable, multiple answers are possible)?
a) Prevention and early treatment of respiratory exacerbations
b) Action Plan for self-treatment of exacerbations
c) End-of-life decision making
d) Coping with chronic lung disease
e) Normal pulmonary anatomy and physiology
f) Pathophysiology of chronic respiratory disease
g) Interpretation of medical testing
h) Breathing strategies
i) Proper use of medication, including oxygen therapy
j) Effective use of respiratory devices
k) Secretion clearance techniques
l) Healthy food intake
m) Irritant avoidance, including smoking cessation
n) Anxiety \& panic control, including relaxation techniques and stress management
o) Benefits of exercise and maintaining physical activities
p) Energy conservation and work simplification techniques
q) Indications for calling the healthcare provider
r) Leisure, Travel and Sexuality

6) What educational tools were used (if applicable, multiple answers are possible)?
a) PowerPoint presentation
b) flip board with large sheets of paper
c) posters
d) printed material and /or brochure
e) video
f) internet
g) other

7) Which self-management skills are taught (if applicable, multiple answers are possible)?
a) know and control the triggers and symptoms
b) take medications as prescribed
c) control acute episodes and emergencies
d) have a healthy diet
e) do not smoke
f) use relaxation and stress reduction techniques
g) make good use of health care professional
h) ask for information and help; use available resources in the community 
i) modify work and role functions

j) communicate with significant people

k) manage negative emotions and psychological reactions to the disease

8) Did all patients receive the same intervention?

a) yes

b) no (please elaborate on the differences):

9) Which teaching methods and activities (interaction and communication) were used in educating the COPD patients (if applicable, multiple answers are possible)?
a) interactive lecturing
b) passive lecturing
c) assessment of information needs ${ }^{1}$
d) building ambivalence (motivational interviewing technique)
e) demonstrations and practice (educator and / or the learner)
f) simulations or case scenarios
g) feedback and reinforcement
h) have patients summarize transmitted information (evaluation of patient's comprehension)
i) evaluate patient's level of self-efficacy
j) setting learning contracts with patients (for achieving long or short term objectives)
k) group exchange or discussions
l) peer observation (use of an expert patient)
m) learning contracts (homework, goal achievement)
n) written material adapted to patients' level of literacy

10) From experience based on the conducted intervention, can you point out on any additional information needs (or topics) that are not being met by this educational intervention?

\footnotetext{
${ }^{1}$ Defined as: the information patients need to adequately understand their lung disease and to maximise their self-management skills (Hyland, 2006).
} 


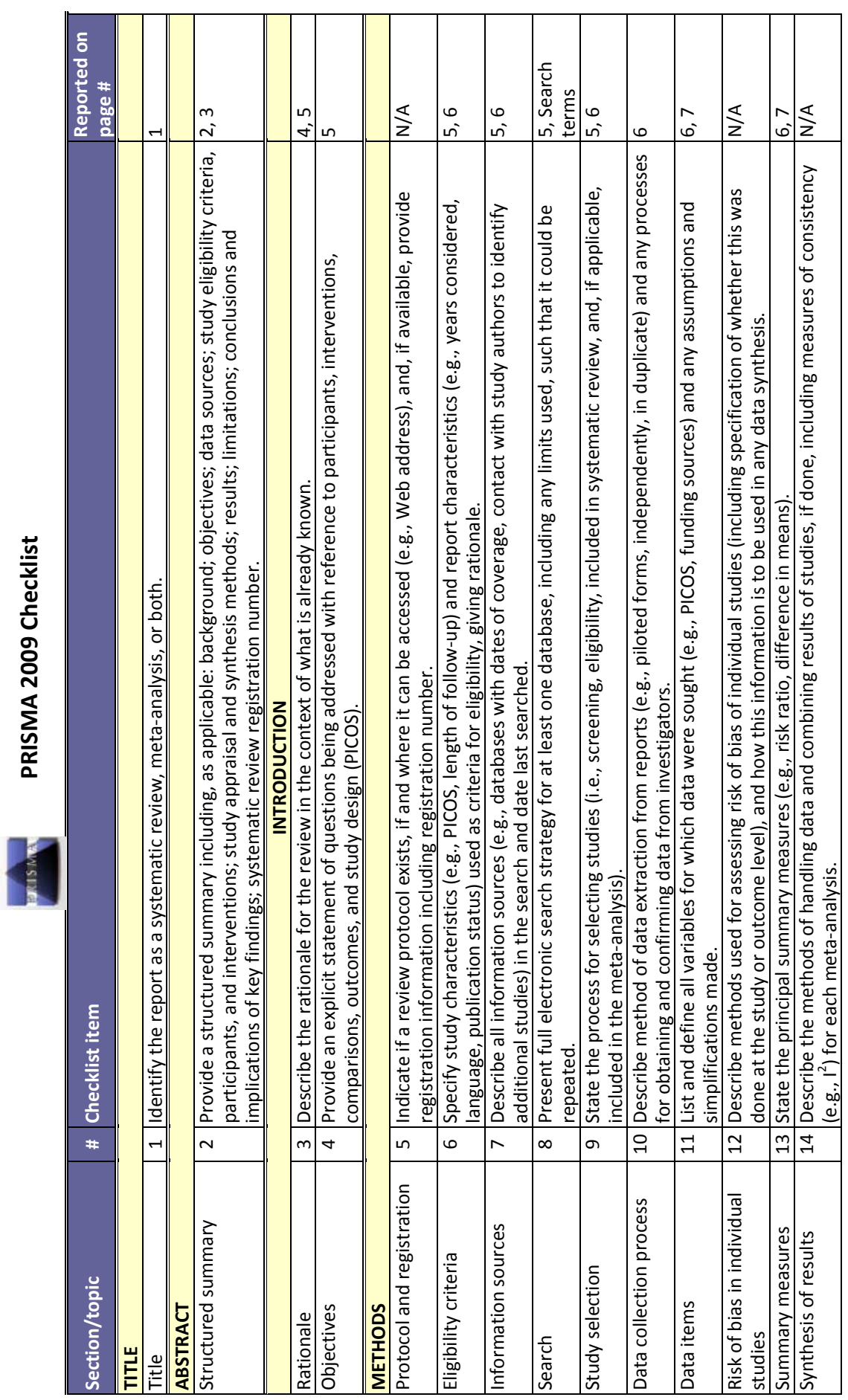




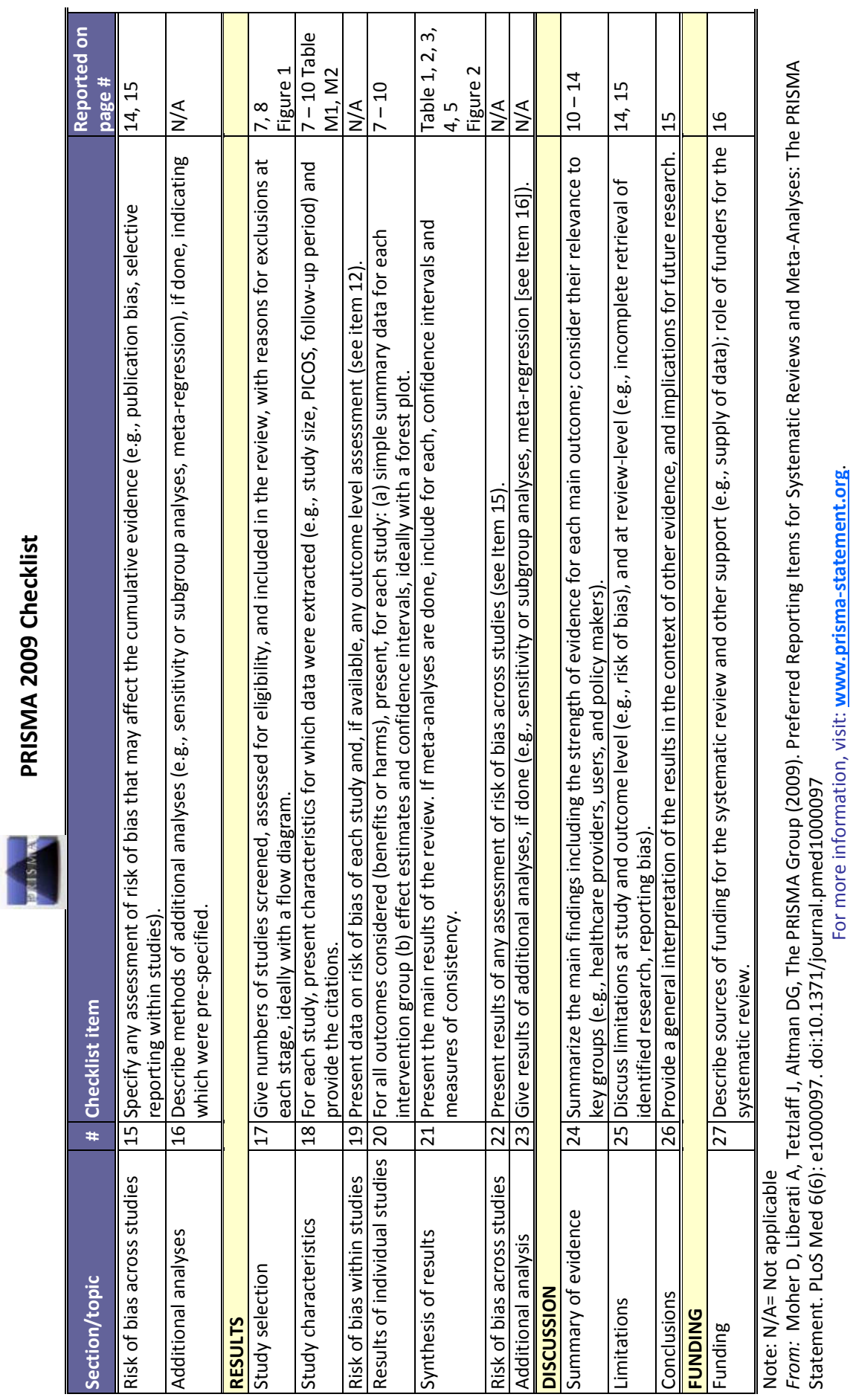




\section{Results}

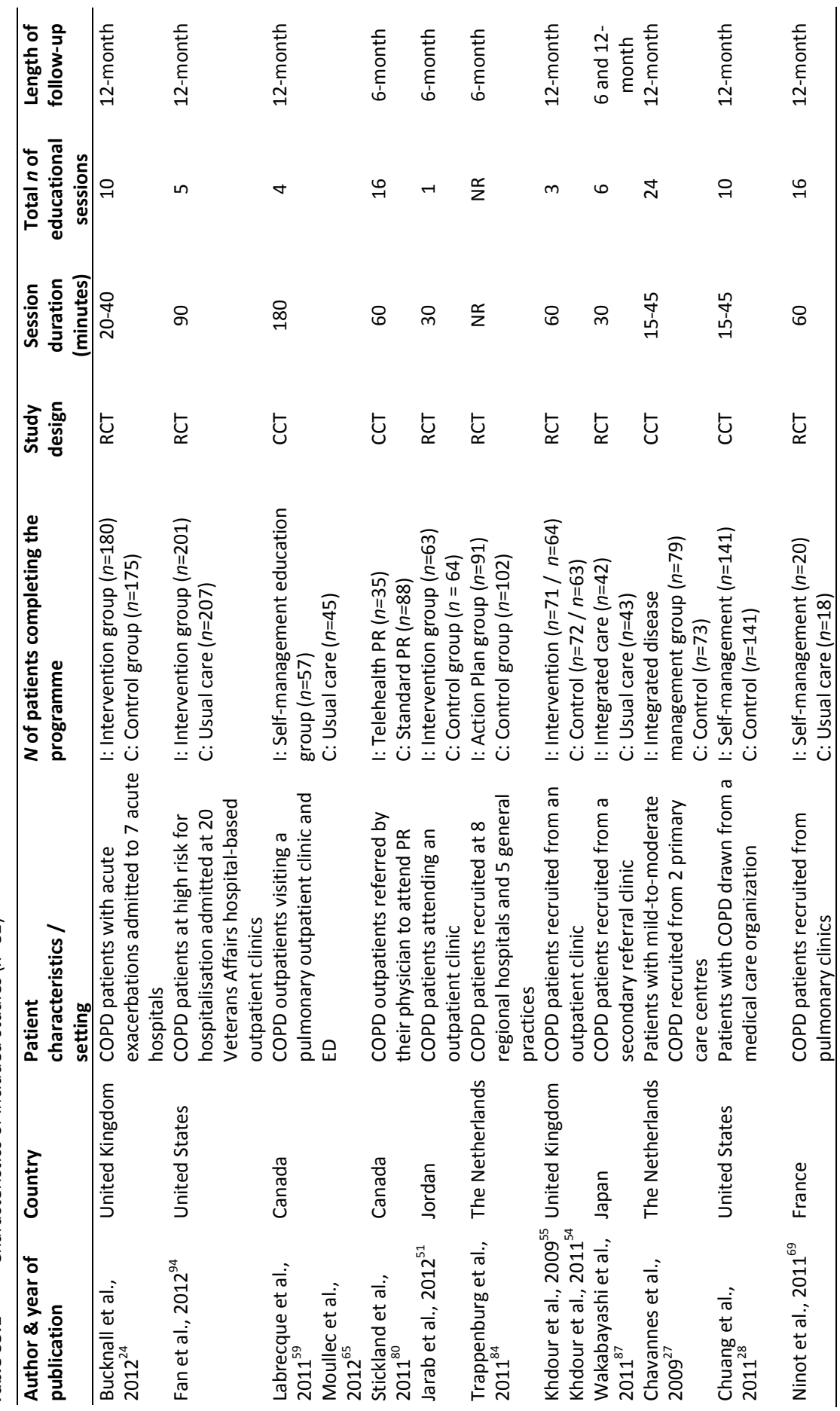




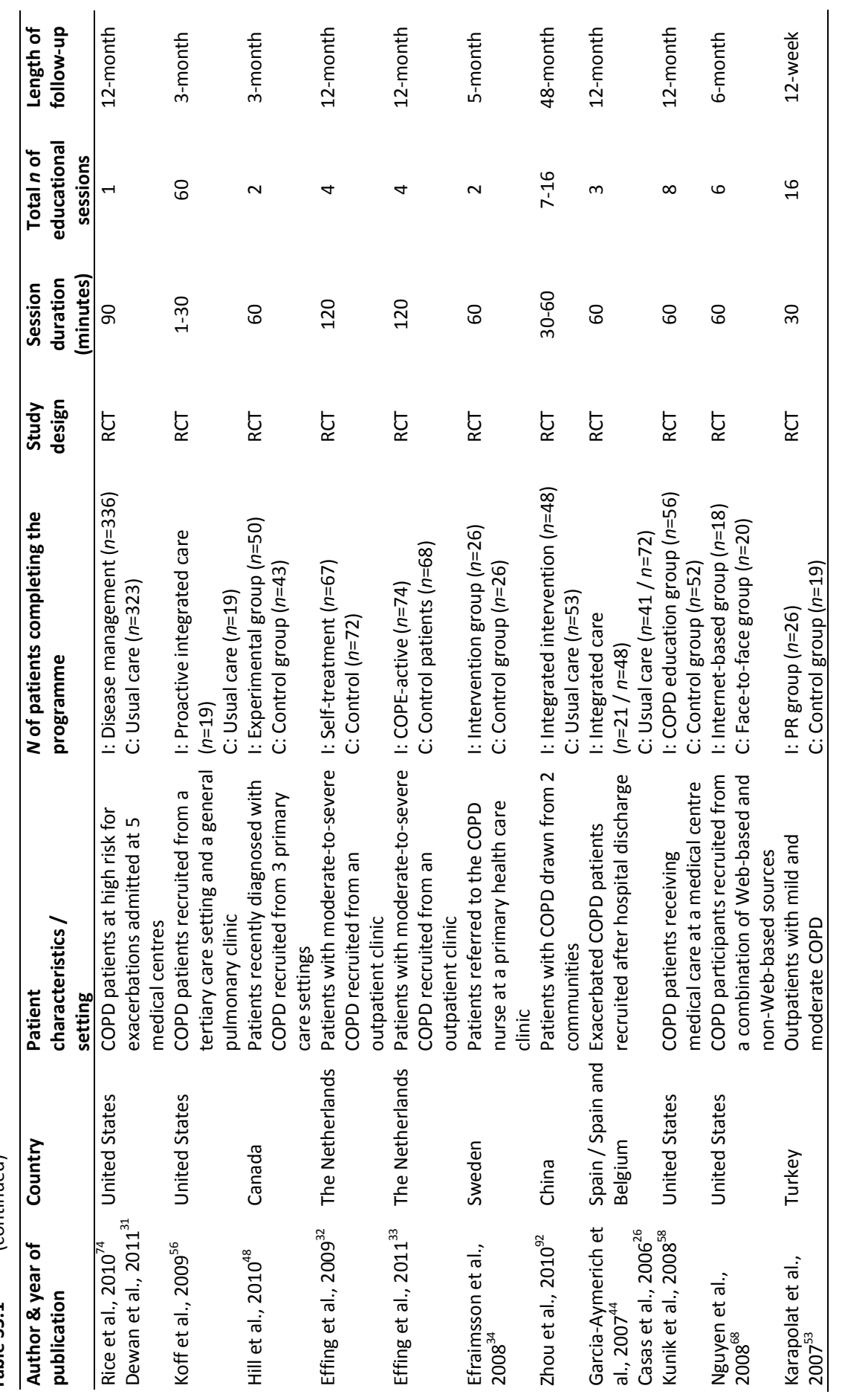




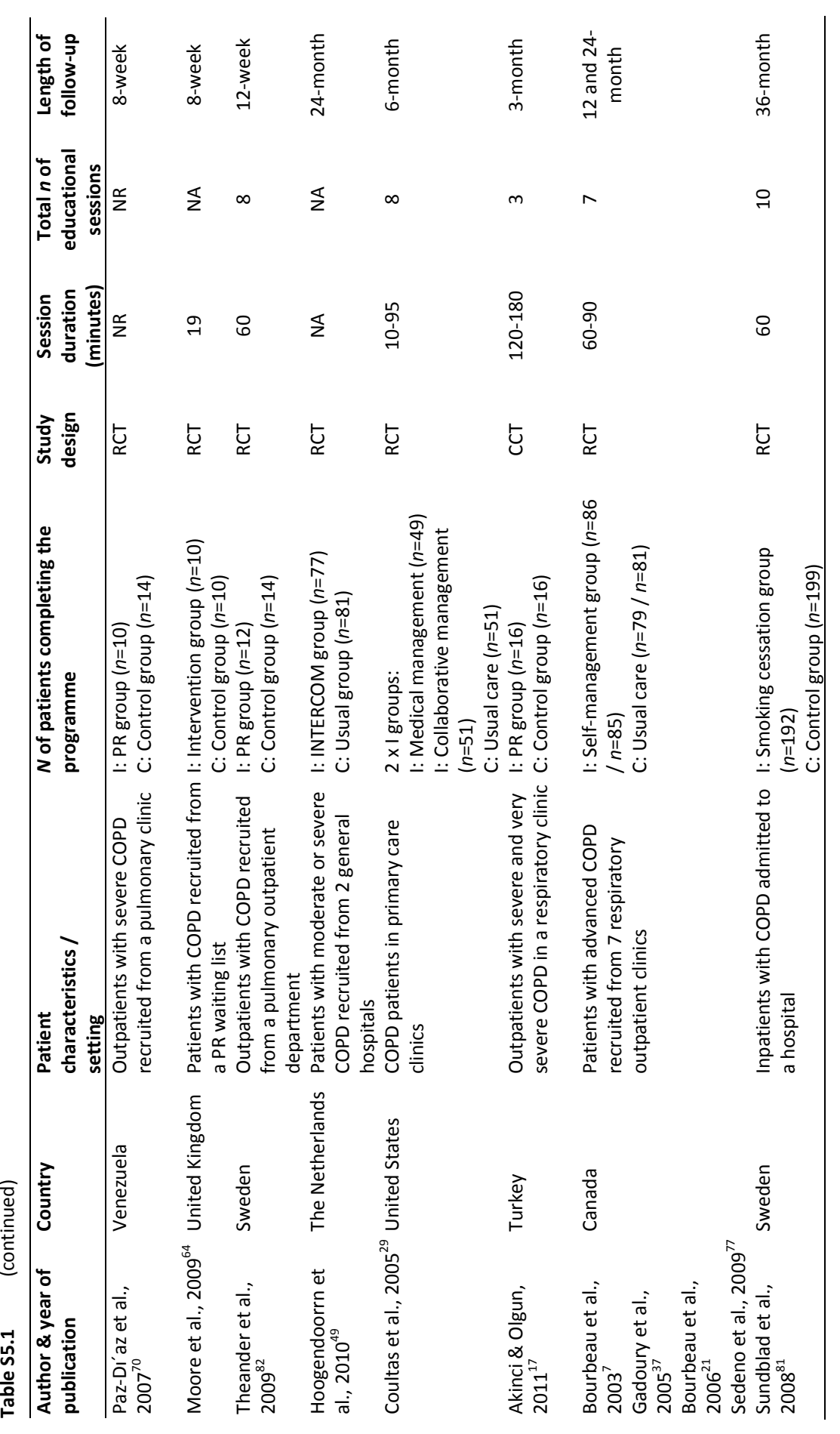




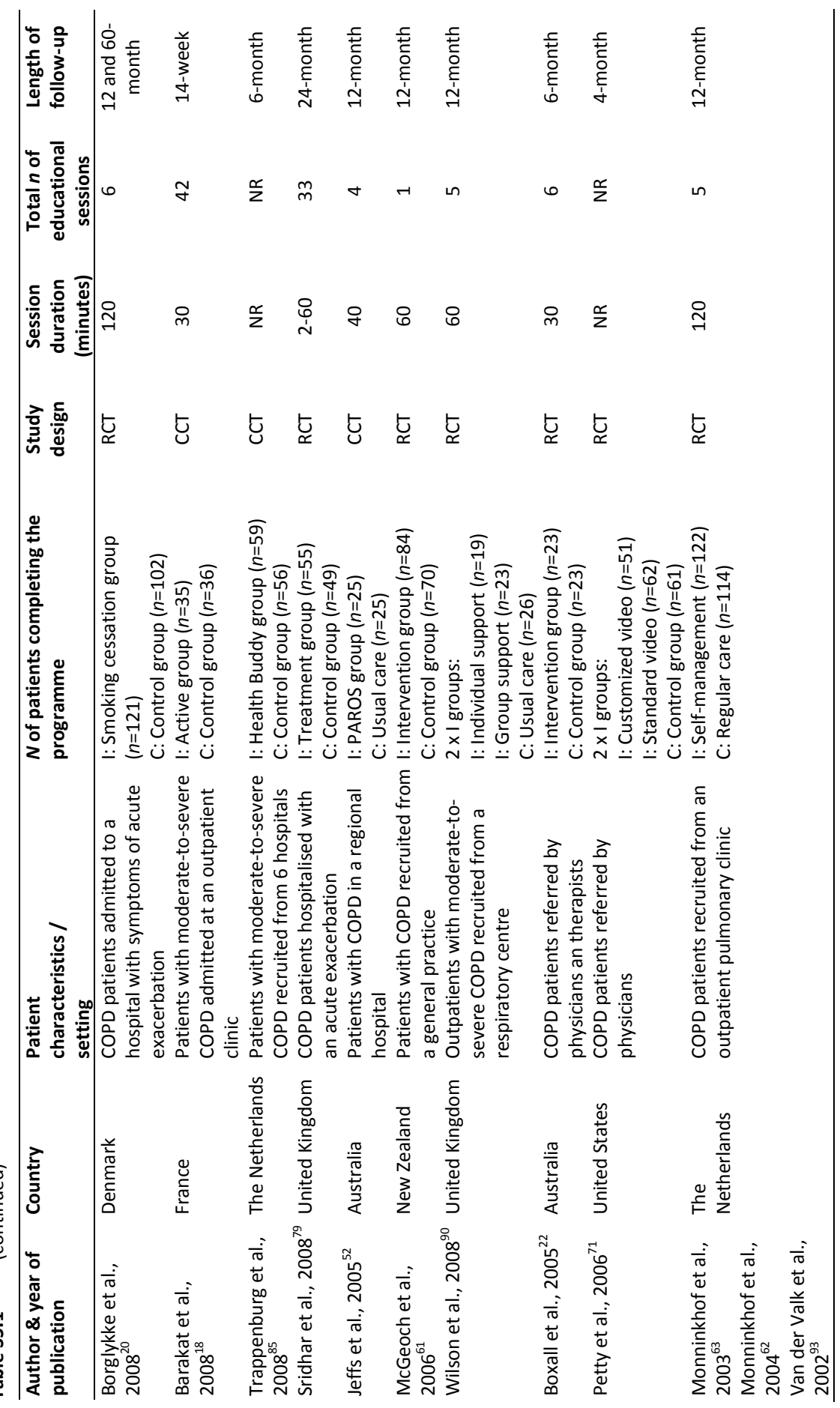




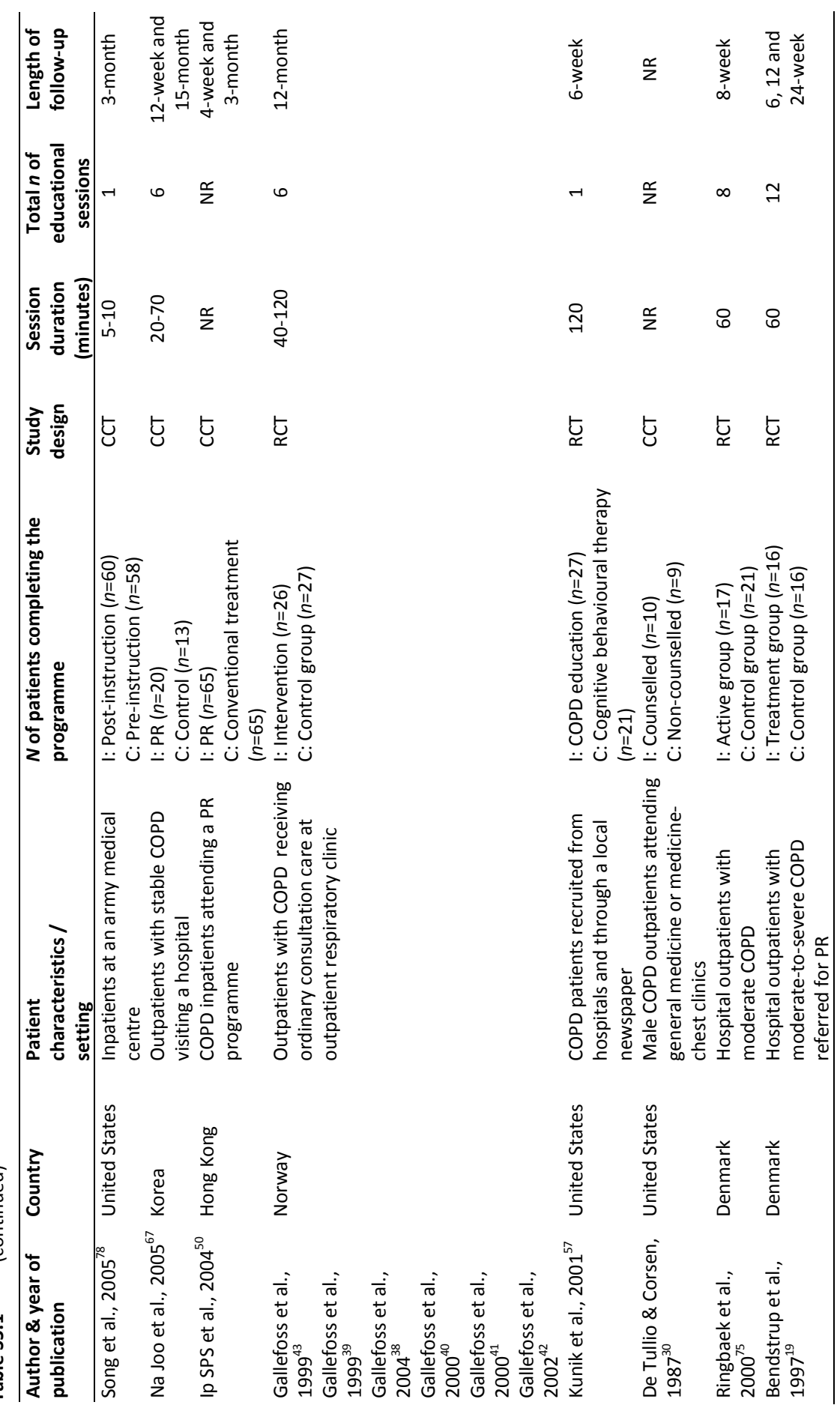




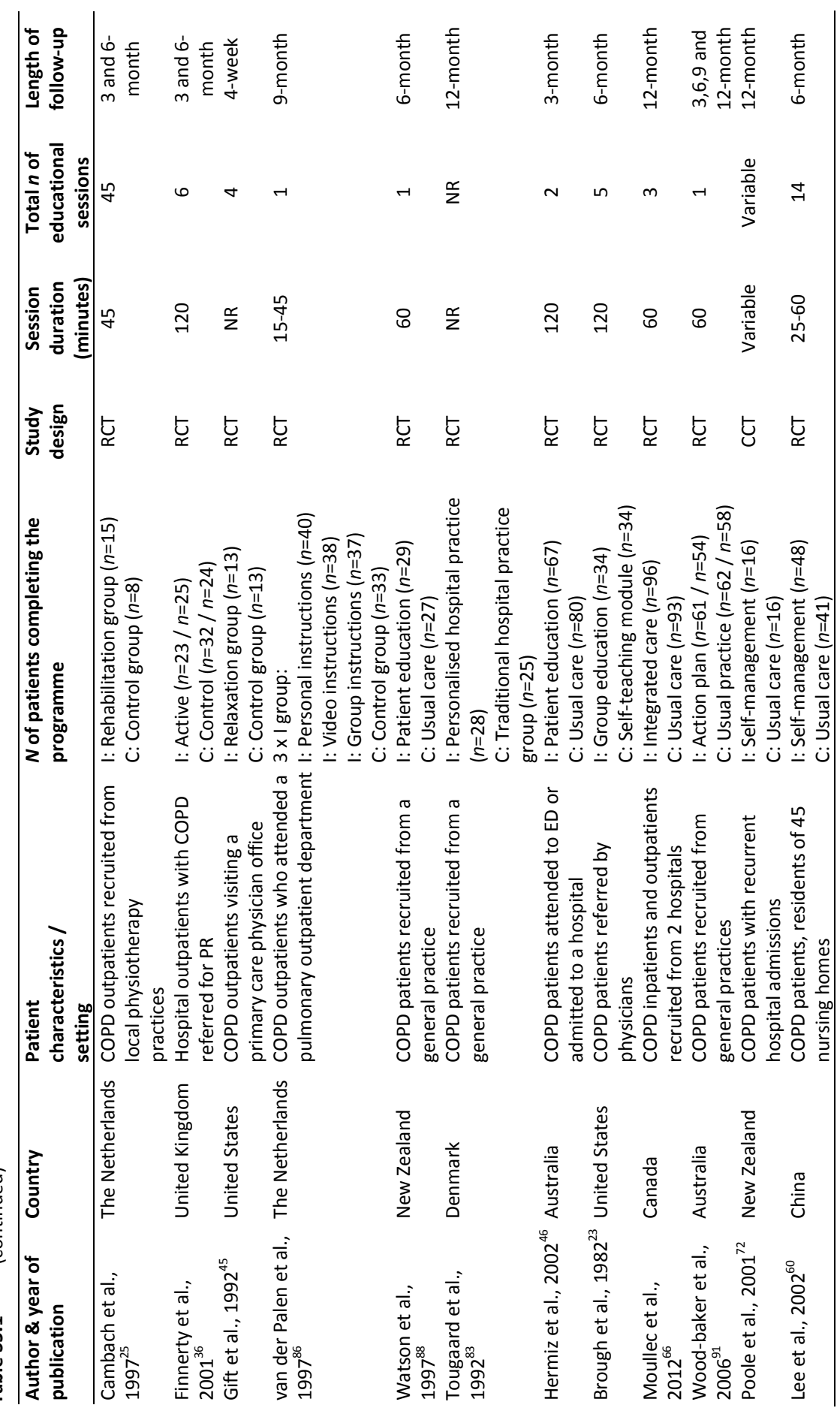




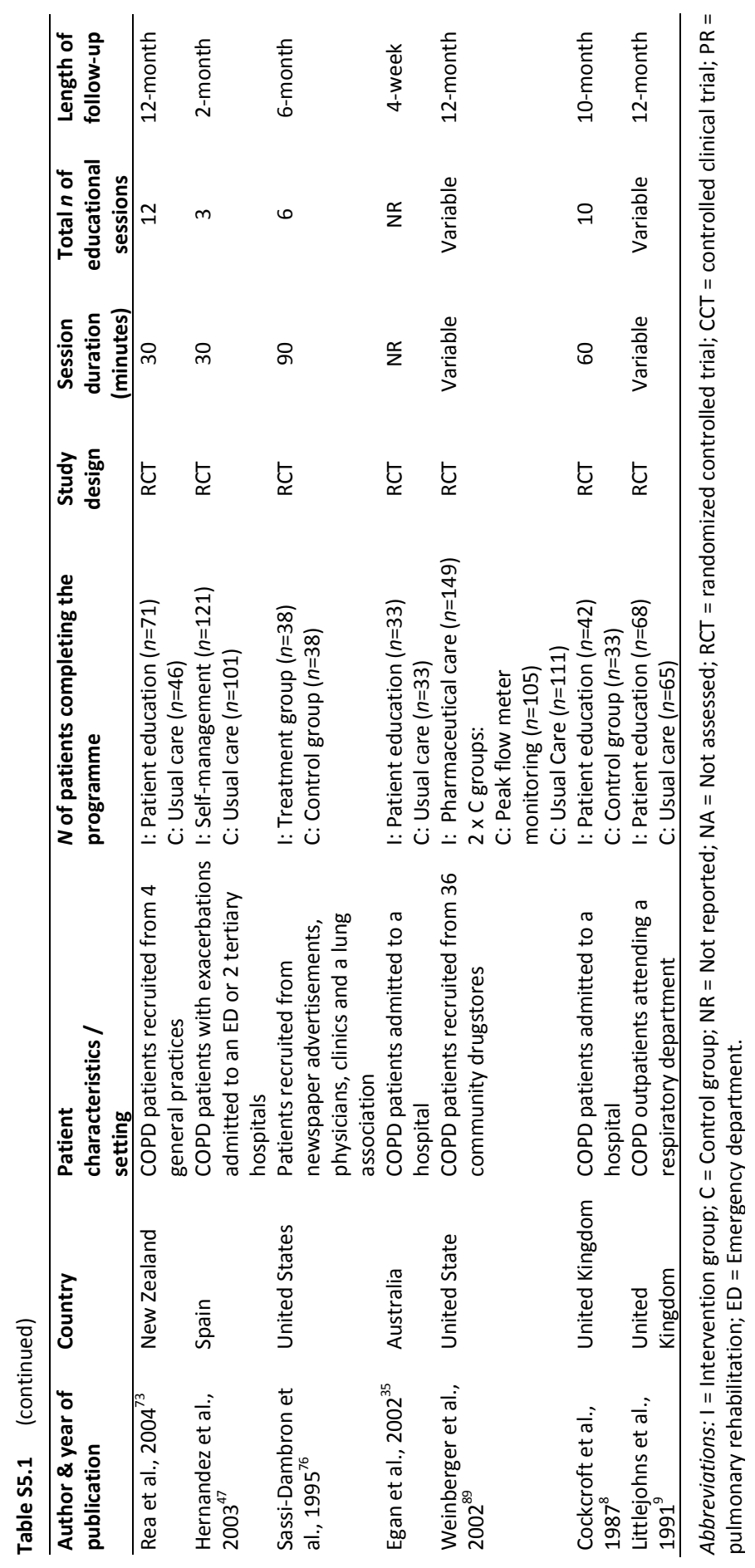


Table S5.2 Summary of outcomes.

\begin{tabular}{|c|c|}
\hline Outcomes, $n=81$ & Effect on outcomes \\
\hline Coping styles, $n=1,(1.2 \%)^{71}$ & - Increase, $n=1,(100 \%)^{71}$ \\
\hline $\begin{array}{l}\text { Anxiety and/or depression, } n=10,(12.3 \%) \\
9,33,35,45,58,60,61,70,76,94\end{array}$ & $\begin{array}{l}\text { - No difference between groups, } n=5 \text {, (50\%) } \\
33,58,61,76,94\end{array}$ \\
\hline $\begin{array}{l}\text { Knowledge/self-management behaviour, } n=22,(27.2 \%) \\
8,23,30,34,44,46-48,51,55,61,63,65,71,78,79,83,86-88,91,94\end{array}$ & 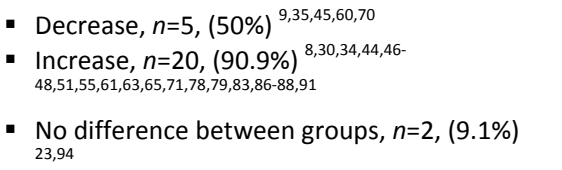 \\
\hline $\begin{array}{l}\text { Dyspnoea, } n=14,(17.3 \%) \\
17,22,27,33,44,45,53,64,68,70,75,76,87,90\end{array}$ & $\begin{array}{l}\text { - No difference between groups, } n=5,(35.7 \%) \\
44,68,75,76,90 \\
\text { - Decrease, } n=9,(64.3)^{17,22,27,33,45,53,64,70,87}\end{array}$ \\
\hline Lung function, $n=14,(17.3 \%)^{17,18,30,43-45,53,57,60,70,73,88,91,92}$ & $\begin{array}{l}\text { - Increase, } n=4,(28.6 \%)^{17,30,45,73} \\
\text { - } \quad \text { No difference between groups, } n=10,(71.4 \%) \\
18,43,44,53,57,60,70,88,91,92\end{array}$ \\
\hline $\begin{array}{l}\text { Exercise capacity, } n=20,(24.7 \%) \\
17-19,22,25,33,36,53,58,63,64,67-69,73,75,76,80,82,91\end{array}$ & $\begin{array}{l}\text { - Increase, } n=12,(60 \%)^{17-19,22,25,33,36,53,64,67,69,73} \\
\text { - } \quad \text { No difference between groups, } n=8,(40 \%) \\
58,63,68,75,76,80,82,91\end{array}$ \\
\hline $\begin{array}{l}\text { Healthcare utilisation: } \\
\text { Emergency department (ED) visits, unscheduled visits, } \\
\text { GP consultations, inhalation medication, courses of } \\
\text { antibiotics/steroids, No. hospital admissions, length of } \\
\text { stay, } n=40,(49.4 \%) \\
7-9,20,22,24,26,28,29,32,37-39,41,44,46,47,50-52,55,58,60,61,65,66,69,72-74,77,79,83- \\
85,87-89,91,94\end{array}$ & $\begin{array}{l}\text { - Increase, } n=12,(30 \%) \text { : } \\
\text { - GP visits }{ }^{9,28} \\
\text { - courses of respiratory medication } 9,31,32,74,77,88,91 \\
\text { - hospital bed days/length of stay/hospitalization } \\
8,52,72,94 \\
\text { - No difference between groups, } n=14, \\
\quad \text { (35\%): } \\
\text { - No. hospital admissions }{ }^{28,29,46,79,89,91} \\
\text { - length of stay/ bed days }{ }^{28,66} \\
\text { - courses of respiratory medication }{ }^{44} \\
\text { - ED visits } 28,29,52,66,89,91 \\
\text { - Decrease, } n=24,(60 \%){ }^{51,55,65} \\
\text { - healthcare/GP contacts }{ }^{32,38,41,79,83} \\
\text { - No. hospital } \\
\quad \text { admissions }{ }^{7,20,22,24,26,31,32,37,50,66,73,74,77,83,85,87} \\
\text { - hospital bed days/length of stay }{ }^{7,47,73} \\
\text { - ED visits }{ }^{37,47} \\
\text { - courses of respiratory medication }\end{array}$ \\
\hline $\begin{array}{l}\text { Self-efficacy, } n=3,(3.7 \%) \\
68,84,94\end{array}$ & $\begin{array}{l}\text { - Increase, } n=2,(66.7 \%)^{84,94} \\
\text { - No difference between groups, } n=1,(33.3 \%)^{68}\end{array}$ \\
\hline Mortality, $n=10,(12.3 \%)^{8,9,18,20,24,26,79,87,92,94}$ & $\begin{array}{l}\text { - Increase, } n=1,(10 \%)^{94} \\
\text { - No difference between groups, } n=4,(40 \%) \\
20,24,26,92 \\
\text { - Decrease, } n=5,(50 \%)^{8,9,18,79,87}\end{array}$ \\
\hline
\end{tabular}


Table S5.2 (continued)

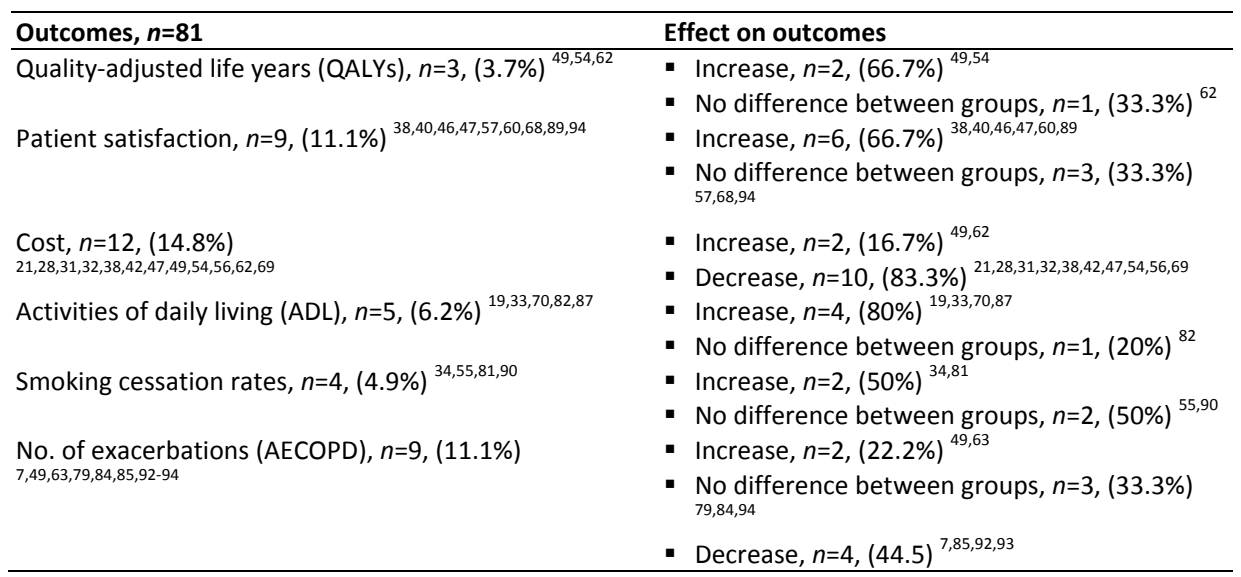

$n$ : number of studies. 



\section{Chapter 6}

\section{ATTITUDES OF HEALTHCARE PROFESSIONALS PROVIDING PULMONARY REHABILITATION TOWARD PARTNERSHIP IN CARE}

Ana Stoilkova-Hartmann, Daisy J.A. Janssen, Frits M.E. Franssen, Martijn A. Spruit, Emiel F.M. Wouters

Heart \& Lung 2015;44:347-352 


\section{Abstract}

\section{Objective}

This multicentre study sought to explore attitudes of pulmonary rehabilitation (PR) professionals toward self-management and which patients' competencies are considered important.

\section{Background}

Self-management in patients with chronic obstructive pulmonary disease (COPD) requires a patients' active role. Whether patient-clinician partnership in care is supported by PR professionals remains unknown.

\section{Methods}

Attitudes of 75 PR professionals were assessed using an online version of the Clinician Support - Patient Activation Measure (CS-PAM) $13^{\mathrm{TM}}$.

\section{Results}

Mean CS-PAM $13^{\mathrm{TM}}$ activation score was 66.5 (11.9) points - professionals support patient's participation in the care process. However, competencies related to 'patient as member of a care team' and 'patient as an independent information seeker' were only extremely important for $30.7-38.7 \%$ and $9.3-17.3 \%$ of the professionals, respectively.

\section{Conclusion}

PR professionals embrace the idea of a patients' active role in the process of COPD self-management. Nonetheless, endorsement of the patient's involvement as an independent information seeker is needed. 


\section{Introduction}

Chronic obstructive pulmonary disease (COPD) is a significant health problem worldwide, characterised by chronic airflow limitation, an abnormal inflammatory response of the lungs and progressive respiratory symptoms. ${ }^{1,2}$ Practice guidelines advocate partnership in care between patients with COPD and their healthcare professionals. $^{3-5}$ Collaborative self-management of COPD relies on acquiring knowledge and skills needed to carry out specific medical regimens and guiding patients' health behaviour change by enhancing efficacy beliefs and confidence in outcomes. ${ }^{6}$ This productive interaction requires an "informed and activated patient" and a "prepared practice team" which will support and promote self-management to their patients within the clinical consultations. ${ }^{7}$

Data from the United Kingdom suggest that only $43 \%$ of the patients with chronic conditions, such as asthma, diabetes or arthritis, are involved in decision-making related to their treatment and $45 \%$ of the patients are involved in making a plan to manage their condition at home. ${ }^{8}$ This has drawn attention to the potential impact of healthcare professionals' role on patient's self-management behaviours and health perceptions. ${ }^{9}$ Moreover, healthcare professionals' attitudes might reasonably be considered to be among the important predictors of patient's enablement. ${ }^{10}$

Pulmonary rehabilitation (PR) including, but not limited to, physical exercise training and education has been shown to improve exercise capacity and quality of life and to reduce symptoms in patients with COPD. ${ }^{3,11}$ Additionally, PR should incorporate self-management support guiding structural behaviour change and the shift from management by healthcare professionals to collaborative management. ${ }^{3,12}$ Exploring the beliefs of healthcare professionals in PR with respect to the importance of supporting the patient as an active partner is necessary for improvement of the effectiveness of self-management programmes incorporated in PR. ${ }^{12}$ Whether and to what extent partnership in care is supported by healthcare professionals providing PR, is currently unknown.

The present multicentre study explores attitudes of healthcare professionals providing PR toward patient self-management and specifically assesses their attitudes about the importance of patients' competencies necessary for this process. A priori, we hypothesised that healthcare professionals providing PR will endorse partnership in care and patients' active role in the process of self-management in PR. 


\section{Methods}

\section{Study population}

Participants were healthcare professionals working in PR, recruited at the Centre of expertise for chronic organ failure (CIRO+) and 6 hospitals of the $\mathrm{CIRO}+$ network in the Netherlands. ${ }^{13}$ In total, 107 healthcare professionals were invited by email to complete an online survey. Respondents were given instructions to answer the questionnaire with a focus only on the COPD patients following PR. Data collection took place in December 2012 and January 2013. Three reminders were sent to increase the response rate.

\section{Instrument}

The online survey consisted of questions concerning demographics, healthcare profession, years in practice with COPD patients and work setting. Healthcare professionals were asked to complete the Clinician Support - Patient Activation Measure (CSPAM) $13^{\mathrm{TM}}$ consisting of 13 items. ${ }^{14}$ The CS-PAM $13^{\mathrm{TM}}$ is a shorter version of the 14 item CS-PAM, which has been shown to be a reliable and valid instrument for assessing clinician attitudes about the patient role in the care process. ${ }^{15,16}$ It measures two aspects: level of endorsement of patient self-management (the CS-PAM activation score) and beliefs about the importance of four patient competency categories (1. patient should follow medical advice; 2. patient can make independent judgments and actions; 3. patient as member of care team; and 4. patient is an independent information seeker). ${ }^{15,16}$ Healthcare professionals providing PR were asked to rate how important it is for them that their patients with COPD participating in PR have certain self-management competencies and behaviours. Five response options for each item were offered: 'not important' (1 point), 'somewhat important' (2 points), 'important' (3 points), 'extremely important' (4 points) and 'not applicable'. ${ }^{14}$ Raw scores were calculated by adding up all responses to the 13 questions. ${ }^{14}$ Items which were answered with a "not applicable" or a question left blank were scored as "missing". In this case, as a correction of the individual scores, the raw score was calculated by dividing the total score by the number of completed items and this score was multiplied by $13 .{ }^{14}$ The raw score was converted into the CS-PAM activation score (0-100 scale). ${ }^{14}$ A CS-PAM $13^{\text {TM }}$ activation score of 37.81 points or lower means that clinicians believe that a patient should follow medical advice (a 'low' CS-PAM $13^{\mathrm{TM}}$ activation score). ${ }^{14}$ A CS-PAM $13^{\mathrm{TM}}$ activation score of 39.23-58.44 points implies that healthcare professionals believe that a patient can make independent judgments and actions (a 'moderate' CS-PAM $13^{\text {TM }}$ activation score). ${ }^{14}$ Finally, a CS-PAM $13^{\mathrm{TM}}$ activation score of 60.13 points or above, means that healthcare professionals believe that a patient is able to function as a 
member of the care team (a 'high' CS-PAM $13^{\mathrm{TM}}$ activation score). ${ }^{14}$ Hence, a higher score on this measure indicates an increased tendency towards supporting the patient's role. ${ }^{15}$ License for use of the CS-PAM $13^{\mathrm{TM}}$ was granted by the developer, Insignia Health, University of Oregon, United States. The questionnaire was translated into Dutch using a forward-backward translation procedure.

\section{Statistics}

Characteristics of healthcare professionals are presented as number and proportion. The CS-PAM $13^{\mathrm{TM}}$ activation scores of the healthcare professionals are shown as mean (standard deviation, SD). Number and proportion of healthcare professionals in each activation level segment are shown. The relationship between CS-PAM $13^{\text {TM }}$ activation scores and sex, age ( $\leq 50$ years versus $\geq 51$ years), ${ }^{15}$ professional background (physicians and nurses versus allied healthcare professionals), years of work experience with COPD patients ( $\leq 20$ years versus $\geq 21$ years) ${ }^{15}$ and workplace setting (centre for inpatient and outpatient PR versus only hospital-based outpatient PR) were assessed using independent-samples $t$-tests. A linear regression model using forced entry method was developed to explore the relationship with sex and age after correction for possible confounders. The mean CS-PAM $13^{\mathrm{TM}}$ activation score was entered as dependent variable, while age ( $\leq 50$ years versus $\geq 51$ years), sex and profession (physicians and nurses versus allied healthcare professionals) were entered as independent variables. Finally, for each item the proportion of healthcare professionals reporting the item as 'not important', 'somewhat important', 'important', 'extremely important', and 'not applicable' are shown. Analyses were carried out with IBM SPSS version 20.0 (SPSS Inc., Chicago, IL). A $p$-value of $\leq 0.05$ was considered as statistically significant.

\section{Results}

\section{Characteristics of healthcare professionals}

The CS-PAM $13^{\mathrm{TM}}$ was completed by 75 healthcare professionals providing PR. Cumulative response rates were $37.4 \%, 64.5 \%$ and $70.1 \%$ in the first, second and third round, respectively. Most of the participants were nurses. Other respondents were physicians, physiotherapists, occupational therapists, dieticians, psychologists, sport trainers, nutrition consultants, managers, a dietician trainee and an art therapist (Table 6.1). 
Table 6.1 Description of the study sample $(n=75)$.

\begin{tabular}{lc}
\hline & $n$ (\%) \\
\hline Profession category & $5(6.7)$ \\
Physicians / chest physicians & $29(38.7)$ \\
Nurses & $16(21.3)$ \\
Physiotherapists & $3(4.0)$ \\
Psychologists & $4(5.3)$ \\
Occupational therapists & $7(9.3)$ \\
Sport trainers & $2(2.7)$ \\
Dieticians & $9(12.0)$ \\
Other & \\
Age (years) & $19(25.3)$ \\
$<30$ years or less & $20(26.7)$ \\
$31-40$ & $23(30.7)$ \\
$41-50$ & $13(17.3)$ \\
$51+$ & $59(78.7)$ \\
Female & \\
Work experience with COPD patients (years) & $22(29.3)$ \\
$0-5$ & $16(21.3)$ \\
$6-10$ & $14(18.7)$ \\
$11-15$ & $10(13.3)$ \\
$16-20$ & $13(17.3)$ \\
$20+$ & \\
Workplace setting & $51(68.0)$ \\
Centre for inpatient pulmonary rehabilitation & $24(32.0)$ \\
Hospital-based outpatient centre &
\end{tabular}

*Nutrition consultants, managers, dietician trainee and art therapist.

\section{Attitudes toward COPD self-management}

Mean CS-PAM $13^{\mathrm{TM}}$ activation score was 66.5 (11.9) points. None of the healthcare professionals reported a low CS-PAM $13^{\mathrm{TM}}$ activation score. A moderate CS-PAM $13^{\mathrm{TM}}$ activation score was reported by 23 (30.7\%) healthcare professionals and a high CS-PAM $13^{\mathrm{TM}}$ activation score was reported by $52(69.3 \%)$ healthcare professionals.

The mean CS-PAM $13^{\mathrm{TM}}$ activation score of physicians and nurses was comparable with the mean CS-PAM $13^{\mathrm{TM}}$ activation score of allied healthcare professionals (Table 6.2). Also, no differences in mean CS-PAM $13^{\mathrm{TM}}$ scores by years of work experience with COPD patients ( $\leq 20$ years versus $\geq 21$ years) and workplace setting (centre for inpatient and outpatient PR versus only hospital-based outpatient PR) were observed. Mean CS-PAM $13^{\mathrm{TM}}$ activation scores were higher for female healthcare professionals than male healthcare professionals. Healthcare professionals aged $\leq 50$ years reported significantly lower CS-PAM $13^{\mathrm{TM}}$ activation score than healthcare professionals $\geq 51$ years of age (Table 6.2 ). This relationship of the CS-PAM $13^{\mathrm{TM}}$ activation score with age and sex (both $p<0.05$ ) was confirmed by linear regression analysis after adjusting for professional background (Table 6.3). 
Table 6.2 The CS-PAM $13^{\mathrm{TM}}$ activation scores.

\begin{tabular}{lccccc}
\hline & Category & CS-PAM & Category & CS-PAM & $\boldsymbol{p}$-value \\
\hline Profession & $\begin{array}{c}\text { physicians and } \\
\text { nurses }\end{array}$ & $68.0(11.4)$ & $\begin{array}{c}\text { allied healthcare } \\
\text { professionals }\end{array}$ & $65.3(12.3)$ & 0.37 \\
Age & $\leq 50$ years & $65.1(11.5)$ & $\geq 51$ years & $73.1(12.0)$ & 0.03 \\
Sex & female & $68.0(11.8)$ & male & $61.0(10.8)$ & 0.04 \\
Work experience & $\leq 20$ years & $65.7(12.2)$ & $\geq 21$ years & $69.9(10.3)$ & 0.25 \\
Workplace setting & centre for PR & $67.4(12.4)$ & hospital-based & $64.4(11.0)$ & 0.32 \\
& & & outpatient PR & \\
\hline
\end{tabular}

The CS-PAM $13^{\mathrm{TM}}$ activation scores are presented as mean (SD). Abbreviations: CS-PAM: Clinician Support Patient Activation Measure.

Table 6.3 The relationship of the CS-PAM $13^{\text {TM }}$ activation score with age and sex: linear regression model.

\begin{tabular}{lccc}
\hline & Correlates & Standardized $\boldsymbol{B}$ & $\boldsymbol{p}$-value \\
\hline CS-PAM 13 & age & 0.26 & 0.02 \\
$\left(R^{2}=0.128, p=0.02\right)$ & sex & -0.24 & 0.04 \\
& profession & -0.04 & 0.74 \\
\hline
\end{tabular}

$n=75$. Abbreviations: CS-PAM: Clinician Support - Patient Activation Measure.

\section{Beliefs about the importance of specific patient competencies}

The healthcare professionals' beliefs about the importance of the four patient competency categories are presented in Figure 6.1. Items focusing on the importance of 'patient should follow medical advice' were strongly supported by the healthcare professionals providing PR. Almost all (98.7\%) healthcare professionals believed that it is important $(24.0 \%)$ or extremely important $(74.7 \%)$ for their patients: "to be able to make and maintain lifestyle changes needed to manage their disease". Moreover, all $(100.0 \%)$ healthcare professionals considered as important $(20.0 \%)$ or extremely important $(80.0 \%)$ that "patients should understand which of their behaviours make their COPD better/worse".

In the category 'patient can make independent judgments and actions', 33.3\% and $48.1 \%$ of the respondents considered "patients' knowledge of the prescribed medication" as important or extremely important, respectively. Further, $24.0 \%$ and $70.7 \%$ of the healthcare professionals considered "patients are able to find solutions when new situations or problems arise with their COPD" as important or extremely important, respectively.

Within the category 'patient as member of care team' $49.3 \%$ and $30.7 \%$ of the professionals considered "patients want to know what procedures or treatments they will receive and why before treatments and procedures are performed" as important or extremely important, respectively. "Involvement of the patient as a full partner in treatment decision-making" was important or extremely important to $44.0 \%$ and 
$38.7 \%$ of the healthcare professionals, respectively. "Patients' understanding of different medical treatment options" was considered important by $46.8 \%$ and extremely important by $37.3 \%$ of the healthcare professionals.

Finally, in the patient competency category 'patient should be an independent information seeker', $45.4 \%$ and $9.3 \%$ of the healthcare professionals reported as important or extremely important, respectively that "patients look for trustworthy information sources related to their condition and health choices". Furthermore, $42.7 \%$ and $17.3 \%$ of the respondents recognised "patients to bring a list of questions to their office visit" as important or extremely important, respectively.

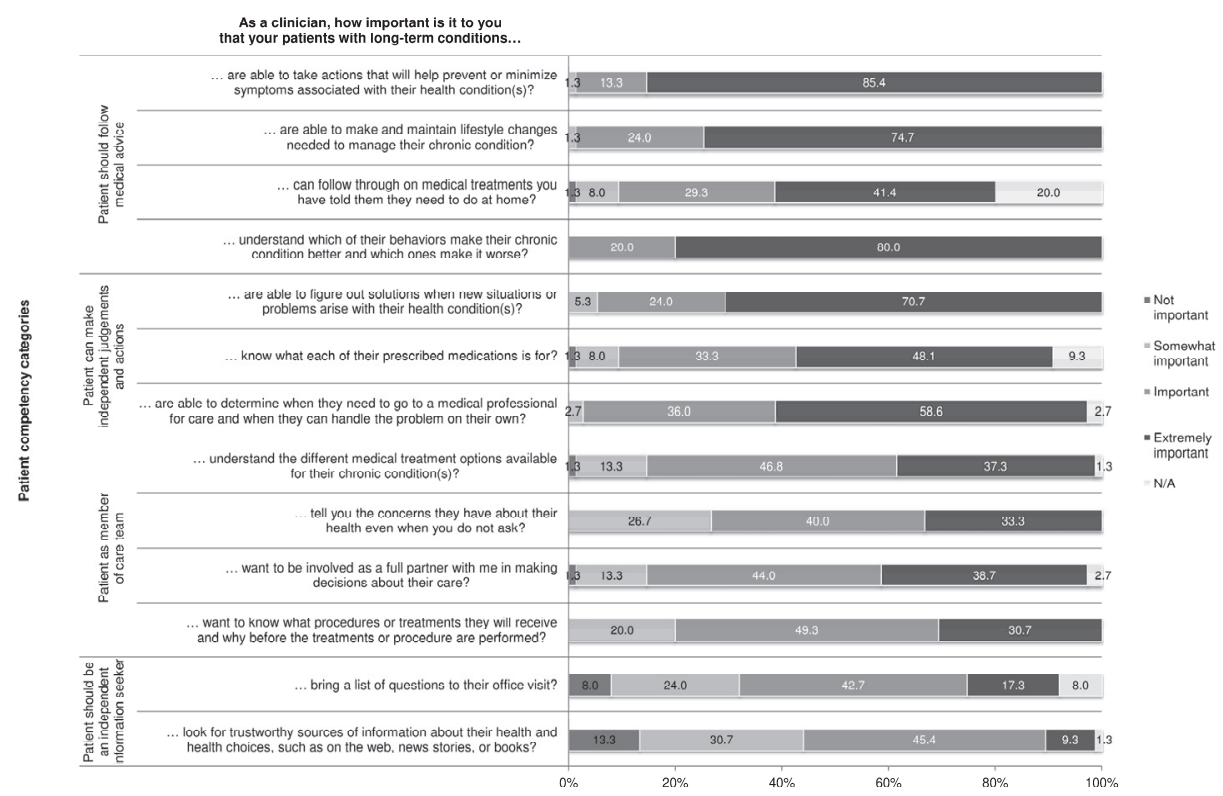

Figure 6.1 Healthcare professionals' beliefs about the importance of the patients' self-management competencies and behaviours.

\section{Discussion}

In line with our hypothesis, we found that healthcare professionals providing PR value patient involvement in their care. Nonetheless, our study shows that only a minority of the healthcare professionals providing PR found the patient's competency categories 'patient as member of care team' and 'patient should be an independent information seeker' extremely important. 
The attitudes and beliefs of healthcare professionals providing PR demonstrated in our study broadly resonate with those of healthcare professionals in other medical disciplines such as primary care physicians, psychiatrists and surgical specialties. ${ }^{15,17-19}$ Mean CS-PAM activation scores of UK and US primary care clinicians using the 14 item CS-PAM (69.0 (12.8) and 69.0 (12.1), respectively), ${ }^{15}$ were somewhat higher than the score in the current study. Similarly to our results, Hibbard et $\mathrm{al}^{15}{ }^{15}$ showed that primary care clinicians mainly supported items such as 'patients following medical advice' or 'patient making independent judgments and actions', while clinicians' support for patients' competencies as 'being able to function as a member of the care team' or 'being an independent information seeker' were less often reported as (extremely) important. Cumulatively, these findings suggest that although healthcare providers support active patient behaviour in the consultation, place value in patient's self-management and express positive attitudes toward patient's participation patient's competencies related to 'patient as member of a care team' and 'patient should be an independent information seeker' were considered as less important.

Within this context, a recent study conducted in psychiatrists and vascular surgeons, using self-constructed questionnaires, assessed healthcare professionals' preferred style of decision-making and rated patients' behaviours. ${ }^{18}$ This study found positive healthcare professionals' attitudes toward active patient behaviour in the process of shared decision-making, but also, ambivalent or negative healthcare professionals' attitudes provoked by patients' behaviours. ${ }^{18}$ As positive behaviours were seen patients giving feedback and stating whether they wanted to be involved in the decision, as well as asking for alternatives or details of the treatment. In contrast, patients expressing doubts, insisting on their own ideas, searching for a second opinion or the Internet, were perceived as less helpful or more annoying patients' behaviours. $^{18}$ One of the reasons for these, not straightforward healthcare professionals' attitudes, might be the existing confidence gap - whether professionals believe in patients' abilities and competencies to successfully manage their disease. ${ }^{17}$ Indeed, a qualitative study assessing primary care physicians' attitudes about selfmanagement of chronic disease, suggested that the medical profession is still a paternalistic profession. ${ }^{17}$ Moreover, it is much easier to take control of the care process, because a lot of confidence is needed in order for the care to be handed over to the patient. ${ }^{17}$

The "paternalistic model" (a one way information exchange, where physicians decide about implementing the treatment) ${ }^{20}$ and the "informed model" (physicians inform patients with treatment options, but withholding their own experiences and recommendations to avoid over-influencing patients in their independent choices) ${ }^{20}$ exist for several decades. Evolving from these current practices and moving forward, to "shared", 20,21 "enhanced autonomy"22 or "participatory decision-making"23 partnership models, which describe partnership-working between a healthcare professional and a patient, in the context of decision-making, is required. These 
models share similarities and refer to an open communication-information process; good physician-patient relationship; and sharing power, influence and responsibilities in all stages of the decision-making process. Within these models, patients are empowered to autonomously make treatment choices based on the medical evidence, as well as on the physicians' experience and recommendations. ${ }^{20,22,23}$ Nonetheless, not all of the patients want to be involved or want to be in charge of the decision-making process. ${ }^{24,25}$ Doherty and Doherty ${ }^{26}$ found that $40 \%$ of elderly secondary care patients preferred a collaborative/shared or passive role, while only $20 \%$ chose an active role in decision-making. ${ }^{26}$ Determinants found to be associated with patients' preferences for participation were: younger age, higher education level, having less severe disease, and patients living alone. ${ }^{24}$

The present study reported a difference in endorsement of the patient's role in the process of self-management between female and male healthcare professionals. McGuire et al, $^{19}$ suggested that this might be related to the general assumption that female healthcare professionals are more likely to be good listeners and having more skills for patient's involvement in the decision-making process. Our findings suggested that older healthcare professionals' value the importance of patients' selfmanagement higher than younger healthcare professionals. Nevertheless, a significant difference by age was not observed by Hibbard et al. ${ }^{15}$ In concordance with their study, no significant differences were found among providers with regard to years of practice. Whether age and sex influence empathy and collaborative orientation warrants further investigation in studies with a larger sample size.

Collaborative self-management should be part of PR.,12 Increased patient activation results in improved self-management behaviours. ${ }^{16,27}$ Indeed, healthcare professionals providing PR should be able to offer supportive coaching with an aim to increase patients' involvement and stimulate patients' active role. ${ }^{6,12,17}$ Nonetheless, difficulties of establishing and maintaining a therapeutic partnership between patients and clinicians are being emphasised. ${ }^{28}$ Namely, only $30 \%$ of clinicians involved in the management of respiratory diseases, reported consistencies in helping patients make decisions about their disease and only $33 \%$ of clinicians reported consistency in tailoring medication schedules to the patient's routines. ${ }^{28}$ Within this context, as core clinical competencies of healthcare professionals providing PR, the following are considered: to utilise active listening and behavioural observation skills in assessment of the patient functioning, to demonstrate understanding of the psychosocial issues affecting patient's treatment adherence, to assess patient's needs for psychosocial services in addition to the PR intervention, and to provide supportive counselling to all participants. ${ }^{29}$ Current research shows that healthcare professionals' attitudes toward PR affect the willingness of patients to accept advice or the willingness to participate in a PR programme. ${ }^{30}$ Moreover, PR professionals should facilitate an open discussion with patients which offers time, compassion and understanding as a means of 
facilitating PR uptake. ${ }^{31}$ Hence, the attitudes of healthcare professionals may have influence on the patients' willingness to actively participate in caring for their health.

Assessment of the patients' preferences and needs and enabling them to take an active role in the process of care, is an on-going task for healthcare professionals. ${ }^{17,20,22}$ Moreover, assessing patients' coping styles within the context of patients' active role might be important. ${ }^{32-34}$ Nonetheless, a minority of the educational programmes incorporated into COPD management interventions, was adapted to the patients' individual differences, needs and environment. ${ }^{35}$ Therefore, healthcare professionals need to develop skills to effectively support patients to selfmanage their chronic disease, ${ }^{36}$ which in turn, may potentially help to bridge the confidence gap and improve partnership-working. Acquiring general communication skills/strategies that could facilitate patient's involvement in decision-making is therefore paramount. ${ }^{17,23}$ For example, setting an explicit agenda, communicating with empathy and warmth, and exploring patient's wishes about involvement in discussions and decisions, may support patient's involvement in decision-making. ${ }^{23}$ Additionally, training healthcare professionals in motivational interviewing technique, which has been proven to increase efficiency of office visits and drive successful patients' behavioural outcomes is recommended. . $^{37,38}$

Several limitations of the study should be taken into consideration. First, the limited sample size and the workplace setting in the Netherlands may influence the generalizability of our findings to other healthcare professionals in other countries. Nevertheless, our findings based on the CS-PAM $13^{\mathrm{TM}}$ show similarities with the results demonstrated in a previous study in primary care clinicians in the UK and US. ${ }^{15}$ Second, while the original testing by Hibbard et al, $^{15}$ of the CS-PAM was performed among primary care physicians, nurse practitioners and physicians' assistants; our assessment was conducted among a heterogeneous group of PR healthcare providers. Third, because of the small sample size of the different profession categories, comparing different professions was not possible. Future studies should explore differences between professions. Fourth, the present study did not explore the actual behaviours of healthcare professionals providing PR. Therefore, future studies should explore how beliefs of healthcare professionals toward self-management translate into behaviour to support self-management.

\section{Conclusions and implications for clinical practice}

This study demonstrates that healthcare professionals involved in PR moderately or highly endorse patient self-management. However, the complex relationship between healthcare professionals and their patients, as well as healthcare professionals' selfreported attitudes and their actual practices warrants greater attention and further 
study. In addition, support of the patient's involvement as an independent information seeker in the process of COPD self-management in PR is required. 


\section{References}

1. Mannino DM. COPD: epidemiology, prevalence, morbidity and mortality, and disease heterogeneity. Chest 2002;121(5 suppl I):121S-6S.

2. Vestbo J, Hurd SS, Agusti AG, et al. Global strategy for the diagnosis, management, and prevention of chronic obstructive pulmonary disease: GOLD executive summary. Am J Respir Crit Care Med 2013; 187(4):347-365.

3. Spruit MA, Singh SJ, Garvey C, et al. An official American Thoracic Society/European Respiratory Society statement: key concepts and advances in pulmonary rehabilitation. Am J Respir Crit Care Med 2013;188(8):e13-64.

4. GOLD. Global Strategy for the Diagnosis, Management, and Prevention of Chronic Obstructive Pulmonary Disease (Updated 2013); 2013.

5. NICE. Chronic Obstructive Pulmonary Disease: Management of Chronic Obstructive Pulmonary Disease in Adults in Primary and Secondary Care (partial update). London: National Institute for Health and Clinical Excellence. 2010.

6. Bourbeau J, Nault D, Dang-Tan T. Self-management and behaviour modification in COPD. Patient Educ Couns 2004;52(3):271-7.

7. Wagner EH. Chronic disease management: what will it take to improve care for chronic illness? Eff Clin Pract 1998;1(1):2-4.

8. Coulter A. Engaging Patients in Their Healthcare: How is the UK Doing Relative to Other Countries? Oxford: Picker Institute Europe. 2006.

9. Gwyn R, Elwyn G. When is a shared decision not (quite) a shared decision? Negotiating preferences in a general practice encounter. Soc Sci Med 1999;49(4):437-47.

10. Entwistle VA. Enabling consultations: the facilitative significance of relational aspects of interpersonal communication. Health Expect 2010;13(1):1-3.

11. Lacasse $\mathrm{Y}$, Brosseau L, Milne $\mathrm{S}$, et al. Pulmonary rehabilitation for chronic obstructive pulmonary disease. Cochrane Database Syst Rev 2002;(3):CD003793.

12. Bourbeau J. The role of collaborative self-management in pulmonary rehabilitation. Semin Respir Crit Care Med 2009;30(6):700-7.

13. Spruit MA, Vanderhoven-Augustin I, Janssen PP, Wouters EF. Integration of pulmonary rehabilitation in COPD. Lancet 2008;371(9606):12-3.

14. Insignia Health L. Clinician Support e Patient Activation Measure (CS-PAM) $13^{\mathrm{TM}}$ : License Materials. 2010:1-5.

15. Hibbard JH, Collins PA, Mahoney E, Baker LH. The development and testing of a measure assessing clinician beliefs about patient self-management. Health Expect 2010;13(1):65-72.

16. Hibbard JH, Mahoney ER, Stockard J, Tusler M. Development and testing of a short form of the patient activation measure. Health Serv Res 2005;40(6 Pt 1):1918-30.

17. Blakeman T, Macdonald W, Bower P, Gately C, Chew-Graham C. A qualitative study of GPs' attitudes to self-management of chronic disease. Br J Gen Pract 2006;56(527):407-14.

18. Hamann J, Mendel $\mathrm{R}$, Buhner $\mathrm{M}$, et al. How should patients behave to facilitate shared decision making - the doctors' view. Health Expect 2012;15(4):360-6.

19. McGuire AL, McCullough LB, Weller SC, Whitney SN. Missed expectations? Physicians' views of patients' participation in medical decision-making. Med Care 2005;43(5):466-470.

20. Charles C, Whelan T, Gafni A. What do we mean by partnership in making decisions about treatment? BMJ 1999;319(7212):780-2.

21. Charles C, Gafni A, Whelan T. Shared decision-making in the medical encounter: what does it mean? (or it takes at least two to tango). Soc Sci Med. 1997;44(5):681-92.

22. Quill TE, Brody H. Physician recommendations and patient autonomy: finding a balance between physician power and patient choice. Ann Intern Med 1996;125(9):763-9.

23. Ruiz-Moral R. The role of physician-patient communication in promoting patient-participatory decision making. Health Expect 2010;13(1):33-44. 
24. Deber RB. Physicians in health care management: 8. The patient-physician partnership: decision making, problem solving and the desire to participate. CMAJ 1994;151(4):423-7.

25. Deber RB. Physicians in health care management: 7. The patient-physician partnership: changing roles and the desire for information. CMAJ J1994;151(2):171-6.

26. Doherty C, Doherty W. Patients' preferences for involvement in clinical decision-making within secondary care and the factors that influence their preferences. J Nurs Manag 2005;13(2):119-27.

27. Hibbard JH, Mahoney ER, Stock R, Tusler M. Do increases in patient activation result in improved selfmanagement behaviors? Health Serv Res 2007;42(4):1443-63.

28. Newcomb PA, McGrath KW, Covington JK, Lazarus SC, Janson SL. Barriers to patient-clinician collaboration in asthma management: the patient experience. J Asthma 2010;47(2):192-7.

29. Nici L, Limberg T, Hilling L, et al. Clinical competency guidelines for pulmonary rehabilitation professionals: American Association of Cardiovascular and Pulmonary Rehabilitation position statement. J Cardiopulm Rehabil Prev 2007;27(6):355-8.

30. Harris $D$, Hayter $M$, Allender $S$. Factors affecting the offer of pulmonary rehabilitation to patients with chronic obstructive pulmonary disease by primary care professionals: a qualitative study. Prim Health Care Res Dev 2008;9:280-90.

31. Harrison SL, Robertson N, Apps L, C S M, Morgan MD, Singh SJ. "We are not worthy" - understanding why patients decline pulmonary rehabilitation following an acute exacerbation of COPD. Disabil Rehabil 2014:1-7.

32. Stoilkova A, Wouters EFM, Spruit MA, Franssen FME, Janssen DJA. The relationship between coping styles and clinical outcomes in patients with COPD entering pulmonary rehabilitation. COPD 2013;10(3):316-23.

33. Stoilkova A, Janssen DJA, Franssen FME, Spruit MA, Wouters EFM. Coping styles in patients with COPD before and after pulmonary rehabilitation. Respir Med 2013;107(6):825-33.

34. Wempe JB, Wijkstra PJ. The influence of rehabilitation on behaviour modification in COPD. Patient Educ Couns 2004;52(3):237-41.

35. Stoilkova A, Janssen DJ, Wouters EF. Educational programmes in COPD management interventions: a systematic review. Respir Med 2013;107(11):1637-50.

36. Kosmala-Anderson J, Wallace LM, Turner A, Barwell F. Development and psychometric properties of a self report measure to assess clinicians' practices in self management support for patients with long term conditions. Patient Educ Couns 2011;85(3):475-80.

37. Miller WR, Rose GS. Toward a theory of motivational interviewing. Am Psychol. 2009;64(6):527-37.

38. Rubak S, Sandbaek A, Lauritzen T, Christensen B. Motivational interviewing: a systematic review and meta-analysis. Br J Gen Pract 2005;55(513):305-12. 


\section{Chapter 7}

DISCUSSION

\section{PERSPECTIVES ON EDUCATION IN COPD}

Ana Stoilkova-Hartmann, Frits M.E. Franssen, Ingrid M.L. Augustin, Emiel F.M. Wouters, Katharine D. Barnard 


\section{Abstract}

Medicine is undergoing a revolution that will transform the traditional practice of healthcare into a proactive discipline which will promote patient behaviour change. Whether or not, personalised medicine will yield effective treatment and management solutions without providing a holistic approach to the patient as an individual operating in complex networks, is yet to be determined. Although progress has been made in the development of diagnostics, therapeutics, and care guidelines for patients with chronic obstructive pulmonary disease (COPD), many questions remain with regard to the implementation of best practice in COPD education. In this Perspective, we provide an overview of the current educational programmes, patient's limitations and preference for education, patient-clinician communication and the role of pulmonary rehabilitation in modification of coping styles and behaviour - to understand barriers to optimal COPD education and propose potential solutions. Recommendations on how to personalise activities and/or motivate patients to achieve the goals they perceive as the most important in their daily life, are urgently needed and may help healthcare professionals and funders to realise that one size does not fit all in the vast population of COPD patients. 


\section{Phase of personalised medicine, where are we at the moment?}

Medicine is undergoing a revolution that will transform the traditional, prescriptive, reactive practice of healthcare into a proactive discipline, ${ }^{1}$ which in addition will promote patient behaviour change through more interactive coaching that targets individual problem areas. The U.S. National Institute of Health states: "In the future, research will allow us to predict how, when, and in whom a disease will develop. We can envision a time when we will be able to precisely target treatment on a personalised basis to those who need it, avoiding treatment to those who do not. Ultimately, this individualised approach will allow us to prevent disease before it occurs, utilising the participation of individuals, communities, and healthcare professionals in a proactive fashion, as early as possible, and throughout the natural cycle of a disease process." ${ }^{2}$ Moreover, this will lead to creation of new types of strategic partnerships between patients, physicians, large clinical centres, consortia of clinical centres and patient-advocate groups. ${ }^{1}$

It was in this context that early adopters of the term 'personalised medicine' began to think about a future in which individual genetic variability, newly available on an unprecedented scale, would affect the way that therapeutics would be designed and applied. ${ }^{3}$ Since then, the term has been used broadly to describe medicine that utilises a range of individual variability - from variations of common laboratory measurements to large 'omics' data - in order to provide better applications and dosing of drugs and improved clinical stratification of patients, as well as to identify biomarkers that indicate susceptibility to or severity of disease. ${ }^{4}$ In the traditional disease context, a number of terms have been used interchangeably to describe this approach, including P4 medicine: predictive, preventive, personalised and participatory, ${ }^{1}$ individualised medicine, ${ }^{5}$ precision medicine, ${ }^{6}$ network medicine, ${ }^{7}$ and stratified medicine. ${ }^{8}$

Nevertheless, it remains uncertain whether identifying patients' subgroups through analysis of patients' similarities, such as biomarkers and/or mechanistic pathways resulting from the big data, ${ }^{9}$ will be sufficient when making treatment and management decisions. This type of care might change health care, but can this type of care change patients' behaviours? Whether or not, this new discipline should extend far beyond what is usually covered by the term personalised medicine ${ }^{10}$ and provide a holistic approach to the patient as an individual operating in complex networks, is yet to be determined.

Although education in chronic obstructive pulmonary disease (COPD) is still far from this level of knowledge, we can try to plan personalised, tailored educational programmes taking into account individual patients' clinical, psychological, social and spiritual factors. ${ }^{11}$ 


\section{Educational programmes}

Patient education is a process of teaching and learning of patients in all clinical settings in a planned systematic, sequential and logical manner. ${ }^{12}$ The purpose of patient education is to increase the competence and confidence of patients for selfmanagement, with an ultimate goal - to increase the patients' responsibility and independence for self-care. ${ }^{13}$ However, education alone is insufficient in accomplishing this; in addition, changes in behaviour, especially the acquisition of selfcare skills, are also required. ${ }^{14}$ Thus, self-management education is part and parcel of modern, patient-oriented biopsychosocial care. ${ }^{15}$

Different guidelines attach several meanings to COPD education. According to the American Thoracic Society/European Respiratory Society (ATS/ERS) Statement on pulmonary rehabilitation (PR), ${ }^{16}$ the educational component stands next to exercise training as an essential component of comprehensive PR and promotes adaptive behaviour change, especially collaborative self-management. It lists 15 educational topics concerning self-management education (Table 7.1$){ }^{16}$ nonetheless, almost all are focusing on biomedical issues. The National Institute for Health and Clinical Excellence (NICE) guidelines, ${ }^{17}$ recommends that specific educational packages should be developed for patients with COPD, which should take account of the different needs of patients at different stages of their disease. These guidelines suggest 19 educational topics (Table 7.1). ${ }^{17}$ In the 2007 American College of Chest Physicians (ACCP) and the American Association of Cardiovascular and Pulmonary Rehabilitation (AACVPR) guidelines, ${ }^{18}$ content wise, education should include information on collaborative self-management, specifically, on the prevention and treatment of exacerbations only. Interestingly, in its updated guideline from 2011, "19 "education" is mentioned only once, while naming the main components of most reported PR programmes, next to endurance and exercise training, behavioural modification and outcome assessment. In this context, it is striking to see that "education" is not included in the Global initiative for chronic Obstructive Lung Disease (GOLD) guidelines. $^{20}$ 
Table 7.1 Educational topics in the current COPD guidelines.

\begin{tabular}{|c|c|}
\hline $\begin{array}{l}\text { American Thoracic Society/European } \\
\text { Respiratory Society (ATS/ERS) } \\
\end{array}$ & $\begin{array}{l}\text { The National Institute for Health and Clinical } \\
\text { Excellence (NICE) }\end{array}$ \\
\hline Normal pulmonary anatomy and physiology & $\begin{array}{l}\text { Disease education (anatomy, physiology, pathology } \\
\text { and pharmacology, including oxygen therapy \& } \\
\text { vaccination) }\end{array}$ \\
\hline Pathophysiology of chronic respiratory disease & $\begin{array}{l}\text { Dyspnoea/symptom management, including chest } \\
\text { clearance techniques }\end{array}$ \\
\hline Communicating with the health care provider & Smoking cessation \\
\hline Interpretation of medical testing & Energy conservation/ pacing \\
\hline Breathing strategies & Nutritional advice \\
\hline Secretion clearance techniques & Managing travel \\
\hline $\begin{array}{l}\text { Role and rationale for medications, including } \\
\text { oxygen therapy }\end{array}$ & Benefits system and disable parking badges \\
\hline Effective use of respiratory devices & Advance directives (living wills) \\
\hline Benefits of exercise and physical activities & Making a change plan \\
\hline Energy conservation during activities of daily living & Anxiety management \\
\hline Healthy food intake & Goal setting and rewards \\
\hline Irritant avoidance & Relaxation \\
\hline Early recognition and treatment of exacerbations & $\begin{array}{l}\text { Identifying and changing beliefs about exercise and } \\
\text { health related behaviours }\end{array}$ \\
\hline Leisure activities & Loving relationships/sexuality \\
\hline Coping with chronic lung disease & $\begin{array}{l}\text { Exacerbation management (including when to seek } \\
\text { help, self-management and decision making, coping } \\
\text { with setbacks and relapses) } \\
\text { Home care support } \\
\text { Managing surgery (non-thoracic) } \\
\text { The benefits of physical exercise } \\
\text { Support groups - such as the British Lung Foundation } \\
\text { Breathe Easy groups, which operate throughout the } \\
\text { UK }\end{array}$ \\
\hline
\end{tabular}

Current practices in COPD education were summarised in our recent systematic review investigating educational programmes integrated in current COPD management interventions aimed at facilitating skills and knowledge of COPD patients. ${ }^{21}$ Eighty-one published studies, describing 67 interventions were identified. Subsequently, there was a need for additional data and/or clarification of data which were provided from majority $(n=43)$ of contacted corresponding authors of the included studies. We reported that over half of educational interventions had 
$\geq 10$ topics incorporated within a programme. Twelve educational topics were the most included, with the following topics frequently addressed: smoking cessation, medication, exercise, breathing strategies, exacerbations, and stress management. However, we did not seek to identify whether any specific educational topics were more successful than others in contributing to behaviour change and successful COPD management. Nevertheless, this review underscored the heterogeneity of the educational topics and models, highlighting the inconsistent approach to teaching patients with COPD and the lack of process evaluation to demonstrate which aspects of the teaching are most effective in changing patients' behaviour. ${ }^{21}$

Despite the continued investment of time, effort and resources, best practice in COPD education remains unclear. Researchers undertaking systematic reviews in education of COPD patients frequently identify the lack of detailed reporting and the large variation of educational interventions as an issue. ${ }^{21-23}$ In 2003, Monninkhof et al., ${ }^{23}$ had difficulty to clarify the effectiveness of self-management educational programmes in COPD. It was due to heterogeneity in interventions, a broad spectrum of outcome parameters with different follow up periods, variety of diagnostic criteria used in defining the COPD population, as well as because of the fact that most of the studies included in their review were not aimed at improving self-management skills or behavioural change. Few years later, the problem persisted, with Effing et al., ${ }^{22}$ unable to draw clear conclusions about the form and contents of self-management education programmes in COPD included in their systematic review due to the similar inconsistencies.

The consistent appeal from authors of systematic reviews is for improved detail in the reporting of the educational content, mode of delivery of educational interventions for COPD, as well as for employment of more rigorous study designs and methodology, and the use of robust outcome measures. ${ }^{21-23}$ Reporting guidelines in the form of a checklist, flow diagram or explicit text provide a way for research reporting to be consistent and transparent. ${ }^{24}$ The reporting guidelines specific to study design, such as STROBE for observational studies, ${ }^{25}$ CONSORT for randomised trials ${ }^{26}$ and PRISMA for systematic reviews and meta-analysis ${ }^{21,27}$ have led to greater accuracy in the reporting of health research. ${ }^{28}$ Moreover, a position statement on structured education which will provide the evidence on when- and what-strategies for the provision of education and support services to all adults living with COPD, as it has been provided elsewhere, ${ }^{29}$ is an imperative. 


\section{Barriers to optimal education}

\section{Adaptation to an individual patient and patient's limitations: One size does not fit all}

In the majority of the studies incorporating educational programmes, all patients in the intervention group received the same educational curriculum, whereas in a minority of the studies, the educational component was tailored to some extent according to the patients' characteristics. ${ }^{21}$ In contrast to the current practices of conducting COPD education, the heterogeneous group of COPD patients frequently experience high level of anxiety, depression and impaired coping with the disease which increases their personal vulnerability. ${ }^{30-32}$ Furthermore, patients with COPD are characterised by substantial variety in health status and an increased risk of comorbid diseases. COPD patients commonly suffer from cognitive deterioration and functional impairments in activities of daily living. ${ }^{33,34}$ Hence, they often require the support of partners, relatives and/or caregivers. ${ }^{11,15,33}$ Their health can change rapidly, requiring urgent and expensive treatment, while recovery may be slower, longer and partial necessitating long term health and social care. These aforementioned issues suggest that the individualisation of the educational programmes, potentially based on subtyping of COPD severity, comorbidities, level of anxiety, depression and coping styles is warranted. Moreover, patients' complex health condition requires the collaboration and coordination between a wide spectrum of health and social care professionals, as well as partners and relatives. ${ }^{15,21}$

\section{Patient-clinician communication: HCPs teaching skills vs. patients' learning skills}

Patient-clinician communication is important in order to enhance quality of care for patients with COPD by empowering and engaging patients in better disease management. ${ }^{35}$ Healthcare professionals (HCPs) may have a desire to motivate their patients and they generally may support the idea of a patient's active role and partnership-working in the process of COPD management. ${ }^{36}$ However, they often lack the power and skills to do so. Typically, HCPs interrupt their patients 18 seconds into their conversation; in $50 \%$ of consultations patients and HCPs disagree on the central problem presented, as well as approximately half of patients' concerns are not discussed. ${ }^{37}$ In todays', although increasingly criticised, still paternalistic healthcare system, HCPs expect that they are the medical decision makers and patients have a passive role as recipients - "expert" doctor directing submissive patient. ${ }^{36,38}$ Conversely, patients with COPD may lack motivation or they may be motivated to achieve their own (different) goals. Additionally, teaching does not guarantee learning and learning cannot occur without a good educator. ${ }^{39}$ Parallel to HCPs' teaching skills, 
which are specific evidence-based content skills relevant to COPD, they should be able to demonstrate psychosocial skills to facilitate patients' behaviour change: listening, empathy, understanding how adults learn, stimulate learners' motivation toward the desire to change and take responsibility for the change process, elicit learners' feedback and allow time for personal reflection. ${ }^{40}$ Major deficits in undergraduate HCPs' education; feelings of anxiety, unpreparedness and insecurity in their patient education; as well as underestimating the difficulty of HCPs' managing change and reshaping thinking, misjudging their skills and whether they are able to integrate this with their other roles, are pointed out as reasons for this mismatch in preparedness for effective patient-clinicians communication. ${ }^{40-42}$ Therefore, effective strategies for teaching communication and assessment of the HCPs' perceived competence and attitudes in caring for these patients are critical to success. ${ }^{43}$ On the other hand, many barriers to learning are present in COPD patients. Some of these factors can have a great impact on the lives of COPD patients and result in situations in which they are unable to learn productively: presence of daily symptoms such as shortness of breath and fatigue, exacerbations, complications such as chronic hypoxemia, comorbidities, invalidity leading to early retirement and financial problems, social isolation, stress, anxiety and depression, important changes in family roles and involvement and stigma reducing self-esteem and enhanced dependency on others for care. Consequently, memory dysfunctions are common in COPD patients. Deficits in verbal short-term and long-term memory, ${ }^{44,45}$ in visual memory, ${ }^{46}$ and in spatial memory ${ }^{47}$ were documented by the majority of researchers. Self-management education programmes for COPD patients must ensure that all these barriers are taken into account in the planning and implementation of educational interventions in order to lead to efficient results. Moreover, exclusion of the people with low literacy or learning disabilities from the development process of patient-reported outcome measures may result in measures and health systems that are inherently unequal in terms of quality of care delivered across different social groupings. ${ }^{48}$

\section{Behaviour change and the role of patient's psychology}

Distressing and disabling chronic illness, challenges patients' effective coping, ${ }^{49}$ whereas previous coping styles certainly impact how patients react under the stress of chronic illness. ${ }^{50}$ As an adaptive response to a chronic illness, coping is defined as selecting and acting on the information derived from the individual's symptom recognition and interpretation. ${ }^{51}$ Some patients deal with their duties and difficulties, which are the result of their confrontation and evaluation of their chronic illness, more successfully than others. ${ }^{52}$ It is worth noting that when compared to the general population, COPD patients rely less on problem-focused coping styles (e.g. active confronting coping style) needed for acting upon the illness or modifying the situation, which may result in better adjustment with regard to the patient's disease. ${ }^{53}$ A passive 
reaction pattern coping style in patients with advanced COPD, was related to an impaired level of daily functioning; ${ }^{54}$ whereas, inability to cope with the effects of their disease was linked to an increased mortality. ${ }^{55}$ In addition, poor coping is further suggested by maladaptive behaviours such as non-adherence to lifestyle recommendations, missing medical appointments, not taking prescribed medication, or avoiding laboratory testing. ${ }^{56}$ In turn, these patients' behaviours may be associated with judgements by HCPs which actually deter patients from engaging, resulting in an ever-decreasing circle of poor coping and poor healthcare responses leading to even greater isolation, poorer coping and poor health outcomes. A more individualised and empathic healthcare system may help in avoiding this circulus vitiosus.

Having strong support systems enhances resilience and widens access to coping strategies, ${ }^{56}$ thus, learning effective coping styles is particularly important for patients with COPD. Moreover, adequate coping styles are important for self-management of COPD. ${ }^{57,58}$ Knowledge of the patient's baseline coping styles and a high index of suspicion for factors that threaten resilience, are essential to accurate assessment and achievement of optimal patient coping. ${ }^{59}$ Recognition of the differing patterns helps to inform healthcare provider responses that, if tailored appropriately, will be perceived as supportive rather than confrontational. ${ }^{60}$

\section{Patients' preference for education / information}

A collaborative care approach to COPD management has long been advocated, by which care is individualised, with the person with COPD at the heart of decisionmaking. ${ }^{16}$ Furthermore, person-centred care refers to care that is respectful of and responsive to individual patient preferences, needs, strengths, future plans and rights and ensuring that patient's values guide all clinical decisions. ${ }^{61}$ It implicates actively involved patients, as partners, in their care throughout the hospital stay and beyond. ${ }^{62}$ What person-centred care means in practice, however, remains unclear.

Patients identify a variety of educational topics important when living with COPD, including managing anxiety and relaxation techniques, chest clearance, recognising symptoms of an exacerbation and its subsequent management, energy conservation, managing relationships (and sexuality), and healthy eating. ${ }^{63}$ Some of these defer from the educational topics suggested by clinical practice guidelines and position statements. Incorporating case studies was recognised as being an important teaching method which provides opportunities for patients to normalise their experiences and learn through peer comparisons. Additionally, some patients recognise that the physicians are unlikely to be the most suitable educators because they lack the psychosocial skill set required in this regard; while in contrast, psychologists, who are skilled in empathy, compassion, exploring ambiguity and guiding patients in appropriate decision-making strategies, but rarely involved in the educational interventions, may have greater success in facilitating sustainable behavioural 
change. $^{21,63-65}$ Furthermore, individual preferences for receipt of information about the disease (as much information at the earliest stage of the disease vs. staggered education for an individual with a new diagnosis) and the manner in which that information is delivered (face-to-face contact with a HCP or telephone contact) vary as well. $^{63}$ Thus, suggesting that not all patients with chronic conditions may be able and/or willing to be an equal partner and equally participate in decision-making about their own management or to be fully involved in their care.

\section{Modification of coping styles and behaviour by pulmonary rehabilitation}

Pulmonary rehabilitation (PR) in COPD refers to the collaboration among the patient and HCPs, with one of the goals, to promote the long-term adherence to healthenhancing behaviours. ${ }^{16}$ Behaviour change with PR starts with education of the HCP and patient on the health benefits of this comprehensive intervention. ${ }^{66}$ However, this will first require better understanding of the complexity of behaviour change, followed by more effective behaviour modification strategies. ${ }^{16,67}$

Even though, coping styles seem to be important for the maintenance of postrehabilitation effects, ${ }^{68}$ the effect of PR on coping styles of patient with COPD has rarely been studied. Coping styles of patients with COPD entering PR, although not associated with disease-specific health status, they were shown to contribute to patients' symptoms of anxiety, depression and exercise tolerance. ${ }^{30}$ Following these findings, in a longitudinal study assessing coping styles of COPD patients before and after PR, we demonstrated that comprehensive PR, even without an inclusion of intervention aiming at changing patient's coping, can in fact change patients' coping styles. ${ }^{31}$ For instance, the levels of avoidance, passive reaction pattern and reassuring thoughts coping styles decreased, whereas the level of active confronting coping style increased following PR. ${ }^{31}$ We concluded that these changes in coping styles can be considered as positive outcome of PR. In other words, patients with COPD after PR will be more willing to confront their situation and address the problems resulting from their chronic disease. In concordance with our previous study, ${ }^{30}$ this study noted that coping styles may be determinants of improvement in: exercise tolerance, anxiety and depression. ${ }^{31}$ Furthermore, in order to compare changes in coping styles of patients undergoing PR, we looked for a profile of response to PR in 439 COPD patients based on a pre-defined cut-off threshold level of a composite outcome measure improvements in either disease-specific health status and/or exercise tolerance. ${ }^{32}$ Analysis led to clustering of patients into three groups with different response profiles and different prevalence: "good responder" (54.0\%), "moderate responder" (22.1\%) and "non-responder" (23.9\%). The "good responder" had more severe dyspnoea, 
anxiety and depression; worse exercise tolerance and disease-specific health status; higher level of passive reaction pattern coping style and was more likely to report larger decrease in the level of passive reaction pattern coping style following PR, compared with the other two categories. Interestingly, within the groups, changes in coping styles after PR occurred among the "good responders", whereas the majority of coping styles of "moderate responders" and "non-responders" were not significantly influenced by PR. Despite that this PR programme was not containing coping behaviour intervention; it suggests that maybe PR can be a venue for such interventions. Furthermore, whether including interventions targeting coping styles may modify coping behaviour of COPD patients, as well as improvement in exercise tolerance or health status after PR needs to be determined. Finally, these findings emphasise that the key performance measures to evaluate effectiveness of PR programmes have to integrate what patients perceive in their daily life, including the adaptation into the limitations caused by the disease, as well as they have to be selected within multiple domains. ${ }^{11,69}$

\section{Kaleidoscope Model of Care}

A model of care for people living with diabetes, the Kaleidoscope Model of Care, which is at the same time cohesive, holistic and tailored to individual needs to support optimum diabetes outcomes and which helps to understand the driving forces behind behaviour and their impact on diabetes management, has been proposed by professor Barnard and colleagues. ${ }^{70}$ The model incorporates external factors, such as social support (or lack thereof), environment and lifestyle; regimen factors, such as therapies, devices and education; and intrinsic personal drivers. These are separated into distinct but linked core components that interact to reflect individual experience and priorities for specific treatment needs.

Nevertheless, these factors, whilst not necessarily diabetes-specific, impact an individual's ability for optimal self-management and thus, may be applicable to patients with COPD as well. These concepts as presented in the Kaleidoscope Model of Care were used in a model proposed for patients with COPD (Figure 7.1).

Two additional components were applied to create this adapted model: coping styles of patients with COPD (as part of the personal factors) and the role of HCPs (as part of the regimen factors). Namely, while coping in diabetes has received substantial attention in the past decade; $;^{71,72}$ research on coping in COPD is rather scarce. Furthermore, several studies in patients with diabetes found consistent evidence that depression and anxiety symptoms which are linked to adverse health outcomes and worse well-being, were associated with coping styles. ${ }^{73-75}$ This is in concordance with 
our research. ${ }^{30,31}$ The role of the HCPs in the process of patients' self-management and partnership-working was addressed earlier. ${ }^{36}$

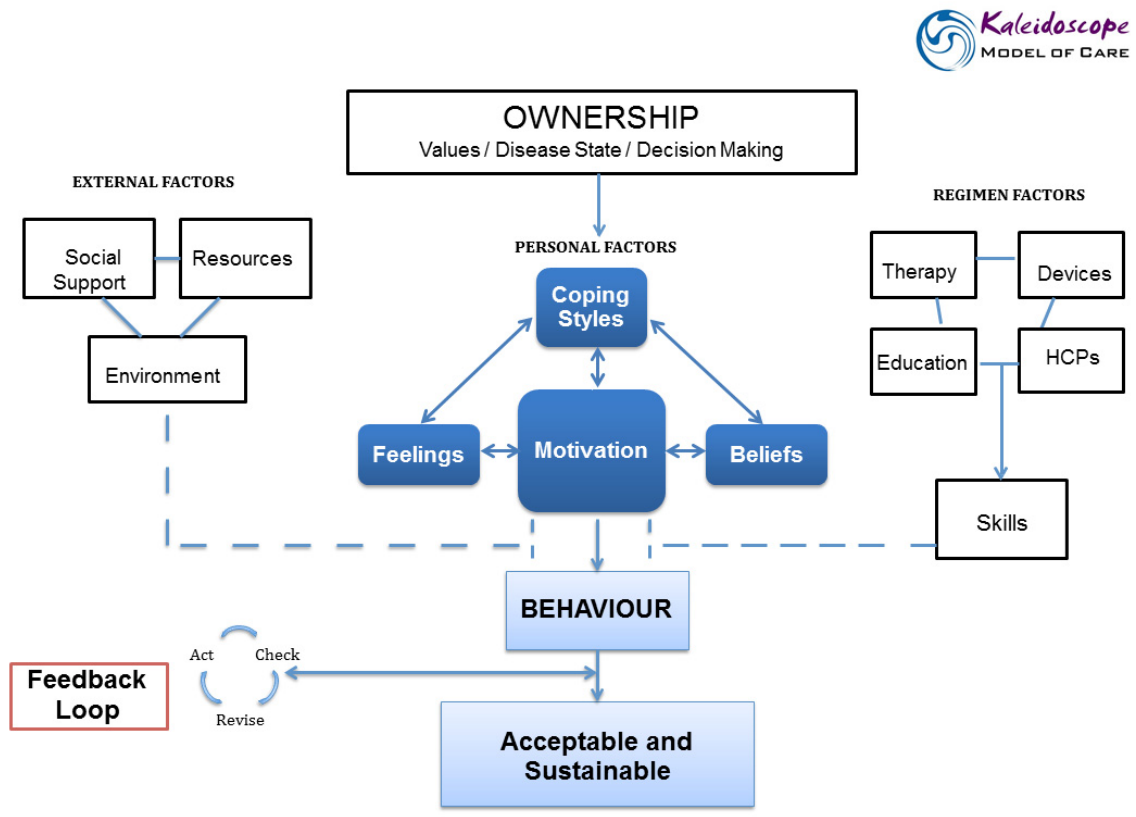

Figure 7.1 Adapted Kaleidoscope Model of Care.

\section{KALMOD - sustainable intervention for COPD management}

As a novel model in the field of diabetes care, which supports HCPs in providing care pathways that are mapped to an individual's priorities and present the basis for an individualised care plan of holistic diabetes care has been proposed KALMOD Behaviours for Health. Based on the Kaleidoscope Model of Care, ${ }^{70}$ KALMOD addresses the pressing need by providing an enhanced decision support system with predictive personalised risk modelling, to increase individual awareness, to facilitate provision of and access to best-fit care pathways based on clinical, therapeutic, behavioural, environmental and lifestyle factors thus, targeting the whole-life priorities and concerns of people with diabetes for optimal health outcomes. Information alone is insufficient to promote sustained action. KALMOD is a dynamic, motivational, person-centred approach that helps individuals understand their own personal risk factors, their own barriers and facilitators to optimal self-management, 
and the potential benefits of any given behaviour change in the context of their own lived experience.

KALMOD is an individually tailored intervention, it comprises a brief personalised assessment used by the individual with diabetes and completed by the HCP with medical results, aligned to highly efficient and effective clinical care based on individuals' identified needs. These priorities/needs are immediately mapped via algorithm to provide personalised predictive outcomes and potential care pathways available to facilitate person-centred, joint goal-setting, co-decision making consultations in order to enhance diabetes self-management and improve overall health.

The intervention, applied as a practical tool (on personal mobile technology such as smartphone, tablet or computer), may also be suitable for patients with COPD (see Figure 7.2 for adapted KALMOD intervention process). Nonetheless, although KALMOD is based on established psychological theory, it is important to evaluate its feasibility, effectiveness and acceptability for COPD patients and professionals, through a rigorous clinical trial programme that assesses biomedical and psychosocial outcomes.

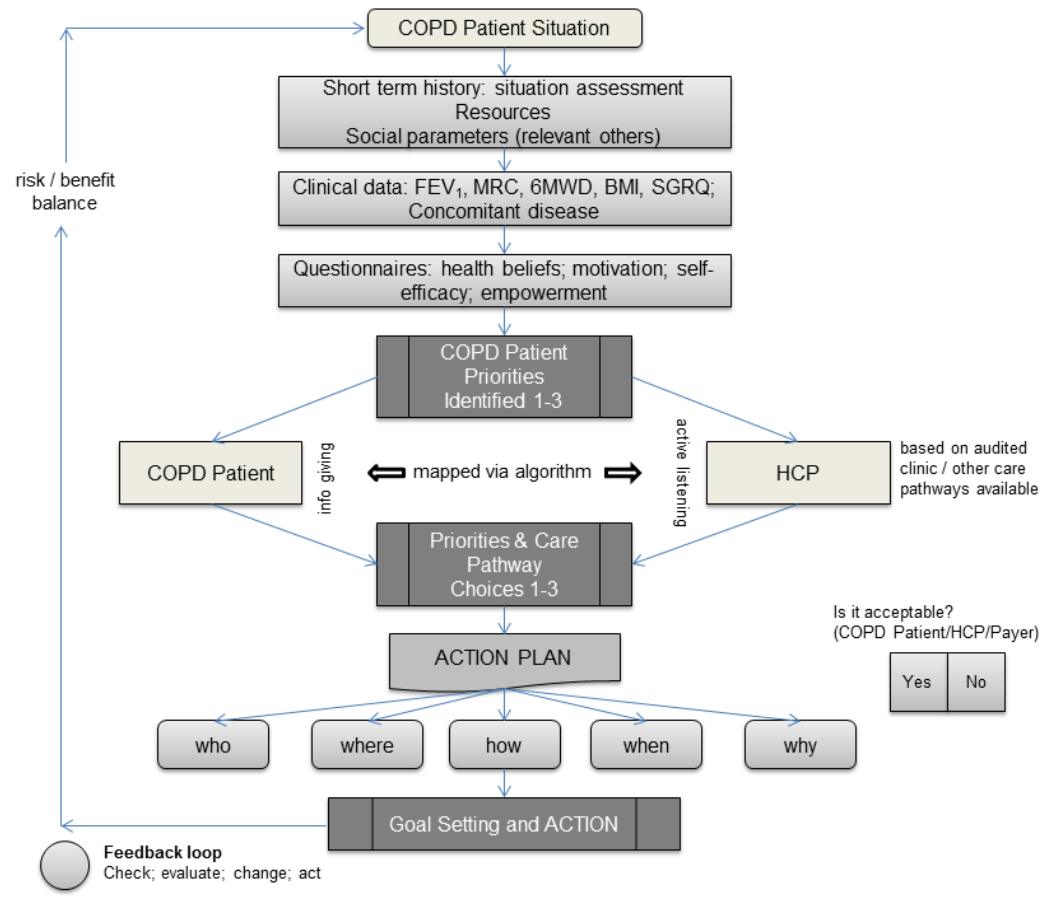

Figure 7.2 Adapted KALMOD intervention process. 


\section{Conclusion}

Inconsistent and incomplete reporting of information in educational interventions for COPD patients is common, thereby limiting the ability to compare, interpret and synthesise findings from these studies. Despite the recommendations from the current practice guidelines that education should be tailored to the individual patient, still all patients receive the same educational curriculum. HCPs need to develop skills to effectively support patients to self-manage their chronic disease, which in turn, may potentially help to bridge the confidence gap and improve partnership-working. ${ }^{36}$ Moreover, motivating patients and their family to adopt behaviours that will help them manage illness requires effective teaching based on understanding the individual needs of the patient. Therefore, assessment of individual patients' educational needs and preferences, as well as engaging patients and innovative thinkers in the development of solutions is crucial.

The adapted Kaleidoscope Model of Care may present a mechanism whereby patients with COPD are able to bring expertise about their lived experience to the consultation by recognising the barriers to their own self-management, identifying priorities for action and engaging in collaborative goal-setting with their HCP on an equal basis. ${ }^{70}$ Within this context, the novel approach KALMOD - Behaviours for Health differs from traditional medical model interventions by repositioning control of COPD management. It may optimise patient empowerment, individual awareness and predictive modelling to reduce personal uncertainties, exploring whole-life factors that impact COPD care and improving interactions between individuals and HCPs. Nonetheless, health economic evaluation will be needed to determine short-term and long-term cost-effectiveness of this simple and safe enhanced holistic decision support system which may positively support appropriate and effective COPD selfmanagement. 


\section{References}

1. Hood L, Friend SH. Predictive, personalized, preventive, participatory (P4) cancer medicine. Nat Rev Clin Oncol 2011;8:184-7.

2. Jeraj R. Future of physics in medicine and biology. Acta Oncol 2009;48:178-84.

3. Langreth $\mathrm{R}$, Waldholz $\mathrm{M}$. New era of personalized medicine: targeting drugs for each unique genetic profile. Oncologist 1999;4:426-7.

4. Agusti A, Bel E, Thomas M, Vogelmeier C, Brusselle G, Holgate S, et al. Treatable traits: toward precision medicine of chronic airway diseases. The European respiratory journal 2016;47:410-9.

5. Shastry BS. Pharmacogenetics and the concept of individualized medicine. Pharmacogenomics $J$ 2006;6:16-21.

6. Collins FS, Varmus H. A new initiative on precision medicine. N Engl J Med 2015;372:793-5.

7. Silverman EK, Loscalzo J. Developing new drug treatments in the era of network medicine. Clin Pharmacol Ther 2013;93:26-8.

8. Hall IP. Stratified medicine: drugs meet genetics. Eur Respir Rev 2013;22:53-7.

9. Gomez-Cabrero D, Abugessaisa I, Maier D, Teschendorff A, Merkenschlager M, Gisel A, et al. Data integration in the era of omics: current and future challenges. BMC Syst Biol 2014;8 Suppl 2:I1.

10. Redekop WK, Mladsi D. The faces of personalized medicine: a framework for understanding its meaning and scope. Value Health 2013;16:S4-9.

11. Almagro $P$, Castro A. Helping COPD patients change health behavior in order to improve their quality of life. Int J Chron Obstruct Pulmon Dis 2013;8:335-45.

12. Dreeben O. Patient education in rehabilitation: Jones and Bartlett Publishers, LLC; 2010.

13. Bourbeau J, Julien M, Maltais F, Rouleau M, Beaupre A, Begin R, et al. Reduction of hospital utilization in patients with chronic obstructive pulmonary disease: a disease-specific self-management intervention. Arch Intern Med 2003;163:585-91.

14. Rice K, Bourbeau J, MacDonald R, Wilt TJ. Collaborative self-management and behavioral change. Clin Chest Med 2014;35:337-51.

15. Kaptein AA, Fischer MJ, Scharloo M. Self-management in patients with COPD: theoretical context, content, outcomes, and integration into clinical care. Int J Chron Obstruct Pulmon Dis 2014;9:907-17.

16. Spruit MA, Singh SJ, Garvey C, ZuWallack R, Nici L, Rochester C, et al. An official American Thoracic Society/European Respiratory Society statement: key concepts and advances in pulmonary rehabilitation. Am J Respir Crit Care Med 2013;188:e13-64.

17. National Clinical Guideline Centre. (2010) Chronic obstructive pulmonary disease: management of chronic obstructive pulmonary disease in adults in primary and secondary care. London: National Clinical Guideline Centre: Available from: http://guidance.nice.org.uk/CG101/Guidance/pdf/English.

18. Ries AL, Bauldoff GS, Carlin BW, Casaburi R, Emery CF, Mahler DA, et al. Pulmonary Rehabilitation: Joint ACCP/AACVPR Evidence-Based Clinical Practice Guidelines. Chest 2007;131:4S-42S.

19. Qaseem A, Wilt TJ, Weinberger SE, Hanania NA, Criner G, van der Molen T, et al. Diagnosis and management of stable chronic obstructive pulmonary disease: a clinical practice guideline update from the American College of Physicians, American College of Chest Physicians, American Thoracic Society, and European Respiratory Society. Annals of internal medicine 2011;155:179-91.

20. Vestbo J, Hurd SS, Agusti AG, Jones PW, Vogelmeier C, Anzueto A, et al. Global strategy for the diagnosis, management, and prevention of chronic obstructive pulmonary disease: GOLD executive summary. Am J Respir Crit Care Med 2013;187:347-65.

21. Stoilkova A, Janssen DJ, Wouters EF. Educational programmes in COPD management interventions: a systematic review. Respir Med 2013;107:1637-50.

22. Effing T, Monninkhof EM, van der Valk PD, van der Palen J, van Herwaarden $\mathrm{CL}$, Partidge $\mathrm{MR}$, et al. Self-management education for patients with chronic obstructive pulmonary disease. Cochrane Database Syst Rev 2007:CD002990.

23. Monninkhof EM, van der Valk PD, van der Palen J, van Herwaarden CL, Partidge MR, Walters EH, et al. Self-management education for chronic obstructive pulmonary disease. Cochrane Database Syst Rev 2003:CD002990. 
24. Simera I, Altman DG, Moher D, Schulz KF, Hoey J. Guidelines for reporting health research: the EQUATOR network's survey of guideline authors. PLoS Med 2008;5:e139.

25. STROBE statement--checklist of items that should be included in reports of observational studies (STROBE initiative). Int J Public Health 2008;53:3-4.

26. Schulz KF, Altman DG, Moher D. CONSORT 2010 Statement: updated guidelines for reporting parallel group randomised trials. BMC Med 2010;8:18.

27. Moher D, Liberati A, Tetzlaff J, Altman DG. Preferred reporting items for systematic reviews and meta-analyses: the PRISMA statement. PLoS Med 2009;6:e1000097.

28. Turner L, Shamseer L, Altman DG, Weeks L, Peters J, Kober T, et al. Consolidated standards of reporting trials (CONSORT) and the completeness of reporting of randomised controlled trials (RCTs) published in medical journals. The Cochrane database of systematic reviews 2012;11:MR000030.

29. Powers MA, Bardsley J, Cypress M, Duker P, Funnell MM, Hess Fischl A, et al. Diabetes Selfmanagement Education and Support in Type 2 Diabetes: A Joint Position Statement of the American Diabetes Association, the American Association of Diabetes Educators, and the Academy of Nutrition and Dietetics. Diabetes Care 2015;38:1372-82.

30. Stoilkova A, Wouters EFM, Spruit MA, Franssen FME, Janssen DJA. The relationship between coping styles and clinical outcomes in patients with COPD entering pulmonary rehabilitation. COPD: Journal Of Chronic Obstructive Pulmonary Disease 2013;10:316-23.

31. Stoilkova A, Janssen DJA, Franssen FME, Spruit MA, Wouters EFM. Coping styles in patients with COPD before and after pulmonary rehabilitation. Respir Med 2013;107:825-33.

32. Stoilkova-Hartmann A, Janssen DJ, Franssen FM, Wouters EF. Differences in change in coping styles between good responders, moderate responders and non-responders to pulmonary rehabilitation. Respir Med 2015;109:1540-5.

33. Janssen DJ, Wouters EF, Spruit MA. Psychosocial consequences of living with breathlessness due to advanced disease. Current opinion in supportive and palliative care 2015;9:232-7.

34. Cleutjens FA, Janssen DJ, Ponds RW, Dijkstra JB, Wouters EF. COgnitive-pulmonary disease. BioMed research international 2014;2014:697825.

35. Slatore CG, Cecere LM, Reinke LF, Ganzini L, Udris EM, Moss BR, et al. Patient-clinician communication: associations with important health outcomes among veterans with COPD. Chest 2010;138:628-34.

36. Stoilkova-Hartmann A, Janssen DJ, Franssen FM, Spruit MA, Wouters EF. Attitudes of healthcare professionals providing pulmonary rehabilitation toward partnership in care. Heart Lung 2015;44:347-52.

37. Barnard KD, Cradock S, Parkin T, Skinner TC. Effectiveness of a computerised assessmenttool to prompt individuals with diabetes tobe more active in consultations. Pract Diabetes Int 2007;24:36-41.

38. Rodriguez-Osorio CA, Dominguez-Cherit G. Medical decision making: paternalism versus patientcentered (autonomous) care. Curr Opin Crit Care 2008;14:708-13.

39. Gessner BA. Adult education. The cornerstone of patient teaching. Nurs Clin North Am 1989;24: 589-95.

40. Bourbeau J, van der Palen J. Promoting effective self-management programmes to improve COPD. The European respiratory journal 2009;33:461-3.

41. Kwekkeboom KL, Vahl C, Eland J. Companionship and education: a nursing student experience in palliative care. J Nurs Educ 2005;44:169-76.

42. Zakrisson AB, Hagglund D. The asthma/COPD nurses' experience of educating patients with chronic obstructive pulmonary disease in primary health care. Scand J Caring Sci 2010;24:147-55.

43. Lippe MP, Becker H. Improving Attitudes and Perceived Competence in Caring for Dying Patients: An End-of-Life Simulation. Nurs Educ Perspect 2015;36:372-8.

44. Kozora E, Tran ZV, Make B. Neurobehavioral improvement after brief rehabilitation in patients with chronic obstructive pulmonary disease. J Cardiopulm Rehabil 2002;22:426-30.

45. Ortapamuk $\mathrm{H}$, Naldoken S. Brain perfusion abnormalities in chronic obstructive pulmonary disease: comparison with cognitive impairment. Ann Nucl Med 2006;20:99-106.

46. Kozora E, Make BJ. Cognitive improvement following rehabilitation in patients with COPD. Chest 2000;117:249S. 
47. Borak J, Sliwinski P, Tobiasz M, Gorecka D, Zielinski J. Psychological status of COPD patients before and after one year of long-term oxygen therapy. Monaldi Arch Chest Dis 1996;51:7-11.

48. Jahagirdar D, Kroll T, Ritchie K, Wyke S. Patient-reported outcome measures for chronic obstructive pulmonary disease : the exclusion of people with low literacy skills and learning disabilities. Patient 2013;6:11-21.

49. Blumenthal JA, Emery CF, Smith PJ, Keefe FJ, Welty-Wolf K, Mabe S, et al. The effects of a telehealth coping skills intervention on outcomes in chronic obstructive pulmonary disease: primary results from the INSPIRE-II study. Psychosom Med 2014;76:581-92.

50. Mohr C, Braun S, Bridler R, Chmetz F, Delfino JP, Kluckner VJ, et al. Insufficient coping behavior under chronic stress and vulnerability to psychiatric disorders. Psychopathology 2014;47:235-43.

51. O'Neill ES. Illness representations and coping of women with chronic obstructive pulmonary disease: a pilot study. Heart Lung 2002;31:295-302.

52. Lazarus RS, Folkman S. Stress, appraisal and coping. New York: Springer; 1984.

53. Scharloo M, Kaptein AA, Weinman JA, Willems LN, Rooijmans HG. Physical and psychological correlates of functioning in patients with chronic obstructive pulmonary disease. J Asthma 2000;37:17-29.

54. Scharloo M, Kaptein AA, Weinman J, Hazes JM, Willems LN, Bergman W, et al. Illness perceptions, coping and functioning in patients with rheumatoid arthritis, chronic obstructive pulmonary disease and psoriasis. J Psychosom Res 1998;44:573-85.

55. Ashutosh K, Haldipur C, Boucher ML. Clinical and personality profiles and survival in patients with COPD. Chest 1997;111:95-8.

56. Grady KL, Wang E, White-Williams C, Naftel DC, Myers S, Kirklin JK, et al. Factors associated with stress and coping at 5 and 10 years after heart transplantation. J Heart Lung Transplant 2013;32: 437-46.

57. McCathie HC, Spence SH, Tate RL. Adjustment to chronic obstructive pulmonary disease: the importance of psychological factors. Eur Respir J 2002;19:47-53.

58. Monninkhof E, van der Aa M, van der Valk P, van der Palen J, Zielhuis G, Koning K, et al. A qualitative evaluation of a comprehensive self-management programme for COPD patients: effectiveness from the patients' perspective. Patient Educ Couns 2004;55:177-84.

59. Blount RL, Simons LE, Devine KA, Jaaniste T, Cohen LL, Chambers CT, et al. Evidence-based assessment of coping and stress in pediatric psychology. J Pediatr Psychol 2008;33:1021-45.

60. Ramfelt E, Lutzen K. Patients with cancer: their approaches to participation in treatment plan decisions. Nurs Ethics 2005;12:143-55.

61. Leplege A, Gzil F, Cammelli M, Lefeve C, Pachoud B, Ville I. Person-centredness: conceptual and historical perspectives. Disabil Rehabil 2007;29:1555-65.

62. Olsson LE, Jakobsson Ung E, Swedberg K, Ekman I. Efficacy of person-centred care as an intervention in controlled trials - a systematic review. J Clin Nurs 2013;22:456-65.

63. Apps LD, Mitchell KE, Harrison SL, Sewell L, Williams JE, Young HM, et al. The development and pilot testing of the self-management programme of activity, coping and education for chronic obstructive pulmonary disease (SPACE for COPD). Int J Chron Obstruct Pulmon Dis 2013;8:317-27.

64. Bourbeau J, Nault D, Dang-Tan T. Self-management and behaviour modification in COPD. Patient Educ Couns 2004;52:271-7.

65. Michie S. Designing and implementing behaviour change interventions to improve population health. $J$ Health Serv Res Policy 2008;13 Suppl 3:64-9.

66. Rochester CL, Vogiatzis I, Holland AE, Lareau SC, Marciniuk DD, Puhan MA, et al. An Official American Thoracic Society/European Respiratory Society Policy Statement: Enhancing Implementation, Use, and Delivery of Pulmonary Rehabilitation. Am J Respir Crit Care Med 2015;192:1373-86.

67. Sohanpal R, Steed L, Mars T, Taylor SJ. Understanding patient participation behaviour in studies of COPD support programmes such as pulmonary rehabilitation and self-management: a qualitative synthesis with application of theory. NPJ Prim Care Respir Med 2015;25:15054.

68. Wempe JB, Wijkstra PJ. The influence of rehabilitation on behaviour modification in COPD. Patient Educ Couns 2004;52:237-41. 
69. Ambrosino N, Clini EM. Response to pulmonary rehabilitation: toward personalised programmes? The European respiratory journal 2015;46:1538-40.

70. Barnard KD, Lloyd CE, Dyson PA, Davies MJ, O'Neil S, Naresh K, et al. Kaleidoscope model of diabetes care: time for a rethink? Diabet Med 2014;31:522-30.

71. Thorpe CT, Fahey LE, Johnson H, Deshpande M, Thorpe JM, Fisher EB. Facilitating healthy coping in patients with diabetes: a systematic review. The Diabetes educator 2013;39:33-52.

72. Fisher EB, Thorpe CT, Devellis BM, Devellis RF. Healthy coping, negative emotions, and diabetes management: a systematic review and appraisal. The Diabetes educator 2007;33:1080-103; discussion 104-6.

73. Kraaij V, Garnefski N. Cognitive, behavioral and goal adjustment coping and depressive symptoms in young people with diabetes: a search for intervention targets for coping skills training. Journal of clinical psychology in medical settings 2015;22:45-53.

74. Tuncay T, Musabak I, Gok DE, Kutlu M. The relationship between anxiety, coping strategies and characteristics of patients with diabetes. Health and quality of life outcomes 2008;6:79.

75. Kraaij V, Garnefski N. Coping and depressive symptoms in adolescents with a chronic medical condition: a search for intervention targets. Journal of adolescence 2012;35:1593-600. 
SUMMARY

की 



\section{Summary}

Chronic Obstructive Pulmonary Disease (COPD) is the only major cause of death whose incidence is on the increase and is expected to be the third leading cause of death worldwide by 2030. Clinicians select pharmacologic strategies based on COPD severity to reduce symptoms and prevent COPD exacerbations. Nevertheless, the symptom burden of anxiety and depression and impaired quality of life in patients with COPD are not simply consequences of the underlying physiological disorder but, also depend on the patients' adaptation to their illness, treatments, and comorbidities. Collaborative self-management education promotes self-efficacy through increasing the patients' knowledge and skills required to participate with healthcare professionals in optimally managing their illness. In turn, establishing effective partnership between patients and healthcare professionals is essential to collaborative self-management education and support. This thesis sheds light on the potential contributing factors to self-management and partnership in care for patients with COPD such as coping styles, educational programmes and attitudes of healthcare professionals.

\section{Potential contributing factors to self-management and partnership in care for patients with COPD: coping styles}

In Chapter 2 the distribution of coping styles in patients entering pulmonary rehabilitation (PR) with and without anxiety and depression were examined. We demonstrated that COPD patients entering PR rarely report high levels of active confronting coping style, whereas majority of patients use medium and high levels of passive reaction pattern coping style. In addition, differences in coping profiles were present between patients with and without anxiety and/or depression. In fact, patients with symptoms of anxiety and/or depression reported a lower use of active confronting coping style and an increased use of avoidance and passive reaction pattern coping style than patients without symptoms of anxiety and/or depression. The chapter also shows that not only patient characteristics like age, dyspnoea, lung function, body composition and disease-specific health status are determinants of exercise intolerance, but also coping styles. Indeed, a higher level of active confronting coping style is positively related to exercise intolerance, while higher levels of avoidance coping style are associated with increased impairment in exercise intolerance. In contrast to our hypothesis, coping styles were not associated with disease-specific health status.

To further extend these findings, it was hypothesised that coping styles are predictors of change in clinical outcomes of a comprehensive PR. Chapter 3 provides evidence for the relation between coping styles and the improvements in exercise intolerance, anxiety and depression, but coping styles are not related to changes in 
disease-specific health status after PR. The effects of PR on improving symptoms and reducing disability in patients with COPD have been particularly well studied, but not its possible influence on coping styles. This chapter revealed that comprehensive PR, which did not contain a specific coping intervention that targeted coping styles of all enrolled patients, results in change in coping styles of COPD patients. The level of active confronting coping style (resulting in better adjustment with regard to patient's COPD) increased, whereas the levels of avoidance, passive reaction pattern and reassuring thoughts coping styles decreased following PR. This suggests that patients with COPD after PR will be more willing to confront their situation and address the problems, which can be considered as positive outcome of PR. Additionally, the majority of patients changed their level of active confronting, passive reaction pattern or expressing emotions coping style. Altogether, these data suggest that coping styles are associated with symptoms of anxiety, depression and exercise intolerance, thus, they may be important factors to consider in self-management interventions which should be routinely carried out in the current practice of PR.

Insight in coping styles of good responders, moderate responders and nonresponders to PR may support in adapting the treatment programme of these patients to their needs with the aim of improving patients' benefit from PR. Therefore, Chapter 4 sought to compare changes in coping styles after PR between patients who had a very good response in exercise intolerance and/or disease-specific health status, patients with a moderate response and patients with no improvement in these two outcomes after PR. The results suggest that good responders significantly decreased their passive reaction pattern coping style in contrast to non-responders after a PR programme free of any coping intervention. Passive reaction pattern coping style is associated with worse mental health and it may prevent patients from taking the appropriate initiatives during an exacerbation. Within the groups, in general, changes in coping styles after PR occurred among the good responders, whereas PR did not change the coping among moderate and non-responders.

Taken together, these studies show that coping styles are prone to change, rather than people are being "pre-programmed" to use the same coping behaviour regardless of the stressful situation and that PR and its educational component may be a venue for integrating interventions aimed at improving coping styles of patients with COPD. Future studies are warranted to investigate the effects of interventions targeting coping styles which may modify coping behaviour of COPD patients, as well as improvement in exercise intolerance or health status after PR.

\section{Potential contributing factors to self-management and partnership in care for patients with COPD: educational programmes}

Over the past decade, practice guidelines and PR statements emphasise the important role of educational component in COPD interventions. However, studies evaluating 
outcomes of education in patients with COPD show extremely varied results. Chapter $\mathbf{5}$ provides a critical review of the current literature regarding the content and the method of delivery of educational programmes integrated in current COPD management interventions. Educational programmes frequently include smoking cessation, medication use, exercise, breathing strategies, exacerbation prevention, and stress management. Despite widespread recommendations for education tailored to the patient, in a minority of the studies, the educational component was tailored to some extent according to the patients' characteristics. Most educational programmes were delivered in an outpatient hospital setting, while a third were provided by telephone calls from nurses and less than $5 \%$ were delivered over the internet or using telehealth technology. Nevertheless, this review underscored the heterogeneity of the educational topics and models, highlighting the inconsistent approach to teaching patients with COPD and the lack of process evaluation to demonstrate which aspects of the teaching are most effective in changing patients' behaviour. It can be concluded that educational interventions should cover topics recommended by the COPD guidelines, in addition to task sharing, facilitated by a multidisciplinary team of healthcare professionals. Moreover, these findings may imply that more in-depth recommendations on the content and structure of educational programmes in the practice guidelines and statements are warranted.

\section{Potential contributing factors to self-management and partnership in care for patients with COPD: attitudes of healthcare professionals}

PR should incorporate self-management support guiding structural behaviour change and the shift from management by healthcare professionals to collaborative management. Moreover, healthcare professionals' attitudes might reasonably be considered to be among the important predictors of patient's enablement. In turn, exploring the beliefs of healthcare professionals in PR with respect to the importance of supporting the patient as an active partner is necessary for improvement of the effectiveness of self-management programmes incorporated in PR. Thus, Chapter 6 in a multicentre study explored attitudes of PR healthcare professionals toward patients' self-management and specifically, assessed their attitudes about the importance of patients' competencies necessary for the process of partnership in care. In line with the hypothesis, the study demonstrated that healthcare professionals providing PR value patient involvement in their care. Nonetheless, the findings in this chapter suggest that although healthcare professionals support active patient's behaviour in the consultation, place value in patient's self-management and express positive attitudes toward patient's participation - patient's competencies related to "patient as member of a care team" and "patient should be an independent information seeker" were considered as less important. In addition, female and older healthcare professionals value the importance of collaborative self-management higher than 
their male and younger counterparts, respectively. In conclusion, the complex relationship between healthcare professionals and their patients, as well as healthcare professionals' self-reported attitudes and their actual practices, warrant greater attention and further study.

\section{Education in COPD}

In order to provide exciting future perspectives, the insights resulting from the original research data described in this thesis, were critically evaluated and integrated with current knowledge in Chapter 7. To understand barriers to optimal COPD education and propose potential solutions, this chapter provides a state-of-the-art overview of the current educational programmes, patient's limitations and preference for education, patient-clinician communication and the role of PR in modification of coping styles and behaviour.

An improved understanding of the driving forces behind behaviour and their impact on COPD management (Kaleidoscope Model of Care) is projected to result in new personalised therapeutic directions to support optimum outcomes and reduce disease burden. In conclusion, an ample novel model was provided which supports individualised care plan of holistic COPD care and healthcare professionals in providing care pathways that are mapped to patient's priorities (KALMOD Behaviours for Health). 
SAMENVATTING 



\section{Samenvatting}

Chronisch obstructief longlijden is de enige significante doodsoorzaak waarvan de frequentie aan het toenemen is er wordt verwacht dat het de derde belangrijkste doodsoorzaak zal zijn in 2030. Clinici kiezen farmacologische behandel strategieën gebaseerd op de ernst van de COPD om zo symptomen te verlichten en ziekte exacerbaties te voorkomen. Desalniettemin, zijn de beleefde gespannenheid en depressiviteit als ook de verminderde kwaliteit van leven van COPD patiënten niet simpelweg consequenties van de verminderde fysieke gesteldheid, maar hangen ze ook nauw samen met de mogelijkheid van de patiënt om zich aan te passen aan de ziekte, de behandelingen en de co-morbiditeiten. Samenwerkend zelfmanagement promoot eigenaarschap van de patiënt door het verhogen van de patiënts kennis en kunde welke nodig zijn om samen met gezondheidsmedewerkers hun ziekte te managen. Anderzijds is het bewerkstelligen van een goede samenwerking tussen patiënt en gezondheidsmedewerkers essentieel voor het slagen van samenwerkend zelfmanagement scholing en support.

Dit proefschrift verhelderd factoren die bijdragen aan zelfmanagement en samenwerking in verpleging van COPD patiënten, zoals manieren van ziekte acceptatie, onderwijs programma's en houding van gezondheidsmedewerkers.

\section{Factoren die potentieel bijdragen aan zelfmanagement en samenwerking in zorg voor patiënten met COPD: coping stijlen}

In hoofdstuk 2 worden de verschillende coping stijlen van patiënten met en zonder angst en depressie die longrevalidatie ondergaan onderzocht. We hebben laten zien dat COPD patiënten die longrevalidatie ondergaan zelden een hoge mate van actief aanpakken als coping stijl laten zien. Het grootste deel van de patiënten laat een middelmatige tot hoge mate van passief reactiepatroon coping stijl zien. Daarbij komt nog dat er verschillen in coping profiel zichtbaar was tussen patiënten met en zonder angst en/of depressie. In feite lieten patiënten met symptomen van angst en/of depressie een lagere mate van actief aanpakken coping stijl zien en een verhoogde mate van vermijden en passief reactiepatroon coping stijlen zien in vergelijking met patiënten zonder symptomen van angst en/of depressie. In dit hoofdstuk laten we ook zien dat patiënten karakteristieken zoals leeftijd, dyspnoe, longfunctie, lichaamssamenstelling en ziekte specifieke gezondheidstoestand cofactoren zijn van zowel inspanningstolerantie als coping stijlen. $\mathrm{Er}$ is een positieve relatie gevonden tussen hogere mate van de actief aanpakken coping stijl en inspanningstolerantie, terwijl hoge mate van vermijden coping stijl was geassocieerd met een verminderde inspanningstolerantie. In tegenstelling tot onze hypothese, waren coping stijlen niet geassocieerd met ziekte specifieke gezondheidsstatus. 
Hierop aansluitend werd de hypothese geformuleerd dat coping stijlen een voorspellende waarde hebben met betrekking tot klinische uitkomst van een gecomprimeerde longrevalidatie. Hoofdstuk 3 demonstreert een correlatie tussen coping stijlen en verbeterde inspanningstolerantie, angst en depressie. Echter zijn coping stijlen niet geassocieerd met veranderingen in ziekte specifieke gezondheidsstatus na longrevalidatie. Het effect van longrevalidatie op het verbeteren van symptomen en verminderen van fysieke beperkingen in patiënten met COPD zijn specifiek bestudeerd, echter niet de mogelijke invloed op coping stijlen. In dit hoofdstuk laten we verder zien dat gecomprimeerde longrevalidatie zonder een speciale coping interventie gericht op de coping stijlen van opgenomen patiënten, resulteert in veranderingen in coping stijlen van COPD patiënten. De mate van een actief aanpakken coping stijl (resulterend in een verbeterde aanpassing van de patiënt aan de COPD) verhoogde, terwijl de mate van vermijden, passief reactiepatroon en geruststellende gedachten coping stijlen verminderde na longrevalidatie. Dit suggereert dat COPD patiënten na een longrevalidatie meer geneigd zijn om hun situatie onder ogen te komen en problemen aan te pakken, wat als een positief resultaat van longrevalidatie gezien mag worden. De meerderheid van de patiënten veranderde hun mate van actief aanpakken, passief reactiepatroon of expressie van emoties coping stijlen. Alles tezamen, suggereert deze data dat coping stijlen geassocieerd zijn met symptomen van angst, depressie en inspanningsintolerantie, en het dus belangrijke factoren kunnen zijn in zelfmanagement interventies welke frequent zou moeten worden uitgevoerd in het huidige longrevalidatieproces.

Inzicht in coping stijlen van patiënten die goed, matig of niet reageren op longrevalidatie zou ondersteunend kunnen werken bij het aanpassen van het behandelplan aan de behoeften van deze patiënten met als doel de patiënten meer te laten profiteren van de longrevalidatie. Aansluitend was het doel in hoofdstuk 4 om de veranderingen in coping stijlen na longrevalidatie te vergelijken tussen patiënten die zeer veel verbeterde in inspanningsintolerantie en/of ziekte specifieke gezondheidstoestand ten opzichte van patiënten die een matige of geen verbetering van deze twee uitkomstmaten van longrevalidatie lieten zien. De resultaten suggereren dat patiënten die goed reageren de mate van passief reactiepatroon coping stijl significant verminderde in tegenstelling tot de patiënten die niet reageerden op longrevalidatie programma zonder coping interventie. Passief reactiepatroon coping stijl is geassocieerd met een slechtere mentale gezondheid wat mogelijk voorkomt dat patiënten gepast initiatief nemen tijdens een opflakkering van de ziekte. Binnen de groepen lieten de patiënten die goed op longrevalidatie reageerden, meer veranderingen in coping stijl zien ten opzichte van de patiënten die matig of niet reageerden op longrevalidatie.

Alles bij elkaar genomen laten deze studies zien dat coping stijlen kunnen veranderen en niet dat mensen 'voorgeprogrammeerd' zijn om op dezelfde manier de reageren ongeacht de oorzaak van stress. Verder laten deze studies zien dat 
longrevalidatie en het onderwijs component hierin een goed moment kunnen zijn om interventies gericht op het verbeteren van coping stijlen bij COPD patiënten te integreren. Toekomstige studies zullen bekijken hoe coping stijlen te beïnvloeden, als ook de inspanningsintolerantie en de gezondheidsstatus na longrevalidatie te verbeteren.

\section{Factoren die mogelijk bijdragen aan zelfmanagement en samenwerking in zorg voor patiënten met COPD: educatie programma's}

In de afgelopen decennia zijn de zorg- en longrevalidatie richtlijnen gericht op te belangrijke rol van educatie in COPD interventies. Echter, studies welke de uitkomst maten van deze educatie meten laten grote verschillen in resultaten zien. Hoofdstuk $\mathbf{5}$ is een kritische review van de huidige literatuur met betrekking tot de inhoud en aanlever methode van de educatie programma's welke momenteel geïntegreerd zijn in COPD management interventies. Educatieve programma's includeren vaak stoppen met roken, medicatie gebruik, inspanning, ademhalingsmethodieken, preventie van ziekte opflakkering en stress management. Ondanks wijdverspreide aanbevelingen voor educatie specifiek toegespitst op een patiënt was in een minderheid van de studies de educatie component tot op zekere hoogte toegespitst op de karakteristieken van de patiënt. De meesten educatie programma's vonden plaats in een setting buiten het ziekenhuis, terwijl een derde liep via telefoon gesprekken met verpleging. Minder dan 5\% verliep via het internet of via tele-gezondheidstechnologie. Dit review benadrukt de heterogeniteit van de onderwerpen van educatie en de gebruikte modellen, waarmee de inconsistentie van de onderwijs benadering van COPD patiënten en het gebrek aan evaluatie van het onderwijsproces tot gevolg hebben dat niet duidelijk is welke aspecten van de educatie meest effectief zijn in het veranderen van patiënten gedrag. Er kan geconcludeerd worden dat het aanbevolen is om educatieve interventies onderwerpen uit de COPD richtlijnen te includeren, tezamen met taakverdeling, gefaciliteerd door een multidisciplinair team van gezondheidsprofessionals. Verder suggereren deze bevindingen dat meer specifieke aanbevelingen met betrekking tot de inhoud en structuur van de educatie programma's in de richtlijnen noodzakelijk is.

\section{Factoren die potentieel bijdragen aan zelfmanagement en samenwerking in zorg voor COPD patiënten: attitude van gezondheidszorg medewerkers}

Longrevalidatie zou zelfmanagement welke tot structurele gedragsveranderingen en een verschuiving van managent door gezondheidszorg medewerkers naar samenwerking in zorg moeten incorporeren. Specifieker, de attitude van gezondheidszorg 
medewerkers zou als een van de belangrijke factoren van de enablement van patiënten kunnen worden beschouwd. Daar tegenover staat dat het noodzakelijk is onderzoek te doen naar de overtuiging van gezondheidszorg medewerkers in het longrevalidatie proces van het belang van hen actieve bijdrage voor het verhogen van de effectiviteit van zelfmanagement programma's als onderdeel van longrevalidatie. Daarom beschrijft hoofdstuk 6 een multicenter studie welke de attitude van longrevalidatie gezondheidszorg medewerkers met betrekking tot het zelfmanagement van patiënten onderzoekt. Hierbij werd specifiek gekeken naar de attitude van gezondheidszorg medewerkers ten opzichte van noodzakelijke competenties van patiënten voor een geslaagd samenwerking in zorg. In overeenstemming met de hypothese laat de studie zien dat gezondheidszorg medewerkers betrokken bij longrevalidatie waarde hechten aan de betrokkenheid van de patiënt bij hun zorg. Hoewel de bevindingen in deze studie suggereren dat gezondheidszorg medewerkers actief patiënten gedrag in consultatie steunen, waarde hechten aan patiënten zelfmanagement en uitten dat zij positief tegenover patiënten participatie staan - patiënten competenties gerelateerd "patiënt als onderdeel van het zorgteam" en "de patiënt zou onafhankelijk informatie moeten zoeken" werden echter als minder belangrijk beschouwd. Verder hechten vrouwelijke en oudere gezondheidsmedewerkers meer waarde aan het belang van samenwerken binnen zelfmanagement dan mannelijke en jongere gezondheidsmedewerkers. Concluderend, de complexe relatie tussen gezondheidsmedewerkers hun patiënten als mede gezondheidsmedewerkers zelf gerapporteerde attitude en hun daadwerkelijke gedrag, verdienen meer aandacht en verder onderzoek.

\section{Educatie in COPD}

Om in de toekomst goede perspectieven te kunnen bieden, zijn de originele onderzoeksdata uit dit proefschrift in kritisch perspectief gezet en geïntegreerd in de huidige kennis in hoofdstuk 7. Om de blokkades tot optimale COPD educatie goed te begrijpen en oplossingen hiervoor te kunnen bieden, beschrijft dit hoofdstuk een hoogstaand overview van de huidige educatie programma's, patiënten limitatie en voorkeur voor onderwijs, patient-arts communicatie en de rol van longrevalidatie in het aanpassen van coping stijlen en gedrag.

Meer inzicht in de factoren welke gedrag sturen en hun impact of COPD management (Kaleidoscope Model of Care) zou moeten leiden tot vernieuwde persoonlijke richtlijnen welke bijdragen tot optimale zorg en verminderde ziekte last. Concluderend, een geheel vernieuwend model is voorgesteld dat een persoonlijk behandelplan van COPD ondersteunt en om gezondheidsmedewerkers tot een verzorgingsplan te laten komen dat de patiënt op de eerste plaats stelt (KALMOD Behaviours for Health). 


\section{VALORISATION}





\section{Valorisation}

\section{What is the problem?}

Chronic obstructive pulmonary disease (COPD), although preventable not a curable disease, causes high levels of disability and it is an increasing public health problem worldwide. COPD is characterised by irreversible airflow limitation in the lungs. Active smoking is the main risk factor for developing COPD; however second-hand smoking, frequent respiratory infections, dust, and air pollution in the workplace or the environment are also contributing factors. As well, there are genetic disorders that predispose to develop COPD. According to estimates by the World Health Organisation, approximately 65 million people worldwide are affected by COPD, and with the ageing population, this burden is bound to increase and impose great demands to public health care and society. Moreover, COPD tends to be underdiagnosed and undertreated by healthcare professionals. In the Netherlands 1 in 50 people are diagnosed with COPD, while almost one quarter of the Maastricht population aged $\geq 40$ years had COPD.

The tremendous distress that COPD poses on the quality of life of those who suffer is obvious. However, the psychological impact of COPD goes far beyond the individual, as patients become heavily dependent on family members and professional caregivers. This underlines the magnitude of the burden that COPD has on our society and the urgent need to develop effective treatments. The paradoxical issue about the current management of COPD is that pharmacologic strategies are being selected based on COPD severity to reduce symptoms and prevent COPD exacerbations. On the contrary, it is known that the symptom burden is not simply a consequence of the underlying physiological disorder. Thus, interventions targeting only physiological parameters may not lead to improved patients' adaptation to their illness, treatments and comorbidities.

Pulmonary rehabilitation (PR) has been shown to enable patients with respiratory diseases to improve their day-to-day activities and restore the highest level of independent functioning. Indeed, as defined by the American Thoracic Society/European Respiratory Society statement, this non-pharmacological comprehensive intervention should contain patient tailored therapies designed to improve the physical and psychological condition of people with chronic respiratory disease and to promote the long-term adherence to health-enhancing behaviours. Nonetheless, individual responses to PR are variable, highlighting the importance of discerning this complex concept. 


\section{How do we contribute?}

The current thesis significantly adds to the understanding of coping styles present among COPD patients entering, as well as undergoing PR. In addition, critical evidence was provided about the role of coping styles as predictors of change in clinical outcomes following PR, such as symptoms of anxiety, depression and exercise tolerance. Further exploration of the effects of PR on coping behaviour of patients who respond very well, and those patients with a moderate or no response to PR is of crucial importance. The results reported in this thesis suggest that PR per se can influence the coping of good responders. Furthermore, the present research sheds light on the content and delivery of educational programmes integrated in the current COPD management interventions and on the attitudes of PR healthcare professionals toward partnership in care. Cumulatively, these insights may support in adapting the treatment programme to the patients' needs with an aim of improving patients' benefit from PR; and may trigger greater attention and provide the basis for further study of the complex relationship between healthcare professionals and their patients. Moreover, this dissertation provides recommendations on how to motivate patients to achieve their goals by proposing the Kaleidoscope Model of Care, as well as how to individually tailor interventions for a holistic COPD care by suggesting the novel KALMOD - Behaviours for Health intervention. Consequently, the research described in this thesis has substantial societal impact.

\section{What do we know now?}

\section{Insights in coping styles}

One of the main findings of this research was that majority of the patients entering PR use medium and high levels of the maladaptive passive reaction pattern coping style, whereas they rarely report high levels of the beneficial active confronting coping style. In addition, a lower use of active confronting coping style and an increased use of avoidance and passive reaction pattern coping style are specific for the patients with symptoms of anxiety and/or depression compared to those patients without this symptomatology. Thus, this present research shows a relationship between coping styles and psychological distress in patients with COPD entering PR. Another main finding described in this thesis is that coping styles are predictors of change in clinical outcomes such as exercise intolerance, anxiety and depression of PR. As well as, that a comprehensive PR not containing a coping intervention, may result in change in coping styles of COPD patients by increasing the level of the coping style referring to better adjustment to the disease, while consequently, decreasing the levels of maladaptive coping styles associated with worse health outcomes. In fact, the research among patients with a very good response in exercise tolerance and/or disease-specific health status, patients with a moderate response and patients with no 
improvement in these two outcomes after PR, demonstrated that changes in coping styles after PR occurred among good responders, whereas PR did not change the coping among moderate and non-responders. Furthermore, the results suggest that good responders significantly decreased their passive reaction pattern coping style in contrast to non-responders after a PR programme. Altogether, the studies on coping styles of patients with COPD which are part of this dissertation, yield new findings which implicate that coping styles may be important factors to consider and they may be influenced by coping interventions incorporated in PR.

\section{Insights in education in COPD}

Findings from the systemic review shed light on the educational topics frequently included in the educational programmes integrated in current COPD management interventions. These are: smoking cessation, medication use, exercise, breathing strategies, exacerbation prevention, and stress management. Importantly, in minority of the current interventions, the education was tailored to the patient. Nevertheless, this review underscored the inconsistent approach to teaching patients with COPD, highlighting the need of more in-depth recommendations on the content and structure of educational programmes in the practice guidelines and statements.

\section{Insights in attitudes of healthcare professionals providing PR}

Finally, the findings in this thesis suggest that although healthcare professionals providing PR support active patient's behaviour in the consultation, place value in patient's self-management and express positive attitudes toward patient's participation - patient's competencies related to "patient as member of a care team" and "patient should be an independent information seeker" were considered as less important. Healthcare professionals' attitudes might reasonably be considered to be among the important predictors of patient's enablement, thus these insights may draw attention to the potential impact of healthcare professionals' role on patient's self-management behaviours and health perceptions.

\section{For whom is it of interest and how to proceed?}

\section{Scientific community}

We have undertaken various efforts to ensure that the knowledge obtained from our studies reaches this target group. First of all, I have presented most of our findings at several international conferences which are frequented by researchers and clinicians from all over the world. In addition, we aimed to publish the research articles that constitute this thesis, in various international scientific journals that target scientific, as well as clinical audiences. Therefore, researchers in the field of collaborative self- 
management or PR in general, can benefit from the new information we have added to the existing knowledge in this field. For example, we have shed a new light on the potential contributing factors to self-management and partnership in care for patients with COPD. Although our findings do not lead to a full and complete understanding of all factors contributing to successful partnership working, we have made a contribution to disentangling this complex relationship. Researchers could build on these findings, as well as the paradigms we have used when designing new studies in the field. Our increased knowledge about these processes can eventually lead to better PR interventions.

\section{Patients}

Findings offered by this dissertation put the individual patient at the centre of the COPD care, thus they strongly advocate for a patient-driven care. It stands to reason that incorporating interventions tailored to the individual patient's coping styles into $\mathrm{PR}$, can further improve patient's health and reduce healthcare costs. It is crucial to translate these findings into behavioural observations and also, to correctly interpret behavioural changes in a meaningful way. Moreover, our research emphasise that in the world of participatory medicine, patients are no longer a target group and passive recipients of care, but crucial and active members of the care team, involved in the decision-making process at every step.

\section{Healthcare professionals}

The results of this thesis, which may help to optimise the COPD therapy and improve patients' quality of life, are of interest for general practitioners (GPs), lung physicians, nurses and all healthcare professional providing PR. GPs are in position to recognise symptoms of COPD in an early stage and to contribute in counteracting patients' maladjustment to COPD already in its early stage. Furthermore, our research demonstrated that nurses are the most involved healthcare professionals in delivery of educational programmes integrated in current COPD management interventions. Therefore, the insights shared in this dissertation may influence their day-to-day approach to individual patients. Analyses by the American Thoracic Society and European Respiratory Society indicate that PR in COPD is cost-effective: hospitalisations are of shorter duration and lower frequency in the years following PR. Exploring the attitudes and beliefs of PR healthcare professionals on the importance of supporting the patient as an active partner, as it was done in this thesis, may indeed be necessary for improvement of the effectiveness of self-management programmes incorporated in PR. Moreover, findings offered by this dissertation, potentially suggest that clinicians should do their best to collaborate with patients, to understand their needs and desires and to jointly design plans of care that are as 
consistent as possible with those needs and desires. Simple? No. But the upside may be huge, for both, if they can learn how to do it.

\section{Industry}

The idea that physiological parameters and data analysis is not enough, but that integrated solutions need to address chronic diseases much more comprehensively, is understood by the leading medical companies on the market. Thus, most major medical devices and pharmaceutical companies, especially the ones in diabetes care, are claiming personalised treatment plans, prevention and "selling outcomes" vs. "selling hardware", as stated strategic goals. In fact, the vision of medical technology companies is increasingly focused on integrated solutions to empower patients and drive behaviour change. Hence, motivation (to optimise disease control) has been promoted by these companies as one of the most crucial factors contributing to treatment success. Therefore, promotion and maintenance of motivation is a declared goal in the development of their new medical products. Subsequently, medical companies strive to provide patient's services with reimbursement related to patient's outcomes, which will be more holistic and personalised vs. population management. They plan to achieve this through education, coaching and adherence support, which in turn, will result in patient engagement characterised with enhanced health literacy and therapy adherence. Care coordination across stakeholders, remote patient monitoring and tele-consultation are also the ways, which will eventually, empower patients and drive behaviour change. Partnership networking between patients, healthcare professionals and (food, care) providers has been also highlighted.

Cumulatively, these aforementioned concepts strongly resonate with the findings and recommendations provided in this dissertation. Hence, this makes our research contextually relevant and highly attractive for industrial players involved in bringing innovative solutions, not only to COPD, but to any chronic disease. In fact, adapted versions of both, Kaleidoscope Model of Care and KALMOD - Behaviours for Health, already applicable to patients with diabetes, have been proposed in this thesis with an aim to prevent long-term COPD related complications and escalating healthcare costs. These models of care, applicable and adaptable to different chronic diseases, may also have an impact on mHealth, patient safety and patient empowerment.

Mobile self-management applications and innovative technologies that can: enhance health literacy on clinical condition and the roles of dietary choices, lifestyle and therapy; track and compare daily data vs. guidelines provided by the healthcare professionals; facilitate the dialog between patients and their specialists to better manage the disease; help monitor and record disease evolution; follow tailored exercise programme; find trustworthy information on the disease and treatment options are warranted. Additionally, integrated solutions with feedback loop (patient and/or healthcare professionals receive alerts and coaching), as our suggested 
adapted KALMOD - Behaviours for Health internet intervention for COPD management, will facilitate treatment support for high-value therapies. Therefore, collaboration with medical technology companies is paramount to achieve this goal as soon as possible.

On the other hand, we are moving toward a New Cognitive Era defined as: Cognitive "internet of things" which involves infusing connected devices with the ability to understand, reason, learn, and generate their own hypotheses and confidence levels to help people make data-driven decisions. Cognitive computing may drive the field forward. 
ABBREVIATIONS 



\section{Abbreviations}

AACVPR American Association of Cardiovascular and Pulmonary Rehabilitation

ACCP American College of Chest Physicians

ANOVA Analysis of Variance

ATS/ERS

American Thoracic Society/European Respiratory Society

BMI Body-Mass Index

BODE Body-Mass Index, Airflow Obstruction, Dyspnoea, and Exercise

CIRO Centre of Expertise for Chronic Organ Failure

CONSORT Consolidated Standards of Reporting Trials

COPD Chronic Obstructive Pulmonary Disease

CS-PAM Clinician Support - Patient Activation Measure

DPIs

Dry-Powder Inhalers

FEV $_{1} \quad$ Forced Expiratory Volume in the First Second

FFMI Fat-Free Mass Index

FVC Forced Vital Capacity

GOLD Global Initiative for Chronic Obstructive Lung Disease

GPs General Practitioners

HADS Hospital Anxiety and Depression Scale

HADS-A Hospital Anxiety and Depression Scale, Anxiety Subscale

HADS-D Hospital Anxiety and Depression Scale, Depression Subscale

HbCO Carboxyhaemoglobin

HCPs Healthcare Professionals

LINQ Lung Information Needs Questionnaire

LTOT Long-Term Oxygen Therapy

MCID Minimal Clinically Important Difference

MDIs Metered-Dose Inhalers

MRC Medical Research Council

NICE National Institute for Health and Clinical Excellence

n.s. non-significant

P4 Predictive, Preventive, Personalised and Participatory

PaCO2 Partial Pressure of Arterial Carbon Dioxide

PaO2 Partial Pressure of Arterial Oxygen

PR Pulmonary Rehabilitation

PRISMA Preferred Reporting Items for Systematic Reviews and Meta-Analyses

QoL Quality of Life

RCT Randomised Controlled Trial

RE-AIM Reach, Efficacy, Adoption, Implementation and Maintenance

6MWD Six-Minute Walking Distance

SD

Standard Deviation 
SGRQ St. George's Respiratory Questionnaire

SPSS Statistical Package for the Social Sciences

STROBE Strengthening the Reporting of Observational Studies in Epidemiology

UCL Utrecht Coping List

UCOPD Understanding Chronic Obstructive Pulmonary Disease

UK United Kingdom

US United States

WHO World Health Organisation 


\section{ACKNOWLEDGEMENTS}





\section{Acknowledgements}

This $\mathrm{PhD}$ thesis is a result of a challenging journey, upon which many people have contributed and given their support. Therefore, I feel deeply indebted and I would like to extend my great appreciation to all the people who have made this PhD thesis possible and helped me scientifically and/or emotionally throughout this endeavour.

Prof. Wouters, my mentor. At the time when I was invited to join your department, I came across with an interview of yours in a university newspaper, which I still cherish today. You were saying: "To my mind, science is all about daring to colour just outside the lines and giving young people opportunities." You provided me with that opportunity by allowing me to conduct a research, initially as a Master's student and then, encouraged me to further pursue my studies by doing a PhD. "Sometimes you need to convince the world about your ideas" were the words which I heard from you during our work together on the topics of this dissertation, aiming to contribute to the improvement of the doctors' reductionist approach to patients. I assume that meant exactly that - with our work, we were actually colouring outside the lines! :) Your invaluable guidance, academic stimulus, constant support in my efforts and believing in me, were the essentials which were the source of my motivation and helped me to face all the obstacles and continue with my work all these years. I have learnt a lot from you and I am very grateful for the fruitful time that I had the privilege to spend with you. Prof. Wouters, you are indeed, a big man. Thank You so much!

Daisy and Martijn, thank you for your input and support on the manuscripts you coauthored. They would not have been possible without your help. You sharpened the clinical perspectives of my research.

Frits, although you joined my team of mentors later, your contribution is tremendous. You co-authored the most of the manuscripts and your genuine support and friendly advice were crucial for finalisation of the last pieces of this PhD-thesis-puzzle. You sincerely encouraged my ideas and efforts, for which I am sincerely grateful.

Prof. Schols, even though we didn't work directly together, my research project was part of the NUTRIM research school which is under your scientific lead. It was a pleasure over several years to present my findings and to be part of the Annual Symposium which brings the interdisciplinary COPD research together.

Prof. Barnard, dear Kath. Thank you for your collaboration and support which started in Roche Diabetes Care. The chapter on perspectives on education in COPD in this dissertation is largely inspired by your extremely valuable contribution in the field of 
holistic diabetes management, as well as to Roche Diabetes Care, where you are part of the Advisory Board. I am glad that we have been able to extent your previous work in diabetes to COPD, and with that, potentially to the other chronic diseases. I am happy that our work together will continue in the future.

Ingrid, thank you for your indirect support and initial encouragement to start this $P h D$ voyage of discovery.

Gerrie, I greatly appreciate your assistance on the healthcare professionals study. The distribution of emails to the employees and contacts in the CIRO network was of a paramount importance for completion of this multicentre study.

Manon, many thanks for your telephone conversations, help and organisation of all practical things which were happening behind the Dutch non-existing curtains. :)

I would like to thank the members of the thesis reviewing committee consisting of Prof. Smeenk (chairman), Prof. Singh, Prof. van der Palen, Prof. Ponds and Prof. Kremers for critically reviewing and evaluating this dissertation. As well, I would like to thank the members of the corona; it is truly an honour to have you.

My A - Team (Koen, Astrid, Alex, Nicky), my very good friends. Thank you for the great discussions, your constant friendly support, for the Belgian spontaneity and the Dutch directness. The great number of events and parties we have attended together, just complement the list of wonderful memories we have shared together. I was happy to have you all at my wedding day! I am happy to know every single one of you.

Koen, my roomie, my friend, my paranymph. The whole PhD experience was not going to be the same without you. How it started: you surprised me by coming on my Master's graduation. Although, you were not so happy with the colour of the orchid that you brought as a present - that beautiful white flower is generously blooming for eight years in a row. :) We used our coffee breaks, as well as we were often interrupting the scientific silence in our office, called room, with vast variety of topics - from spirituality to travels to Thailand. We laughed. Actually, we laughed a lot about so many things. Those were the days! I truly acknowledge your practical advices in the final phase of preparation of this thesis and all your friendly help you have given at all times. Our paths are crossing at present and as you mentioned in your book, they will surely cross again in the future. Cheers!

Astrid, my friend, my paranymph. The love toward the Spanish tapas food brought us together, especially on our ERS conference travel to Barcelona. Remember? Later we found our tapas bar in the heart of Maastricht, where we continued to nurture our 
senses while looking with optimism toward the future. () The birth of our daughters with several months of a difference, Emma and Lea, brought us even closer. The exchange of information and experience on raising a daughter is set on " $\infty$ " (infinity), as well as our friendship. Thank you for the Dutch translation of the summary part in this book. Best for your future with Marcel. Cheers!

Alex, my friend. Few weeks after I joined the department, you had your PhD defence. That was my first attendance at a Dutch PhD defence. You set the stage by raising the bar high: you did it perfectly. Although I was residing in the Netherlands, together with Koen, you introduced me to the extreme variety of tasteful and high-alcohol Belgian beers. :-) I still have a respect for the devil: the Duvel! That was and still is our favourite. I wish you a very happy and bright future ahead privately daddy, as well as professionally. Cheers!

Nicky, my friend. As you mentioned in your acknowledgment section of your book, I was considering you as one of my girlfriends. Although a bit troubling for you - I was having the best intentions when saying that. :) You are the most sincere, openhearted and ready-to-help person that I can call my good friend. I am sure that I have acknowledged these on many occasions. We really had the greatest of times together - you had me laughing tears most of the times. To you and Ilse, I wish all the best. Cheers!

Pieter and Harry, thank you for your instant IT support and for keeping me up to date and with relevant information.

In addition, thanks to all colleagues from the department of Respiratory Medicine and CIRO for the fruitful collaboration and nice years.

All patients in CIRO, who have contributed to the studies on coping styles; thank you for your efforts and continued dedication to participate in the surveys. Many thanks to all the doctors and nurses who have taken part in the data collection and care of the participants.

Eline, it was a pleasure to be part of your SuperCool NightBalance team! You thought me that perfectionism, self-critic and tirelessly collecting information, aka researching, for a longer period of time before making the final decision, are not the best assets that one can have when working in the industry vs. the academic work. :) As a true leader, you were reinforcing my strong sides and supporting and developing the weaker ones. You inspired me with your arrogant-less self-confidence and influenced me personally and indirectly, you impacted my work on the last chapters of this dissertation. I am grateful to you. Among the other things, I really miss our 
champagne moments! I am proud to know one of the fifty most inspiring tech-women in the Netherlands! Best to you, Bo and Nanco.

Laura, the work in NightBalance brought us so close in such a short period of time. I will always remember our emotional saying goodbye when I was leaving the company, and by doing that, leaving the country as well. Having you and Lisardo at my wedding day was legendary! :) Organising my "bachelorette party", but this time together with our daughters Sofia and Lea, would be an enjoyable moment to look forward to. Barcelona can also be an option. ;)

Kerstin, thank you for your time spent on the Sundays for brainstorming on the variety of ideas that we both had and for your professional efforts in creating this great cover for this book!

Tiny, thank you for your flexibility and the incredible hard work that you did on the layout for this thesis to look like it does.

Roche Diabetes Care colleagues. The work in the company has been providing me with insights which inspired me for writing, especially the valorisation part of this dissertation. Although in the field of diabetes, on a daily bases I am immersed in discussions and efforts to provide solutions to empower patients, drive behaviour change and increase partnership working. All these concepts are highly resonating with the presented ideas and in turn, providing me with proof and confirmation of the importance of the work elaborated in this book. I greatly appreciate that.

Dear mum, dad, Goran and Marina. The basis that I have received from you is the fundament of what I am today, as a person, medical doctor, researcher and hedonist. My gratitude for everything that you are doing and have done for me is not possible to explain with words. Your understanding, faith, advise, intellectual spirit and indescribable support for me throughout my whole life are invaluable. Even from far away, across borders and on couple of thousand kilometres of a distance. I appreciate your honesty, including compliments and criticisms. I am very grateful for your care, your love and trust in me, and further thank you for your constant interest. You were always stimulating me to be the best version of myself and this book is here to confirm that. I love you so much.

Драги мамо, тато, Горан и Марина. Базата која што ја добив од вас е фундамент на она што сум денес како личност, доктор, истражувач и хедонист. Мојата благодарност за сѐ што правите и направивте за мене, не е возможна да се искаже со зборови. Вашето разбирање, верба, совет, интелектуален дух и неизмерна поддршка која што ја добивав низ животот, се од непроценливо 
значење за мене. Дури и од далеку, преку граници и на неколку илјади километри оддалеченост. Ја ценам вашата искреност, вклучувајќи ги комплиментите и критиката. Благодарна сум за вашата грижа, вашата љубов и верба во мене, и повторно благодарам за вашиот постојан интерес. Вие секогаш ме стимулиравте да бидам моја најдобра верзија од себе и оваа докторска теза е тука да го потврди тоа. Ве сакам неизмерно многу.

Dear parents in law, Magdalena and Alwin; dear Rebecca and Marcus. Thank you for your time and willingness to take care of Lea. You provided me with peace of mind while writing the last words in this thesis, as I knew that my baby is in safe hands. My schwiegermutter, your support from across the border while I was still in the Netherlands, is not forgotten and it was equally appreciated then, as it is still today.

Liebe Schwiegereltern, Magdalena und Alwin; liebe Rebecca und Marcus. Vielen Dank für Eure Zeit und Bereitschaft auf Lea aufzupassen. Durch Eure Unterstützung fand ich die nötige Ruhe, um die letzten Worte dieser Doktorarbeit zu verfassen. Ich wusste immer, dass mein Baby Lea bei Euch in guten und sicheren Händen ist. Meine Schwiegermutter, Deine Unterstützung über die Grenze hinaus bis nach Holland ist nicht vergessen und es bedeutete mir damals genausoviel wie heute.

Dear Lea, dear Martin, my dearest small family. Lea, my love. You are the softest point of my heart. Every morning when you look at me, I get the sweetest, most heartwarming, melt-me-to-my-core smile. Thank you for providing me with the best start of my day ever since you are here. I love you too much! Martin, my love. This thesis would not have been written without your immense support. You have been the rock to steady and support me almost from the beginning of my PhD. Leaving the Netherlands and joining you in Germany to enable us living together, was an extraordinary challenge for both of us. However, we stood and we are standing tallproud parents of our precious daughter who brings even more sunshine to our lives, as well as ready to deal with anything. Thank you so much for your extraordinary strength and consistency. Thank you for your invaluable loving help and your patience. Enjoying a wonderful life with you, I am looking forward to countless happy and exciting years together!

\section{Ana}





\section{LIST OF PUBLICATIONS}





\section{List of publications}

1. Stoilkova-Hartmann A, Franssen FM, Augustin IML, Wouters EF, Barnard KD. Perspectives on education in COPD. [submitted]

2. Stoilkova-Hartmann A, Janssen DJ, Franssen FM, Wouters EF. Differences in change in coping styles between good responders, moderate responders and non-responders to pulmonary rehabilitation. Respir Med. 2015;109(12): 1540-1545.

3. Stoilkova-Hartmann A, Janssen DJ, Franssen FM, Spruit MA, Wouters EF. Attitudes of healthcare professionals providing pulmonary rehabilitation toward partnership in care. Heart Lung. 2015;44(4):347-352.

4. Stoilkova A, Janssen DJ, Wouters EF. Educational programmes in COPD management interventions: a systematic review. Respir Med. 2013;107(11): 1637-1650.

5. Stoilkova A, Wouters EF, Spruit MA, Franssen FM, Janssen DJ. The relationship between coping styles and clinical outcomes in patients with COPD entering pulmonary rehabilitation. COPD. 2013;10(3):316-323.

6. Stoilkova A, Janssen DJ, Franssen FM, Spruit MA, Wouters EF. Coping styles in patients with COPD before and after pulmonary rehabilitation. Respir Med. 2013; 107(6):825-33. 



\section{CURRICULUM VITAE}





\section{Curriculum vitae}

Ana Stoilkova-Hartmann was born on $12^{\text {th }}$ of June 1979 in Skopje, Macedonia. She studied medicine at the Faculty of Medicine, University of Ss. Cyril and Methodius, Skopje, Macedonia, where she received her Medical Doctor degree in 2006. Subsequently, as Health Consultant, she joined the International Rescue Committee in Islamabad, Pakistan. From 2008 until 2009 she worked as Medical Office Manager in the field of stem cells for Cryo-Save Macedonia and Switzerland. In 2008 she was awarded with a MTEC Scholarship for her Master's studies, fully covered by the Dutch Ministry of Foreign Affairs and Faculty of Health, Medicine and Life Sciences Maastricht University, The Netherlands. During her studies she conducted her thesis research project in the field of pulmonary rehabilitation for COPD patients. In 2009 she obtained her Master of Science degree in Public Health with a specialisation in health education and promotion. From 2009 until 2013, under the supervision of Prof. dr. Emiel Wouters, she continued her research as a PhD candidate at the Department of Respiratory Medicine, Maastricht University Medical Center+ and the Centre of Expertise for Chronic Organ Failure (CIRO), The Netherlands. Her PhD project was aimed at elucidating the potential contributing factors to self-management and partnership in care for patients with COPD. From the end of 2013 until the end of 2014, she worked as a Clinical Trial Manager for NightBalance B.V., Delft, The Netherlands. Since the beginning of 2015, she has been appointed as Medical Advisor for Medical Safety in Global Medical \& Scientific Affairs at Roche Diabetes Care in Mannheim, Germany. 


is $-\cdots \cdot 4$
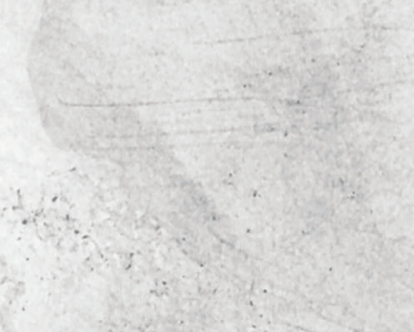

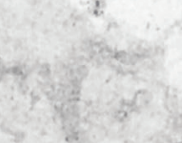

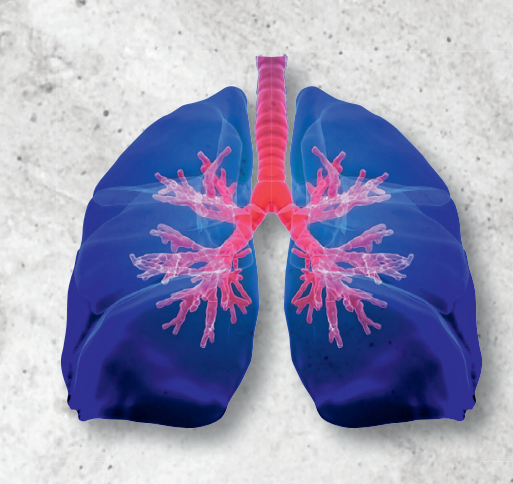

